Portland State University

PDXScholar

\title{
The Knowledge Systems Transfer Project: A Multiple Perspective Investigation into the Integration of a New Technology within a Business Unit
}

Steven Craig Tarr

Portland State University

Follow this and additional works at: https://pdxscholar.library.pdx.edu/open_access_etds

Part of the Management Information Systems Commons, and the Technology and Innovation Commons

Let us know how access to this document benefits you.

\section{Recommended Citation}

Tarr, Steven Craig, "The Knowledge Systems Transfer Project: A Multiple Perspective Investigation into the Integration of a New Technology within a Business Unit" (1990). Dissertations and Theses. Paper 1190. https://doi.org/10.15760/etd.1189

This Dissertation is brought to you for free and open access. It has been accepted for inclusion in Dissertations and Theses by an authorized administrator of PDXScholar. Please contact us if we can make this document more accessible: pdxscholar@pdx.edu. 
THE KNOWTLEDGE SYSTEMIS TRANASFER PROJECT:

\begin{abstract}
A MULTIPLE PERSPECTIVE INVESTIGATION INTO THE INTEGRATION OF A NEW TECHNOLOGY WITHIN A BUSINESS UNIT

by

STEVEN CRAIG TARR
\end{abstract}

A dissertation submitted in partial fulfillment of the requirements for the degree of

\title{
DOCTOR OF PHILOSOPHY \\ in \\ SYSTEMS SCIENCE
}

\author{
Portland State University \\ 1990
}

Copyright by Steven C. Tarr, 1990

All Rights Reserved 


\section{TO THE OFFICE OF GRADUATE STUDIES:}

The members of the Committee approve the dissertation of Steven Craig Tarr presented May 4, 1990.

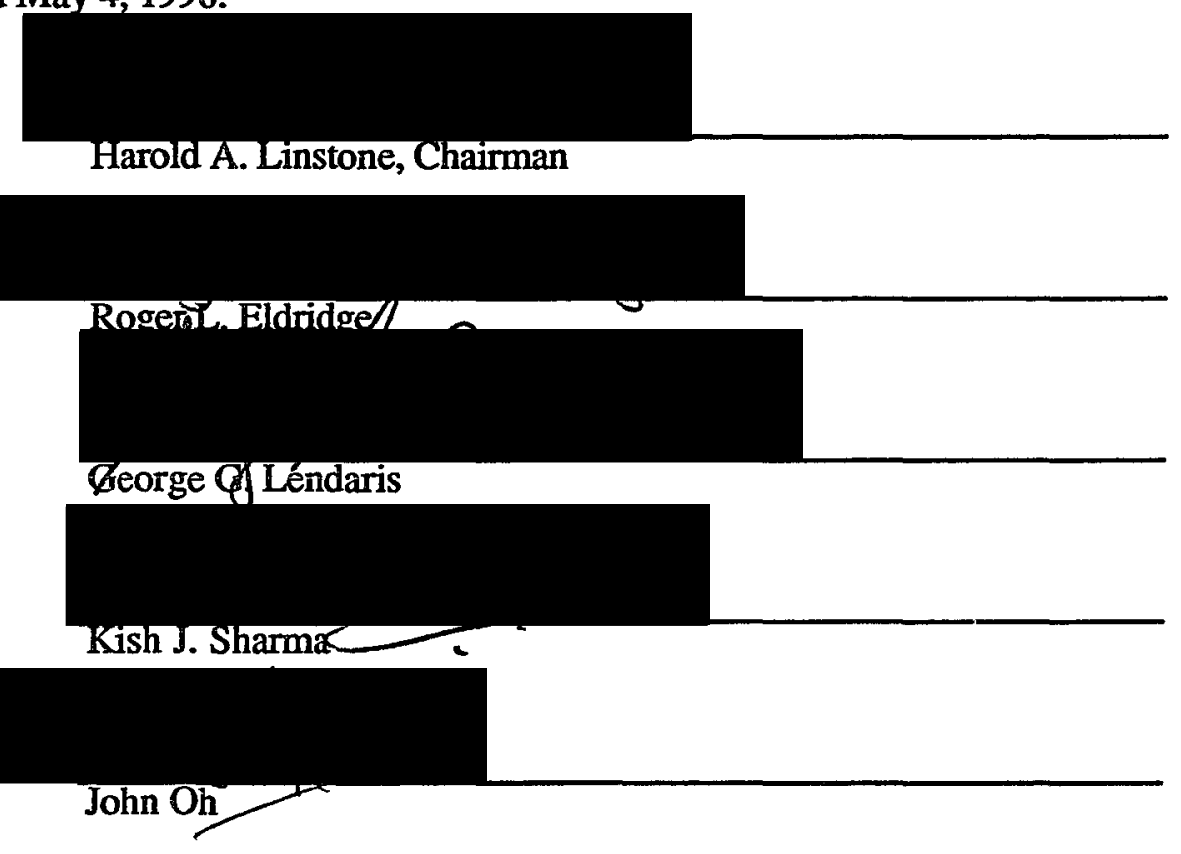

APPRQVED: , ic

Roy w. Koch, Director, Systems Science Ph.D. Program 1

C. William Savery, Vice Provost for Greduate Studies and Research 


\section{AN ABSTRACT OF THE DISSERTATION OF Steven Craig Tarr for the Doctor of}

Philosophy in Systems Science presented May 4, 1990.

Title: The Knowledge Systems Transfer Project: A Muitiple Perspective Investigation into the Integration of a New Technology within a Business Unit

\section{APPROVED BY MEMBERS OF THE DISSERTATION COMMITTEE:}

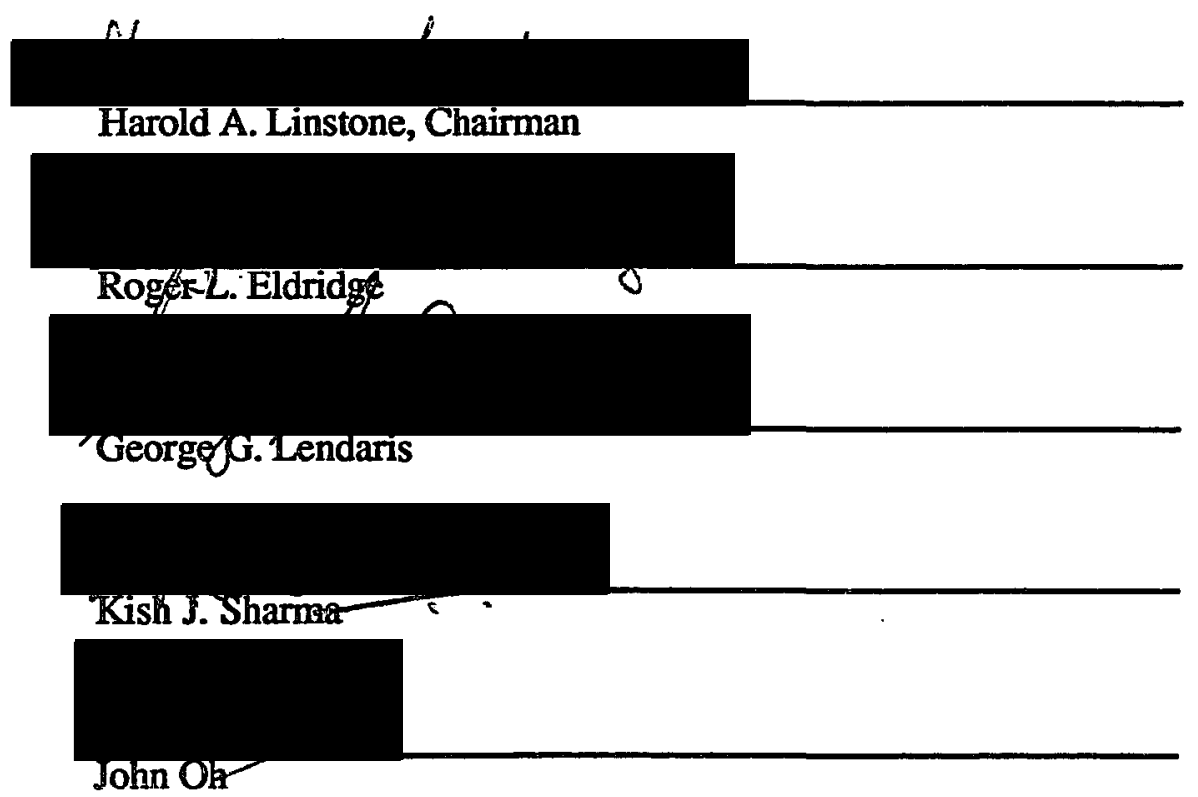

Many organizations have been attempting to build a conceptual framework for managing technology, with varying degrees of success. Most begin by consulting leading technology authorities, borrowing elements of their thinking, and adapting these elements to their organizational and personai situations. This dissertation extends this process by using the formal research methodology of multiple perspectives (technical, organizational, personal, and cross-cuing) to build a case-based model of the technology integration 
process. The research and the model construction benefits from a solid foundation established through a review of technology management and knowledge systems literature.

The significant aspects of the research are tied to its objectives which can be divided into academic and industrial classifications:

Academic Objectives:

1. Use multiple perspectives in real-time (for input to decisions as events unfold)

2. Focus on a multiple perspectives view of technology integration into an organization

Industrial Objectives:

1. Improve project effectiveness by increasing understanding of the technology integration process

2. Establish a model for the integration of a new technology into an organization

The development of the case-based model was the primary objective, with the other objectives providing the methodology and subject-matter content to support model development.

These four objectives are of interest to three parties: scholars who are interested in the theoretical and methodological aspects of technology integration and inquiring systems, technology developers in general who cas benefit from improved means to integrate technology and analyze success/failure, and technology developers in information systems organizations who can obtain specific insight as well as utilize the general industrial results.

From the multiple perspectives investigation, thirteen conciusions were reached about the process of integrating knowiedge systems into an information systems organization. These conclusions are specific to the case study, but may have general applicability. 
The multiple perspectives methodology is then presented as the foundation for a technology integration model, on which the technology usage phases of awareness, motivation, and functioning capability can be completed. The model is described and then illustrated with two knowledge systems development project cases.

With regards to the research objectives, it is concluded that:

1. The use of multiple perspectives in real-time are difficult and requires practice

2. Because technology integration is dependent upon technical, organization, and personal factors, the use of multiple perspectives are appropriate and useful. Eight of 13 conclusions were dependent upon the cross-cuing process

3. Multipie perspective analysis improved the understanding of the technology integration process. This understanding was sometimes helpful and sometimes harmful to the effectiveness of the integration process

4. The proposed technology integration model, using the awareness, motivation, and functioning capability phases, was developed and exercised. This model proved useful in limited application

Finally, a method for organizing and navigating the perspectives, cross-cuing, and conclusions is presented and used. 


\section{ACKNOWLEDGEMENTS}

So many people helped me with this research in so many ways. The years of courses and the years doing my research and writing were filled with people who helped me better understand the pursuit of knowledge and, most importantly for me, the application of that knowledge to the issues facing society.

I give special recognition and gratitude to Professor Harold A. Linstone, whose book on multiple perspectives first attracted my attention years ago while browsing the stacks at the University of Washington Engineering Library. Dr. Linstone emphasized the importance of confronting the breadth of the issues affecting the use of technology. $\mathrm{He}$ taught me that it was insufficient to consider only the virtues of the technology, and more important, was to have a formal process for systematically analyzing the multiple perspectives. His teachings have changed my life forever.

Each member of my dissertation committee gave freely of their time and energy throughout my research period. Drs. Roger L. Eldridge and Kish J. Sharma provided their academic experiences using multiple perspectives with their knowledge of public and private sector technology utilization. Both of these men generously assisted me in my research in spite of many geographical and logistical barriers. Professor George G. Lendaris devoted significant time and effort to teaching me many systems concepts and then ensuring that I clearly communicated the application of these concepts in this research.

As a U S WEST Doctoral Fellow, I received time and money for this research. I thank the original Fellowship Review Committee of Gene Haugen, Dick Senseney, and Margaret Ernest for recognizing the value of my educational program and having the confidence in me to do this work. 
A number of people in industry also were very helpful to me: Tilak Dissanayake from Boeing (now Xerox), Jack Pepping from Allstate Insurance, Ed Mahler from DuPont, and Randy Davis from MIT. These people were part of an industrial consortium which was trying to determine how knowledge-based systems could be made an effective part of a company's competitive edge. We shared ideas and some of them ended up in this research.

The members of the Knowledge System Transfer Project were remarkable individuals. Larry Scott, Rich Bauer, Bill Luce and Don Ford didn't know what they were getting themselves into, and they contributed immensely to this research as well as being great people to work with on a team.

Any work of this size requires a significant amount of detail work to edit and format the document. Jennifer Miller did an excellent job proofreading the many drafts, and made sure that copies were bound and distributed to the right people and at the right time. I could not have finished on time without her help.

I have saved my final words for my family. They endured over three years of my mental and physical absence. My wife, Lael, and children Emily and David, were always there to support me and keep my life in balance. They always came first. Their love, encouragement, and devotion enabled me to finish this research. 
TABLE OF CONTENTS

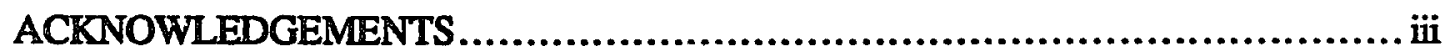

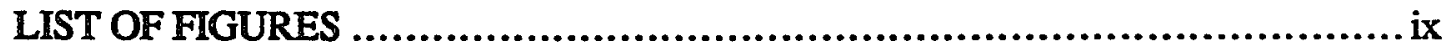

\section{CHAPTER}

I PURPOSE AND OBJECTIVES $\ldots \ldots \ldots \ldots \ldots \ldots \ldots \ldots \ldots \ldots \ldots \ldots \ldots \ldots$

Statement of the Problem...............................................2

Significance and Objectives of the Research ...........................5

Document Preview .....................................................8

Sponsorship Statement ............................................. 11

II $\quad$ BACKGROUND AND CONTEXT .............................. 13

Technology Transfer Before Divestiture.................................. 13

Technology Transfer After Divestiture.................................... 14

Description of U S WEST............................................ 15

A Brief History of the Knowledge Systems Transfer Project............... 19

III REVIEW OF SELECTED LITERATURE.......................... 21

Computer-Based Knowledge Systems .............................21

Artificial Intelligence

Expert and Knowledge Systems

Knowledge Systems and Information Processing

Technology Transfer.

An Orientation to Technology Transfer

Types of Technology Transfer

Different Names for Technology Transfer

Technological Rates of Change

Technology and Market Linkage

Market and Technology Convergence 
Leadership and Personnel Components

Communications

Technology Transfer Models and Concepts

Systems-Oriented Analysis Methodologies

Systems Engineering Morphology

Aspects of Planning and Value Systems

The Task-Oriented, Transient Organization

Multiple Perspectives Methodology

IV MULTIPLE PERSPECTIVES METHODOLOGY .....................92

Traditional Problem Solving ............................................ 92

Different Inquiring Systems.................................................94

Approach to the Investigation...........................................99

V THE TECHNICAL PERSPECTIVE ..................................... 104

The Technology of Knowledge Systems................................. 104

Computer Operating Environment

Software Tocls

New Technology Fit with Current Technology

Application Identification and Selection

Employee Base Attributes

Company Profile Comparisons

Advanced Technical Education Program

Educational Statistics

Technical Skills Assessment

Origins of KSTP

Training Costs

Resource Allocation

Formal Organizational Structure.

Project Measurement.

Contact Log

Spreadsheet Analysis

VI THE ORGANIZATIONAL PERSPECTIVE

Identification of the Organizations.

U S WEST 
Corporate Information Systems

Rules and Procedures

Limited Knowledge of New Technologies

Technical Skills Assessment Organizations

Recruiting

Budget management

Summing up the CIS Organizational View

The Knowledge Systems Transfer Project

Mainframe Project
Consulting
Training Project
Small Tool Project
Marketing
Development
Other KSTP Organizational Issues

The Artificial Intelligence Center ................................... 161

Bell Communications Research........................................... 164

Vendors............................................................... 164

The Carnegie Group

IBM

Other Mainframe Tool Vendors

Other Groups 168

The Media

AI Teams

Lookers and Talkers

Technopromoters, Blue-Skyers, Turf Protectors

VII THE PERSONAL PERSPECTIVE.................................. 172

Identifying the Players................................................ 173

Louis Schroder, Department Head of Computing \& Communications

Alan Medina, Director of Application Support Services

Doug Gunter, Director of Marketing Applications

Donald Malek, Department Head of Application Services

Jim Hicks, Vice-President of CIS

Tony Pearch, Department Head of Planning

Bob Haberman, Vice-President of Advanced Technologies

John Fitzpatrick, Industrial External Consultant

Bill Hoyt, Training Director

Kathy Dobbs, Director of Billing Applications 
Ron Garcia, Manager of the Information Systems

viii

Technoiogy Group

Glen Dillon, Head of the Expert Systems Development

Group

Alvin Vail, Head of the Expert Systems Development Group

Sid Thompson, Head of KSTP

Mike Janzen, Training Insuructor

Mark Tyson, Knowledge Engineer

Gary Ashley, CIS Programmer/Analyst

Andy Shuler, IBM Marketing Person

VIII INTEGRATION AND CROSS-CUING................................... 203

Cross-Cue Chart of the Knowledge Systems Transfer Project........... 203

Instructions for Using Cross-cuing, Analysis, and

Conclusions

Description of the Cross-Cue Chart

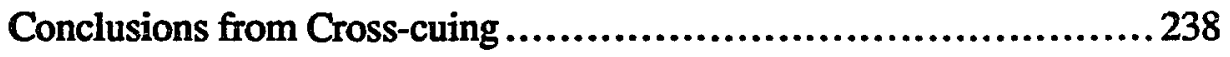

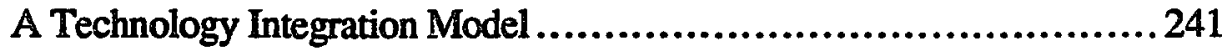

XI CONCLUSIONS.................................................. 257

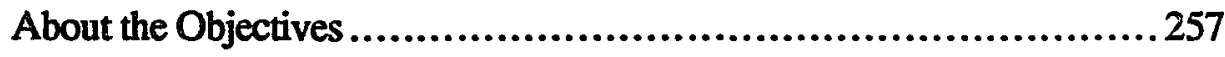

Academic Objectives

Industrial Objectives

Observations about the Research Process ............................. 262

REFERENCES............................................................. 266

\section{APPENDICES}

A MULTIPLE PERSPECTIVES $\ldots \ldots \ldots \ldots \ldots \ldots \ldots \ldots \ldots \ldots \ldots \ldots . \ldots . \ldots \ldots$

B APPLICATION IDENTIFICATION AND SELECTION .......278

C MEMORANDUM OF AGREEMENT...........................291

D RESEARCH COMMITTEE ON EXPERT SYSTEMS

REPORT ...................................................296

E LOANER PROGRAM PROPOSAL...........................305 


\section{LIST OF FIGURES}

Figure $\quad$ Page

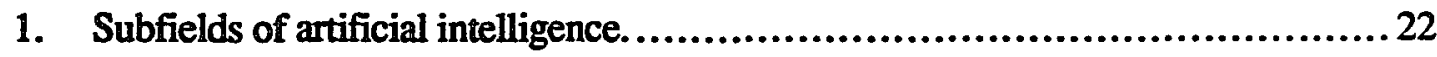

2. The players in building an expert system ..........................................27

3. Components of an expert system .....................................................29

4. Trends towards computing decentralization ........................................32

5. Trends towards small computers ................................................... 33

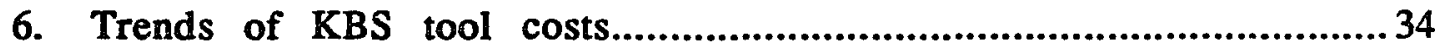

7. Predicted sales growth of KBS products .......................................... 56

8. Different types of technology transfer........................................................44

9. Substitution of one technology for another.......................................50

10. Misleading test market results for a technology ...................................56

11. Strategies for specific market and technology positions. ..........................57

12. Funding for certain market and technology positions ..............................58

13. A conceptual framework for skills development....................................65

14. Organizational types and staff requirements.....................................66

15. Minimizing company expansion and contraction .................................71

16. Communications among scientists and technologists ........................... 75

17. Effect of distance on worker communication................................................76

18. The science-technology-utilization topology model ................................8 82

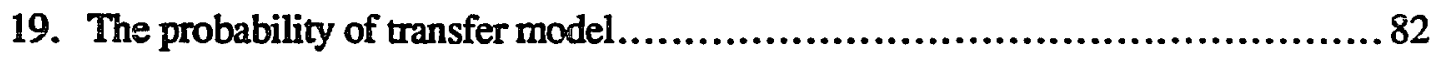

20. The magnitude of transfer model .................................................. 83

21. The GTE technology transfer model ............................................... 84 
Figure Page

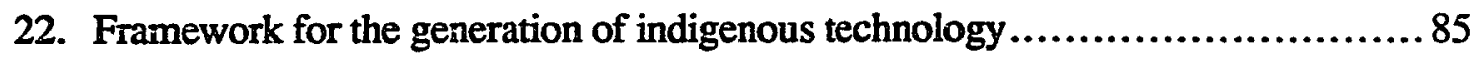

23. Multiple perspectives.......................................................96

24. Cross-cuing of T-O-P perspectives.............................................. 99

25. Attributes of regional company computing capacities ........................... 105

26. Company size data for regional companies.................................. 105

27. Company internal personal computing hardware ................................ 106

28. Approved expert system shells................................................... 107

29. Relative IS operating budgets 1988 ....................................... 110

30. IS staffing levels of the regional companies................................. 112

31. Workers dedicated to new IS development.................................... 113

32. Technical expertise needed pre- and post-divestiture........................... 115

33. Percentage of employees with four-year degrees .............................. 117

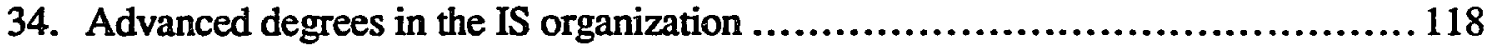

35. Educational level of new hires. ............................................ 119

36. Computer science degrees by geographic region. ............................. 120

37. Percentage resource allocations for KSTP..................................... 122

38. Estimated dollar distributions for KSTP expenses $\ldots \ldots \ldots \ldots \ldots \ldots \ldots \ldots \ldots \ldots \ldots \ldots \ldots$

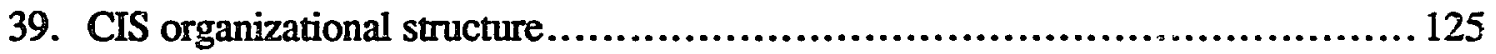

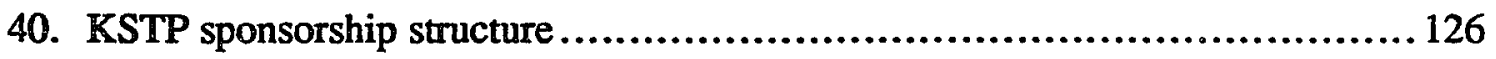

41. Geographic distribution of IS employees.................................... 127

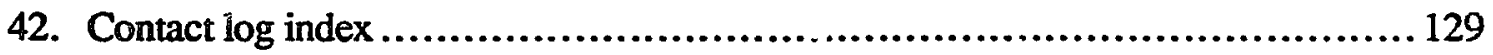

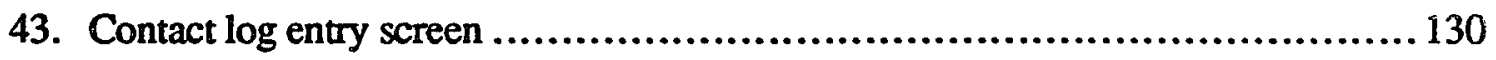

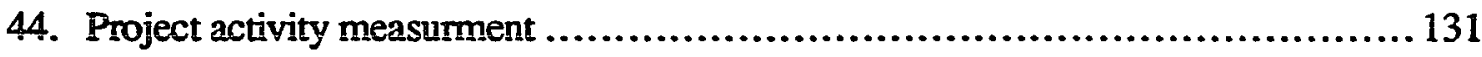

45. Development activity measurement........................................ 132

46. KSTP Subprojects.................................................... 151 
Figure

47. The AI center concept activities and relationships ................................ 163

48. Cross-cue chart ................................................................ 206

49. Navigating the conclusions, cross-cuing, and T-O-P detail .......................210

51. A technology integration model.............................................. 242

52. Awareness, motivation, and functioning capability ............................ 248

53. Matrix details in the TIM model.................................................250

54. Completed matrix for a failed application project ............................... 253

55. Compieted matrix for a successful application project .............................254

56. Number of conclusions from the various perspectives..............................259 


\section{CHAPTER I}

\section{PURPOSE AND OBJECTIVES}

"But the moment man first picked up a stone or a branch to use as a tool, he altered irrevocably the balance between him and his environment. From this point on, the way in which the world around him changed was different. It was no longer regular or predictable. New objects appeared that were not recognizable as a mutation of something that had existed before, and as each one emerged it altered the environment not for a season, but forever. While the number of these tools remained small, their effect took a long time to spread and to cause change. But as they increased, so did their effects: The more the tools, the faster the rate of change." [Burke]

"About 85 percent of all of the scientists who have ever lived are alive today. This sheer mass, coupled with advanced tools and numerous creative opportunities has increased the rate of change to the fastest point in human history. It has been said that the Industrial Revolution increased productivity by a factor of 100. According to Carver Mead at Cal Tech, the microelectronic revolution is estimated to have increased information based productivity by a factor of $1,000,000 . "$ [Wriston]

The management of technology is a newly named field of practice and study.

Functionally, it has existed for thousands of years, but the increasingly rapid rate of change in recent years has caused the management of technology to emerge from the background of scientific and industrial activities as an essential focus of modern researchers and managers. Many companies were designed for a time past, when rapid technological change was not as pervasive. Today, technological change must be accompanied by organizational changes which are compatible with the technology and with changes in the personal working styles of the employees working within the organization. These modifications must be designed to encourage and accommodate innovation and change. Part of the process involves identifying and removing obstacles to adopting new 
technologies and part involves developing mechanisms to rapidly, smoothly, and soundly adopt new technologies.

The National Research Council [Management] defines the management of technology as a field of activity which "links engineering, science, and management disciplines to plan, develop, and implement technological capabilities to shape and accomplish the strategic and operational objectives of an organization." Beyond the innovative processes in $\mathrm{R} \& \mathrm{D}$, the management of technology includes the controlled introduction and use of technology in products, manufacturing processes, and internal organizational functions. A key focus is the integration of technology into the overall business operations instead of isolating the technology within special purpose functions.

Many companies have been trying to piece together a conceptual framework for managing technology, with varying degrees of success. Most begin by consulting leading technology authorities, borrowing elements of their thinking and adapting these elements to their organizational and personal situations. This dissertation extends this process by using the formal research methodology of multiple perspectives to build a case-based model of the technology integration process. My research and model construction benefit from a solid foundation established through a review of technology management and knowledge systems literature.

\section{STATEMENT OF THE PROBLEM}

At the center of the larger topic of technology management are questions which relate to processes and decisions about specific technologies or technological approaches:

1. In what new technologies should an organization invest?

2. What technology integration methods should be used?

3. How fast should integration proceed?

4. How should the integration methods be structured? 
5. What are the technical, organizational, and personal impacts of changing technologies?

For this research, the first question had been answered prior to my involvement using acceptable technological forecasting and assessment procedures. My research problem was to provide an initial basis with which to answer the remaining four questions by building a case-based model of technology integration. Understanding of the issues needed to build this first approximation model should improve the capabilities of U S WEST Information Technologies - Services to integrate new technologies in a welldefined, responsive (to company and market demands) manner. My research is intended to improve the process by the thorough analysis of the integration of knowledge systems technology into the business unit, which provides the insight needed for the development of the model (based on the findings of the case study) of the infrastructure needed for effective technology integration to occur. The major assumption is that such a model accurately captures the essential aspects of the business unit being studied and it is in a form that can be used by practitioners. The model has been developed by discovering and capturing the essential elements (technical factors, groups, and people) along Technical, Organizationail, and Personal (T-O-P) dimensions. The context in which the organizational and personal actors view other T-O-P perspectives are used to gain understanding of the Knowledge Systems Transfer Project, which is described in Chapter 2. Some examples of the types of questions that can be asked of this model are "What factors facilitate and/or inhibit the technology integration process?," "What are the factors dependent on the nature of the technology, on the characteristics of the receiver, on the characteristics of the provider, and on the nature of communications between the provider and receiver?"

Before continuing further, I would like to relate my use of the term "technology integration" to the term "technology transfer." I differentiate because of the greater depth connoted by "technology integration" and because this research focusses on using the 
technology in an organization after the technology has been acquired. As this paper proceeds, my focus on "integration" will become increasingly clear. However, at this point let me clarify the more common term to provide a basis on which to build.

The process of integrating a new technology into an organization is often called technology transfer. This term is often misused, misunderstood, and misinterpreted. By examining the two words in this phrase, a possible cause becomes clear.

In Webster's Ninth Collegiate Dictionary, "technology" is defined as "a scientific method of achieving a practical purpose" and as "the totality of means employed to provide objects necessary for human sustenance and comfort." While the latter definition is more general and elusive, it adds an important dimension to the former: technology need not be science-based. Most of our technology development is based upon empirical evidence, often based on practical experience rather than scientific theory.

Webster's defines "transfer" as "an act, process, or instance of transferring" and "the carry-over or generalization of learned responses from one type of situation to another." The first definition indicates the action orientation and the second describes the content of the action.

In the case of technology transfer, the carry-over of learned responses is with respect to some objects that are used for human sustenance and comfort. This carry-over can be viewed in two distinct dimenstions, one which is personal and the other which is organizational. People and organizations have the capability to transfer information and a number of combinations are possible, e.g. person to person, person to organization, organization to organization, etc. Additionally, the organizations involved may be at varying levels of size and function, further adding to the complexity.

To this point, my argument has not addressed the technological aspects of technology transfer, other that to put in perspective that technology need not be sciencebased. While technology transfer, if the above definitions are accepted, is primarily 
concerned with personal and organizational issues, the technology itself is central to the transfer process. When technically-oriented people and organizations engage in technology transfer, there may be a tendency to rely on the merits of the technology as the propelling mechanism for successful technology transfer, when in fact a balance must be struck between technical and non-technical factors.

As will be described, there has historically been little need for efficient or timely technology transfer to be conducted within U S WEST. The current status of knowledge systems as an emergent technology provided a convenient case in which to study the internal technology integration mechanisms and to develop an initial model, based on the U S WEST case study, that can be utilized for other emerging technologies. Reliance on my literature review made it possible for my results to be presented in a manner which may be useful to other technology transfer practitioners.

Technology integration mechanisms are needed that are sufficiently robust and at the same time address the practical implications for the organizational unit. This requires striking a balance between flying-by-the-seat-of-your-pants technology integration and overdone technology integration projects that lose sight of the purpose and goals of the integration process, often through excessive study of the problem, drawn out planning, and encumbering measurement procedures.

\section{SIGNIFICANCE AND OBJECTIVES OF THE RESEARCH}

Though the multiple perspectives methodology has historically been used for retrospective analysis, the present research is based upon the belief that the multiple perspectives (MP) methodology ${ }^{1}$ can be used a) proactively in real-time (i.e. to examine events as they occur) to guide the technology integration process and b) in retrospect to

1See Chapter IV. Multiple Perspective Methodology for a description of multiple perspectives. 
facilitate the development of an integration model. The significant aspects of the research are tied to its objectives which can be divided into academic and industrial classifications:

Academic Objectives:

1. Use multiple perspectives in real-time (for input to decisions as events unfold)

2. Focus on a multiple perspectives view of technology integration into an organization

Industrial Objectives:

1. Improve project effectiveness by increasing understanding of the technology integration process

2. Establish a model for the integration of a new technology into an organization

Development of a case-based model is the primary objective, with the other objectives providing the methodology and subject-matter content to support model development.

First, a description of the academic objectives:

1. Use multiple perspectives in real-time (for input to decisions as events unfold): The first academic objective tests the use of multiple perspectives in real-time (i.e. to examine events as they occur). Previous in-depth studies have shown the usefulness of Linstore's MP for planning and determining the future of a project [Umbdenstock] and for historical analysis to be used for future decisions [Sapp]. The Knowledge Systems Transfer Project was initiated in April of 1988 and was coming to its end in December of 1989. By using multiple perspectives (T-O-P) to plan project activities and to deal with problerns as they occurred, the intention was to determine if multiple perspectives could be used to guide a systems approach to the technology integration project. The results of activities throughout the project were available to assess the utility of the methodology. 
2. Focus on a multiple perspectives view of technology integration into an organization: The second academic objective examines the value of multiple perspectives when applied to the process of technology acquisition and deployment. The intention was to determine, for this case study, if understanding of the technical, organizational, and personal perspectives, and their cross-cuing could result in either a) successful technology integration or b) a substantial ability to analyze and understand failure or inadequate results, thus enabling faster, more effective corrective actions.

Secondly, a description of the industrial objectives:

1. Improve project effectiveness by increasing understanding of the technology integration process: The first industrial objective uses multiple perspectives to increase understanding of technology integration. Central to this was to enable one perspective to provide insight to another when problems are encountered or when project plans were being developed.

2. Establish a model for the integration of a new technology into an organization: This is the primary objective. Multiple perspectives methodology was used to provide increased understanding of the business unit environment, which provided the basis for a model of new technology integration. This integration model is based on the information gained from the Knowledge Systems Transfer Project (of which I was project manager), my literature review, and my participation in an industry consortium. ${ }^{2} \mathrm{~A}$ technology integration model could be applied in industrial settings because of the frequency with which new technologies must be integrated to maintain a competitive position. The essential T-O-P infrastructure and process as established for the Knowiedge Systems Transfer Project is used as the basis for the technology integration model.

${ }^{2}$ See the Sponsorship Statement for a description of the consortium which will provide access to this information. 
The activity under study involve a large number of factors which may have had some relevance to the overall plan. The task in building a model is not just to construct a theoretical model that will take all of these factors and their interrelationships into account, but to extract those factors that are found to have the most significant effects on the technology integration process and construct a model using these factors. There is no guarantee that an overlooked area will not have a significant impact on the result. These are the "gray areas" which [Karatsu] refers to when contrasting various management styles, and being aware that gray areas exist is one strength of the multiple perspectives methodology.

The four research objectives are of interest to three parties: scholars who are interested in the theoretical and methodological aspects of technology integration and inquiring systems, ${ }^{3}$ technology developers in general who can benefit from improved means to integrate technology and analyze success/failure, and techrology developers in information systems organizations who can obtain specific insight as well as utilize the general industrial results.

\section{DOCUMENT PREVIEW}

As will be discussed, Linstone's multiple perspectives is a systems approach which considers a problem from three distinct perspectives: technical, organizational, and personal. ${ }^{4}$ Each of these perspectives illuminate a problem from different angles and can affect each other through cross-cuing, which is the influence of one perspective on another. Using the following outline of the dissertation as the guide, this section will discuss each chapter, giving examples of what each contains:

I. Purpose and Objectives

3 see Chapter IV for a brief presentation of inquiring systems.

${ }^{4}$ The perspectives are discussed in Chapter IV. 
II. Background and Context

III. Review of Selected Literature

IV. Multiple Perspective Methodology

V. The Technical Perspective

VI. The Organizational Perspective

VII. The Personal Perspective

VIII. Integration and Cross-Cuing

IX. Conclusions about the Objectives

X. References

XI. Appendices

Chapter I briefly introduces the problem area, the issues, and the research approach. The purpose and significance of the research is briefly described, as well as the academic and industrial objectives.

Chapter II provides the background and context relevant to the U S WEST Knowledge Systems Transfer Project. This includes descriptions of events and processes leading to the establishment of the Project.

In Chapter III, selected literature is reviewed in the three areas relevant to this research: Computer-based knowledge systems, technology transfer processes, and systems-oriented analysis methodologies.

Chapter IV presents the methodology for this research. Included in this section is a discussion of traditional problem solving, how different inquiring systems affect an observer's views, an explanation of basic multiple perspectives concepts, and the guiding philosophy for this research project. The specific T-O-P components of the methodology and associased analysis will be given in the following descriptions of chapters V, VI, and VII.

In Chapter V, the technical (T) perspective is used to examine the rational aspects of the technology integration including the technology of knowledge systems, employee-base attributes and statistics, origins of the Knowledge Systems Transfer Project, financial analyses, knowledge system project selection techniques, and quantitative goals and 
measurements of the Project. These are presented, explained, and critically evaluated to show their influence on the Project.

In Chapter VI, the organizational $(\mathrm{O})$ perspective is used to view the technology integration project, looking at the various organizations individually, their dynamics, and their interactions. The internal and external views are researched and documented, providing a basis for analyzing organizational interactions as a group of systems operating within a larger supersystem. Many distinct organizational perspectives exist both outside and inside an organization and understanding these different views is central to the analysis of actions and events. In addition to the formal organizations, informal organizations are identified and assessed since they often play a role equal to or greater than those which are formally defined.

Descriptions of U S WEST internal organizational responsibilities as seen by organization actors will address the centralized/decentralized control issue, the departmental control issues within Information Technologies - Services, and traditional organizational response to new technologies. Case study materials are supplemented by organizational material obtained via two industrial consortia: One is Bell Communications Research (composed of the seven post-divestiture regional telecommunication firms) and the other is an expert systems implementation group which draws major corporate members from the United States (and occasionally abroad). The latter is more completely described in the Sponsorship Statement.

In Chapter VI, the personal (P) perspective is used to examine the third dimension of the technology integration process. The central characters, their backgrounds, their behaviors, and key actions and decisions are identified and assessed for the impact on the Knowledge Systems Transfer Project. Analysis is focussed on the identification of personal and situational characteristics which predispose these characters towards the 
tendencies shown by their behaviors. As in the O-perspective, the informal roles are identified and examined with as much attention as the formal roles.

In Chapter VIII, the depth and diversity of T-O-P dimensions are integrated to provide the basis for cross-cuing. Combining the results obtained through these selective filters enabled a composite picture to be built of the project dynamics. I then use the insight gained from cross-cuing to present a Technology Integration Model and describe its use on two knowledge systems projects.

Chapter IX, Conclusions, contains a section describing my conclusions with respect to the research objectives, followed by a presentation of my observations about the research process.

\section{SPONSORSHIP STATEMENT}

U S WEST has established an Advanced Technical Education Program (ATEP), principally within Information Technologies, Marketing, and Engineering organizations. As a sponsored participant in ATEP, educational funds were provided to me to conduct this research. Additionally, significant official company support exists because the results of this research will be directly beneficial to the Information Technologies Group.

My position as an employee of U S WEST and head of KSTP provided access to the resources necessary for successful completion of my proposed research. In addition to ongoing access to the technology, work groups, and individuals associated with the Project, I was able tc obtain significant documents describing the events leading to the formation of the Project.

Over many years, I have developed working relationships with a large number of people in the information systems, human resource, financial, and manageriai staffs. This facilitated access to information that might otherwise have been unobtainable. A key part of 
this involvement is with the TechForum, a semi-formal organization of senior technical people. This group operates as an effective mechanism for internal information exchange.

A significant resource for personal and organizational perspective issues was my participation in an expert system implementation group, organized by Decision Support Technology, Inc. in Boston. This group brought together a number of leading pioneers ${ }^{5}$ in the field of applied artificial intelligence, expert systems, and information systems development, to create a unique and practical approach for organizations ${ }^{6}$ to implement those technologies. The group has worked together for one year, which has given the participants an opportunity to see the evolution of the technology in different organizational settings.

5Primary advisors were Randall Davis (MIT) and Ed Mahler (DuPont).

6Participating organizations included: Allstate Insurance, American Airlines, American Express, Boeing, Colgate-Palmolive, FMC, GTE Laboratories, Harvard Business School, Metropolitan Life, MIT Sloan School, Sea-Land, U.S. Postal Service, U $S$ WEST, Xerox. 


\section{CHAPTER II}

\section{BACKGROUND AND CONTEXT}

To better understand the research setting, this chapter provides background and context information about technology transfer before and after the divestiture of Bell Operating Companies from AT\&T, a description of U S WEST, and a brief history of the Knowledge Systems Transfer Project.

\section{TECHNOLOGY TRANSFER BEFORE DIVESTITURE}

The Bell System led the development and use of communications technology throughout most of the 20th century by focussing on the goal of universal serviceproviding basic telephone service anywhere in the United States at an affordable price. This goal had far-reaching ramifications for the manner in which new technologies were explored, developed, and deployed.

With the goal of universal service, a functional approach to company organization was taken. AT\&T and its subsidiaries were aligned so that tasks in each functional area were performed by specialists in that area in order to maximize efficiency. The local operating companies were responsible for satisfying the particular needs of the communities they served, but they all used standard technology and procedures which were centrally developed.

All of the switching and transmission technologies needed to operate the telecommunications network were developed by Bell Laboratories, produced by Western Electric, and implemented by the operating telephone companies. Pari of the operational computing technology was also deployed in such a manner. During field trials within the 
operating companies, field characterization studies provided the data needed to set realistic performance objectives and to supply the developers and systems engineers with essential feedback. These field trials were conducted by employees of Bell Labs, Western Electric, or AT\&T with the operating company employees assisting. There was little attempt to transfer the technology to the operating companies at any depth other than that needed to operate the new technology, because the roles of the Bell System component companies were well defined.

These roles were radically altered as a result of the 1982 Modification of Final Judgment (MFJ), which terminated an eight year old U.S. Department of Justice antitrust suit against AT\&T. The MFJ ordered the divestiture of the integrated Bell System and AT\&T set January $1, i 284$, as the target date for completion of the massive ${ }^{7}$ restructuring.

\section{TECHNOLOGY TRANSFER AFTER DIVESTITURE}

Since divestiture of the 21 operating telephone companies into seven independent, competitive regional corporations, a number of changes in regulation and market orientation have occurred. Where the Bell System was once the near-exclusive provider of many telecommunications products and services, nearly all of them are now open to the forces of competition.

One of the seven dwarves is U S WEST, which conducts regulated telecommunications business in 14 western states (exclusive of California and Nevada) and unregulated telecommunications through the world. As can be expected, the relationships between the seven regional companies and their principal technology supplier, Bell Laboratories, changed significantly. Bell Labs was reorganized into AT\&T Bell Laboratories and Bell Communications Research (Bellcore), with the latter to serve the

7Just prior to the time of divestiture, the integrated Bell System had about 1 million employees and about $\$ 160$ billion in assets. 
regional telecommunication companies. Unlike the pre-divestiture situation where AT\&T owned its subsidiaries, these seven regional companies are co-owners of Bellcore. Additionally, AT\&T's subsidiaries cooperated with each other, while the seven postdivestiture regionals are competitors in most of their lines of business except basic telephone services. This means that the major $R \& D$ source for each regional company is shared with sir competing companies. While Bellcore has an important role to play in certain technology areas, a proprietary internal technology source is also needed.

In 1984, U S WEST commissioned SRI to review its technological capabilities. The SRI report indicated that their were deficiencies in U S WEST's ability to develop new technology and move it through development into the marketplace. This was not unexpected and indicated the historical lack of need for efficient or timely technological capabilities within the old Bell operating companies. At present, the task is not only to build the internal technology source, but also to establish an understanding of technology transfer in the new company which is as effective as the infrastructure of the old integrated Bell System.

\section{DESCRIPTION OFU S WEST}

In order to understand what U S WEST is today, some of its historical roots must be explained. U S WEST's predecessor, the Bell System, was a very successful institution. Early in this century, it brought about tremendous changes in the communications industry. Just before World War I, the Bell System was threatened by the Department of Justice with an antitrust suit, subiected to private antitrust suits and other expensive litigation on all sides, and embroiled in some of the fiercest competition in American history. Theodore Vail, who was then president of AT\&T, took on all of these problems and created the environment of regulated monopoly. In the process, the Bell System persuaded the Department of Justice not to file an antitrust suit. 
The key in that success was the signing of an agreement with the Department of Justice, which, among other things, caused the Bell System to divest itself of the ownership of Western Union. AT\&T was also able to win most of its private antitrust suits, and then to use statutes which created regulation to completely eliminate competition in the telephone industry. In that new environment it didn't take long before the telephone replaced the telegraph as the primary means to communicate, and by the end of World War II, the era of regulated monopoly and the era of the so-called natural monopoly had begun.

The real advantages of regulated monopoly did not become apparent until after World War II, when technological innovation allowed the Bell System to convert from operator services to dial tone service. In addition, microwave technology became a dominant way to provide long distance communications, and Bell Laboratories developed solid state technology. These technological advances were the main components in facilitating the re-introduction of competition in the telecommunications industry. By the end of the 1960's the phenomenon of the natural monopoly had become obsolete by virtue of the presence of competitors who were using the new technologies. The management of the Bell System did not recognize the reality of this change, or if it did, it resisted the reality.

It adopted a strategy that can be characterized as the castle syndrome [DeMuth]. The castle syndrome required management to pull up the drawbridge, barricade itself behind the parapets, and defend itself against the barbarians who wished to turn the industry over to competition. Those within the fortress did not believe that competition was in the best interest of the kingdom. They thought that regulation was a protection from antitrust violations, and that there was only one market, the telecommunications service market, which involved end-to-end responsibility which was in the best interest of the public. 
The events that have transpired since then have shown that these managers were wrong on all points. Regulation proved to be no protection from the antitrust laws. Instead of one market, the telephone industry had been divided into four markets by changing technology: customer premise equipment, long distance, equipment manufacturing, and local exchange. As important, the public, and in particular the business community, no longer supported end-to-end responsibility. Businesses were spending millions of dollars on customer premise equipment and inter-city communications provided by competitors to AT\&T.

AT\&T's managers did not realize that it was the public, not company management, who determined what was in the best interest of the public. They didn't acknowledge that the status quo of natural monopoly could not be maintained when technology and society were changing.

The major assault on the Bell System was the antitrust suit filed by the Department of Justice in 1974. Depending on your view, the lawyers who were responsible for the filing of this suit were either anti-Bell System or pro-competition. It was clear that they believed that regulation was inadequate for protecting the public or for provide the technological advances for future telecommunication products and services.

When the divestiture occurred on January 1, 1984, U S WEST quickly positioned itself as one of the leaders of the deregulation and a major proponent of full competition. So U S WEST has essentially come full circle. Theodore Vail converted competition into a regulated monopoly and now the regulated monopoly is being converted back to competition. It is the forces of competition which guide the U S WEST directions of the present day, and these forces have significant impact on its use of technology.

A major business strategy of U S WEST is to be one of the best companies in the world in the total spectrum of activities required to meet customer needs, from research, through product development, into marketing and delivery. A simple examination of this 
shows major information flows in two directions: from research to the markets and from markets to research. Technology transfer occurs at this macro level and at innumerabie levels within the vast continuum, throughout the relationships of the U S WEST subsidiaries. While the specific names of subsidiaries, their organization, and their relationships to customers continually changes, the identities of core U S WEST businesses have remained constant. They are:

- Communications

- Marketing services

- Data solutions

- Financial services

The largest subsidiary is U S WEST Communications, largely composed of three former Bell operating companies. ${ }^{8}$ A major unit of U S WEST Communications is Information Technologies - Services (ITS), which has existed in various forms for over 20 years. In addition to the AT\&T/Bell Laboratories technology influence previously described, this business unit has been greatly affected by computer hardware and software vendors. These vendors play a significant role by introducing technology 9 to people in ITS, selling these people on the benefits of the technology, and sometimes assisting with the first few applications of the technoiogy. This style of introducing new technology has had varying degrees of success, depending on the technical, organizational, and personal preparedness within ITS. As fairly new technology (for vendors selling systems and industry and academic workers building systems), knowledge-based systems technology (sometimes interchangeably called expert systems) is a good area in which to examine technology transfer using an explicit, controlled methodology.

8Mountain Bell, Northwestern Bell, and Pacific Northwest Bell.

9Such technology is usually "new" to the organization, but less than state-of-the-art from an industrial and/or academic perspective. The technology is often on the leading edge of vendor products which lags the leading edge of computer systems technology. 


\section{A BRIEF HISTORY OF THE KNOWLEDGE SYSTEMS TRANSFER PROJECT}

A project known as the Knowledge Systems Transfer Project (KSTP) had its origins within Information Technologies - Services (ITS) in late 1984 with the beginning of expert systems interest among Pacific Northwest aircraft, heavy machinery, financial, telecommunications, and insurance companies. In mid-1985, a formal expert systems project was proposed and potential applications were solicited from throughout what was then Pacific Northwest Bell. Gradually, interest in the technology grew, not only within U S WEST Communications, but also at U S WEST Advanced Technologies (AT). In 1986, AT's identification of expert systems as a strategic technology for U S WEST encouraged and stimulated the building of two prototypes within Communications. Summer of 1987 found two people in the ITS organization fully engaged in prototype building and at least four other groups expressing serious interest in developing expertise in building expert systems. The fragmentation of training, tool understanding, and knowledge engineering capabilities were seen as inhibitors to effective use of this new technology. On April 15, 1988 the Knowledge Systems Transfer Project was formed with a two year charter to facilitate and coordinate the transfer and integration of knowledge systems technology into ITS.

The initial charter of KSTP was to work with its subject-matter partners, the Expert Systems Technology Group at AT, to facilitate the transfer of knowledge systems technologies (such as theories, methods, development tools, and languages) into the ITS application software groups, software development groups, and system maintenance groups The major goal of the project was to transfer knowledge systems technology into the ITS work environment, and into the environments of the ITS client groups, such as the financial, engineering, and marketing departments. 
In-depth presentation of the founding of KSTP, its specific objectives, its evolution, its relationships with the Expert Systems Technology Group, with Bell Communications Research, with vendors, and with clients, will be defined and analyzed in the multiple perspective sections of this paper. 


\section{CHAPTER III}

\section{REVIEW OF SELECTED LITERATURE}

This research was dependent on understanding the status of knowledge in three areas:

1. Computer-based knowledge systems

2. Technology transfer processes

3. Systems-oriented analysis methodologies

The first area is important as it is the subject matter of the transfer process which was studied, the second area was the focus of the study, and the third represents the methodology I have used in carrying out the research. In the following sections, I have developed a description of each of these three areas at a level appropriate to provide a sound basis for the research.

\section{COMPUTER-BASED KNOWLEDGE SYSTEMS}

To understand the technological part of the research a brief literature review is presented on the topics of artificial intelligence, expert and knowledge-based systems, and industrial information processing.

\section{Artificial Intelligence}

Artificial intelligence (AD) is a term used to describe machine systems that produce behavior normally attributed to living systems, such as the ability to adapt, reason, set and work toward goals, and understand relationships. This behavior must be demonstrated at a level which an observer would call intelligent. This observer dependence is precisely 
where the ambiguity about what $\mathrm{AI}$ is and what it is not. With such an encompassing definition of AI, most workers in the field define one that better suits their purposes, such as "expert problem solving in complex, unstructured environments with multiple obstacles and no strategy which can guarantee a solution" [Dede].

From an historical view, Earl Sacerdoti reports that the term artificial intelligence was coined by John McCarthy in the 1950's to distinguish a new area of research from automata theory. 10 The key concepts developed in the early years included symbolic computation, knowledge-directed search, complex representation structures, and methodologies for integrating multiple kinds of knowledge.

Examples of AI can be seen in robotics, natural language processing, expert systems, and robotics (Figure 1), but even the types of problems solved in these domains change, contributing to extended confusion about what $\mathrm{AI}$ is and what it is not. A simple rule-based expert system was once thought of as a prime example of AI. Now that such systems are in greater usage and being implemented in high-level software using standard programming languages, there are beliefs that this is not AI but rather another style of programming.

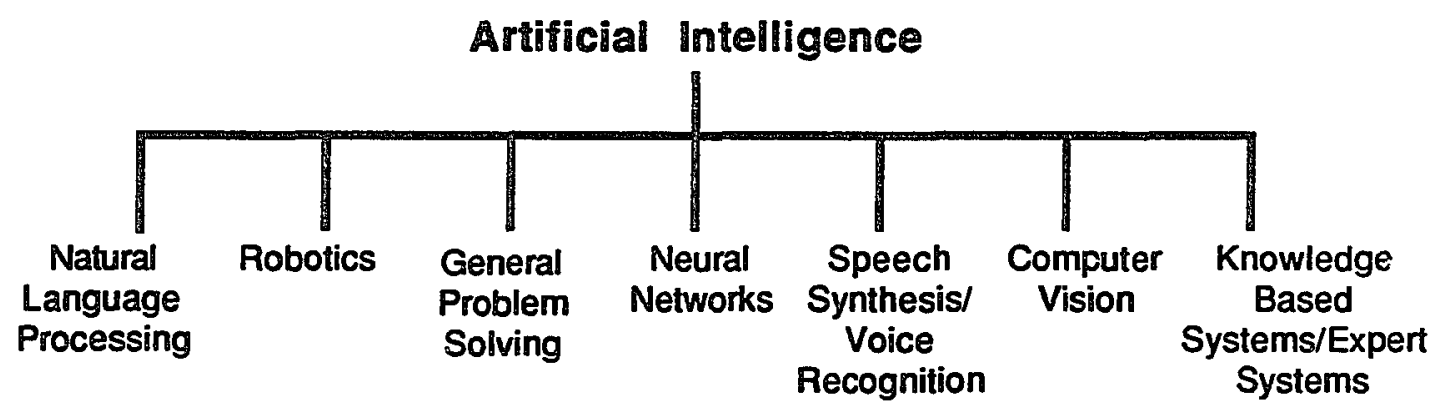

Figure 1. Subfields of artificial intelligence.

10 A different view, told by Joseph Weizenbaum, is that the new mathematical field was not attracting sufficient research funds to grow. A little brainstorming came up with the term artificial intelligence which would provide a disuinct and attractive focus for research. He reported that the great success of this has left us with a term that we would now be better off without. 
There is no fixed definition of $\mathrm{AI}$ anymore than there is a fixed definition of intelligence. A feeling for what activities could be considered under the AI umbrella would be those associated with human mentality [Rhine]:

- To respond to situations very flexibly

- To take advantage of fortuitous circumstances

- To make sense out of ambiguous or contradictory messages

- To recognize the relative importance of different elements of a situation

- To find similarities between situations despite difference that may separate them

- To draw distinctions between situations despite similarities that may link thern

- To synthesize new concepts by taking old concepts and putting them togethrs an new ways

- To come up with ideas that are novel

Contrasting these aspects of human mentality, or real intelligence, with AI points out that artificial connotes "unreal." However, it is clear that AI systems are very real combinations of applied usage of knowledge, hardware, and software. However, some argument can be made about the term AI being inappropriate for what people build in this field, much as it would be inaccurate to say that Boeing or McDonnell-Douglas makes artificial birds.

While birds fly and airplanes are flying machines, it is disputable that since people think, then AI deals with thinking machines. Arguments abound about the idea of machine intelligence, but most fall into four broad categories [Feigenbaum]:

1. Arguments of emotion. Thinking is, by definition, a human attribute.

2. Arguments of insuperable differences. Thinking requires creativity and originality, and no machine can be creative or original. 
3. Arguments of no real examples. If machines can be intelligent, why hasn't someone made one.

4. Arguments of ethics. Assuming intelligent machines can be made, should we do it?

These arguments are all rooted in the ambiguity of the definition of intelligence and certainly the observer's interpretation of it. These types of arguments will be exhibited by people described later in this paper.

There is a distinction that must be made about AI in order to come to grips with the range of activities it encompasses. As an intellectual discipline, AI crosses the boundaries of computer science, psychology, and biology, investigating the nature of knowledge and intelligent behavior. It is an experimental science that embodies theories in executable code whose performance is used to evaluate the theories and suggest refinements.

As an engineering discipline, $\mathrm{AI}$ is used to apply relatively well understood techniques (such as search mechanisms and data representations) to build functioning systems which assist in the problem formulation and solution. In some cases, an AI system may do more than assist by providing the complete set of information and actions needed in a problem situation. It is in this engineering discipline that expert systems are primarily oriented.

\section{Expert and Knowledge Systems}

As with artificial intelligence, it is hard to be precise, in strict definitional terms, about what characteristics a computer program must have to solve the types of problems that would allow this program to be called an expert system. Some dimensions for consideration include [Chandrasekaran]:

- Expertise in the subject-matter domain and the ability to apply that expertise in problem solving 
- Search through the space of possibilities

- The ability to cope with uncertainty

- Symbolic representation of data in rules, frames, nets, etc.

- Explanation facilities to deal with recent questions and entire lines of reasoning

- A separation of representation, control, and inferencing

There is a difference between an expert system and a knowledge system that is important but not usually made. An expert system is a program that uses combinations of encoded information (data with context) to arrive at conclusions not apparent in the separate pieces of information. Knowledge is the combination of the information, in an active form, to yield new results. An example of the data:information:knowledge sequence follows:

1. Data: $(8,0),(8,2),(8,0)$

2. Information: The above represents the daily hours worked, regular and overtime for three consecutive days.

3. Knowledge: If an employee is occupational or non-exempt mäanàgement, overtime hours entitle the employee to extra pay.

The data is meaningless without a context relevant to the reader. Putting two pieces of information together (employee classification and hours worked) permits some action to be taken, and it is this active form which is the basis for knowledge.

An expert system and a knowledge system both use knowledge. The distinction is with the narrowness/breadth of the domain and the levei of system performance. An expert system performs a task at the level of periormance we would expect from an expert. A human expert performs within a narrow domain and so does an expert system. A knowledge system need not perform at an expert level (but certainly can), and must be able 
to draw upon a knowledge-base to provide assistance in problem solving. An expert system is a special form of a knowledge based system.

As with AI, people disagree as to whether the level of performance must equal that of human experts, or must only exhibit expertise at some useful level. The perspective adopted here is that expert systems need only display some useful expertise. That is, expert systems technology can produce intelligent tools ranging from assistants to colleagues to experts, and that even the simplest case, assistants, have many useful applications [Scott].

Expert systems are appropriate for whole classes of problems which are poorly, if at all, addressed by traditional computer programming, such as: interpretation, prediction, diagnosis, design, planning, monitoring, debugging, repair, instruction, and control [Waterman]. It is interesting to note that today primary responsibility for most of those same functions lies with humans, which is an indication of the white-collar productivity gains which expert systems could make possible.

Some specific applications for which expert systems have been implemented are [Hayes-Roth]:

- communication network fault diagnosis,

- instruction,

- medical diagnosis,

- equipment repair,

- computer configuration,

- computer system monitoring and control,

- chemical data interpretation and structure elucidation,

- speech and image understanding,

- financial decision making,

- signal interpretation, 
- mineral exploration,

- military intelligence and planning,

- advising about computer system use, and

- VLSI design.

Expert systems do not so much replace human expertise, as they leverage it to allow its wider usage. When experts are imminently leaving an organization, an expert system which incorporates the departing expert's knowledge may be the only alternative to a painful period while an apprentice gains expertise. For companies with complex tasks requiring consistent treatment for different cases, an expert system can leverage human expertise, speed processing, insure uniformity, and ease coordination during changes.

A look at the expert systems development process will provide some insight into how companies use expert systems. Waterman presents an informative picture of, as he calls it, "the players in the expert system game" [Waterman]. His chart is reproduced, with slight modification, in Figure 2.

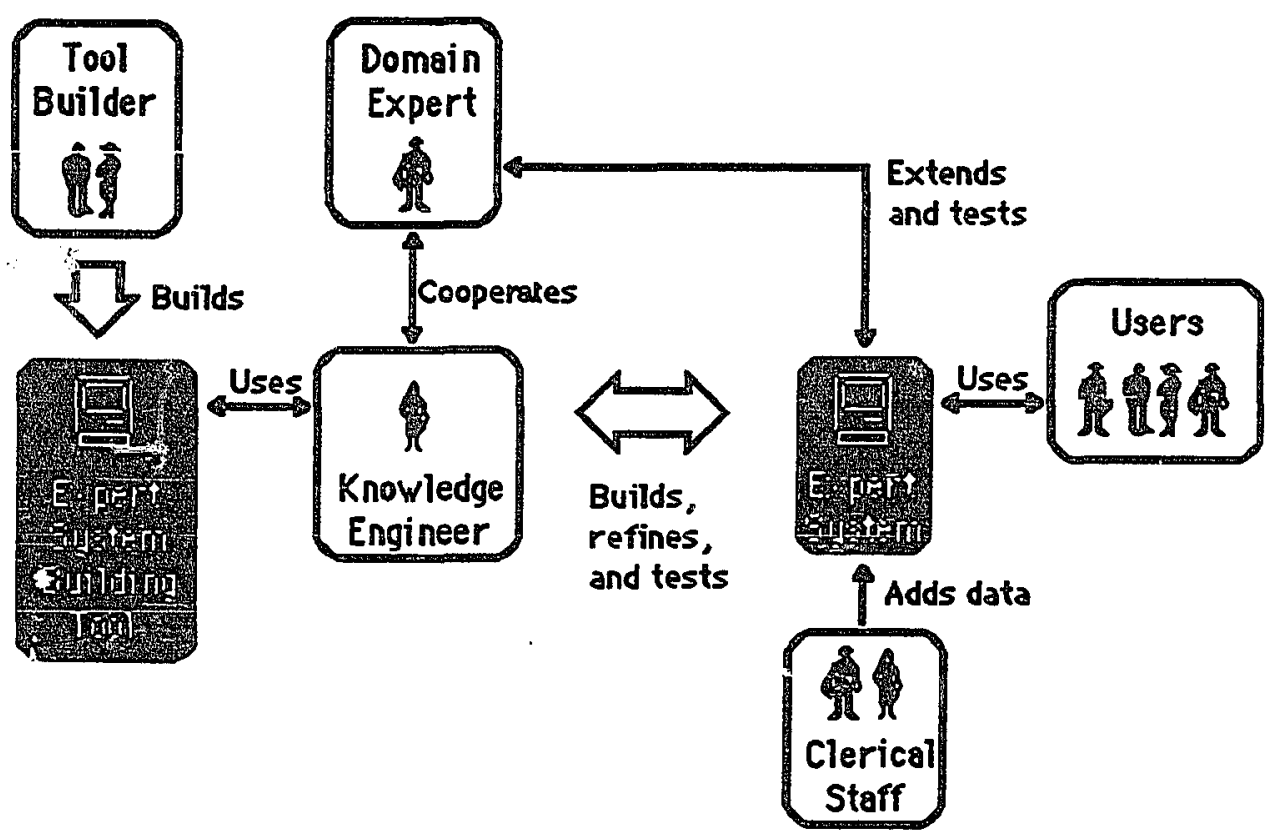

Figure 2. The players in building an expert system 
The tool builder is an outside vendor who markets and supports an expert system building tool. The expert system building tool is a programming language or environment used by a knowledge engineer to build an expert system. The domain expert is an articulate, knowledgeable person with a reputation for producing good solutions to problems in the field of interest. The knowledge engineer is a person, usually with a background in computer science and artificial intelligence, who knows how to build expert systems. The expert system is a collection of programs that solves problems in the field of interest. The users are anyone who uses the expert system.

The development of expert systems is by nature subject to experimentation, prototyping, sometimes stopping and entirely re-coding in a different way. It can seem quite unruly and unmanageable. That is a mistaken impression, because expert system construction requires good software engineering principles, just like conventional programming efforts [Martin].

The expert system itself may be analyzed to contain the components indicated in Figure 3, again modified from [Waterman].

The knowledge base contains facts and structures, such as rules, relating those facts. Rules, it must be noted, are but one means of expressing knowledge; others are discussed in the section below contrasting databases and knowledge bases. The inference engine contains an interpreter that decides how to apply the knowledge in the knowledge base to infer new knowledge and a scheduler that decides the order in which to apply the knowledge. The user interface is the mechanism for communicating with the users by appropriate means, i.e. text, graphics, natural language, audio, video, and so on. 


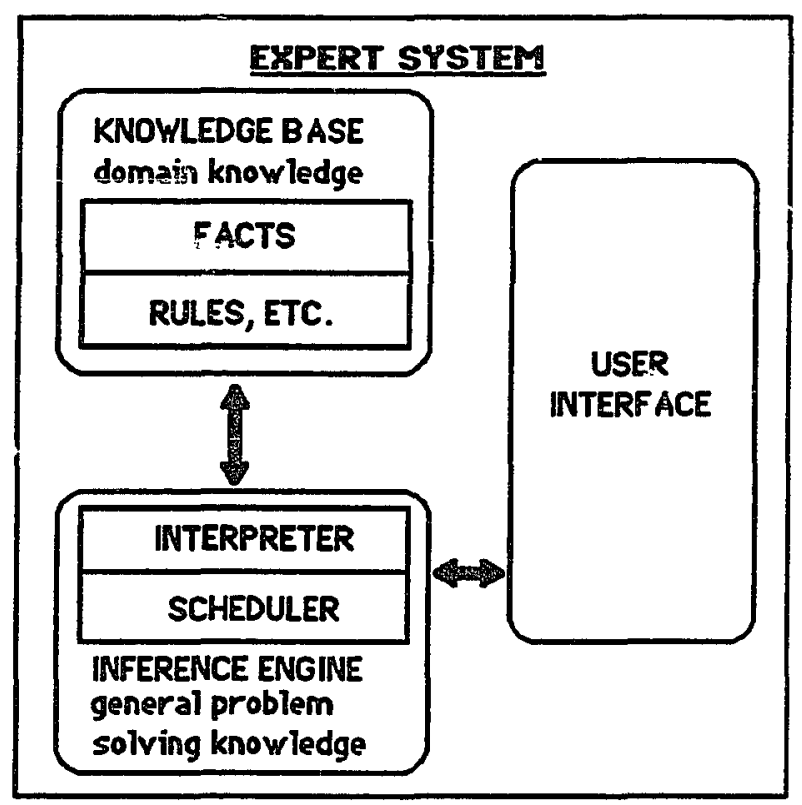

Figure 3. Components of an expert system

The expert system building tool may simply be a programming language, such as LISP, PROLOG, OPS5, C, FORTRAN, and others. Obviously, with just a language, the knowledge engineering staff's task is formidable: the team must craft the entire expert system, including the inference engine and user interface. This tack is appropriate for only specialized applications being developed by a highly skilled team.

A second form of expert system building tool is the expert system shell, which is an inference engine containing no knowledge of a specific problem domain. Within the scheme for knowledge representation provided by the shell, the knowledge engineer builds a knowledge base of facts, rules, and other knowledge structures.

An emerging form of expert system tool is the specialized expert system, into which a domain expert inputs facts about a specific implementation. Specialized expert systems have been fielded in the financial, legal, and medical arenas [Waterman, Harmon]. 
The remainder of this section will briefly discuss expert system shells. Space and time limits the discussion to generalities, but for more complete descriptions of various shells, the reader may refer to [Harmon] and [Waterman].

Besides the inference engine, small, PC-based expert system shells provide the following capabilities: (1) to carry on a text-based consultation in pseudo-English, and (2) an explanation facility to retrace and justify why questions are asked and how conclusions are reached. Most small PC-based shells are rule-based.

Past generations of mainframe-based shells have had about the same capabilities as the PC-based shells, but this has changed recently. Mainframe tools are beginning to emerge with the industrial strength features needed to interact with existing large-scale applications and large-scale databases.

Large, industrial strength expert system shells have existed on workstation-type machines for a number of years. They provide addiiionai modes of knowledge representation, logical control, and user interface. This class of shells facilitates construction of systems that represent the knowledge from a variety of problem domains and that include a rich user interface.

Expert system shells may present undesirable constraints if not carefully matched to the application being developed. The developer using a small expert system shell may constantly bump into limits the shell imposes on representing and reasoning about the knowledge base or on input/output with the user and external processes. For example, a small shell can make simple processes which fall outside the rule-based paradigm, like sequential or iterative processing, difficult to implement.

When required by the application, the knowledge engineer must program, in some fashion, any user interface beyond that which comes with a shell, e.g. a sophisticated textual interface or a graphics interface. In some expert system development efforts as 
much as $40 \%$ of the computer code developed is dedicated to creating the user interface [Martin].

Martin also makes comparisons between expert systems development projects and traditional software development projects, with the conclusion that they are different, but not dramatically. The differences revolve around the knowledge acquisition process and its inherent uncertainties for the knowledge engineer and the domain expert, which lead to greater use of small incremental development of prototypes with constant revision and iteration. At this stage of technological development, these differences can impact other associated information systems projects, which has made many developers look for stand alone expert system applications. A notable exception is that of the American Express Authorizer's Assistant, which has expert systems workstations tied to large mainframes. This cooperative work mode is clearly a trend of the future [Miller].

\section{Knowledge Systems and Information Processing}

Datamation's hot technologies for 1989 included expert systems among the "projects IS execs will feverishly pursue in the year ahead." One must wonder what will happen to these expert systems projects in 1990, when expert systems may be displaced from the "hot technologies" list. Even though it may be hot, most companies are not committing large sums of money to the technology [Runyan]. Knowledge systems are actually one component of a more general trend in information processing: to deliver the right information to the right consumer at the right time. While this may seem obvious, it has only been recent years that dramatic changes in technology has made significant progress possible. One of these technological changes is the increased computing power available to the end-user, which is driving the decentralization trend shown in Figure 4 [Statland]. 


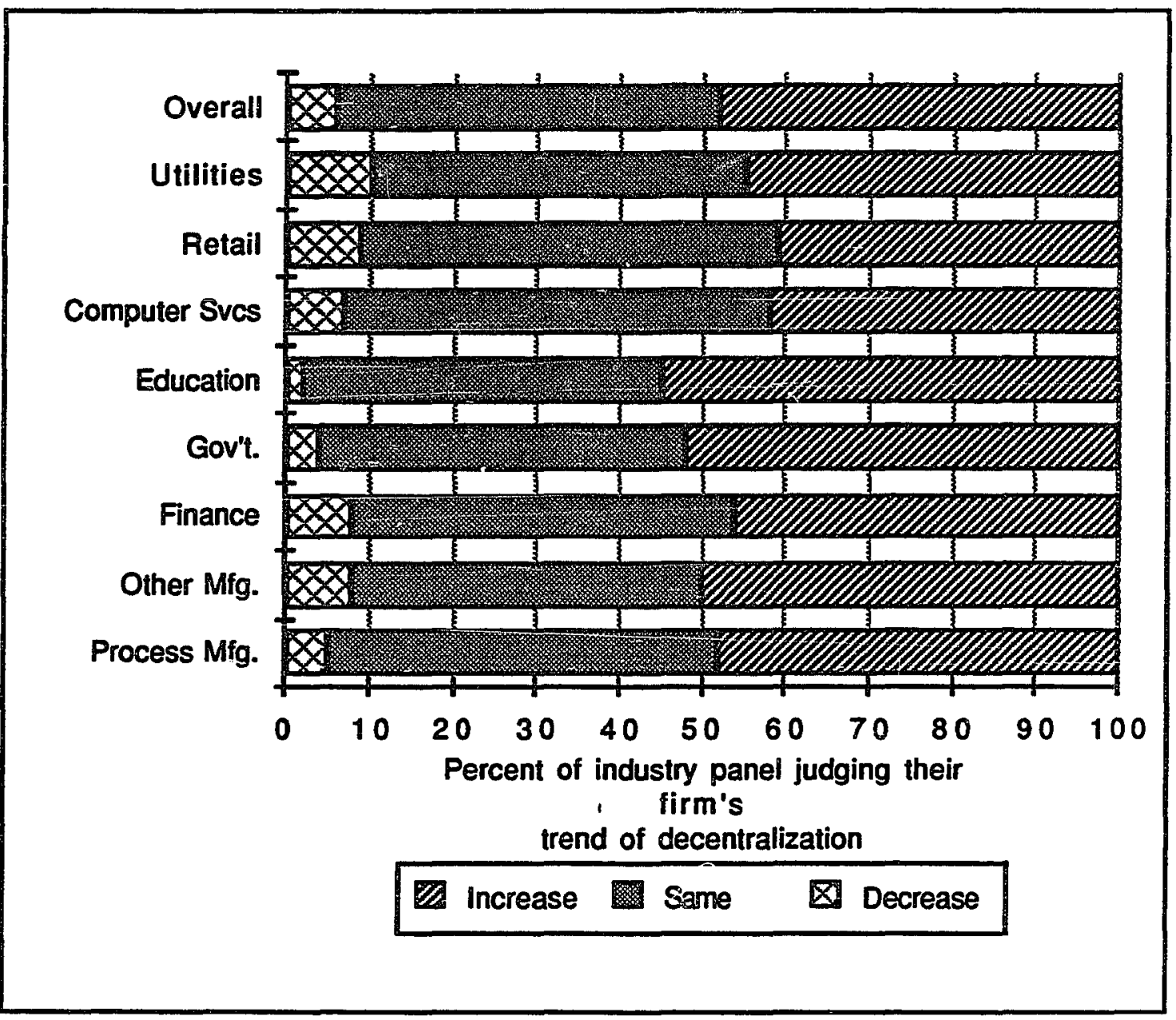

Figure 4. Trends towards computing decentralization.

This trend has had dramatic impact on the software industry in nearly all hardware classes, but has been most visible in the microcomputer and workstation classes. AI technologies such as expert systems and neural networks have also benefited from the affordable platforms and powerful operauing environments. A survey on knowledge systems [Miller] asked participants "What percentages of computers do you see as being used for knowledge systems delivery?" The results in Figure 5 indicate the trend. 


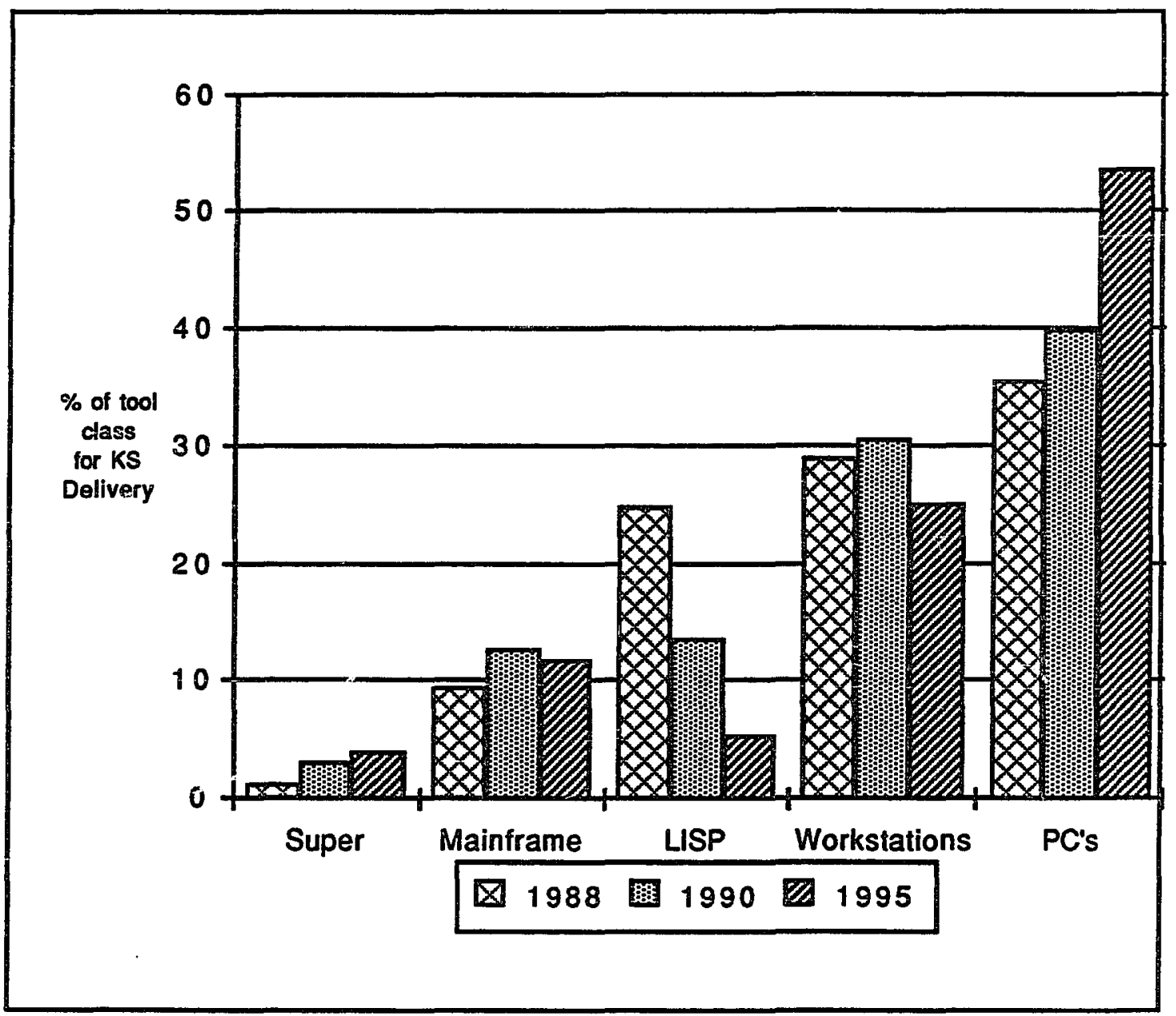

Figure 5. Trends towards small computers.

With a trend towards the use of lower cost PC hardware, one would expect a similar trend towards lower cost software. Indeed, the survey by Miller has shown this to be the case, by asking "what do you see as the distribution of the KBS tool market?" distinguished by tool cost in Figure 6. 


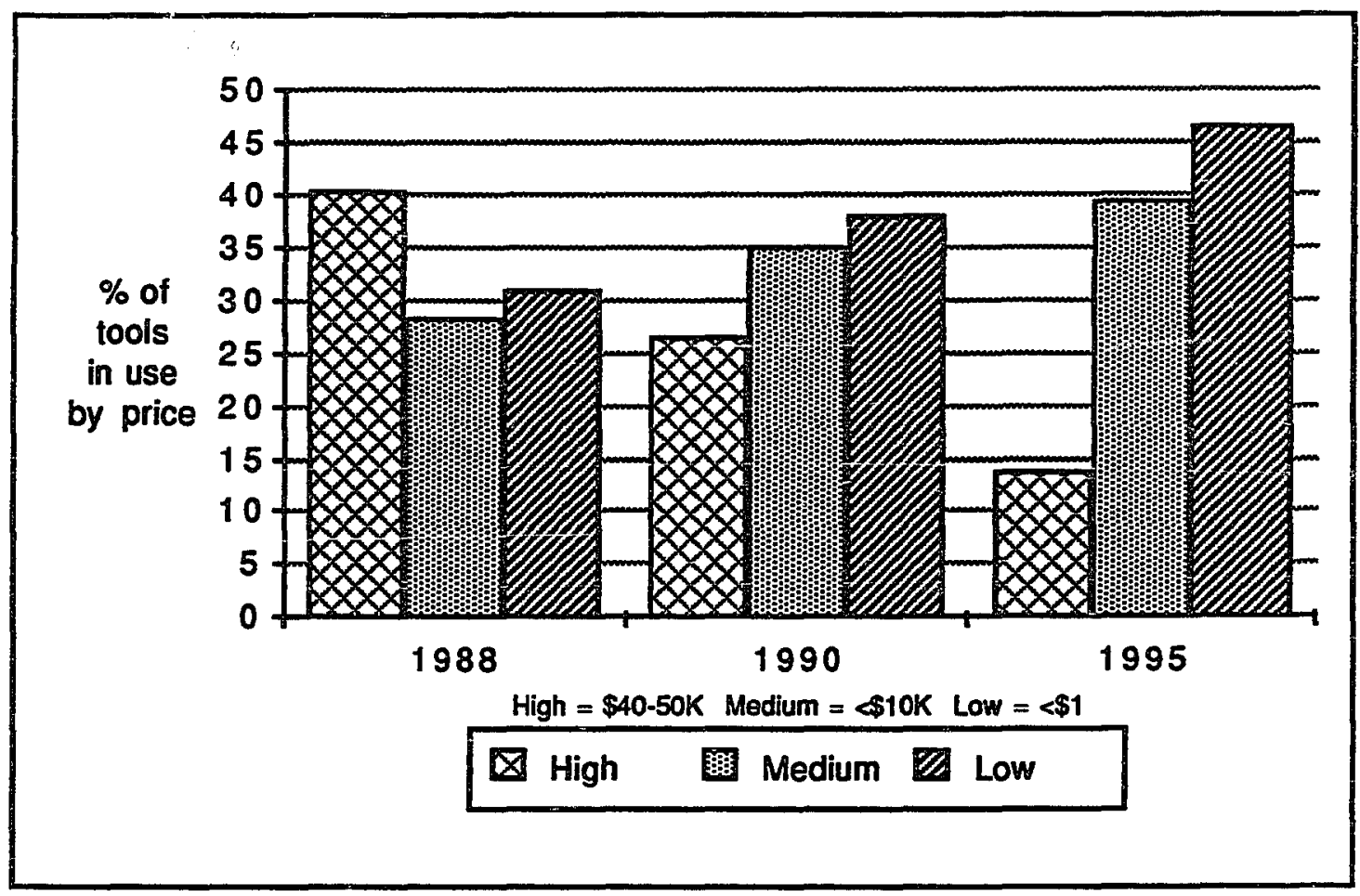

Figure 6. Trends of KBS tool costs.

With these projections, the issue of integration of these smail systems into existing and planned information systems must be considered. To integrate knowledge systems, the issues of reliability, performance to specifications, consistency, and accuracy will be paramount [Sheil]. These issues have already been raised in the cases of medical domain knowledge systems. Who is responsible for the patient care: the doctor or the knowledge system or the doctors who provided the knowledge or the knowledge engineer who built the system? What these philosophical questions reduce to, are the personal and social determinations, not the technological issues. In many domains, knowledge system technology is fully capable of providing as good or better information in a shorter time. If knowledge systems are to achieve widespread commercial use, these operational issues muse be addressed. One suggestion is to take a low profile approach by calling the technology by a different name. This would serve to remove the notion of intelligence and 
the objections previously discussed. ${ }^{11}$ Other approaches include focussing on errortolerant applications or advertising knowledge systems as assistants instead of as replacements.

The right-information, right-place, right-time goal is sufficiently desirable that an organization's employees at all levels have responsibilities to take action. Lucas has made recommendations for action at the senior management, division management, and IS management levels and all include actions to "encourage the use of new technologies."

This was demonstrated at DEC in the case of the XSEL 12 expert system, a sales force aid which guides and check computer configuration designs. To integrate such a system with XCON, Leonard-Barton found that DEC tended to three management domains simultaneously:

1. Cultivating the users as co-developers

2. Creating a network of project supporters and ensuring an adequate delivery environment

3. Organizational prototyping, which is experimentation and planned learning about the integration of new technology 13

Leonard-Barton's research has shown that the domains are deceptive in their simplicity due to the dynamics of the new information systems technology development process and the complexities of individuals and organizational groups. She also found that inadequate infrastructure (primarily support groups and resources) accounted for a surprising number of problems when implementing the technology. Once the technology was ready to be deployed, the organizational impacts were not predictable, and they were

11 Sheil reports that at least one Silicon Valley company which produces engineering workstations, has instituted a company policy forbidding use of the term artificial intelligence.

12 eXpert SELing assistant, which operates as a preprocessor to the vamoose XCON configuration expert system.

13I discovered Leonard-Barton's paper nearly a year into this research project and the similarity of her concept and my research are clear. 
not able to adequately simulate or anticipate its effect on the deployment of XSEL. This is particularly the case of a new technology with which an organization has little or no experience.

The effort required to understand how to integrate knowledge systems will pay off if one considers the potential growth of the technology. In Figure 7, the trends as analyzed by two different organizations, Artificial Intelligence Miarkets Newsletter and DM Data show the following growth of the knowledge systems market [Miller]:

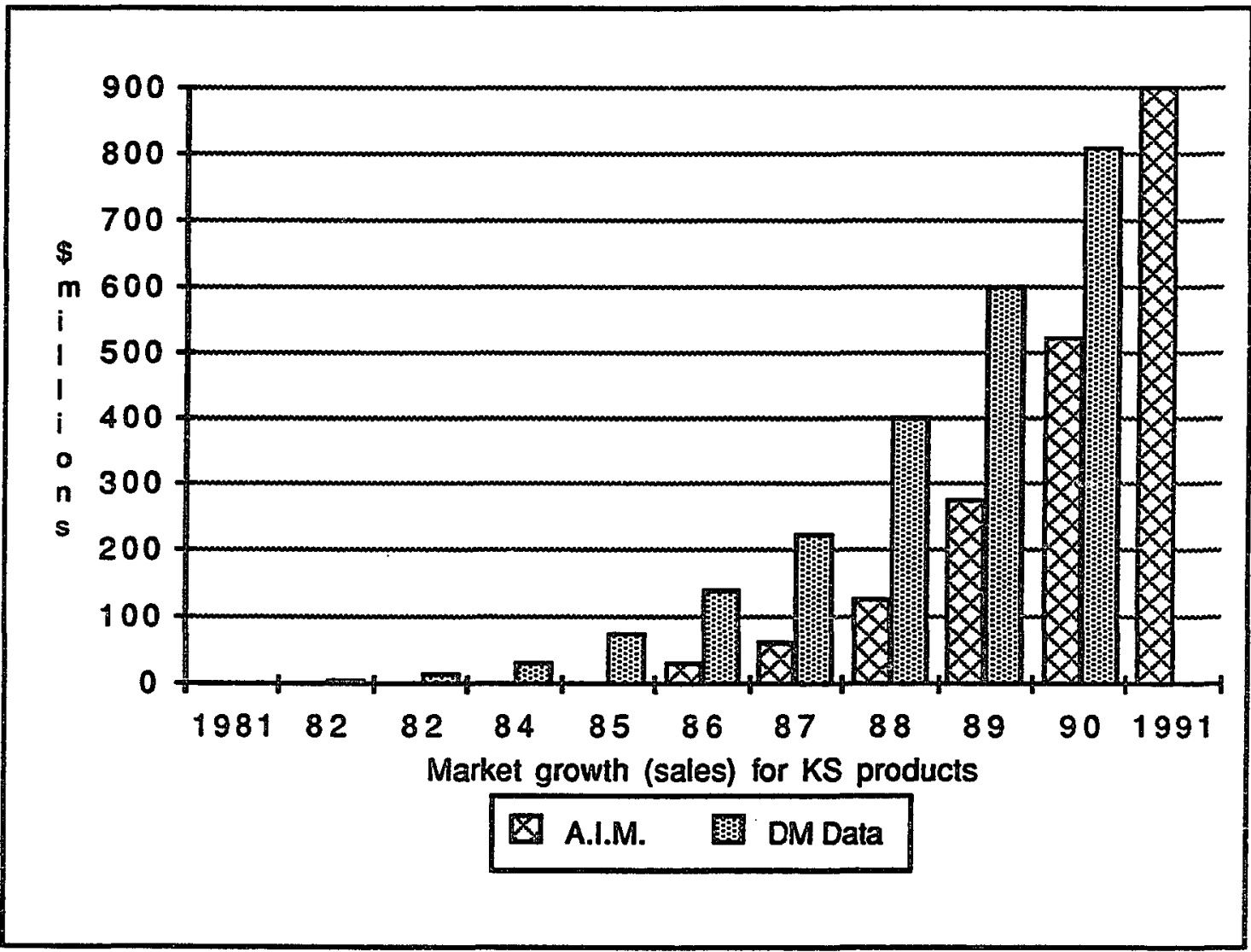

Figure 7. Predicted sales growth of KBS products.

But before reading too much into such projections, consider that many expert system tools require the efforts of skilled knowledge engineers, who are in short suppiy. So in order to fully integrate knowledge systems into information processing, tools must be 
available for both the traditional applications programmer/analyst and the domain expert with minimal computer expertise. To reach such goals, a number of extensions and improvements to tools are needed.

First is improved facilities for acquiring and testing knowledge. These facilities must simplify the task of transferring knowledge from the domain expert to the knowledge base. They must further help maintain the integrity of the knowledige base by supporting control of sequencing, semantic checking, and cross-referencing.

Second is the development of knowledge representation facilities that support reasoning from first principles, allow natural representation of spatial and temporal relations, and furnish improved methods for specifying uncertain knowledge.

Third are aids to help determine the appropriate knowledge representation and inferencing mechanisms which would affect the performance of the knowledge system. This is especially important for real-time and mission-critical applications.

Last are features to allow good integration of the knowledge system with existing applications and their data base management systems.

It will not be possible to achieve these goals in the frameworks provided by current tools. Robust and weili-integrated implementations of these features will require new designs. These advanced tools in combination with appropriate organizational and individual actions will accelerate the growth of knowledge systems as a component of an organization's total information systems services.

\section{TECHNOLOGY TRANSFER}

To provide the reader with a sound basis for the my research, a number of facets of the literature on technology transfer are reviewed in the following sections. Because there are so many factors involved in successful technology transfer, only the major concepts are 
briefly reviewed. This is followed by a discussion of technology transfer models in the literature.

\section{An Orientation to Technology Transfer}

At the most fundamental level, technology transfer is concerned with the communication of information between people and/or organizations for the purposes of applying that information to innovation [Hardy, Altenpoh], Allen 1969, Allen 1977, Cavusgil, Quinn]. As a special case of the general problem of human communications, technology transfer has great significance in the process of innovation, but the very term technology transfer is actually a cause for poor communication of what the process involves. The image of moving or transferring something from one area to another is totally misleading. The ossence of true transfer (or more precisely integration) is an extremely complex process. This can be seen by the cost of producing the first successful commercial jet, the Boeing 707 . While the 707 was based on military predecessors, it took $\$ 127$ million and several years in the late 1950 's to transfer the technology from the military division to successful commercial implementation [Hardy].

Although people in industry spend about 72 percent of each working day communicating [Hardy], very few have had any directed training in this vital activity. Some people are said to be "born communicators" and others quite dramatically blunder their way along. Communication depends upon cooperation, so it follows that technology transfer is also dependent upon cooperation. There can be no human cooperation (no communication) without feedback and no technology transfer without participation in

$=$ communications. Only intensive, continual, and extensive participation can insure successful communications and the resultant technology transfer. Some of the mechanisms to achieve this participation wiil be discussed later. 
Once communication has occurred, action is required to produce the product or service (which is based on the technology that was transferred). There are a number of barriers to such action, some of which are:

- Communications style. Much scientific and technological communication is dry and boring. The pursuit of objectivity and precision are the justifications for such style. 14

- Market lag: An invention may occur at a time to meet needs, but the time and effort to complete the innovation process, including product and market development, may impact the technology transfer.

- Detrimental attitudes: The "not-invented-here" syndrome and professional superiority attitudes 15 are two examples.

- Educational deficiencies: R\&D workers do not understand the markets their company targets and market workers do not understand the technologies being developed.

Reducing these barriers are a key part of increasing the efficiency of the technology transfer process. These few examples point out some characteristics of the process: it is concerned with people, organizations, and technical matters, and as such it is quite complex. It is an ongoing process, which is multifaceted, diversified, and constantly

${ }^{14} \mathrm{~A}$ quote from Arthur Koestler from The Act of Creation: "... I must mention one specific factor which is largely responsible for turning science into a bore, and providing the humanist with an excuse for turning his back on it. It is the academic cant, of relatively recent origin, that a self-respecting scientist must be a bore, that the more dehydrated the style of his writing, and the more technical the jargon he uses, the more respect he will command. I repeat, this is a recent fashion, less than a century old, but its effect is devastating."

15 This is particularly noticeable in AI. Workers with advanced degrees, often working in specialized environments (expensive hardware and software, LISP, Prolog, and the pretense of the research lab), often view industrial application (which is the completion of the innovation process) as a less worthy endeavor. Conversely inose involved with industrial application characterize the R\&D workers as "blue sky folks" and "people who play with toy problems." What neither group is willing to admit is that the full spectrum is necessary and one could not exist without the other. 
changing, thus requiring skilled, knowledgeable management. Not surprisingly, these preceding characteristics indicate another, that technology transfer is costly if it is done well and extremely costly if done poorly.

The Asian and Pacific Centre for Transfer of Technology, 16 in their Technology Atlas, has prepared a description of problems and constraints in achieving technology induced progress [Sharif]. The following material is derived from the Technology Atlas.

The problems can be grouped into five sets. The first set includes those related to the understanding of the unique characteristics and related aspects of technology:

- Technology is a combination of both tools and knowledge on how to use the tools

- A technology has value beyond a product or process in isolation. It has economic, social, and political value.

- Technological specialization has increased the interdependence of technologies, with the need for integration processes and the people and organizations designed to perform the integration.

- Technological advaricement can be viewed as a measure of organizational development.

A second problem set is due to variances in perceptions and preferences, such as:

- The "not-invented-here" syndrome

- The converse of the "not-invented-here" syndrome, where it is perceived that external technologies have greater value than those developed internally.

16 of the Economic and Social Commission for Asia and the Pacific. The Technology Atlas included twelve country policy studies including Bangladesh, China, India, Indonesia, Japan, Republic of Korea, Malaysia, Nepal, Pakistan, the Philippines, Sri Lanka, and Thailand. 
- Following the trends, without selectivity, when deciding the focus for building technological capabilities.

A third problem area concerns organizational infrastructure and its associated management practices, including:

- Ineffective $R \& D$ programs

- Effective R\&D programs, but ineffective linkage to technology application

- Greater emphasis on gaining knowledge, lesser on applying it.

- Absence of formal technology monitoring, forecasting, and assessment processes (including delivery of findings to the point of use).

- Compartmentalization of technology by organizational design (within groups, divisions, departments).

- Ineffective coordination by organizational officers and managers who have other pressing concerns.

- Technologicai directions considered at low levels of management (often due to unqualified senior managers or ineffective leadership).

A fourth problem area concerns the level of commitment to technological considerations and leadership behavior:

- Policy makers not getting sufficient financial, organizational, and political support.

- Technologists not being exposed to management and market concepts which affect their work.

- Planners and managers depending on their biases and inclinations rather than understanding other perspectives.

- Poorly planned and executed changes in policies, organizations, and technological directions. 
The fifth and last set of problems are those represented by the attitudes and preoccupations of people, such as:

- Top leadership operating in a crisis mode, attending to the hot issue of the moment instead of controlled, thought out management.

- Policy decisions made in response to immediate political and economic pressures, at the expense of longer-term technological strategy.

- Scarcity of time to develop and act upon sound technological plans, due to ceremonial duties, crisis mode of operation, and intellectual clutter.

- Turf wars, empire building, suspicions, lack of confidence, fingerpointing, and failure to accept responsibility.

Most of the problems are internally focussed and within the control of the people within the organization, assuming the necessary levels of commitment can be obtained. A number of problems are more extemal and not within the control of the organization. These are viewed as constraints, three sets of which are listed below.

The first constraint set is due to dependence on external assistance, from other organizations or consultants, during the organizational development pariod, such as:

- Decisions to select development projects, as influenced by competing organizations.

- Directions presented by consultants which reinforce dependence on outside assistance.

- Irrelevant work being done due to external pressures (market forces, the latest technical wizardry) in the presence of ill-defined and unmanaged internal priorities.

A second set of constraints results from the very communications that is the essence of technology transfer: 
- Unrealistic aspirations due to mass media hype, which is especially true in artificial inteliigence.

- Illusions of achieving in a short period of time what other role model organizations have achieved over a much longer time period.

As previously stated, the practicing technologist gets much of the information from internal associates, but the external information sources contribute to these communications pressures. Allen has found that consultants, government representatives, customers, and vendors are all sources of information for technologists [Allen 1977]. Each of these sources carry their own perspectives and apply pressures as listed above.

The third set of constraints applies primarily to late starters as they engage in the dual problems of situational change and developing strong technological directions:

- Old practices and procedures must be replaced by those more appropriate for the new situation, as defined by the operating environment.

- There is a high propensity for suboptimization due to narrow specialization, organizational fragmentation, and professional isolation.

- The siiii siructure of the labor force is in conflict with the needs of the organization as defined by the new operating environment.

These lists of constraints are not intended to be exhaustive, but are meant to give some examples of what a changing organization faces. When they are considered with the preceding problems, barriers, and communications issues, a sense of the breadth of the technology transfer process can be obtained.

\section{Types of Technology Transfer}

There are a number of different types of technology transfer. Among them are nation to nation, company to company, department to department (within one organization), group to group, and person to person. This is shown in Figure 8. Transfer 
can also occur between any of these, and by inheritance, a transfer to a low level can also be viewed as a transfer at a higher level. For example, if Company A transfers technology to a group in Company B, we may call it company to group transfer, but it is also a company to company transfer because the group is a member of Company $B .17$

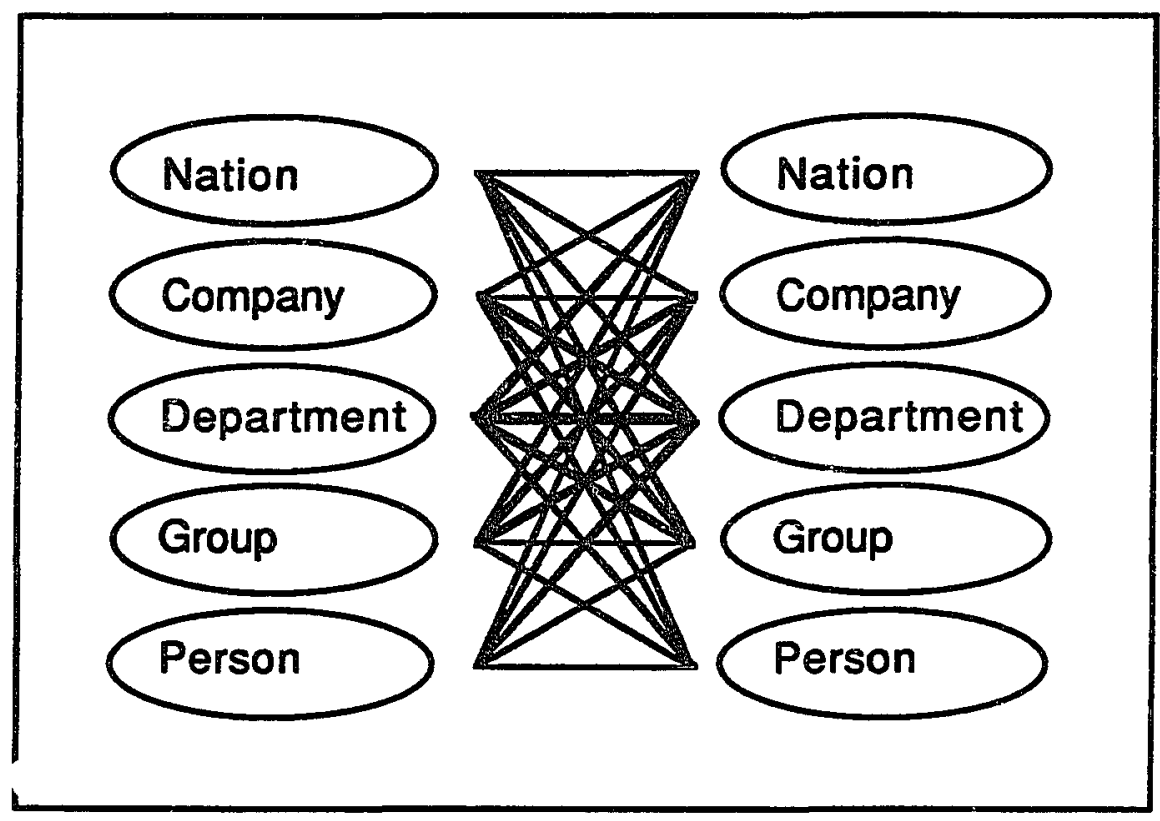

Figure 8. Different types of technology transfer.

Consideration of technology transfer at the international level requires the inclusion of factors such as geography, culture, economy, social structures, religion, business climate, and government policies [Samli]. While reduced in magnitude, a number of these factors also apply to technology transfer at the lower levels, such as differences between work groups in separate cities or organizations but still within the same company.

Mechanisms for effecting the transfer depend upon the characteristics of the technology provider and the technology receiver. When both are advanced, licensing is an effective mechanism; from an advanced to a developing receiver, infusion of capitai,

17 Of course all technology transfer can be viewed exclusively as person to person, since this is where the exchange occurs, either personally or through documents or artifacts. 
management and technical knowledge and skills, and sponsored $R \& D$ are effective; from a developing provider to a developing receiver, cooperative ventures can be used to share costs, knowledge, and risk [Cavusgil].

At the industrial level, a number of technology transfer mechanisms are possible, but they must be carefully used because they can also be used to suppress technology. Acquisition of patents through R\&D or purchase can lead to patent consolidation, which allows control of the rate of development of the technology; sharing of key patents with a select group via a patent pool enables the control of common markets by preventing new competition from outside the group; licensing a technology for limited use allows the licensor to suppress the use of the technology in a particular market; and takeovers enable the acquiring company to take control over the development of a new technology which may threaten an existing technology controlled by the acquiring company.

Patent acquisition and development as a defensive technology transfer measure is exemplified by AT\&T's entry into radio technology. 18 As reported by Dunford:

"AT\&T was the first company to organize a coordinated research effort aimed at producing a quality system of radio ("wireless telephony") transmission and reception, but it entered radio research as a defensive measure because of the claims teing made about the potential of radio which, if true, could have had a serious impact on AT\&T's investment in wire communications. AT\&T secured for itself a central position in the development of both radio and telephone through securing the patents on a few specific inventions: loading coils, the mercury-arc repeater, and the three-element vacuum tube.

Since the beginning of the Bell system, it had been company policy to consolidate patents to maintain its telephone monopoly... More than just providing a monopoly, patent consolidation can delay the introduction of new technology. AT\&T held back the combined handset and dial system for 20 years because of its investment in the existing technology and associated emphasis on cost-saving through standardization."

${ }^{18}$ This sheds more light on the evolution of the AT\&T monopoly described in the Background and Context section. 
To narrow down these diverse considerations to the domain of the Knowledge Systems Transfer Project, a distinction of reliance on technology sources is helpful. In a study on entrepreneurship and technology, Roberts made four distinct sub-definitions of technology transfer [Roberts 1969], which viewed how dependent a new company was on its technology:

- Direct technology transfer specifies those situations in which the new company could not have been founded without technology that was taken from a source organization by an entrepreneur and deployed in his company. The transferred technology was essenticl to the existence of the new company.

- Partial technology transfer is when the technology from the source organization is important, but technologies from other sources also contributed to the success of the new organization.

- Vague technology transfer occurs in the situations in which some technology transfer occurred, but the transfer was of general skills rather than of specific ideas or devices.

- No technology transfer is when nothing from the source company could be specifically identified as being transferred into the new company. By applying these categories to the general industrial arena, they are helpful in characterizing the type of technology transfer occurring with the Knowledge Systems Transfer Project. Knowledge systems technology was not created by U S WEST or any of its predecessors. There is no primary source organization for the technology, but there is a large number of general skills and knowledge that has been imported to the Project for transfer to other organizations. While this falls into Roberts' "vague" category, and the term "vague" has misleading connotations, it illustrates that KSTP is assimilating the technological components from a wide variety of external and internal sources and 
transferring it to other people and organizations within US WEST for application in new problem domains. It is this level of technology transfer that is the focus of this research.

\section{Different Names for Technology Transfer}

Technology transfer means more than "taking a thing that is here and moving it over there" [Schon]. There are many terms in use which attempt to put a symbolic label on a very complex, broad process. Having already discussed the definition of technology transfer and my preference for the term "technology integration," I have willingly submitted to using technology transfer as the commonly used phrase. This section describes a few more terms and what some authors mean when they use them.

The Technology Atlas report [Sharif] is produced by an organization that uses "transfer of technology" in its name. 19 This usage basically follows the definition developed earlier in the paper you are now reading. However, the report [Sharif, page 28] discusses "issues in technology assimilation," "steps involved with assimilation," "prerequisites for assimilation," and presents a framework for assimilation. The concept of assimilation is much closer to my preference of "integration" by connoting activity to incorporate the technology into an organization (or in the report's case, a country) for productive use.

Erdilek and Rapoport report on a philosophical argument about when transfer has occurred [Erdilek]:

"Some participants in this debate contend that technology is not really transferred unless the knowledge that has been transferred is actually used by the transferee. Others argue that what the transferee does or can do with the knowledge he or she receives should not be a factor in determining whether a transfer has occurred, although they recognize that the mastery of that knowledge is a critical factor in examining the effect of any given transfer. The fact that the technology is knowledge rather than some tangible product makes the concept of transfer a difficult one to define operationally. When a product crosses a national boundary, it is on longer in its original location. Whether it is used or not, it can be said to have been transferred. However, in transferring

${ }^{19}$ That organization is the Asian and Pacific Centre for Transfer of Technology 
knowledge, the transferor is not giving up the knowledge, but is essentially sharing it with others. If the recipient does not understand what he receives, can it still be called knowledge? We do not think so."

I would concur that understanding of what is received is necessary, and would further agree that putting the knowledge to actual use is a prerequisite for successful technology transfer. In my preference, if a recipient does not actively use the knowledge and skills in some innovative way, effective transfer or integration has not occurred.

Another term occasionally used is "technology diffusion" which is used synonymously with "technology transfer" by the recently formed Technology Policy Task Force of the U.S. House of Representatives Science, Space, and Technology Committee. The Task Force's emphasis is on "facilitating the diffusion of technology through the economy." More insight into what this might mean can be gained by a review of diffusion models in the next section.

Monger introduces another term, "technological absorption," which is not explicitly defined. However, this short passage provides a definition by context [Monger]:

"Rapid change introduces confusion about when to buy into a new technology and when to discard an old one. Thus, many managers have come to believe that they are scrambling to keep up with technological innovations in vain. No matter how hard a manager may try, absorbing new technology as quickly as it develops seems impossible ... Generally speaking, the ability to rapidly absorb new technology is desirable."

This idea of absorption gives the impression that new technology is somehow soaked up like a sponge, without any conscious directed effort.

One last phrase is the "management of technology transfer" [Cavusgil]. This quite simply and importantly states that the technology transfer process, whatever name you 
attach to it, must be managed with the skills and knowledge of the field. It will not happen by itself, and will not have good results without proper management. 20

\section{Technological Rates of Change}

Technological change often occurs through a series of successive substitutions and diffusions. In this section, I will briefly introduce the topic of technological substitution and how it is related to the technology transfer process. Diffusion will be explored in greater depth, as a phenomena in its own right, and as related to internal organizational diffusion.

At an individual level, the rate at which new technology is introduced is dependent upon the recognition of need and acceptance of the new technology by people [Pearson]. This individual behavior, however, has been shown to have a remarkably consistent behavior when examined from a larger view. This is the S-shaped curve and its sequential overlap through successive evolutionary changes in technology. In this view, technical advance is when one product or service is substituted by another, such as horse buggies by cars, paper mail by electronic mail, or natural materials by synthetic.

Also incorporated in the concept of diffusion is the behavioral theory that acceptance is an adoption-imitation process [Teotia]. The new technology is first adopted by a few pecple, the innovators, who in turn influence other people to adopt it.

The discovery or invention phase of a new technology involves a broadening of the concept, testing it, and assimilating the finds into an accessible technical knowledge base. Matching of the discovery or invention to a technological need and creating a first viable product is the next phase. Then the diffusion phase begins, in which the new product or service spreads throughout its target population. It is during the diffusion phase that

20 This also brings to mird the many people and organizations who say they are engaged in technology transfer bust are clearly unaware of the breadth of the process and the commitment required to successfully integrate a new technology. 
substitution of one technology for another occurs, as shown in Figure 9, where Technology A is displaced by Technology B, then Technology B is displaced by Technology C.

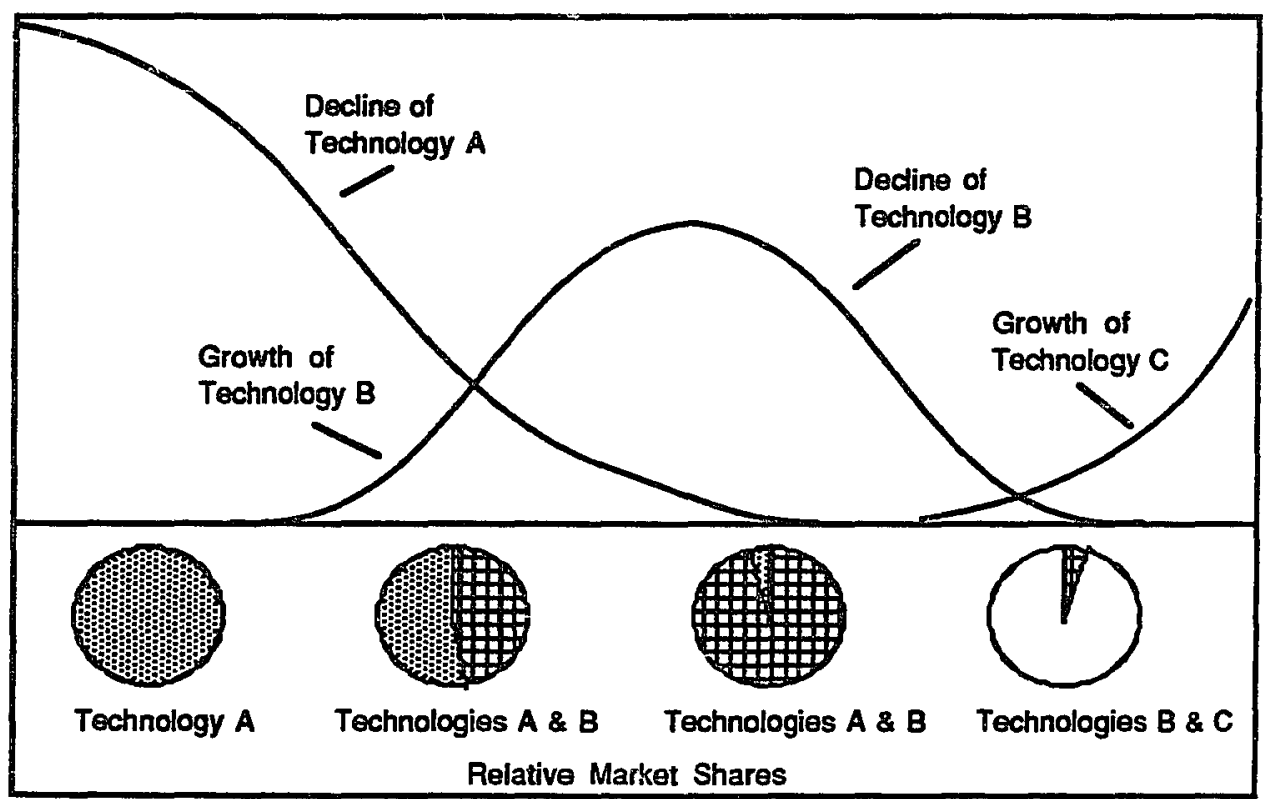

Figure 9. Substitution of one technology for another.

Mensch theorized that there were institutional barriers which caused the S-shaped curve in technological adoption [Mensch]. He calls this the bandwagon effect, where "individuals - instead of passing by with a somewhat uniform frequency rate - first do not come at all, bist shortly after some forerunners do show up, the whole party marches by together." Once initial barriers are broken, this gives rise to the dramatic steepening of the slope of the S-shaped curve.

Within an organization, some specifically cited barriers to diffusion in a study of 100 major corporations [Vandermerwe, Debreyne] were:

- Difficulty communicating observable benefits and showing evidence to support them. 
- Risks are perceived as too high, which some call "corporate inertia," "lack of entrepreneurial thinking," and "internal ideological attachment to prior technology."

- Interdepartmental resistance and lack of consensus on benefits, with conflicts aligning along departmental boundaries.

- Politics and psychological barriers such as fear, rivalry, jealousy, bias and self-interest.

- Lack of clear access to power base, getting to the right people and the right time.

Once these barriers have been overcome, Fisher and Pry, based on the study of several technological substitutions, concluded that when a technology captures about $5 \%$ of the market, there is a high probability that it will continue to spread until it completely replaces the former technology. This observation is useful in the case of knowledge systems adoption from a heuristic viewpoint, but not absolutely, because there is no concise definition of what the displaced technology would be, and therefore no possible definition of the size of the market. So it is not possible to know when the critical mass has been achieved, other than to perhaps observe a rapid increase in the usage of the technology.

Achievement of critical mass has implications for the technology-leader and technology-follower strategies often adopted by organizations. 21 These strategies ask the basic questions of whether it will pay to be a leader or a follower, and if a follower, what will give the best technological competitiveness. In these leader-follower cases, the individual growth curves for the two organizations give rise to the concept of coupled technology transfer [Raz] in which the curve of one uniformly lags that of the other.

${ }^{21}$ This is described in the section on Technology and Market Linkage. 
Depending on the characteristics of the two organizations, leadership advantages can be quickly lost if the follower is a fast follower with superior non-technological strengths.

As the technology spreads, there will naturally be an increased number of organizations in these leader and follower roles, which can accelerate the growth of the technology. This spreading of a new technology among the universe of potential adopters is what is referred to as diffusion. To increase the likelihood of an organization gaining its share of benefit from a diffusing technology, it must plan to implement appropriate modifications to the technology so as to shape the characteristics of each group of potential users of the technology in their market segments [Talaysum]. In this view the adoption of knowledge systems technology will benefit from tailoring the technology offered to clients so as to more directly benefit their needs. For example, offer PC software if the client owns and uses PC's, workstation software if the client owns and uses workstations, etc.

Stoneman notes two main themes which are not always adhered to in the study of diffusion and which has bearing on the adoption of knowledge system technology. First, is that the observed diffusion pattern will be the result of interaction between the consumers and the suppliers of the technology. From this it follows that changing the frequency or quality of interaction will change the rate of diffusion. Second, the diffusion process is based on rational behavior. This is less certain with knowledge systems technology due to 1) its association with the mystique of artificial intelligence and 2) the irrational desire of many managers and technologists for the "magic bullet" which will solve their major problems.

Having examined the concept of diffusion, there are weaknesses in the concept that must be pointed out [Gold 1983]. First, is that the diffusion model makes enormous simplifying assumptions, such as that prospective users have fixed and basically similar objectives, operations, decision processes, products, and evaluation criteria. Second, the technology itself, especially knowledge systems technology, undergoes numerous 
significant changes in capabilities over time, such as reliability, operating flexibility, and efficiency. Third, is that the universe of potential adopters is known and fixed. This is definitely not the case for knowledge systems technology.

To conclude, the diffusion process must be kept in perspective, using the sigmoid curves as a rough mental image, but tempered by knowledge of their limitations. Research has shown [Gold 1983] that errors in estimating the expected technological benefits of innovations center on underestimation (often considerable) of the time needed to achieve functioning innovation, overestimating utilization rates when determining benefits, and underestimating the need to make adaptive adjustments in areas of the business associated with the new technology. And finally, Tressel observed that "the process of industrial technology transfer depends upon a critical and random diffusion of ideas." The process must be better than "random" if it is to be amenable to direction-setting and management.

\section{Technology and Market Linkage}

With evolutionary technology, there is a natural sequence of events that provides a clear path from an idea to a marketable 22 product and this path is typically a variation of a previously traveled path. Revolutionary technology, on the other hand, has no clear sequence of events, no map for guidance, and less protection from heading towards a deadend. This implies that there should be different management techniques for each of these situations, and while this is true, it is perhaps more surprising that there are fundamental similarities in managing each situation.

The primary similarity is that both evolutionary and revolutionary are based on the same core strengths of current corporate technologies in products, materials, systems, or production processes. It is logical to start a revolutionary project from the technology areas

22Market, as used here, refers the domain of people willing to invest in a product, either as a finished good or a service which the people can use. The latter is more applicable to KSTP. 
that an organization has most familiarity and expertise. The additional benefit from this is that an organization's present markets can also be used to evaluate progress in such areas as customer needs, competition, pricing, distribution, service, and reputation. Even in internal technology integration, these market forces are active.

To effectively use these core strengths requires an integrating process that can be used to plan and control the alternatives for future technology directions.

There are a number of arguments about the desire to relate revolutionary technology to the marketplace because there may not be a market or even a perceived market need for the technology being researched. Evolutionary technology is much easier and more accurately related to the markets. Strategic technology planning can use the technology and market knowledge to provide some help in determining the $R \& D$ areas to emphasize. These four steps suggest how this can work:23

1) Establish an explicit framework for analyzing markets and technology

2) Analyze the market requirements

3) Analyze the technology requirements

4) Determine levels and priorities for technology investments

This is not necessarily a process for technology planning but provides a structure for organizing and thinking about the task of defining priorities. Step one requires close interaction between technology and market planners to develop "units of analysis" to relate operating unit strategy to technology and provide a common basis for comparing and integrating technology and market factors. The desired situation is to have market pull dominate the technology push, although revolutionary technology often results in the latter.

Step two determines the most important markets based on future returns and relationship to core business areas. The market leverage is based on needs or wants that

23I am indebted to Robert C. Larson for discussions about these steps and helping me understand their usefulness in setting corporate $R \& D$ direction. 
affect the clients purchase decision inciuding function, acquisition cost, ease-of-use, operating cost, reliability, serviceability, and compatibility. Different products and services in knowledge systems technology will be more or less sensitive to any number of these acquisition factors. Those that make a difference to the customer are the ones chosen for further evaluation. An example of this would be the current status of robust knowledge systems software. Such software requires relatively expensive hardware. This is a barrier to purchase for many consumers and is therefore a worthwhile area for an appropriate company to pursue, and a number of companies are doing this.

Included in the market analysis is a competitive product profiling in the same criteria listed previously. This puts the absolute market demand into a usable perspective by comparing an organization's competitive technology position with that of other organizations. Where a strong demand is shown from customers and an advantage exists over competitors, the market is viable for further development.

A difficulty in the market analysis is found when dealing with technologies that may be discontinuous in their life span. This may cause incorrect analysis of test market results as shown in Figure 10 [Tauber].

Over time, the discontinuous technology is a much better investment for an organization, but the short test market period would obscure that observation. The obvious point is that the discontinuity is not seen until time has passed, as there is no guarantee that the technology would exhibit continuous behavior and perform miserably. One possible solution to this is to conduct a longer test market period to see if the curve continues to rise. Even this will not always work because market research depends on clients to recognize their own needs and seek products to fill them. With discontinuous technologies, the consumer does not recognize the need until use of the technology creates the need. 


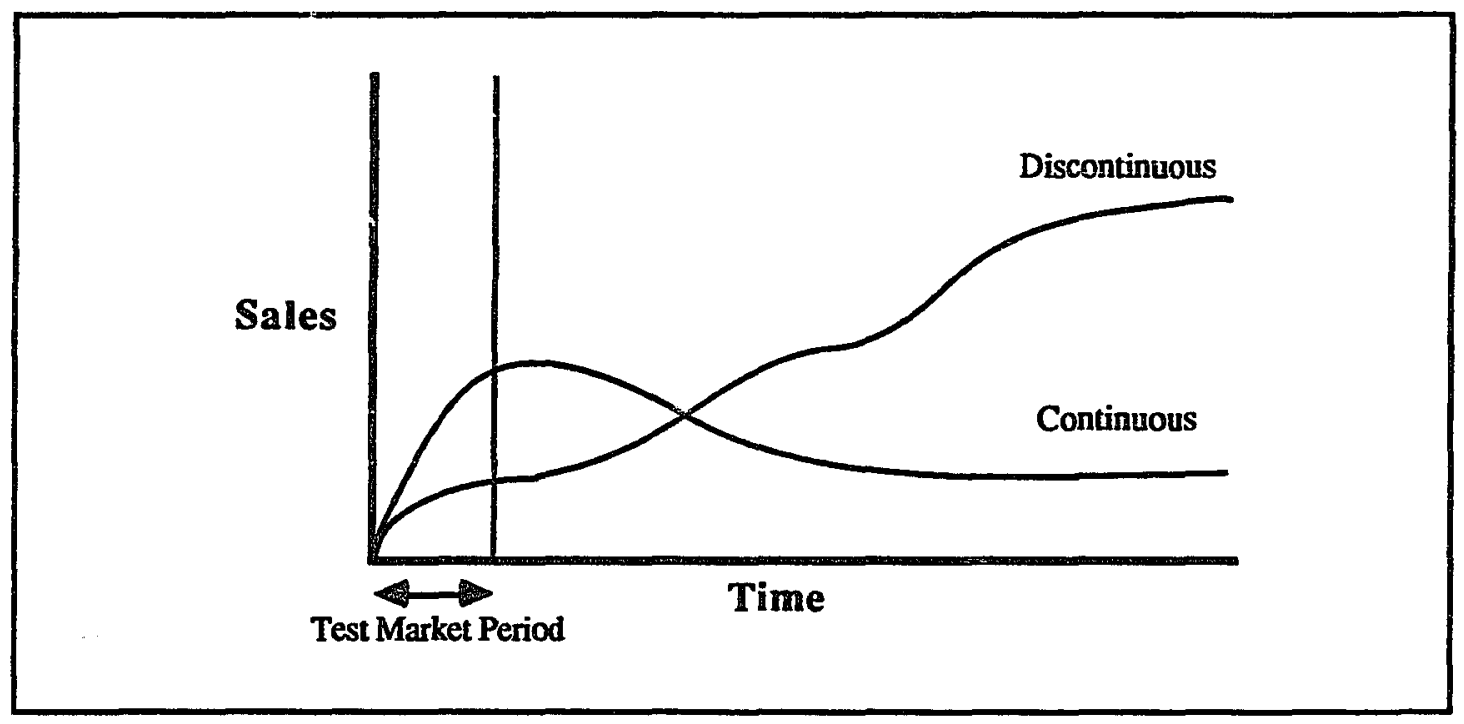

Figure 10. Misleading test market results for a technology.

Step three defines the technologies which could support the market-based technology requirements, determines the maturity of the technologies via technology forecasting, evaluates the current resource base including required skills, and examines future competing products to determine how cost and performance might change over time. The primary objective of this step is to identify the technology options which are available to the organization.

The technology forecasting process has not been as useful to corporations as the availability of techniques might suggest, due to forecaster's inattention to implementation factors. Critical elements necessary for forecasting include [Fusfeld 1980]:

1) A formal integrating mechanism into organizational planning

2) Forecast presentations that meet the planners' needs

3) A planning cycle in synch with technology change

4) Top management support

5) Complete forecasting including competitor capabilities 
Technology forecasts that are not driven by corporate strategic planning needs will not be as successfully used as those that are so driven. Much of the historical emphasis in technology forecasting has been on technique development as opposed to full utilization of existing techniques.

\section{Market and Technologv Convergence}

The combination of steps two and three lead to a view of four guiding strategies for an organization's direction depending on specific market and technology positions, as shown in Figure 11:

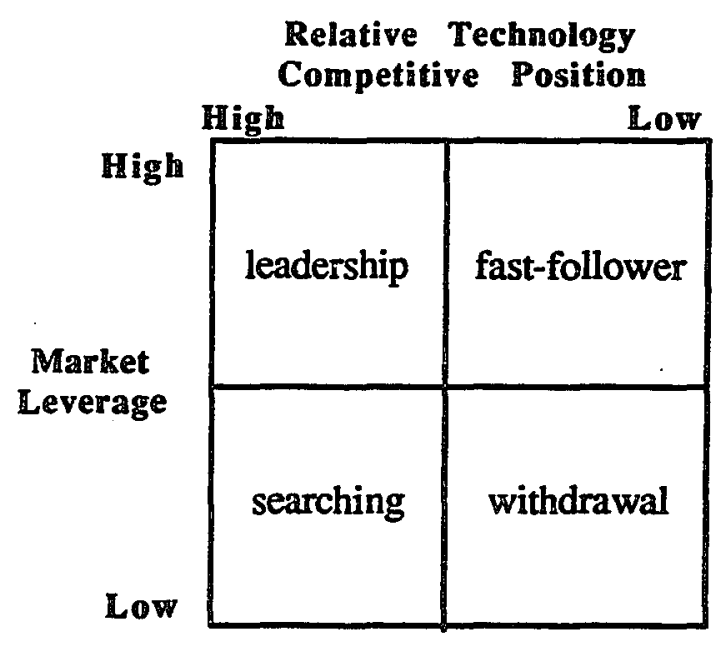

Figure 11. Strategies for specific market and technology positions.

Depending upon the relationship of market leverage to competitive position, a company will choose the most feasible strategy. The fast follower strategy is common to large organizations which enjoy a certain amount of stability simply due to their size or entrenchment. Fast followers try to learn from leader's mistakes so they can develop an improved, more reliable product that may include advanced features while avoiding innovations that may turn out to be failures. A technolog: leader with no market searches for customers. Finally, low market leverage and low competitive position guides a 
company to withdraw from that technology. But if there is sufficient motivation to pursue a technology, alternative development plans may be utilized. By noticing the similarity of Figure 11 with Figure 12 [Fusfeld 1985], you can see that a withdrawal may lead an organization to the use of venture capital, or that other gradations of weakness may lead to joint ventures. While Fusfeld developed this for external applications, it can also be applied to internal technology transfer activities.

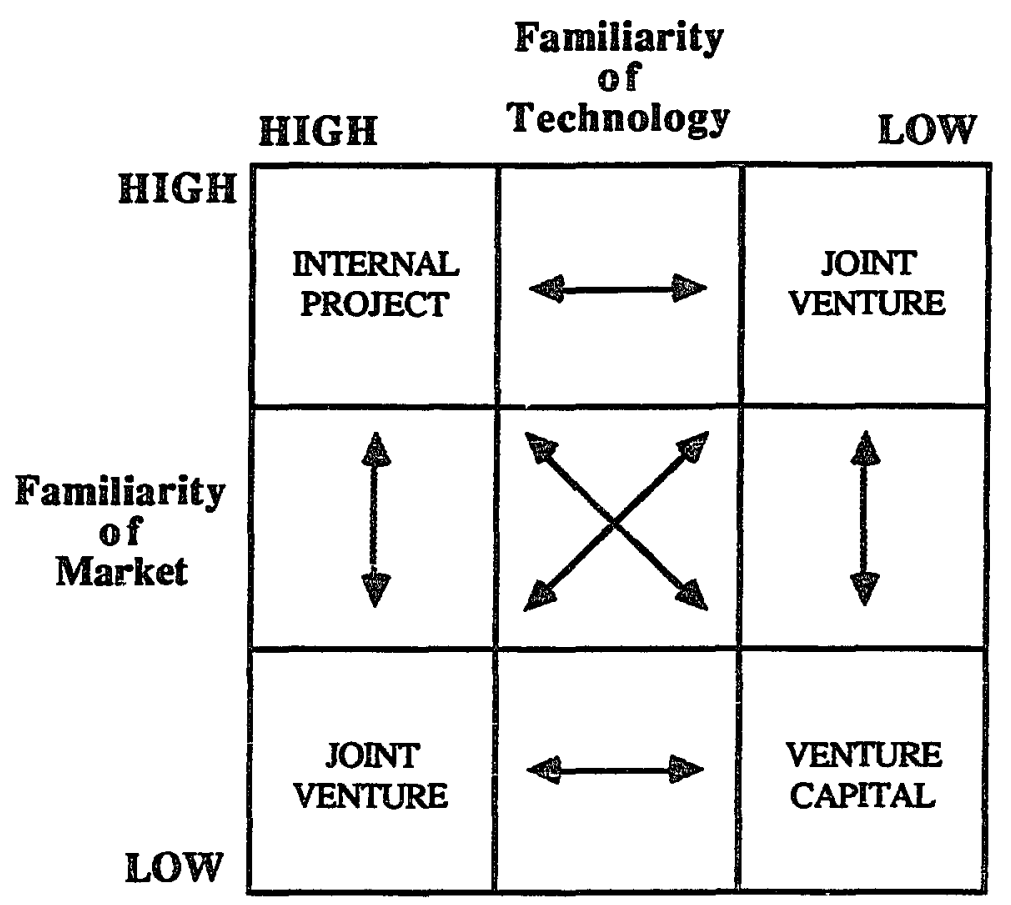

Figure 12. Funding for certain market and technology positions.

The fourth step uses the results of the these market/technology analyses to determine levels and priorities for technology investments and the mix of funding options. The objective is to establish a balance between short and long term business goals and ensure a continual flow of technology to meet the needs of the business. Even though this stepwise description implies a procedure for mechanically generating technology directions, it cannot be performed as such. The meeting of the market and technology dimensions in 
this framework are meant to provide a way of thinking about the development of a business strategy, and Philip Smith points out that thi market-technology linkage process should create some tension [Smith]. If it does not, the analysis process probably isn't working and the market and technology should be revisited.

\section{Leadership and Personnel Components}

There are three major aspects of the personal dimension of technology integration. First, leadership from managers and executives must create the atmosphere which enables the staff to work productively. Second, personnel issues are an essential part of creating and maintaining a productive environment. Third, communications transcends all levels of management and all types of work functions as the binding factor in technology integration. Each of these three major aspects will be discussed in the following sections.

Leadership. Effective use of technology in a company cannot be limited to formal mechanisms for passing ideas and new developments into and out of the technology organization. Technology must be viewed as a vital part of a corporation, and as such, must have the attention and active support of executives. ${ }^{24}$ At the heart of managing technology effectively is managing the entire company effectively. A few factors appear to be central to this effectiveness.

Risk Taking. By nature, new technology is risky. Out of 100 ideas, 10 may be worth pursuing, and only 1 may end up being produced. In order to find that one survivor, the executive must be willing to take substantial risks and accept the accompanying losses. The one survivor is not to be labeled "the successful idea" because it is the process that succeeds or fails. The undeveloped ideas provide a learning environment and a rich history for later use by the organization.

${ }^{24}$ For my purposes executive includes those throughout the corporation in addition to those in the technology organizations. 
The practice of innovation will be cause for organizational unrest because it leads to new ideas and change. Any new idea will not be accepted at first, no matter how good it seems to the originators. At best, open-minded people will listen attentively and remain neutral, gradually giving support as the idea is further developed and presented. At worst, resistance forms, defensive maneuvers begin, and the opposition solidifies. Perseverance and commitment are required if the idea is to gain widespread acceptance.

This situation poses certain problems for executives, who must know what to support and when and how to support it. This requires the ability to trust the idea champions, even when the risk seems great.

An example of this is provided by Walter Wriston, former chairman and CEO of Citicorp. He took explicit measures to stimulate innovative learning which had a high risks [Bennis]:

- He authorized many experiments; almost any good idea that someone had was supported. Furthermore, he convinced managers that this was the way to succeed.

- He encouraged the hiring of bright nonconventional types like his successor, John Read, an engineer who headed consumer banking and Edwin Hoffman, an executive vice president with a Ph.D. in molecular biophysics. He promoted them quickly, too, when they succeeded.

- He did not fire people when a risky venture failed. Instead, he'd assign the person to a more senior executive for a year or two to recover and recharge for another experiment. Consistent failure, of course, did result in dismissal, but Wriston seemed to think if you haven't made mistakes, you having been trying hard enough.

This executive behavior is not widespread in Western corporations and is even more rare in Japan where the demerit personnel system is used to evaluate employees. A 
person with a demerit or a failure is eliminated from the list of candidates under consideration for promotion to higher positions. ${ }^{25}$ Employees with no or few demerits are not eliminated, causing managers to tend not to take risks which may lead to a failure. Researchers and developers are also risk averse, choosing the wait-and-see strategy for someone to step forth as an advocate of a new research area. This is at least one cause of the perception of slow progress in Japanese R\&D. To attempt to alleviate the problem, a government agency (the Ministry of International Trade and Industry, MIT) breaks the stagnation by being a leader for promoting new directions in industrial innovation [Eto].

Finally, there are cases where the risk decision lies only with an individual, which points out the need to have the right type of person in that decision role. Experiences at General Motors Research Laboratories has shown that some problems or opportunities are of such vital importance to the organization that work should proceed without a clear mechanism for moving the research from the labs into production [Wolff]. Without individuals having the intuitive sense that the research must proceed without the traditional organizational proof, the $R \& D$ is destined to plod along in a predictable, controllable, and unsatisfying manner.

Treatment of Failure. To underscore the contrast between the demerit system and Wriston's style at Citicorp is a particularly strong illustration of the productive treatment of the occasional failure. At IBM many years ago, a promising junior executive was a central figure in a high risk venture that ended up losing \$10 million. IBM's founder and then chairman Thomas Watson, Sr. called the nervous man into his office. Before Watson could say anything, the junior executive said, "I guess you'll want my resignation," to

${ }^{25}$ The extent of this practice is disputable, for the DEC/SRC study [Report] states that "Japanese culture does not punish individuals for failure, with the result that failures can be lessons." Nevertheless, the point here is that any practice resembling a demerit system can reduce innovative behavior. 
which Watson replied, "You can't be serious. We've just spent $\$ 10$ million educating you!"

So while it is necessary for an executive to take risks, it is further required that some means for learning from mistakes and channeling the lessons leamed into a more productive working environment.

Type of Management Style. A major part of the executive culture is a result of individual management style. The effect of style on innovation is profound and must be explicitly addressed. An R\&D executive must search out the factors that encourage innovation and integrate them into his or her personal style.

A number of bureaucratic barriers to innovation have been determined to have severe impacts on large companies [Drucker 1985]:

- Top management isolation

- Short time horizons

- Excessive rationalism

- Inappropriate incentives
- Intolerance of fanatics

- Accounting practices

- Excessive bureaucracy

- Poor atmosphere

While some of these are organizationally entrenched, such as accounting practices, some are clearly within the control of individual executives. Top management isolation is a pervasive problem because risk perception is inversely related to the familiarity one has for the subject matter being considered. Lack of contact with customer and the employees doing the work are the chief causes of isolation. Information filtered through intermediate managers is not sufficient to understand the fundamentals of the business, nor is the direct experience an executive may have had 20 years ago.

Intolerance of fanatics is a common characteristic of executives in large corporations because the path to success for those very executives was through conformation and working within established norms. Fanatics with different ideas about doing things are often viewed as not being team players, and are ostracized from the mainstream. A more 
productive practice for everyone is to actively include these people in important discussions, to value their perspectives as a rich source of innovative ideas. Recall that all innovation is, by definition, a deviation from what currently exists.

Alfred Sloan, Jr. showed not only acceptance of diversity but aggressive pursuit. He felt that disagreement was the best way to expose all of the important facets of an issue. He is reported in [Drucker 1979] as saying at a top General Motors committee meeting, "Gentlemen, I take it we are all in complete agreement on the decision here." As everyone nodded yes, Sloan continued, "Then I propose we postpone further discussion of this matter until our next meeting to give ourselves time to develop disagreement and perhaps gain some understanding of what the decision is all about."

Also under considerable executive control are the incentive and rexard mechanisms. Reward systems in most large companies are designed to minimize surprises, which naturally affects innovative efforts. An innovation may disrupt existing company plans, upset power structures, and challenge the status quo. Few large companies reward innovators with compensation comparable to their contribution. Doing so would alter the perceived stability of the company and might bring on the problem of too much innovation in a company staffed with managers ill-prepared to work with such dynamics.

Highly innovative periods for many companies have been when senior executives have taken personal interest in sponsoring new technologies through the growth stages to commercialization. These executives may or ma 1ot have a technology background themselves. Examples include David Sarnoff wh $\quad d$ RCA for over 40 years through the radio and television eras; Thomas Watson at IBM; Richard Hewlett at Hewlett-Packard; and Frederick Close at Alcoa with the aluminum-clad skyscraper and aluminum cans [Graham]. The limited time of senior executives obviously means that they cannot attend to everything and the recent trends of having financial and legal people fill executive roles has resulted in 
less attention to company fundamentals: the products and services that are their sole support. These trends have resulted in executives in large corporations staying away from the technology, perhaps because they feel it is too complicated or unimportant. Neither case is true.

In technology-oriented companies, essential managerial characteristics include openness to technical possibility, belief in potential, a receptive attitude, and a true interest in technology. Formal education in the sciences and management are helpful, but not sufficient on their own. Many executives who were educated as engineers end up disinterested or bored with technology, while other executives without a formal technical education have a burning desire for technology and what it can do for people. It is the nearly constant enthusiasm for the work that is required for success.

Personnel Components. Issues of human resources are most important in an technology-oriented environment, simply because people are the sources of creativity and innovation. It is often said that creativity cannot be taught and innovation cannot be forced. It is possible, however, to create an environment that is conducive to the innovative process. A first component is having the personnel types match the company characteristics and desires. Second is the use of staffing policies to stimulate innovation. Third is providing the right organizational culture. And a fourth is the creations of a secure working environment. To accomplish the $\mathrm{R} \& \mathrm{D}$ mission of an organization requires explicit formal management of these human resource components.

Personnel Types Needed. Because the staff is the company, its composition will determine what the company can and cannot accomplish. Different types of companies have different characteristics and desires, which lead to different technological requirements.

Operationally, the problem is to be able to assess what is needed and take action to fulfill those needs. An essential part of this is to relate the company type, characteristics, 
and desires with the technological requirements. In terms of evaluating the needs for people with specific skills and knowledge, the long range needs of the corporation can be linked to skills development through a conceptual framework [Yanagishita] as shown in Figure 13. Figure 14 describes some of these organizational types and how they affect the staff requirements [modified from Glasser].

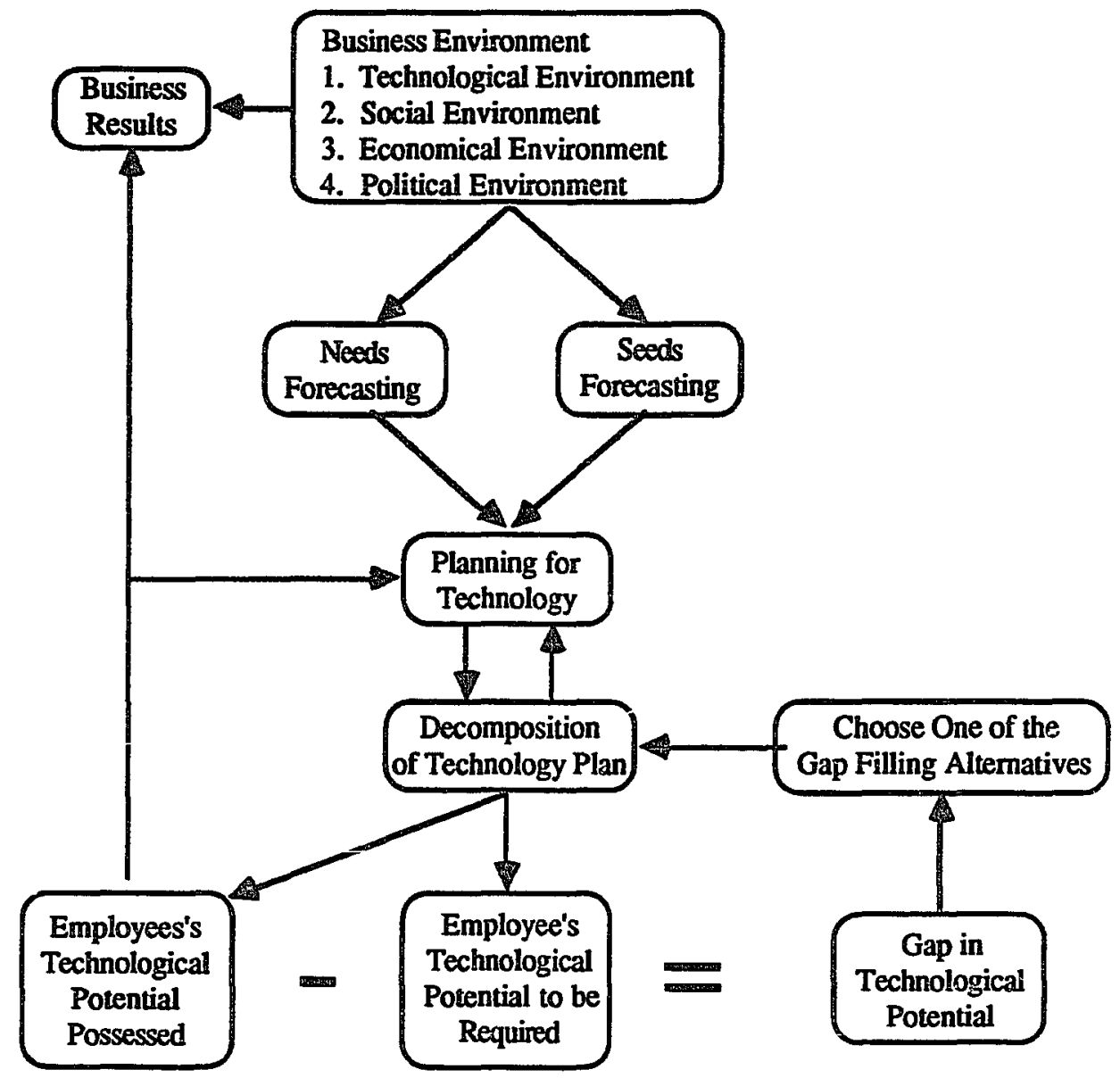

Figure 13. A conceptual framework for skills development. 
Type of Company

Characteristics

Independent Research Lab

Small Instrument Manufectures

Medium-large, hightechnology manufacturing company

Large systems house

Small product factory

Medium-sized product house

Large multiproduct house
Sells recearch and technology development, single researcher or small teams; primarily experimental science; high technology

Conceives, develops, sells small sophisticated instruments or packaged experiments and experimental hardware; high technology

Conceives, develops, and sells a complex line of sophisticated equipment or chemical basic materials and material systems; high technology

Conceives, develops, and sells one- or several-of-akind complex major systems; ultra high technology

Innovative products, low technology, large manufacturing runs

Big daddy of small product factories, some technology, mostly innovative engineering

Substantial research and innovation in manufacturing processes; some product research; medium technology
Company Desires

Continuous outpouring of new technology concepts; expansion of laboratory facilities; er:hancement of reputation

A few sophisticated programs each year leading to new instruments; funding for lab and manufacturing facility development; low-risk, highpotential internal programs

Technical depth in a few significant areas of technology; worldwide reputation in equipment performance; unique innovative devices; aggressive sales and distribution

Depth in critical technologies; systems analysis and synthesis capability; customer / market knowledge and critical assessment; total system design ability and knowledge; system and hardware reputation

One or two new products or product improvements per year; low-cost design; low inventory / large production runs

As above; moderate technology capabilities

Develop critical technologies for product lines; innovative / patentabie product designs; cost and customer conscious designs
Staff Requirements

Independent, highly motivated scientists; contacts with university and government labs; entrepreneurial types

Many high-technology innovators; enteepreneurial skills and motivation; well-directed programs compatible with facilities; competent design of sophisticated equipment

Highly motivated scientific team; innovative engineering concepts and designs; in-depth product improvement and product field support; strong patent position; strength in critical technology areas

Key technology; scientific teams and labs; systems engineering capability; frequent / effective customer contact; pragmatic engineering design and analysis; experienced engineering and developmental testing capability; aggressive personnel development programs

One or two innovative designers; pragmatic engineering skills (i.e. narrow); factory support

As above; some laboratory capability and skills

Some scientific and lab capability; innovative engineering; pragmatic, producible designs; customer and market awareness

Figure 14. Organizational types and staff requirements. 
The external factors affecting long range plans are in the business environment. The market needs and technological seeds (market demand-technoiogy push) are analyzed in combination with business results to estimate opportunity gains and losses. The effect of business results on the technology plan is dependent on how the new technology budget is managed. If the budget is set to accomplish specific long term corporate needs, the business results may have only a small effect on the technology plan. If, however, the budget is a fixed percentage of revenues, it will be subject to every change in corporate financial performance.

The technology plan is decomposed into technological specialties which can be used to assess what potential a staff member has in that specialty and the potential that is required to fulfill the plan. The technological potential gap can then be addressed by:

- Retraining existing personnel

- Hiring from colleges and universities

- Hiring a specialist from another company

- Reassigning a specialist from within the company

If all of these options are determined to be infeasible, then the technological specialty cannot be filled. This would require an iterative adjustment of successively higher organizational plans, and perhaps corporate goals.

Stimulating Innovation Through Staffing. The use of staffing policies to stimulate innovation can be used to bridge two other kinds of gaps: 1) the gap between information available for innovation and the information actually delivered for innovation and 2) the gap between technology results and technology effectively used. Roberts characterizes these as "gaps of input" and "gaps of linkage" [Roberts] and offers some altematives for the technology organization to address these gaps. 26

26 The Technology Atlas [Sharif] also identifies technological gaps, which are characterized by technology, human, organization, or information gaps. The technological gap is a composite of these components. 
One alternative is critical functions staffing, which focuses on having the right people in three key groups. First, the corporation's top management must provide the risk accepting environment I discussed previously; second, the fundamental technical people must be competent in problem finding and solving; and third is a group that provides the essential linkage of the critical functions. This third group is not as easily recognizable as the first two, but they have a similar common denominator: it is to provide the interdepartmental functions for bridging the input and linkage gaps. Briefly, these roles are the:

- idea generator who comes with new ideas

- entrepreneur who is the active proponent of the ideas

- technical, market, and manufacturing gatekeepers [Roberts 1979, Davis, Allen 1977] who each use their expertise in determining the viability and future directions for ideas

- program manager who integrates ideas into the corporation

- sponsor who as a senior manager provides the protection and nourishment for an idea to prosper

In many cases these roles are filled by a number of different people, for example, there may be a number of sponsors working together in there own areas of influence, all of which are required for success. It is also reasonable for one person to fill more than one role, such as the idea generator who has the entrepreneurial desire to carry the idea through. An important managerial observation, though, is that multi-dimensional people are not common, so those who are not entrepreneurs must not be expected to attempt to be so. This would surely mean that ideas would not be as well developed as if a true entrepreneur were to fill that role.

An alternative to critical function staffing is the product team approact The key aspect of this approach is the absence of technological work within a separate function 
group, isolated from the other groups needed to effectively use the technologies. A multifunctional group is created with members from other groups in the corporation, such as manufacturing, finance, and marketing. In a sense, it is combining many parts of the critical function staffing into one team. Such a multi-disciplinary team composition results in products and services very different from those designed in isolation.

Personnel arrangements are an important part of technology transfer. Because the process is essentially social in nature, it involves people in all organizations and at all levels. Technology transfer is all to often viewed as an object or an event: a report, a meeting, or a presentation. This is a mechanistic view of technology transfer and it can be improved upon by establishing a flow of technology. To develop this flow the concept of a receptor is useful. A receptor is an individual within various corporate groups who understand or are willing to learn about linkages between emerging technologies and product opportunities [Soloway]. They act as local champions and paths for two way communication. For example, the marketing and technology departments can be effectively linked with the presence of receptors in each organization. The marketing people become much more aware of the available technology and the research people learn how to focus towards market demand, even over long time frames.

Technology transfer can be attempted by a number of methods which can be categorized as procedural, human, or structural [Roberts 1988]. Procedural methods are mechanistic devices intended to bridge the technology units with the appropriate receiving units, often via joint planning and joint staffing along some predetermined procedures. An example of this is the MCC computer research consortium, which includes over 20 computer corporations as members. Human methods focus more on the personal interactions. These methods include informal meetings, reports, and conversations arising from individual initiative and formal actions such as intergroup movements of personnel to transfer information. MCC also has some of this component, but it is somewhat 
constrained by legal entanglements due to the competitive nature of the member corporations. Informal technology transfer is too hard to control and works best within one corporation or among non-competitive organizations. The structural methods have specific organizational units devoted to technology transfer. Often these units have a finger in many functional groups and are supposed to act as a formal conduit for information.

Of the three methods, the correct combination is subject to the characteristics of the corporation. The structural approach is often the least successful because of conflicting organizational pressures on the group. It can be useful only when a well-defined mission can be stated and accepted by all groups using the technology transfer group as an information source or sink. The human approach is usually the most successful because of the interpersonal dynamics. The procedural methods are most effective when used in combination with human methods. Finding the combination for a particular organization is the key to effective use of technology.

Creating a Secure Working Environment. Technology workers have many motivators which are similar to all workers, such as those that are on Maslow's hierarchy. Perhaps they are somewhat more concerned with higher issues such as seif-actualization. It is beyond my scope to attempt to comprehensively address motivators for such employees, but there are a few factors unique to technology workers that are very important.

One is the need for protecting the job security of high risk workers. This is provided by the executive belief in the uncertainty of research efforts and the belief that this is the way to operate. This is most difficult for managers with experience only in traditional management environments. These managers try to force research-dependent innovation as they would an engineering program. They apply pressure and throw money around without taking the time and effort to think about what they are trying to accomplish. At early stages of exploration, motivation can be encouraged by a manager providing true 
interest (the love of technology mentioned earlier), support, and enthusiasm. Only when a project moves into a state of technical readiness can the usual motivating techniques of pressure, money, resources, and deadlines be effective. If a manager applies the latter techniques inappropriately, the high risk workers may quite justifiably feel that their job is in jeopardy. Premature pressure by RCA managers led to many of the most difficult periods during the development of the videoplayer.

Companies that operate their technology organizations as cost centers which receive a fixed percentage of corporate results add another instability factor. The need for a sustained effort in certain technology areas may be overridden by the limited funding in a period of poor company performance. This could cripple a company for a much longer time than the temporary downturn in business. Figure 15 illustrates one way of minimizing the internal expansion and contraction [Iwata]:

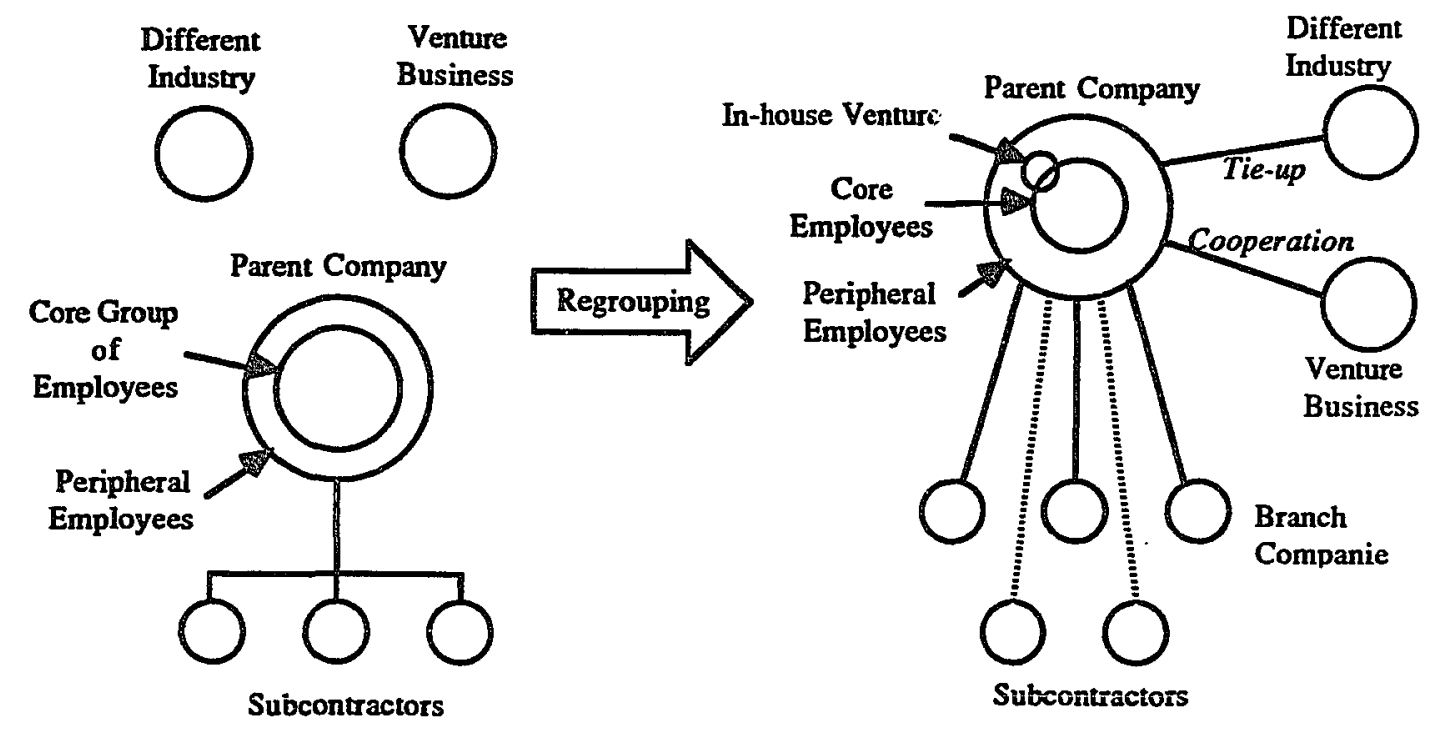

Figure 15. Minimizing company expansion and contraction.

By regrouping the structure of the parent company and its relationships to different industries, venture businesses, and subcontractors, it may be possible for the parent 
company to become more stable. The tradeoff here is in the substantially smaller size of the group of core employees. This is of greater importance in the technology areas, but can be addressed by the tie-ups with different industries and cooperation with venture businesses. The greater number of avenues for technology can provide a needed flexibility in dynamic industries.

The many dimensions of operating a productive technology organization involve executive culture, staff selection, resource planning, incentive policies, outside alliances, and control of development. One area I would like to concentrate on to summarize is the integration of external practices into American business. An attempt to introduce any alien management style into a cultural environment may result in a clash of style that will not realize the desired positive benefits. A manager must carefully select the parts of that alien style and craft a good fit for it within the existing framework. If adopting such styles do not lead to significant benefits, a different strategy may be in order. For example, rather that trying to out perform the Japanese in manufacturing and production (where they have cultural strengths supporting their efforts), channel resources into design work and innovative research (where Americans have cultural strength). This may put more emphasis in software-based computer technologies because of the individualized, creative nature of software development or may mean the growth of the $\mathrm{Ph} . \mathrm{D}$. research staff.

\section{Communications}

In a joint study of Japanese companies by the Digital Equipment Corporation and Semiconductor Research Corporation [Report] technology transfer is defined as the communication of skills among individuals and groups. As simple as this is, it does focus on the essential factor of communications. However, the process is much more complex because 1) there is much information to be communicated in addition to skills and 2) there is often no concentrated, well-defined group of peers with similar goals. Instead, the target audience is scattered, poorly defined, and representative of a broad spectrum of interests. 
A number of questions can be posed about technology transfer communications, such as:

- What are the information sources and channels?

- In what order are sources searched?

- What is the difference between scientific communication and technological communication?

- How does the organization influence communications?

- What is the effect of geographic separation?

The following sections will address each of these questions, and then explore some differences and similarities between horizontal and vertical (in an organizational hierarchy) communications.

What are the information sources and channels? In a study of $17 \mathrm{R} \& D$ projects [Allen 1977], it was found that about $11 \%$ of the ideas for solutions to technological problems came from the technical staff, about $9 \%$ came from company research, about $29 \%$ came from customers, and $51 \%$ came from all other sources. These other sources included the literature, vendors, analysis and experimentation, unpaid consultants, and government agencies. Within a project, Allen found people make essentially no distinction of a co-workers job performance rating when asking for solutions. However, when people ask for solutions outside the immediate project, they ask higher performers seven times more often than poorer performers. When using external contacts to assist in problem solving, most people turned to vendors for generating criteria for idea evaluation, setting limits on the evaluation, and testing altemative evaluation approaches. This is a particularly interesting observation, given the more commonly perceived sales role of vendors.

When accessing literature for their work, workers most often referred to unipublished reports and documents, but accessed professional journais to aid in the direct solution of a problem, broaden their knowledge, and keeping abreast of developments in 
their field. In 134 observed instances [Allen 1977], the desired information was found in personal files about $41 \%$ of the time, in a library (primarily the company library) $27 \%$ of the time, and in a colleague's files $12 \%$ of the time.

In another setting, direct personal communications has been found to be effective in Japan [Report]. Direct person-to-person contact is seen as the most effective way of transferring technology. This is done by numerous face-to-face meetings and the movement of people from organization to organization. As straightforward as this mechanism appears, there are concerns. The experiences at the MCC [Stotesbury] showed problems with employee rotation. MCC, as a consortium of companies willing to invest in breakthrough computer technology, wanted to transfer the technology back to the sponsoring companies via rotations. What they learned very quickly was that if they were to wait for the employees to carry the technology back to their companies, it was far too late. They couldn't wait two years for technology transfer to occur, it had to be a continuous managed process of information flow between MCC and the shareholders. This illustrates the dependency of the desired rate of transfer on the dynamics of the technology being developed.

In what order are the sources searched? In a study of 111 information searches [Allen 1977], written literature was the source most frequently selected first, followed by internal personal contact, and external personal contact. However, the most frequently used sources were internal personal contact, followed by the literature, and then external personal contact.

What is the difference between scientific communication and technological communication? There is a major difference in communications among scientists and communications among technologists which must be recognized within an organization. Technologists publish less and spend less time reading than do scientists [Allen 1977]. A 
major difference on a number of dimensions can be seen in Figure 16 [adapted from Alleri 1977].

Engineers

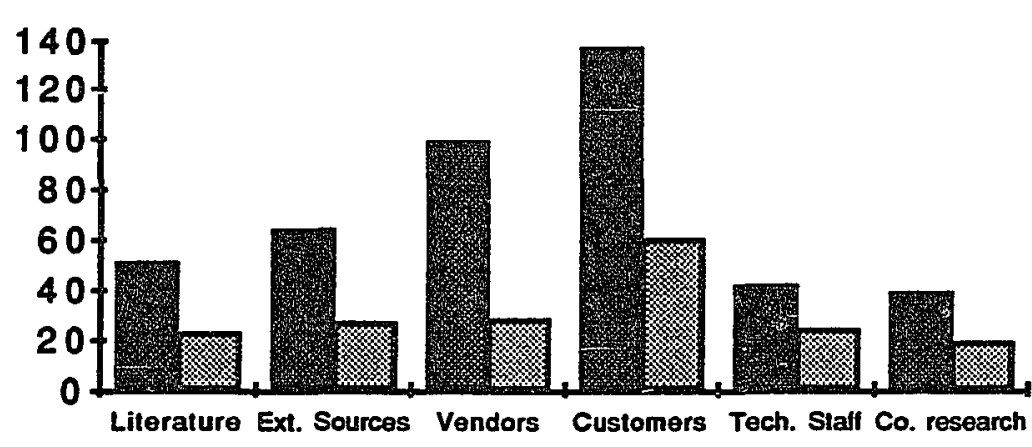

Scientists

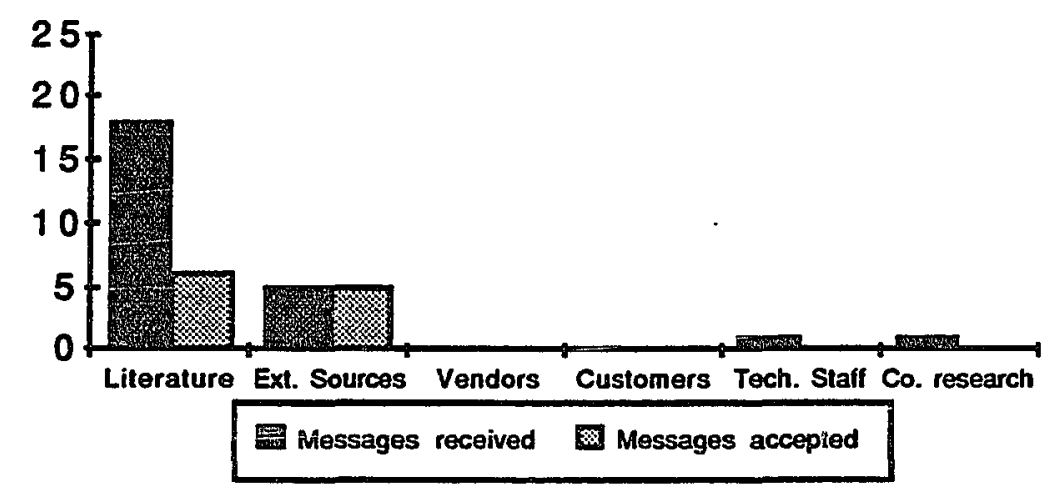

Figure 16. Communications among scientists and technologists.

The different usages of information channels is of major importance in building the technology-market linkage previously described. For field-specific technological information, it is transferred primarily through personal contact, primarily through close association with co-workers in their own organization. Scientists keep track of each other's work through external organizational visits, seminars, and small invitational conference, supplemented by informal exchange of written material long before it reaches 
publication. Technologists are limited in many of these activities by the imposition of organizational barriers.

How does organization influence communications? The structure of internal communications networks were conducted by asking people to report all of their internal communication contacts [Allen 1977]. The pattern of the contacts was then compared with the structure of the formal organization as represented on organizational charts. Informal contacts (lunches, recreational activities) were also recorded. Within the formal organization, communications were much heavier within the confines of the formal boundaries, no matter the number of formal divisions. Within the informal organization, when there was social contact between any two individuals, the probability of technical communication was significantly higher than when no social contact existed.

What is the effect of geographic separation? Research has shown that the tendency to communicate varies dramatically with the distance separating two people [Allen 1977], as shown in Figure 17:

\begin{tabular}{|cc|}
\hline $\begin{array}{c}\text { Distance } \\
\text { (meters) }\end{array}$ & $\begin{array}{c}\text { Probability of communicating } \\
\text { at least once a week }\end{array}$ \\
\hline 1 & 1.00 \\
5 & .25 \\
10 & .10 \\
30 & .05 \\
60 & .04 \\
100 & .03 \\
1000 & .03 \\
10000 & .03 \\
100000 & .03 \\
\hline
\end{tabular}

Figure 17. Effect of distance on worker communication. 
A leveling appears at about the 30 meter distance, after which the probability of personal contact remains fairly constant out to great distances, with the asymptote at .03 . This data is for people without an organizational bond, but the data is very similar for those with such a bond. The asymptote moves to a probability of about .08 at distances over 30 meters, with corresponding increases in the lesser distances. This shows an improvement with an organizational bond, but still quite low. If the other person is in the same building, but on another floor, the communications probability decays much faster.

Communications can be viewed as occurring in at least two dimensions, vertically and horizontally, and combinations of the two. Vertically, managers at every level of the hierarchy respond to a flow of information from above and below. From the technologists and managers below, he or she receives ideas about technical possibilities and for new projects. From above, managers receive signals about directions the company, division or bussiness unit want to move in. This flow occurs informally, as well as through the planning and budget process, frequent program reviews with those immediately above or below, monthly meetings attended by miltiple levels of managers, and periodic meetings with the highest levels of management. As previously discussed, executive behavior has a strong influence on communications because the balancing of ideas from below with signals from above is replicated at every level, resulting in a continuous adjustment of programs and plans.

In a Battelle study [Tressel], innovative methods of communication with executives were developed and tested because of two principal barriers to successful information transfer to this group:

1. Decisions are nade at a management level where time is at a premium and interest is general rather than technical. When selling new ideas it is essential that potential customers come to believe in the quality of the 
ideas and to believe that they are worth exploring even though many may not relate directly to today's problems.

2. Good material is often lost in the deluge of communications, such as the paper blizzard, electronic junk mail, or too many meetings. Time is valuable and the competition for it is intense. A concise, articulate presentation of the idea in an attractive package is necessary.

The basic stages of these communications, whether applied vertically or horizontally, include identifying the target audience, selection of the material, packaging it for the audience, delivering it via the proper channels, and filtering and responding to inquiries.

In addition to the vertical dimension of formal organization communication, there are prestige or status hierarchies [Allen 1977] in which individuals of high status will tend to be attracted to and communicate frequently with one another. Individuals of low status will neither like nor communicate with one another as much. Between these two groups, the lower status individuals direct most of their communication towards the higher status people, but this communications is not reciprocated. For low status people who have some desire to move up the formal organization, their level of communication with high status people is particularly high, serving as a substitute for real upward mobility. Easily identifiable status attributes such as having a doctorate promotes the formation of tightly knit cliques which have free internal communications, but restrained external communications.

Horizontally, technologists have extensive and ongoing contact with the other business units, engineering, product, and marketing people. This interaction occurs among counterparts at every level. Technical people use phone calls, joint working sessions, and exchange of written reports. Managers study each other's strategic plans, visit each other, and engage in joint planning of large programs. The businesses describe their needs the 
technologists, and the technologists describe the technical opportunities and solutions it can offer. Mutual adjustment to address market demands is the desired result.

Horizontal and vertical communication can support each other. Managers can more readily justify their programs to superiors if an operating unit is demonstrably interested. They will also tend to pay more attention to those business units whose businesses are considered by corporate to be higher priority. The two flows of communication can also create tensions. The vertical chain is more likely to stress long-term needs while the businesses often have short-term needs. When strategic decisions or technologies change, it can have a wrenching effect on well-established working relationships built around familiar technologies.

\section{Technology Transfer Models and Concepts}

This section will describe a nümber of technology transfer models and concepts found in the literature. Aspects of these will be used in the construction of the technology transfer model for knowledge systems in the case study.

Zeldman. There are three fundamental parts of the transfer model: 1) champions, 2) transfer teams, and 3) a fully developed transfer plan. A champion is an internal member of the organization who recognizes the potential of the product and pulls team members together to see the product or service produced as a result of the technology transfer. To prepare people to do the specific tasks, a transfer team must be developed. Primary training and personnel development should be focussed on the unique aspects of the technology transfer. The transfer plan includes addressing the issues of manpower, resources, budget, measurements, ${ }^{27}$ status checks, and corrective actions. Standard project management concepts must be applied, such as critical paths, float paths, workforce availability, and resource utilization.

27Warfield makes a distinction between success measures (did you reach the goal) and performance measures (how hard did you iry). 
Roberts [1979]. In technology transfer there is a gap between information available for innovation and the information actually delivered for innovation and 2) the gap between technology resulits and technology effectively used. Roberts characterizes these as "gaps of input" and "gaps of linkage."

Model 1: To bridge these gaps, Roberts has profosed the critical functions staffing model. Briefly, this model is role oriented, including:

- idea generator who comes with new ideas

- entrepreneur who is the active proponent of the ideas

- technical, market, and manufacturing gatekeepers [Roberts 1979, Davis, Allen 1977] who each use their expertise in determining the viability and future directions for ideas

- program manager who integrates ideas into the corporation

- sponsor who as a senior manager provides the protection and nourishment for an idea to prosper

Model 2: Roberts also discusses the product team approach, where the distinct and separate technology group does not exist. Instead, the product team is a multi-functional organization with representative members drawn from the functional parts of the business.

Model 3: The bridging approach views technology transfer processes as procedural, human, or structural. Procedural methods are mechanistic devices to transfer technology, human methods focus more on personal interactions, and structural methods have specific organization units devoted to technology transfer.

The critical functions staffing model, the product team approach, and the bridging approach are more fully discussed in the Personnel Components section.

Leonard-Barton [1985]. Leonard-Barton sees a gap between the inherent value of the new technology and the ability to put it to work effectively. She views the management 
of technological change as a difficult dual role of technology developer and implementer.

The framework of implementing new technology includes the following components:

1. A marketing perspective will involve users in the design phase of a new technology and prepare the organization to receive the technology.

2. Implementation managers must develop internal marketing plans to deal with multiple internal markets.

3. Legitimate resistance to change must be anticipated.

4. An appropriate amount of technology promotion must be used so the promotional activities are not perceived as hype.

5. A pilot operation should be conducted before total introduction of the innovation.

6. An implementation team under the leadership of an executive sponsor should be assembled.

Reilly. At the Control Data Corporation, a successful technology transfer program was implemented in three stages: The first, preparation, involves early involvement by the acceptor, a team approach and commitment, defined objectives and expectations, and management involvement and support. Second, transfer is considered complete when requirements have been met and the acceptor takes ownership of the technology. Third, results are measured using performance to acceptance criteria, acceptor support for the technology, knowledge of whether the technology operates in production with measurable results, and an ongoing process control.

Gruber. As a result of an MIT Conference on the Human Factors in Technology Transfer, three models were developed, the first of which is called the science-technologyutilization topology, shown in Figure 18. 


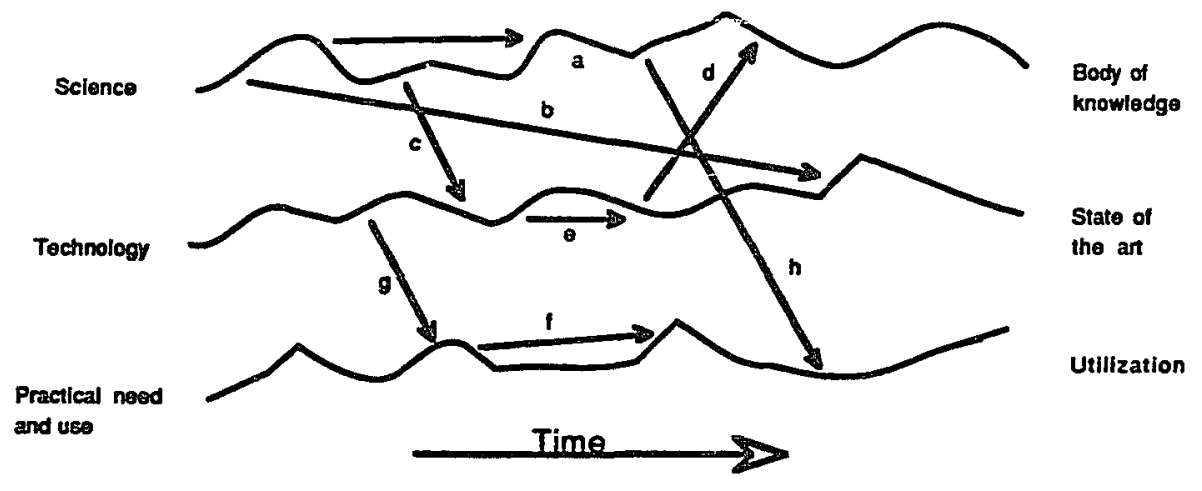

Figure 18. The science-technology-utilization topology model.

The arrows depict the communications paths: a) science to science, b) science to technology (over a long time period), c) science to technology (fast), d) technology to science (such as instrumentation), e) technology to technology, f) use to use, g) technology to use, and $\mathrm{h}$ ) science to use.

This model shows the communications paths among three major channels of activity in technology transfer. It provides a topological view of the relationship between science, technology, and the uses of science and technology. This model makes it possible to identify the various transfer points and to consider possible sources of idea generation. It also illuminates the need to define what type of technology transfer is being proposed in a given situation. However, a severe limitation of this model is its failure to address personal and organizational factors in technology transfer.

The second model, in Figure 19, is a probabilistic one which, in its simpiest form, shows a series of probabilities that might be considered in order to determine whether the given technical information would be transferred into a new use that would result in diffusion.

$\begin{aligned} & \text { Probability } \\ & \text { of transler }\end{aligned}=P($ idea $) \rightarrow P($ research $) \rightarrow P($ development $) \rightarrow P$ (production) $\rightarrow P($ innovation $) \rightarrow P(d i f$ sion $)$

Figure 19. The probability of transfer model. 
In reality, a view of technology transfer based on this model would not be so linear, such as when some aspect must be sent back to the research step because of problems in the development step.

The third model, in Figure 20, examines the magnitude of transfer as a function of a set of factors.

\begin{tabular}{|ll|}
\hline Magnitude of transfer $=$ & $\begin{array}{l}\mathrm{f}(\text { source, nature of item to be transferred, structure of } \\
\text { channels for transfer, potential recipients of item to } \\
\text { be transferred) }\end{array}$
\end{tabular}

Figure 20. The magnitude of transfer model.

This model does not have the directional aspect of the second model. As such the variables are viewed as more independent and more likely solved simultaneously rather than sequentially.

Bums. The communications agent model emphasizes the point that the mechanism of technology transfer is one of agents, not agencies. This is carried forth to the idea that it is the movement of people among organizations that achieves technology transfer, rather than the dissemination of information through communications systems.

Qunjian. At GTE, a study of 21 technology transfers resulted in a model which represents the activities that may be needed to achieve successful transfer as shown in Figure 21. 


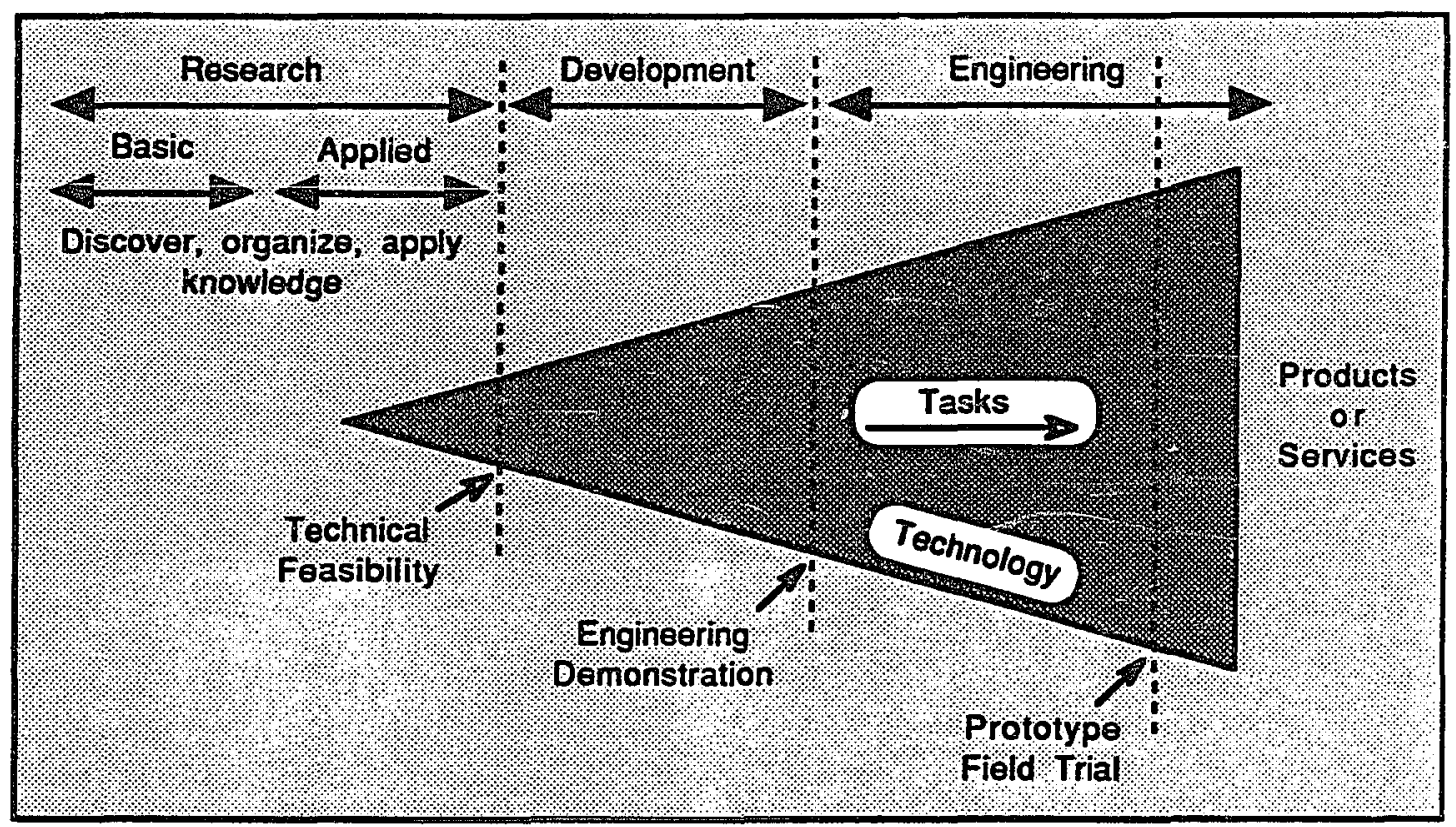

Figure 21. The GTE technology transfer model

This model represents a sequence of situations and the extent of the tasks performed at each stage of the process depends on the nature of the technology and the receiving and sending organizations. For example, with technology transfer within the research laboratories, the tasks may not go past the technical feasibility stage. This is much like the science-to-science technology transfer in the first Gruber model. Because GTE is product and service oriented, the full range of activities depicted in this model are used to drive towards utilization of the technology.

Sharif. The Technology Atlas has proposed a framework for what they call "the generation of indigenous technology," depicted in Figure 22: 


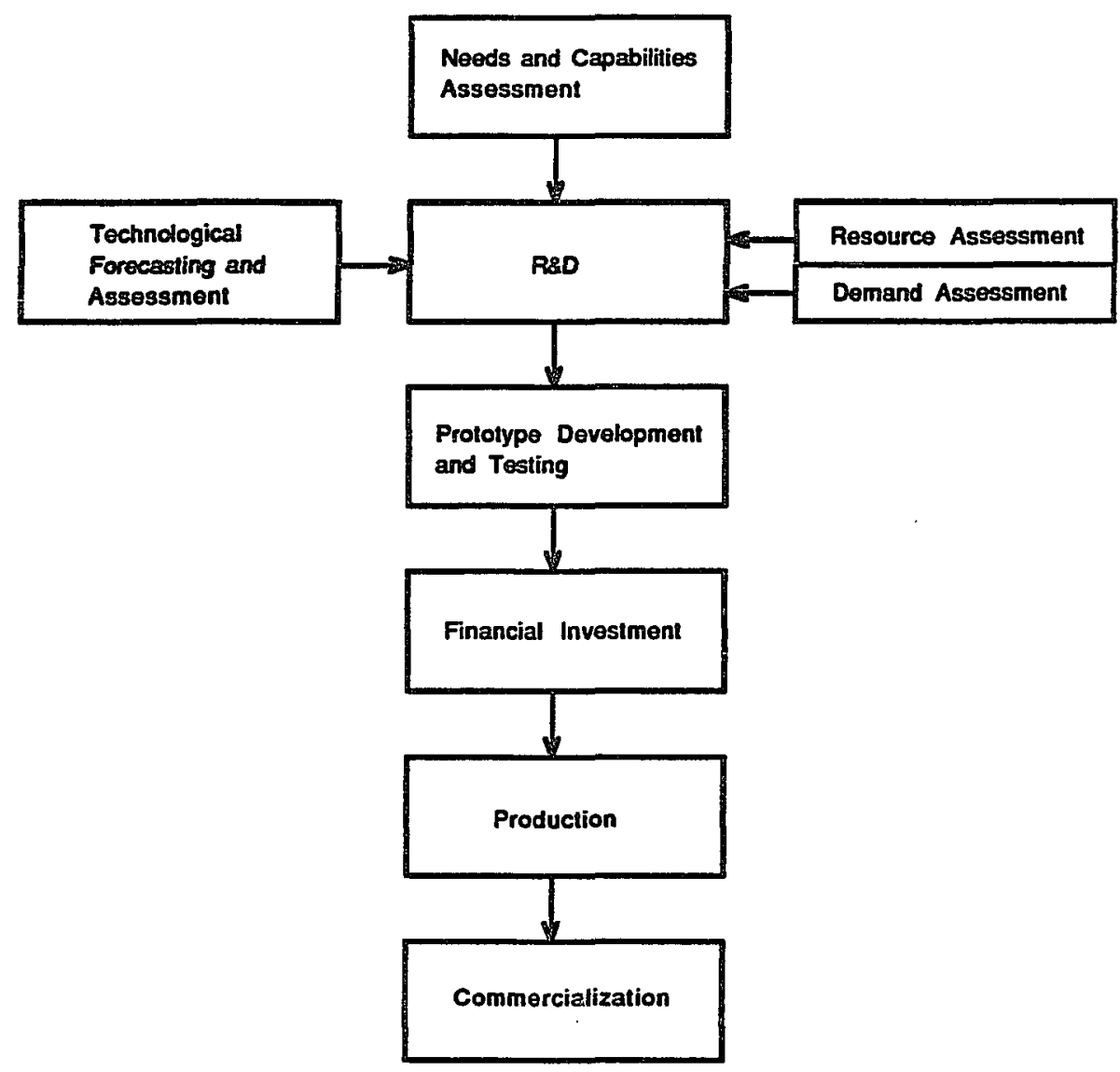

Figure 22. Framework for the generation of indigenous technology

There are a number of requirements to be fulfilled at each step of this framework. Needs assessment requires assessment skills, access to data, and the resources to analyze the data. Resource assessment also requires assessment skills, but needs data specific to the construction of a resource profile. A significant part of the framework is the demand assessment, which requires an assessment of the market for the technology and what the market trends indicate. Often overlooked in this or any other technology transfer model is what must be done in the event of success. The demands of production and commercialization are quite different from earlier stages, and must be addressed by providing such things as maintenance procedures and tools, product and service marketing, distribution networks. 
Tomlin. General Electric views effective technology transfer as part of linking centralized R\&D groups (CR\&D) with the business units. Successful transfer is seen as depending on first building a commitment to the technology/product, and then actually transferring it.

The desire of industrial scientists to see their work commercialized is reinforced by performance measures that include successful technology transfer. Gaining the commitment of the operating business is usually harder. CR\&D engineers, scientists, and project managers must sell their work to the businesses and they are more likely to be successful if they begin in the early stages of the project.

CR\&D then tries to convince the business to invest in the project, even if only on a small scale. If the CR\&D has already done considerable work on the technology, it might argue that, with a bit of business unit funding, it would direct its attention to applying the technology to their needs. Or, the R\&D manager might offer to invest substantial assessed funds in exploring the technology if the business unit would make some investment. Gaining a psychological investment from the business unit is more important than the contract at this stage. Once commitment is secured, the actual transfer tends to be fairly smooth. Movement of personnel in both directions is viewed as a particularly effective mechanism.

\section{SYSTEMS-ORIENTED ANALYSIS METHODOLOGIES}

Systems management techniques offer certain methodologies and procedures to deal with organized complexity. A number of these techniques are briefly reviewed in the following sections.

\section{Systems Engineering Morphology}

This deals with what Hall defines as the three fundamental dimensions of systems engineering: 1) Time, segmented by milestones/phases, 2) Flow of mandatory logic steps, 
and 3) Knowledge of a discipline, profession, or technology. These dimensions can be applied in a general systems approach to solving problems.

The first dimension, the milestones/phases, is also referred to as the coarse structure because it defines the major steps of the systems engineering process:

- Program Plan: what does an organization want to pursue?

- Project planning is one component of a program plan

- Systems development implements the project plan

- Production: actually making what you planned to make

- Distribution or phase in

- Operations: using the product

- Retirement or phase out

The second dimension consists of the logic components, also known as the fine structure. These are usually performed in an iterative manner, not necessarily in order, for each step in the coarse phase.

- Problem definition: study of needs and environment, collection and analysis of data for problem formulation

- Vàue system design: states objectives and decision criteria for all alternatives

- System synthesis: compilation of alternatives

- Systems analysis: deduces consequences of alternatives

- Optimization: Previous four logic steps plus modeling

- Decision making step: uses output of system synthesis and value system design to select best alternative

- Planning for action: communicating results, scheduling, resource allocation, performance measures, feedback control system 
The third dimension consists of the domain knowledge which must be used with the other two dimensions. Examples of these domains include such fields as medicine, engineering, and information sciences.

In these dimensions of systems engineering are two components that need particular attention: 1) the planning aspects and 2) the value system design.

\section{Aspects of Planning and Value Systems}

The planning process is very important to a planning unit because there are limited resources for the process and, to have accurate plans, as many people as possible must use as much relevant information as possible. Planning concepts are transferable among various planning units regardless of their unique attributes. Warfield introduces the planning unit which exists in its environment and is controlled by its managers. 28 By using a transferable process, only the distinctive details need to be added. Greater efficiency is obtained by a common generic process. It is along the lines of this concept of transferability on which the applicability of my technology transfer model is based.

A planning process can be transferred more easily if it is flexible. There are a number of alternative purposes of planning on which technology transfer can be based:

- Deterministic activity programming (e.g. a cookbook recipe, no decision points)

- Milestone programming (activities with decision points)

- Disaster avoidance

- Opportunity identification

- Priority setting

28 In spite of the general applicability of planning concepts, each planning unit is unique in some respects and the environments of two planning units of the same type may be quite different. 
- Renewing management capacity (a fresh outlook on things, away from the day to day operational concerns)

- Setting goals and defining success

- Others, such as personnel needs, career paths, etc.

Future events include some surprise and some expected. If all were surprise, planning would be futile. If all were expected, planning would be minimal. Reality is somewhere in between, varying with the specific situation. By going through the planning process, the uncertainty of the future can be explicitly addressed.

Values dominate the planning activity and must be elucidated in order to determine the desired sequence of events to obtain goals. Once these have been resolved, the planning process is almost alg amic, but getting to that point is most difficult. Part of the value identification process includes forecasting and futures analysis by disciplined methods such as scenarios.

The commonly stated goals and objectives are actually surrogates for values. By clearly stating objectives, it becomes possible to explore the desired and also to operationalize it. If it is known what is desired and why it is desired, it is often much easier to determine how to attain it.

As the foundation for a project, explicit value definition is essential. Inattention to it has often been the cause of project failures because it was "obvious to everyone" that the project was a good idea. Many people seem to think that their enlightened perspective is automatically shared by people in power and that those power people will help a project progress. However, the burden is on the project staff to transfer the new, perhaps conflicting, values to others so that the benefits of their project can be realized. By proceeding through this "selling" process, the project staff will likely refine the view of what the project purpose is. It is too easy for a project team to immerse themselves in 
"what to do" while neglecting "what we want," which results in the tools for achieving goals becoming primary goals themselves.

\section{The Task-Oriented. Transient Organization}

Warfield disclisses the task-oriented, transient organization (TOTO) which has unique composition, purpose, and indefinite life span such that some aspects of traditional management can be applied but others cannot.

If a task is at a level of complexity where an individual effort lacks breadth and a group effort lacks depth, then an organization can be built for the purpose of working on the task. It is created, may change in composition or form, and disbands in a transient fashion. A TOTO realizes its strength from a combination of group activity and the iridividual activity of group members.

Particular attention must be given to group dynamics in a TOTO. Participation in group activities must be regulated and managed to derive greatest benefits. This includes managing the group size and ensuring that all opinions are heard, because their often is no time to repair long festering damage. Conservatism must not be permitted to inhibit progress. Participants in the group must know what the expectations are for the group, help define the value system, and contribute to group direction. The group must also be expected to evolve through the four small group development stages which include forming, storming, norming, and performing. The leader must have sufficient knowledge of the subject area to provide leadership, and must be aware that sponsors and the group will become impatient during the first three group development stages.

In a TOTO, the leader must recognize that mental limits will be revealed during critical time phases including bounded rationality (which may cause premature structuring), avoidance of complexity, abrogation of group results, and self-serving participation. The skills of the leader are instrumental in dealing with disagreements, conflicting interests, risk taking, and time required. It is natural for the burden of integration of work activities to fall 
mostily on the leader, but this task must be shared with group members. Sharing of these burdens frees the leader to attend to other tasks, and will create greater bonding among group roles. The group and individuals must be balanced for quantity and quality of ideas, including the encouragement of diversity and controlled conflict.

In the case of the Knowledge Systems Transfer Project, certain aspects of a TOTO are evident, as may be the case for other technology transfer processes. KSTP was, by charter, only to exist for two years, with the purpose of integrating knowledge systems technology into the information systems organization and the skill sets of the employees. Additionally, it had unique composition in that team members were sponsored 29 by three different formal organizations within U S WEST, and each of the team members had unusually strong academic education and industrial experience.

\section{Multiple Perspectives Methodology}

Multiple perspectives is a systems approach to analysis which considers three distinct perspectives: technical, organizational, and personal. Each of these perspectives illuminates a problem from different angles and can affect each other through cross-cuing, which is the influence of one perspective on another. These are perspectives as defined by Linstone, and as the primary methodology for this research, they will be discussed in the next chapter.

${ }^{29}$ Salary, expenses, capital funding, and management support. 


\section{CHAPTER IV}

\section{MULTIPLE PERSPECTIVES METHODOLOGY}

Multiple perspectives offer a robust way of looking at decisions and problem domains, especially in sociotechnical areas such as technology integration. Traditional solution methods work well when applied to appropriate problems, but fall short of providing satisfactory information when technological and human systems are involved.

\section{TRADITIONAL PROBLEM SOLVING}

Historically, the practice of systems analysis in socio-technical domains has fallen short of the goals of a systems approach; narrow, quantitative focus has slighted benefits of broad, qualitative view. Well structured problems lend themselves to technical analysis and solution through the use of currently accepted scientific paradigms [Linstone]:

1. Problems can be abstracted from the world so they can be solved

2. Solutions should be optimized

3. Systems are analyzed and attempted to be understood via reductionism

4. Inquiry relies on data and models

5. Information is quantified as much as possible

6. Investigators are characterized as unbiased and objective

7. The individual is ignored in the quest for objectivity

8. The passage of time is viewed as being linear

Many of these have been used to provide significant progress to technological advancement and are well suited when limited to the appropriate situations. However, a systems integration approach means an investigator must solve problems within the context 
of an entire system. Taking a reductionist approach to one small part of the system is insufficient because, while it appears to provide information on that small part, the information may not be accurate at a system level. 30

Any investigator working at the system level knows how messy the investigation can become. It is in these ill-structured inquiries that a broad, cohesive approach must be taken. The softer the problem, the greater the need for a wide scope of inquiry, such as a macroanalysis at broad level. 31

The counterpart to this is microanalysis, which is often used as a façade for pure objectivity. It often relies on many of the data-quantification-optimization type of methods listed above. These are necessary but insufficient parts of analysis of soft systems problems. The differences between the two types of analysis are:

Macro - objectives may not be clear, quantitative data may not be available, uncertainty, somewhat protected from suboptimization, used by professional analysts and decision makers

Micro - clear objectives, controlled suboptimization is allowed, quantitative data is available, certainty, results in technical recommendations, used aimost exciusively by professional analysts

Choosing appropriate style of analysis is difficult, increasing with the number of variables and uncertainty. When studying a system, there are many different levels of knowledge systems ${ }^{32}$ being used and tested against each other. They form knowledge

30 The failed introduction of new Coca-Cola ${ }^{\mathrm{TM}}$ is an example [Gelb]: "The new Coke fiasco might have been avoided had market researchers concentrated more on consumers' emotional ties to the existing product. Coke drinkers believed that Coke stood for traditional values ... so they felt betrayed when the product radically changed overnight. Quantitative research often fails to uncover such fierce but unarticulated loyalties ... Researchers must use more qualitative methods ..."

31There is an urge to use the word comprehensive here, an urge that must be resisted. No investigation is comprehensive or all-inclusive, although it must be sufficiently broad to satisfy its purpose.

32This use of knowledge systems refers to human knowledge applied to the understanding of a system, not the computer-based knowledge system. 
complexes which are much more enlightening and useful than any single knowledge system. The difficulty, however, lies in actually coupling these multi-level knowledge complexes. As will be discussed, this coupling is facilitated by the multiple perspectives methodology.

\section{DIFFERENT INQUIRING SYSTEMS}

A number of different inquiring systems have been described in the literature which have bearing on the development of multiple perspectives. First, a Lockean inquiry would focus on empirical aspects, looking for agreement among observations and/or data as a basis for truth. In this inquiry mode, experience is key and no weight is put on theoretical considerations. Second, a Leibnizian inquiry system relies upon formal models and theoretical explanation. Truth is based on analysis and does not rest on data obtained from experience. Third is a Kantian inquiry system in which empirical data is coupled with a theoretical model to form a truth based on synthesis. Kantian inquiry also can use multiple models which are combined for greater synergy.

There is danger in each of these inquiry systems is their tendency towards oversimplification. Economic studies often drive complex phenomena to simple results such as a pie chart or a curve. An understanding of the construction methods for these results enables a person to appropriately use the results, but far too often this understanding is missing. The limited insight provided by looking at a two-dimensional line graph becomes more troublesome when a person equates the graph's behavior with that of the real world.

A Singerian inquiring system addresses the tendency towards oversimplification by providing much more breadth to the inquiry. Churchman [1971] describes a Singerian inquiry system as: 
- A meta-inquiring system which includes all other types of inquiring systems

- A pragmatic method, so that the truth content is relative to the objectives of the inquiry

- A non-terminating process 33 which is holistically focussed and constantly attempts to pull in more information

- A system in which the investigator is an integral part of the inquiry

This last point openly admits that the observer is part of the system and that it is foolish to masquerade such inquiries as "objective" or "unbiased." This stance is very consistent with the physical law that the position and velocity of a particle cannot be measured simuitaneously because measuring one affects the other. In an inquiry, the investigator is a probe which interacts with what is being observed, selects what is to be observed, and filters out what is considered irrelevant to the investigation.

Multiple perspectives can be classified as a Singerian inquiring system in that it considers three distinct viewpoints from which to conduct an investigation: the technical perspective, the organizational perspective, and the personal perspective ${ }^{34}$ as shown in Figure 23 (ådapted from [Linstone, Bowonder]). Characteristics of these perspectives are listed in Appendix A.

33Which relates to my earlier comment that comprehensive inquiry is not possible.

34 For an excellent, complete explanation of the multiple perspectives subject see Linstone's text, Multiple Perspectives for Decision Making. 


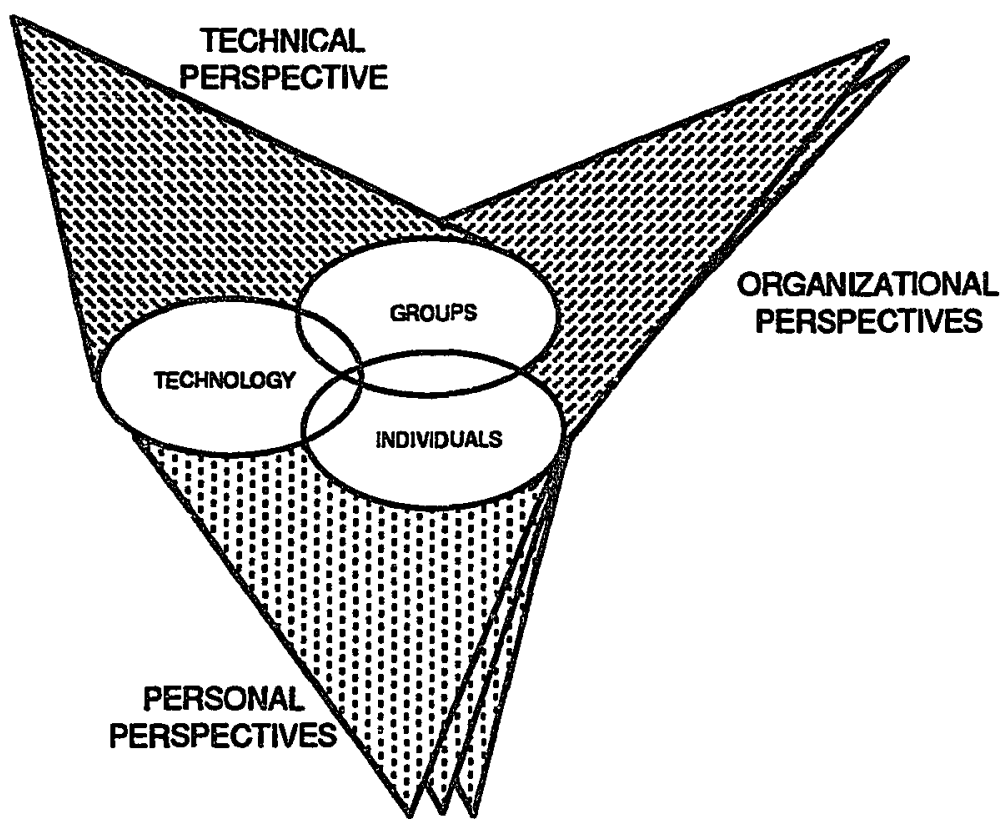

Figure 23. Multiple perspectives.

The technical (T) perspective dominates most research and structured inquiry. It is focussed on quantitative data, models, reductionist methods, optimization, and strives to give the illusion of objectivity. In technical subject-matter areas, such as the information systems domain of this study, the T-perspective reigns supreme. The rational, analytic aspects of the T-perspective is what separates it from the organizational and personal. So in addition to quantitative methods, any formal structuring method is a T-perspective, including such diverse items as organizational charts (or any other type of hierarchical decomposition) and causal digraphs. 35 Information from the T-perspective is easiest to acquire because 1) much T-data already exists, 2) many people are fluent in the methods, and 3) there is often little resistance to parting with T-data. 36

35 A directed graph consists of a drawing of nodes and arrows (showing direction) connecting the nodes.

36 The dominance of the T-perspective is taken to extremes in at least one notable effort to establish a quantitative index to measure the facility with which technology is transferred [Foster]. By such quantification, it is claimed that disparate technologies could then be rank ordered. 
The organizational $(O)$ perspective dominates the inquiry methods within organizational settings, such as companiss, government agencies, and volunteer groups. But further than these, the O-perspective also includes informal groups that may not have a name, may not be readily identifiable, and whose members may not recognize the existence of a group. People in organizations do not deal with their environment from an abstract view. Practical necessities and needs mold their perceptions of their organizational interactions and what they must do to survive and to prosper. The O-perspective is both subjective and objective in that it views the world according to a mix of uncertainties and standard operating procedures, with satisfaction rather than optimization as a goal. Planning, and action on those plans, tends to be incremental and representative of the status quo method of doing business.

Linstone summarizes some of the ways that the O-perspective helps investigators analyze socio-technical systems:

- Identification of the pressures supporting and opposing a technology

- Insight into the ability to absorb a technology as limited by organizational incrementalism

- Increasing the ability to facilitate or inhibit the implementation of a new technology

- Bringing out impacts that may not be evident when viewed by other perspectives

- Development of practical policy

Because there can be many organizational actors within an investigation, there can be many different $\mathrm{O}$-perspectives on the same socio-technical system. Each organization forms its own basis on which its members ground decisions, regardless of the correlation of this basis with other organizational views of reality. This basis may be subtle and thus require in-depth examination to discover. 
The personal $(\mathrm{P})$ perspective is the most difficult perspective to obtain. A major question an investigator faces is the distinction between a person making a statement that reflects either the organizational or the personal view. How does one know which is which? Personal motivations and aspirations play a major part of the P-perspective. Elusive qualities such as leadership, charisma, personality, power, and strength come into play.

P-perspective actors shape the use of new technology to a great degree. What does this offer to the total analysis? First, is that it can serve as a precursor to the organizational perspective, in that organizations are composed of individuals. Second, some individuals exhibit such strong behavior that they dominate a situation, dwarfing the role of the T-perspective and the O-perspective. Third, the communication of complex issues may be more effective from the P-perspective, such as brief stories or quotes. Finally, at a minimum, the personal actors are participants in the adoption of new technology and can therefore add to the understanding of the entire process.

Any phenomena can be viewed from any of the three perspectives, and can be communicated using any of them. The key in choosing which perspective to use to communicate findings is to match the perspective to the audience. Thus if the audience is T-oriented, use a $\mathrm{T}$ presentation methods, $\mathrm{O}$ methods for an $\mathrm{O}$ audience, and $\mathrm{P}$ methods for a $\mathbb{P}$ audience.

While each of the perspectives provides insight into the investigation, it is the combination of these through cross-cuing that is the culmination of the study. Cross-cuing provides an integrated view of the situation, illuminating aspects that may have remained undiscovered by any of the perspectives alone. This is shown pictorially in Figure 24: 


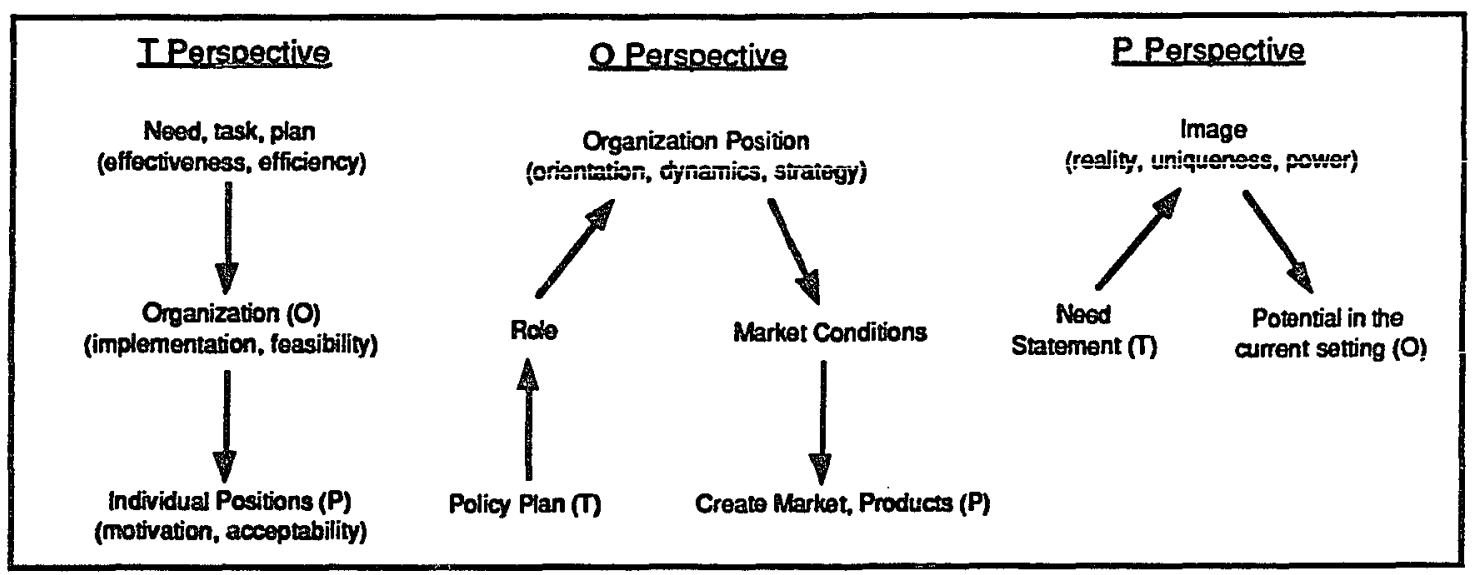

Figure 24. Cross-cuing of T-O-P perspectives.

This wide applicability of multiple perspectives can be seen in the precursors to Linstone's work as given by Allison's models of the Rational Actor, Organizational Process, and Bureaucratic Politics [Allison], Steinbruner's Analytic, Cybernetic, and Cognitive paradigms [Steinbruner] , and Anderson's Rational, Organizational, and Cognitive perspectives [Anderson]. Recent additions to the multiple perspective area include Standke's Technical, Philosophical, and Political dimensions [Standke] and the Asian and Pacific Centre for Transfer of Technology's Technoware, Humanware, Inforware, and Orgaware components of technology [Sharif].

\section{APPROACH TO THE INVESTIGATION}

It is within the multiple perspectives concept that this investigation takes place. The study examined the technology transfer process as a system as opposed to a reductionist analysis of one small part of the process. There is a very real danger in either of these two extremes: in the large view, the study can become so general that little meaning is derived; in the small view, the piece chosen for study may be so separated from its context that it is irrelevant to the dynamics of the entire technology transfer process. The use of multiple 
perspectives is intended to give sufficient substance to the large view. 37 The specific T-O-P components of the methodology and associated analysis are given in the following descriptions.

The technical (T) perspective examines the rational aspects of the technology transfer including the technology of knowledge systems, employee-base attributes and statistics, origins of the Knowledge Systems Transfer Project, financial analyses, knowledge system project selection techniques, and quantitative goals and measurements of the Project. These are presented, explained, and critically evaluated to show their influence on the Project.

The organizational $(0)$ perspective is used to view the technology transfer project, looking at the various organizations individually, their dynamics, and their interactions. The internal and external views have been researched and documented, which provides the basis for analyzing their interactions as a group of systems operating within a larger supersystem. Many distinct organizational perspectives exist both outside and inside an organization and understanding these different views is central to the analysis of actions and events. In addition to the formal organizations, informal organizations are identified and assessed since they often play a role equal to or greater than those which are formally defined.

Descriptions of U S WEST internal organizational responsibilities as seen by organizational actors address the centralized/decentralized control issue, the departmental contry l issues within Corporate Information Systems and traditional organizational response to new technologies. Case study materials is supplemented by organizational

37 Linstone argues that "a pluralistic approach is seen as essential for the expansion of knowledge. This ... suggests that the $O$ and $P$ perspectives make us see the limitations of the $T$ perspective, just as three-dimensional space helps us understand the limitations of one-dimensional space. The uitimate value of the multiple perspective concept may be to spur the redefinition of "systems analysis" in the realm of human-social-technological systems." 
material obtained via two industrial consortia: one is Bell Communications Research (composed of the seven post-divestiture regional telecommunication firms) and the other is an expert systems implementation group which draws major corporate members from the United States.

The personal $(\mathrm{P})$ perspective examines the third dimension of the technology transfer process. The central characters, their backgrounds, their behaviors, and key actions and decisions are identified and assessed for their impact on the Knowledge Systems "ransfer Project. Analysis is focussed on the identification of personal and situational characteristics which predispose these characters towards the tendencies shown by their behaviors. As in the 0 -perspective, the informal roles are identified and examined with as much attention as the formal roles.

While individuals at upper, middle, and lower levels of management, and staff members of other organizations are obvious choices for inclusion in the P-perspective, some P-perspectives are client oriented. In other words, the role the clients play in knowledge system identification, selection, and development is important to the evaluation of the technology transfer process.

As in the O-perspective, additional insight into this Project is gained through the use of the industrial consortia.

An important part of the P-perspective comes from Ascher, who indicated the importance of background and context factors which he called core assumptions. These are often unstated, but have significant influence on the phenomena being investigated. The utility of core assumptions to the investigator is dependent on their explicitness, plausibility, and recency. These characteristics are especially relevant in the technology transfer domain because of the increasing rate of technological change and the correspondent difficulty for people and organizations to quickly adapt. 
The depth and diversity of T-O-P dimensions are then integrated to provide the basis for cross-cuing. By that point in the research and dissertation, it will be clear that each of the three perspectives yield results not otherwise obtainable. Combining the results obtained through these selective filters enables a composite picture to be built of the project dynamics. The primary method was to construct an interaction chart to show the relationships between components of the three perspectives. This, in combination with the literature and consortium company information, are the basis of the technology transfer model.

Even though I have treated the perspectives as separate, distinct categories of inquiry, there are sorne important qualifications to such a separation. While the Tperspective is factual and fixed, there exists a continuum of the range of perspectives between the O-perspective and the P-perspective. Personal perspectives are visible in small informal groupings, small formal organizational units, and successively larger organizational units. Each has a distinct perspective which must be considered as part of the large view of multiple perspectives investigation. Additionally, because organizations are composed of individuals, the P-perspective is able to provide better understanding of the O-perspective.

The preceding paragraphs describe what was done at the project level. Additional goals of the research were to examine the utility of multiple perspectives concepts when applied to real-time incident analysis and to post incident analysis. In other words, can T-O-P and cross-cuing be fruitfully applied as events are unfolding, and how well do they work when used to analyze an incident after it occurs. 38 Implicit in this is the idea that if such application is feasible, there would be an impact on the strategy taken during the incident or after the incident. The aspects of multiple perspectives that I have discussed in

${ }^{38} \mathrm{An}$ incident is some event that has a notable impact, pro or con, on the project. It may transpire over a matter of hours, days, or even weeks. 
this section are applied to the secondary research objectives in the Conclusions, Chapter IX. 


\section{CHAPTER V}

\section{THE TECHNICAL PERSPECTIVE}

The technical (T) perspective dominates most research and structured inquiry. It is focussed on quantitative data, models, reductionist methods, optimization, and strives to give the illusion of objectivity. In technical subject-matter areas, such as the information systems domain of this study, the T-perspective reigns supreme. The rational, analytic aspects of the T-perspective is what separates it from the organizational and personal. So in addition to quantitative methods, any formal structuring method is a T-perspective, including such diverse items as organizational charts (or any other type of hierarchical decomposition) and causal digraphs. Information from the T-perspective is easiest to acquire because 1) much T-data already exists, 2) many people are fluent in the methods, and 3) there is often little resistance to parting with T-data.

The following sections explore the technical perspective information which had an impact on the establishment and development of the Knowledge System Transfer Project.

\section{THE TECHNOLOGY OF KNOWLEDGE SYSTEMS}

The intent of this section is to understand the technical aspects of meshing knowledge systems with existing USW ITS technology. A picture of the ITS technology is developed by examining the operating environments, software tools, how new technology fits with this current technology, and application identification and selection procedures. 


\section{Computer Operating Environment}

U S WEST information systems operate primarily in an IBM or compatible largescale mainframe computing environment. As of 1988 the main data center systems can be characterized by the attributes listed in Figure 25 [Ernst]. In addition to U S WEST (company \#6), data is also listed for the other six regional companies which resulted from the AT\&T divestiture.

\begin{tabular}{|l|c|c|c|c|c|c|c|}
\hline Hardware Data & $\# 1$ & $\# 2$ & $\# 3$ & $\# 4$ & $\# 5$ & $\# 6$ & $\# 7$ \\
\hline Computer Centers & 20 & 6 & 12 & 21 & 7 & 17 & 19 \\
\hline Data Center $\mathrm{ft}^{2}(000)$ & 898 & 925 & 762 & 983 & 836 & 832 & 1147 \\
\hline Number of Mainframes & 46 & 45 & 110 & 60 & 36 & 54 & 48 \\
\hline MIPS & 1396 & 1442 & 1385 & 1571 & 997 & 1671 & 1225 \\
\hline Data Storage(terabytes) & 6000 & 4500 & 3418 & 4757 & 2530 & 6047 & 3605 \\
\hline
\end{tabular}

Figure 25. Attributes of regional company computing capacities.

To balance the Information Systems characteristics with certain company characteristics, Figure 26 lists comparative data for size of the seven regions telephone operations [Ernst]:

\begin{tabular}{||l|c|c|c|c|c|c|c|}
\hline Company Size & $\# 1$ & $\# 2$ & $\# 3$ & $\# 4$ & $\# 5$ & $\# 6$ & $\# 7$ \\
\hline Access Lines 12-31-87 & $14.4 \mathrm{M}$ & $16.1 \mathrm{M}$ & $15.7 \mathrm{M}$ & $15.1 \mathrm{M}$ & $11.1 \mathrm{M}$ & $11.6 \mathrm{M}$ & $12.3 \mathrm{M}$ \\
\hline Access Lines 12-31-88 & $14.9 \mathrm{M}$ & $16.6 \mathrm{M}$ & $16.4 \mathrm{M}$ & $15.5 \mathrm{M}$ & $11.3 \mathrm{M}$ & $11.9 \mathrm{M}$ & $12.9 \mathrm{M}$ \\
\hline Customer Bills 1988 & $142 \mathrm{M}$ & $145 \mathrm{M}$ & $167 \mathrm{M}$ & $139 \mathrm{M}$ & $115 \mathrm{M}$ & $112 \mathrm{M}$ & $118 \mathrm{M}$ \\
\hline \# of Toll Messages 1988 & $3.2 \mathrm{~B}$ & $2.8 \mathrm{~B}$ & - & $3.3 \mathrm{~B}$ & $0.9 \mathrm{~B}$ & $1.2 \mathrm{~B}$ & $2.8 \mathrm{~B}$ \\
\hline
\end{tabular}

Figure 26. Company size data for regional companies.

Observe certain facts, such as the greatest number of MIPS, the second to the smallest number of access lines in both 1987 and 1988, and the fewest customer bills distributed in 1988.

Additional computing access resources include the hardware listed in Figure 27. 


$\begin{array}{lr}\text { Terminals } & 54,521 \\ \text { Desktop Computers } & 15,960 \\ \text { Printers } & 18,933 \\ \text { Control Units } & 5,230 \\ \text { Modems } & 75,139 \\ \text { Miscellaneous } & 4,650\end{array}$

Figure 27. Company internal personal computing hardware.

This equipment and the hardware listed in Figure 27 are interconnected via an internal communications network. This network consists of a configuration using SNA, X.25, and BANCS and is available 24 hours a day, 7 days a week. However many applications which users may wish to access are not available continuously.

\section{Software Tools}

A wide variety of knowledge systems software tools have been used and/or recommended by the Knowledge Systems Transfer Project. This is primarily due to the immaturity of the technology. Delaying standardization minimizes the drawbacks a company can experience when standards are set prematurely.

Guidelines are provided in the form of a chart of shells (tools) that are recommended (Figure 28) to be used in developing the software instead of using programming languages such as LISP or PROLOG.

Without detailed knowledge of the project or hardware, it is conceivable that some other development shell or programming language might be appropriate.

In addition to the tools listed in Figure 28, applications have been prototyped, and in some cases developed, using other software such as KEE, a powerful hybrid shell which was operating on a SUN workstation. Also, other major efforts were originally developed in Goldworks, and evolved towards pure LISP implementations. As existing tools evolved and new tools appeared on the market, they were aiso evaluated for potential use on a knowledge-based system. 
EXPERT SYSTEMS SHELLS

\begin{tabular}{|c|c|c|c|c|c|c|}
\hline Shell & Rnowledge Croft & Goldworks & Level 5 & $\begin{array}{c}\text { Persomal } \\
\text { Consunte }\end{array}$ & EXSYS & $\underset{\text { Expert }}{V P}$ \\
\hline Vandor & $\begin{array}{l}\text { Camegie } \\
\text { Group }\end{array}$ & Gold Hill & $\begin{array}{l}\text { Information } \\
\text { Builders }\end{array}$ & $\begin{array}{c}\text { Teres } \\
\text { Instruments }\end{array}$ & CA Intell & $\begin{array}{l}\text { Paperback } \\
\text { Software }\end{array}$ \\
\hline $\begin{array}{l}\text { Cost } \\
\text { Upper range } \\
\text { Ann. Recurring }\end{array}$ & $\begin{array}{l}\$ 0.00 \\
\$ 300 \\
\$ 3500\end{array}$ & $\begin{array}{l}\$ 7,500 \\
\$ 2,500\end{array}$ & $\begin{array}{l}\$ 685 \\
\$ 0.00\end{array}$ & $\begin{array}{r}\$ 3,000 \\
\$ 0.00\end{array}$ & $\begin{array}{l}\$ 395 \\
5,000 \\
50.00\end{array}$ & $\begin{array}{l}\$ 249 \\
\$ 0.00\end{array}$ \\
\hline OS supported & $\begin{array}{c}\text { UNDX } \\
\text { II } \\
\text { Generd } \\
\text { VMS }\end{array}$ & DOS & DOS & $\begin{array}{c}\text { DOS } \\
\text { TI }\end{array}$ & $\begin{array}{l}\text { DOS } \\
\text { UNIX } \\
\text { VMS }\end{array}$ & DOS \\
\hline $\begin{array}{l}\text { MACEHNES } \\
\text { Symbolic } \\
\text { TI Explorer } \\
\text { VAX } \\
\text { SUN } \\
\text { IBM } 370 \\
\text { PC } \\
\text { Macintosh } \\
\text { Others }\end{array}$ & 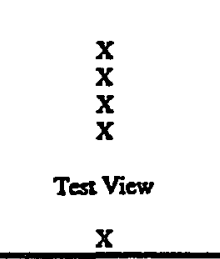 & $\begin{array}{c}286 / 386 \\
X\end{array}$ & $\begin{array}{l}x \\
x \\
\end{array}$ & $\begin{array}{l}\mathbf{x} \\
\mathbf{x}\end{array}$ & $\underset{\mathbf{x}}{\mathbf{x}}$ & $\mathbf{x}$ \\
\hline $\begin{array}{l}\text { Additional } \\
\text { Requirements }\end{array}$ & Common LISP & $\begin{array}{l}\text { Furmuning- } \\
\text { Board } \\
\text { p/286 }\end{array}$ & S12K RAM & S12K RAM & $\begin{array}{l}512 K \\
\text { RAM }\end{array}$ & S12K RAM \\
\hline
\end{tabular}

Figure 28. Approved expert system shells.

Current U S WEST software strategy suffers from a set of problems common in much of industry:

- When to change from the use of one tool to another, either due to changing technology or increased demands of the application. Some applications are initiated on a small PC-based tool, but must be ported to a larger hardware or software platform. One accounting application in U S WEST has faced this issue with much difficulty. In addition to adapting to the new hardware and operating system, such a port may involve risky changes to the knowledge representation.

- Dealing with common weaknesses of software tools, such as nonintuitive interfaces and underlying mechanisms, the presence of bugs, and poor to non-existent integration with large database. 
- Supporting changes and enhancement to the knowledge-base, as rules proliferate or a better domain understanding is obtained. Graphical maintenance tools are desirable and are present in some of the tools. For complex domains, however, maintenance facilities are not satisfactory.

- Managing growth of the application and its proliferation to new areas of business. Knowledge-base control (similar to version control in traditional software development), module communications, and knowledge-base security are not commonplace.

\section{New Technology Fit with Current Technology}

Most of these problems relate to the use of knowledge systems technology with larger databases. Knowledge systems technology has historically worked in stand-alone mode, i.e. an isolated application running on a single machine, restricted to a single domain. A 1987 Teknowledge survey indicated that 50\% of all knowledge systems are standalone. $40 \%$ were loosely coupled systems, in which the knowledge system generates database queries and waits for response, and the last $10 \%$ were tightly coupled, were the knowledge system has direct access to an internal database, such as a PROLOG-relational database implementation.

U S WEST Information Systems Architecture has been pushing towards the loosely coupled model via a distributed technology platform. In this environment, nodes of systems can interact with other nodes through a network of processors and file servers. At certain levels of the network, message protocol standards are enforced. This provides inter-system transparency and establishes whether the protocol will be at the semantic or syntactic levels.

Total service time, as a composite of network time and processing time, are of great importance in all transaction processing. Knowledge-based systems have an additional 
constraint: they are almost always in control, exhibiting asynchronous behavior. The degree to which this loose coupling can provide adequate service intervals to knowledge systems will affect the ability of future systems to provide viable service.

There is expected to be a finite ability for an organization or a person to absorb new technology. One way of looking at the information systems organization's ability is to view how much is invested in new development.

CIS manages a very large operating budget in support of its U S WEST customers. A budget review conducted in 1987 for the combined companies of Mountain Bell, Northwestern Bell, and Pacific Northwest Bell, showed that less than 5\% (\$20 million) of the proposed $1988 \mathrm{IDC}$ budget (\$400M) was available for new development (Figure 29). This compares poorly to an industry benchmark of $11 \%, 39$ and is an indicator of a potential inexperience in developing new software and using new technologies.

${ }^{39}$ U S WEST commissioned the study by Nolan, Norton \& Company in1987. 


\section{Relative Information System 1988 Operating Budgets (CIS vs. Industry)}

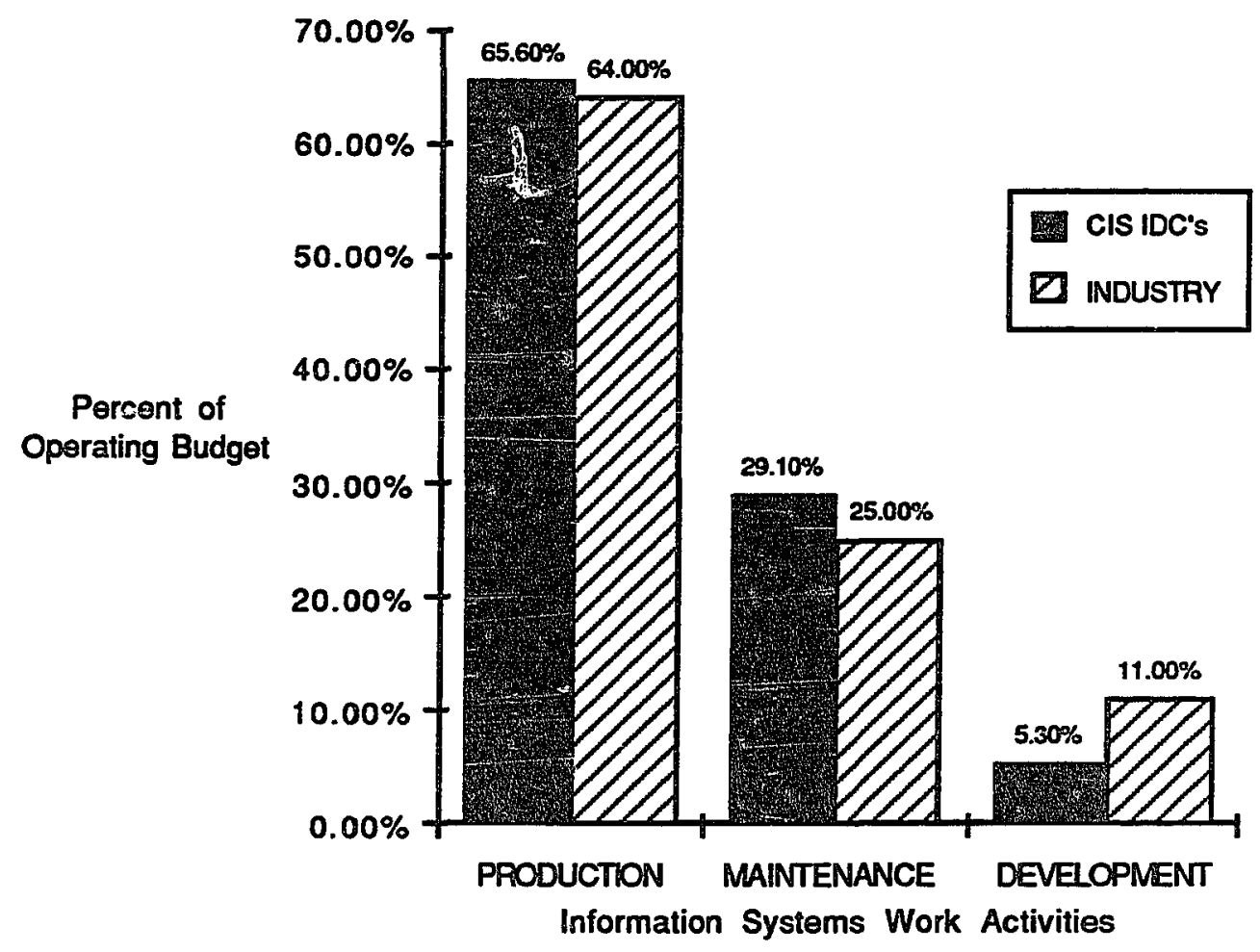

Figure 29. Relative IS operating budgets 1988.

\section{Application Identification and Selection}

Within the Knowledge Systems Transfer Project, a set of documents have been assembled to assist the first-time knowledge system development team in identifying and selecting domains appropriate to the technology. These consist of the following:

1. Expert System Proposal - This is a blank copy of the worksheet used in the assessment of a potential expert system application. It is brief (two 
pages) and fairly simplistic as a first pass screening mechanism. It is generally applicable to all knowledge systems applications.

2. Generic Expert System Benefits - A general survey of possible benefits of using knowledge based technology in a project is contained in this document. It provides suggestions on discovering potential benefits of a proposed application, including such areas as training, level of performance, productivity, responsiveness, auditing, explanation, knowledge preservation, consistency, reproducibility, and many other issues.

3. Qualifying Engagements for Expert Systems - A look at how the Knowledge-Based Systems group determines which applications are appropriate for them to work on. Mostly appropriate for those considering KBS development of their project, but provides insight into what qualifies and what does not.

4. Estimating Return on Investments for Expert Systems Projects Explains how to figure return on investment for an expert system project. It is particularly zelevant to the $T$-perspective in that it reviews traditional investment evaluation techniques in the context of knowledge systems development. Specific areas include net present value, profitability index, internal rate of return, and expected values.

5. Return on Investment Worksheet - This is a spreadsheet to help in figuring return on investment, using techniques described in item 4 , above.

This group of documents comprise the procedural view of how applications are identified and selected for further work. Each of these provide essential insight into the T- 
perspective of KSTP operations. The above listed items 1 through 4 are included in Appendix B.

\section{EMPLOYEE BASE ATTRIBUTES}

The intent of this section is to understand the nature of the employee body on a population basis and to examine the workforce potential to work with new technology. Company profile comparisons and employee characteristics.

\section{Company Profile Comparisons}

To provide a large view of the staffing environment within U S WEST, a comparison is made among the seven regional telecommunications companies which resulted from divestiture. Figure 30 [Emst] shows how U S WEST CIS compares with the information systems organizations in the other six companies. Again, U S WEST is company number 6.

\begin{tabular}{|c|c|c|c|c|c|c|c|}
\hline & \#1 & \#2 & \#3 & $\# 4$ & \#5 & \#6 & \#7 \\
\hline Access Lines (\% of Average) & 104.9 & 116.5 & 115.5 & 108.9 & 79.8 & 83.6 & 90.7 \\
\hline Ranl (bossed on Aceess Lines) & 4 & 1 & 2 & 3 & 7 & 6 & 5 \\
\hline Ranl (bassed on Actual Force) & 4 & 6 & 5 & 2 & 7 & 1 & 3 \\
\hline Actual Force & 4626 & 3227 & 4374 & 5023 & 2729 & 5178 & 4918 \\
\hline Expected Force & 4507 & 5005 & 4962 & 4678 & 3428 & 3591 & 3896 \\
\hline Actun - Expected & 119 & -1778 & -588 & 345 & -699 & 1587 & 1022 \\
\hline
\end{tabular}

Figure 30. IS staffing levels of the regional companies.

All of the comparisons are based upon the assumption that the number of access lines (to the telecommunications network) is a valid measure on which to base information systems needs. The first row was computed by adding the number of access lines of all regional companies and dividing by seven. The average was then used to compute the percentage for each company. Thus U S WEST ranks 6 th on this measure. The total IS workforce was 5178, which is the largest of the IS staff figures. Based on the previously computed average, a company equal to this average (i.e. at $100 \%$ on row 1 ) would have a 
certain expected IS workforce. The last row lists the difference between the actual and expected staff numbers. Observe the large overstaffing in U S WEST IS, using this measure.

Additionally, a comparison can be made on the ratio of the number of workers dedicated to new development projects to the total IS workforce. Figure 31 [Ernst] depicts this.

\begin{tabular}{|l|r|r|r|r|r|r|r|}
\hline & $\# 1$ & $\# 2$ & $\$ 3$ & $\# 4$ & $\# 5$ & $\# 6$ & $\# 7$ \\
\hline New Development Wortaforce & 316 & 337 & 347 & 290 & 129 & 491 & 622 \\
\hline Total Workforec & 4626 & 3227 & 4374 & 5023 & 2729 & 5178 & 4918 \\
\hline Percent of New/Total & 6.83 & 10.44 & 7.93 & 5.77 & 4.73 & 9.48 & 12.65 \\
\hline Rank & 5 & 2 & 4 & 6 & 7 & 3 & 1 \\
\hline
\end{tabular}

Figure 31. Workers dedicated to new IS development.

U S WEST ranks third in new staffing for new development on a ratio basis. However, the company ranks second in terms of actual people deployed on new development. This could imply that significant progress is being made in the use of new technologies, using the new development projects as opportunities to move ahead of the traditional data processing base. Whether this is true or not depends on the effects of the other perspectives and will be explored during cross-cuing.

\section{Advanced Technical Education Program}

A major part of the T-perspective can be seen within the Advanced Technical Education Program, which is designed to upgrade the knowledge of selected management and technical employees in specific areas of technology. The program includes a three tier approach:

Tier I: Employees with undergraduate degrees work toward a graduate degree in information sciences by taking one or two graduate 
courses per quarter or employees wishing to increase their technical abilities through participation in seminars and classes

Tier II: Employees with undergraduate degrees work toward a graduate degree in information sciences by taking two or three graduate courses per quarter while working on a part-time basis

Tier III: Employees with undergraduate or graduate degrees work toward a graduate degree in information sciences on a full-time basis

The selected employees receive full salary, benefits, tuition, books, and miscellaneous expenses. The cost to the company will vary depending on the school and the program requirements. For example, local part-time study could cost less than $\$ 1000$ a year but a full-time Ph.D. program involving a company-paid employee move could top $\$ 300,000$ total.

In the post-divestiture world, the bulk of U S WEST and, in particular the information systems organizations, can be characterized as high-tech companies without a complete set of high-tech capabilities. This is largely because of the historical organizational roles oriented towards operational telecommunications.

Top management sensitivity to this was made evident by their commissioning of SRI International to conduct a study of US WEST technical issues such as software excellence, market focus, and technology systems. This study recommended a number of technical remedies centered around applied research, hardware and technology, and establishing a planning and budgeting mechanism at the corporate level to facilitate these new directions. To increase the chances of success, the recommendations included the creation of technology forums to keep management and staff on the leading edge of key trends and rewarding the technical staff for marketing contributions. Thie intent was to keep the focus of applied R\&D towards the continued financial success of the corporation. 
In Figure 32, a brief comparison of technical expertise used in the Bell System days, and that required in the competitive environment, provides a view of the magnitude of the forthcoming transition:

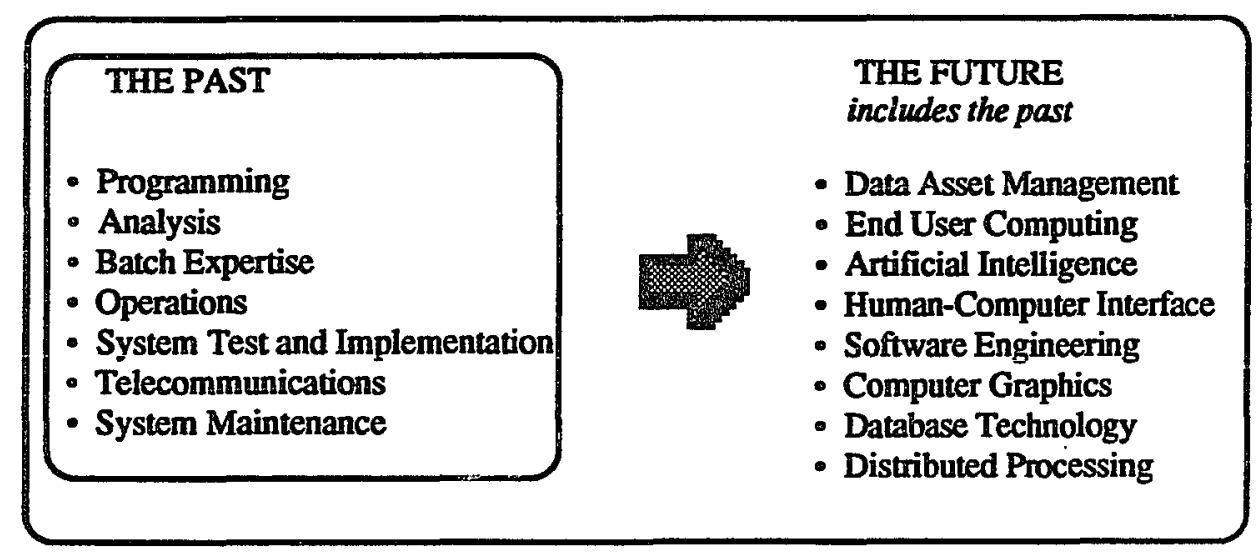

Figure 32. Technical expertise needed pre- and post-divestiture.

\section{Educational Statistics}

Coincident with the top management activity were concerns at the technical and technical management level. To gain an understanding of what they were dealing with, exhaustive data analysis was performed on various attributes of the employee population. One analysis showed that $78 \%$ of all US WEST employees had no college education and $0.4 \%$ had computer science degrees. Restricting the study population to the Information Systems staff showed that even in this technical area, 58\% did not have a college degree (Figures 33 and 34) and only 9\% had computer science degrees. The interest in these numbers has been great, as seen by the volumes of this data that has been produced under such titles as:

- Advanced Degrees Earned by Managers and Analysts: Information Systems Organizations

- Advanced Subjects Studied by Managers and Analysts: Information Systems Organizations 
- Percentage of Employees with Four-Year College Degrees or More, IS Organizations

- Ratio of Degrees Held to Total Number of Managers and Analysts, IS Organizations

- Distribution of Ages of Managers and Analysts, IS Organizations

- Years of Service Distribution in the IS Organizations

The focus on these statistics indicate their association to the real issues of inadequate productivity levels, low level of advanced technical knowledge (as distinct from skills, which can be gained through training), and lack of theoretical background for understanding of the technologies. The demographic statistics are significant because it is hard to motivate middle-aged, loyal, financially secure employees to sacrifice their time and effort to improve their technical capabilities. A DYNAMO model [Tarr] was developed to help understand the effects of these demographics and possible policy implications over the next five to ten years.

To effectively utilize the statistical worker profiles the context of the company's future business plans must be incorporated. Rapid advances in technology, even when purchased from outside suppliers, has led to increased automation and higher operational efficiencies. Coupled with slow economic growth and a steady downsizing of the corporate workforce, the opportunity to hire new, technically qualified employees is decreasing. Additional constraint is imposed buy the fact that demand for technically skilled people, especially in computer science and electrical engineering, is increasing beyond the available supply. These factors put additional impetus into the development of internal programs for employee education. 
Percentage of Employees with Four-Year College Degrees or More, Information Systems Organizations

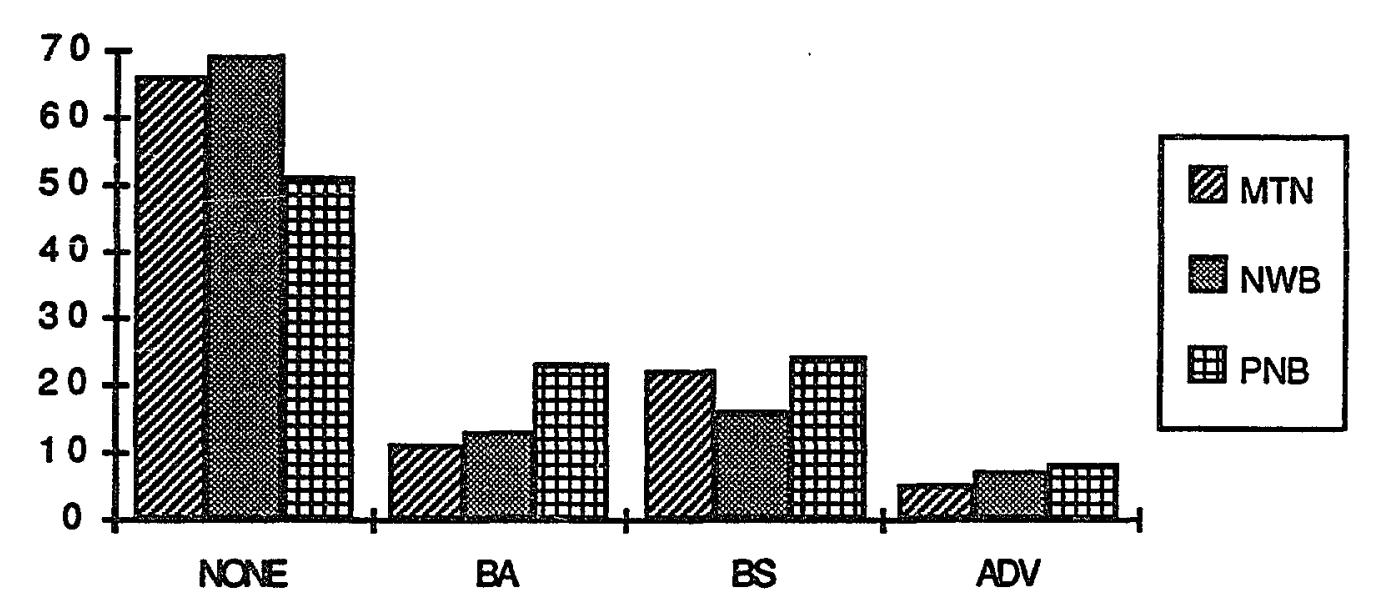

NONE: No four-year degree

BS: At least a Bachelor of Science

BA: At least a Bachelor of Arts ADV: Holds an advanced degree

Figure 33. Percentage of employees with four-year degrees

For an another " $T$ " perspective on the merits of the Advanced Technical Education Program, consider this excerpt from another report commissioned by US WEST and directed by consultants from Nolan, Norton, and Company from 1987:

"Information Systems must be designed, tooled and developed into a streamlined manufacturing facility for competitive and support systems. This facility requires the development or recruiting of highly skilled professionals with many new skills. Massive training and hiring are called for." 


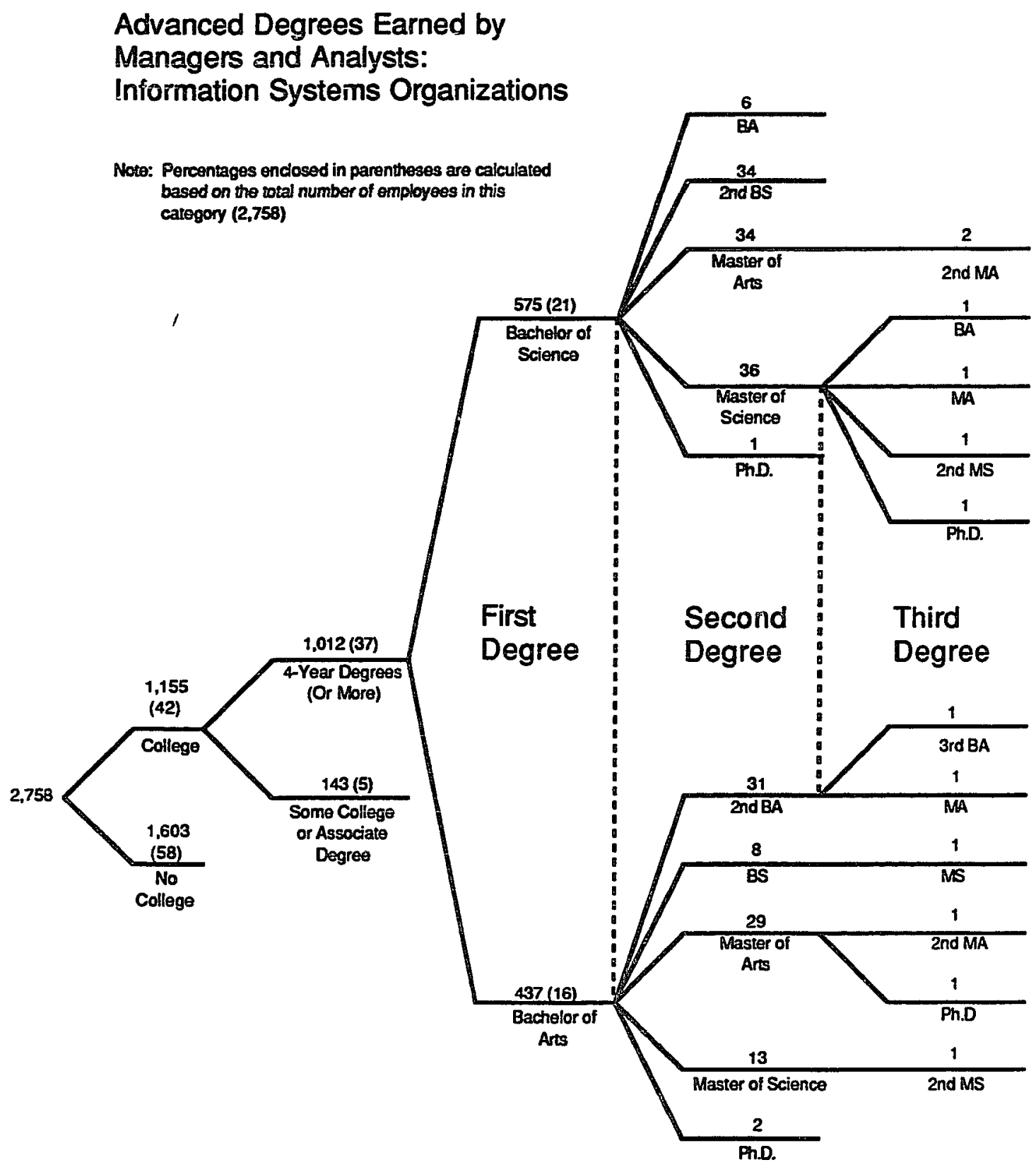

Figure 34. Advanced degrees in the IS organization 
Recent data indicate that the number of ITS employees grew by over $7 \%$ from January 1987 to January 1989, but the percentage of those holding a college degree of any sort remained constant at about $38 \%$. Of 166 newly hired employees, $37 \%$ had a college degree, $17 \%$ of the total had at least a bachelor's degree in computer science, and $11 \%$ had at least a bachelor's in business. Of the 105 new employees without college degrees, 94 were hired as a Member of the Technical Staff. This is shown in Figure 35:

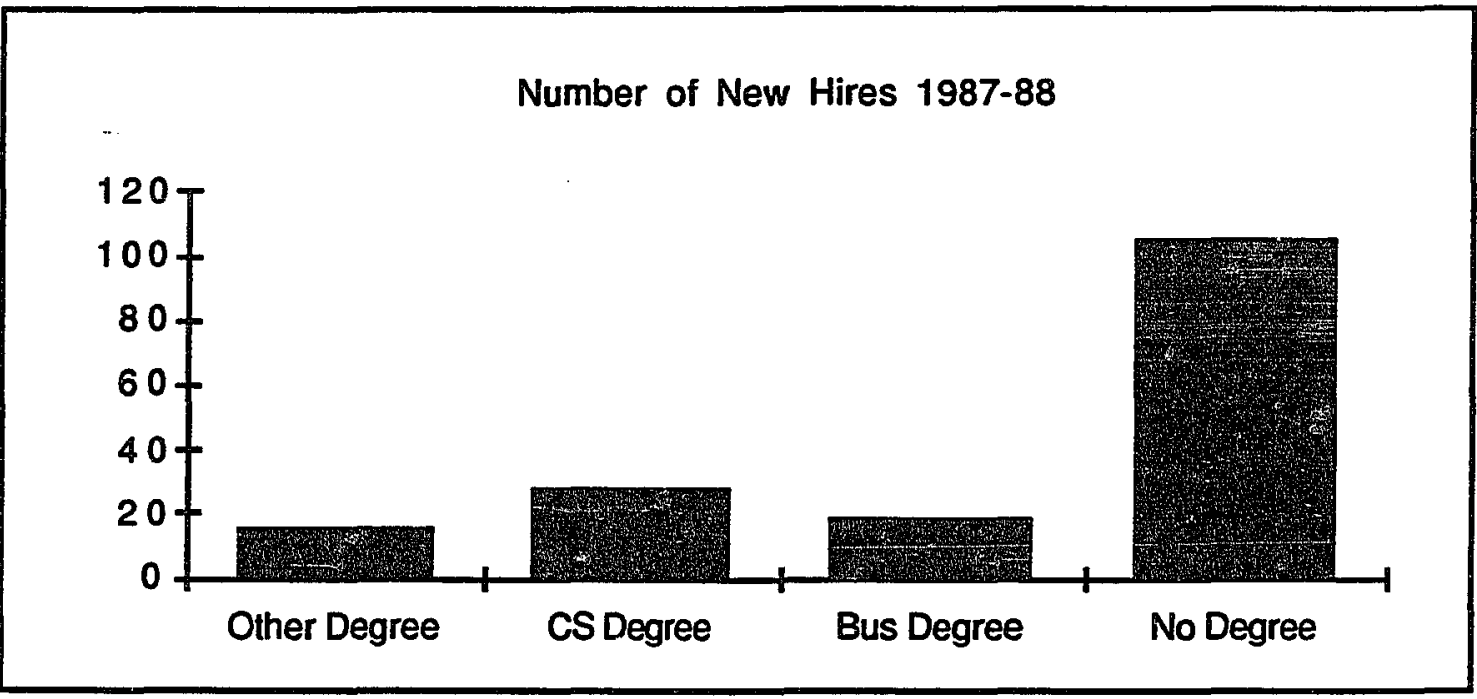

Figure 35. Educational level of new hires.

The total number of employees holding some type of degree in computer science in 1987 was 237 . In 1989 , the number had risen to 247 , but given the increase in the total information systems population, the computer science resource, expressed as a percentage, had declined from about $9 \%$ to $8 \%$. Of additional interest is that the Western and Eastern regions of ITS showed increases in their computer science educated staff. This means that the Central region suffered technical expertise losses so great that they more than offset the gains, as shown in Figure 36: 


\section{Computer Science Degrees By Region}

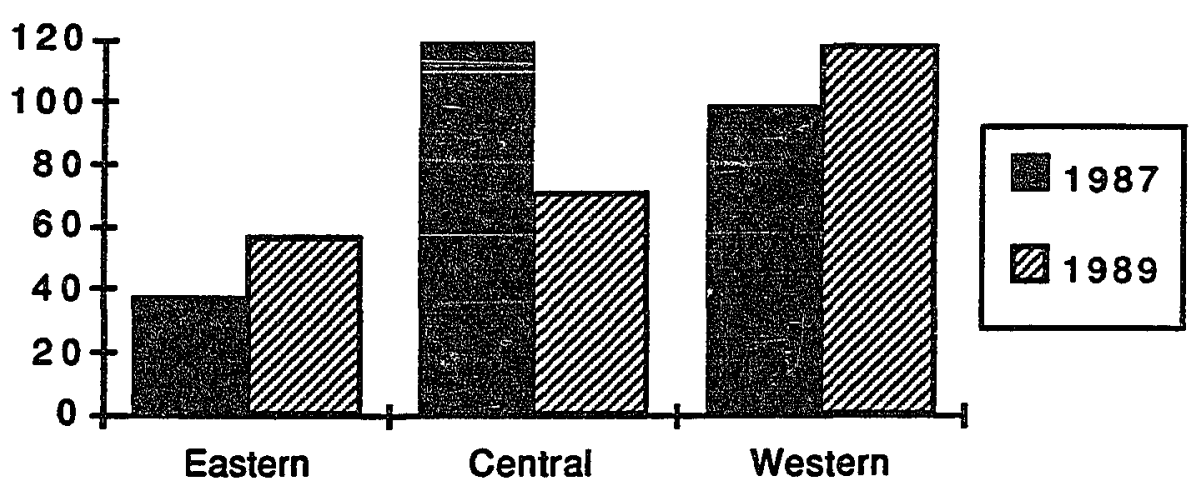

Figure 36. Computer science degrees by geographic region.

Taken together, these data has implications for the preparedness for U S WEST to work with new technologies such as knowledge-based systems, which has an impact on competitive capabilities. The impact of this aspect of the technical perspective can be seen in later sections.

\section{Technical Skills Assessment}

With the movement towards increasing technical capabilities, the need for assessing performance becomes apparent. Prior to divestiture, there was relatively little activity in this area. The company is making up for that now, with every management group including the issue in their plans and deliberations. The "T" focus of these efforts can be seen in the purpose statements of one group:

- Prepare a detailed list of the skills required

- Prepare a recommendation on how to administer and implement the skills list

- Prepare a recommendation on how to validate the reasonableness of the skill levels 
As a result of this personnel evaluation process, advancement is predicated on a completed skills matrix, a satisfactory training record and work history, subjective management assessment, and an employee development plan. Not only must this evaluation be done for prospective promotions, but may also be required for avoiding a demotion due to deficient or atrophied capabilities. Most people become very interested in continuing education when a demotion appears as the alternative.

\section{ORIGINS OF KSTP}

The recognition of expert systems as an important technology for U S WEST was first articulated in 1984, and by 1987, there were a number of work groups exploring the technology. The concern that each of these groups were duplicating certain functions and the concern that external training of people was expensive and of uneven quality, were early motivators towards the establishment of KSTP. A research committee was formed to examine these issues and to make recommendations 40 on future action to take.

\section{Training Costs}

In 1987 , it was estimated that over $\$ 80,000$ was spent on external training by the Bellevue, Washington staff alone. No data was available for the Denver, Colorado and Omaha, Nebraska staff organizations. Using this incomplete data, it was decided that internal course development would be beneficial because such training costs were only going to increase. This was a strong motivator for the formation of KSTP.

\section{Resource Allocation}

Analysis was done on two dimensions. First was an estimate of the dollar distributions over the two year life of the project as shown in Figure 37. This distribution

40 The text of the report, less proprietary references, is included in Appendix D. 
was spread by examining the five major functions (in the left column) and determining what proportion of the available resources would be allocated to each.

\begin{tabular}{|lrlrr|}
\hline & $\begin{array}{c}\text { Year 1 } \\
\text { 1st half }\end{array}$ & 2nd half & $\begin{array}{r}\text { Year 2 } \\
\text { 1st half }\end{array}$ & 2nd half \\
Training & - & $30 \%$ & $25 \%$ & $10 \%$ \\
Technical Support & $30 \%$ & $15 \%$ & $15 \%$ & $15 \%$ \\
Technical Currency & $40 \%$ & $20 \%$ & $15 \%$ & $15 \%$ \\
Development & $15 \%$ & $20 \%$ & $30 \%$ & $45 \%$ \\
ATEP & $15 \%$ & $15 \%$ & $15 \%$ & $15 \%$ \\
\hline
\end{tabular}

Figure 37. Percentage resource allocations for KSTP

These functions, as originally proposed, are described in the following paragraphs.

As will be seen in later sections, these functions did not always turn out as planned.

"The Training function is targeted primarily at the key players in an expert system development project: the knowledge engineer, his or her manager, and the domain expert. The project was to produce a core curriculum of courses covering basic and advanced expert systems concepts. Potential courses included:

- Artificial Intelligence \& Expert Systems Overview

- Introduction to Expert Systems

- Knowledge Representation

- Knowledge Acquisition Techniques

- $\quad$ Expert Systems Project Management

- $\quad$ Specific Expert System Building Tools.

The Technical Support objective is targeted at potential and active knowledge engineers. The project staff will deliver talks and demonstrations on demand to groups interested in learning about the technology in general. To leverage the expertise developed by groups with development efforts across as wide an audience as possible, the project staff will organize and support a users group. In addition, the staff will provide direct consultation to clients with development efforts, including problem identification, preliminary design, rapid prototyping, project-tool matching, and testing and validation. 
The Technical Currency objective is targeted at active knowledge engineers and CIS support groups such as SDME (Standard Development and Maintenance Environment) and Information Resources. Project staff will be responsible for ensuring that the most up-to-date information regarding expert systems theories and tools are reviewed. Via the users group, that information will be shared with all groups actively developing expert systems. Support groups will be kept current on the state-of-the-art for tools in the environments of their areas of responsibility.

The Development objective is targeted at the company at large, focused through client organizations. Project staff will design and implement at least one large expert system with important financial rewards. This effort is intended to be both an opportunity to build full-scale development expertise in the project staff and the client group, and a major vehicle for delivering the benefits of the technology to the corporation. Potential candidates exist today for this application in efforts currently in various phases within the company. The project staff will work with the client group from its current state to a finished production system, and provide support necessary to enable the client organization to maintain the finished system.

The Advanced Technical Education objective is targeted at the company at large, focused through selected members of the project staff. Members of the project staff will participate in ATEP to develop advanced computer science knowledge required to maximize the benefit of the transfer of expert systems and artificial intelligence technology, as they mature, into the mainstream of CIS systems."

The other resource allocation area was specific dollars over the two year time frame, as shown in Figure 38. The objective of staff training was to bring all members of the project staff to the same level of exposure to expert system concepts, to provide training on specific software tools, and to develop expertise in the training of others.

The software estimate was an educated guess, with the original proposal stating "it is premature to specify exactly what software will be purchased for the project." Hardware provided funds for additional workstation and printer purchases. The travel budget was largely due to the U S WEST-wide nature of the project. 


$\begin{array}{lr} & \text { Year 1 } \\ \text { Staff Training } & \$ 30,000 \\ \text { Software } & \$ 100,000 \\ \text { Hardware } & \$ 130,000 \\ \text { Travel } & \$ 36,000 \\ \text { Training Materials } & \$ 7,500 \\ \text { User Group/Affiliates Support } & \$ 10,000 \\ \text { Miscellaneous } & \$ 10,000 \\ \text { Total Expense } & \$ 323,500 \\ \text { Salary } & \$ 250,000 \\ \text { Total Annual Budget } & \$ 573,500 \\ \text { GRAND TOTAL PROJECT BUDGET }\end{array}$

Year 2

$\$ 0$

$\$ 0$

$\$ 0$

$\$ 36,000$

$\$ 2,500$

$\$ 10,000$

$\$ 10,000$

$\$ 58,500$

$\$ 250,000$

$\$ 308,500$

$\$ 882,000$

Figure 38. Estimated dollar distributions for KSTP expenses.

In the research committees recommendation report, the preceding is the extent of the technical perspective analysis. Once the project began, there was an occasional $\mathrm{T}$-issue raised but largely the issues were in the organizational and personal domains.

\section{FORMAL ORGANIZATIONAL STRUCTURE}

Since divestiture, the information systems organization has changed many times. During the existence of KSTP there were two major changes, the first due to regionalization ${ }^{41}$ and the second due to internal conflicts between information systems and the advanced technology organization. These transitions have been phased and continue even today in order to reduce the combined regional staffs and to be more responsive to the market units of U S WEST. When KSTP was initiated, the CIS organization consisted of 5300 employees, organized as shown in Figure 39. Within this organization, there was no clear cut place to position KSTP, so a modified matrix approach was adopted. This is shown in Figure 40.

41 Regionalization is the process by which the separate organizations of the old Mountain Bell, Northwestern Bell, and Pacific Northwest Bell combine into single units to serve the entire new corporation. The information systems staffs work towards establishing single systems, such as one billing system, for the entire company and to standardized on uniform processes and procedures. 


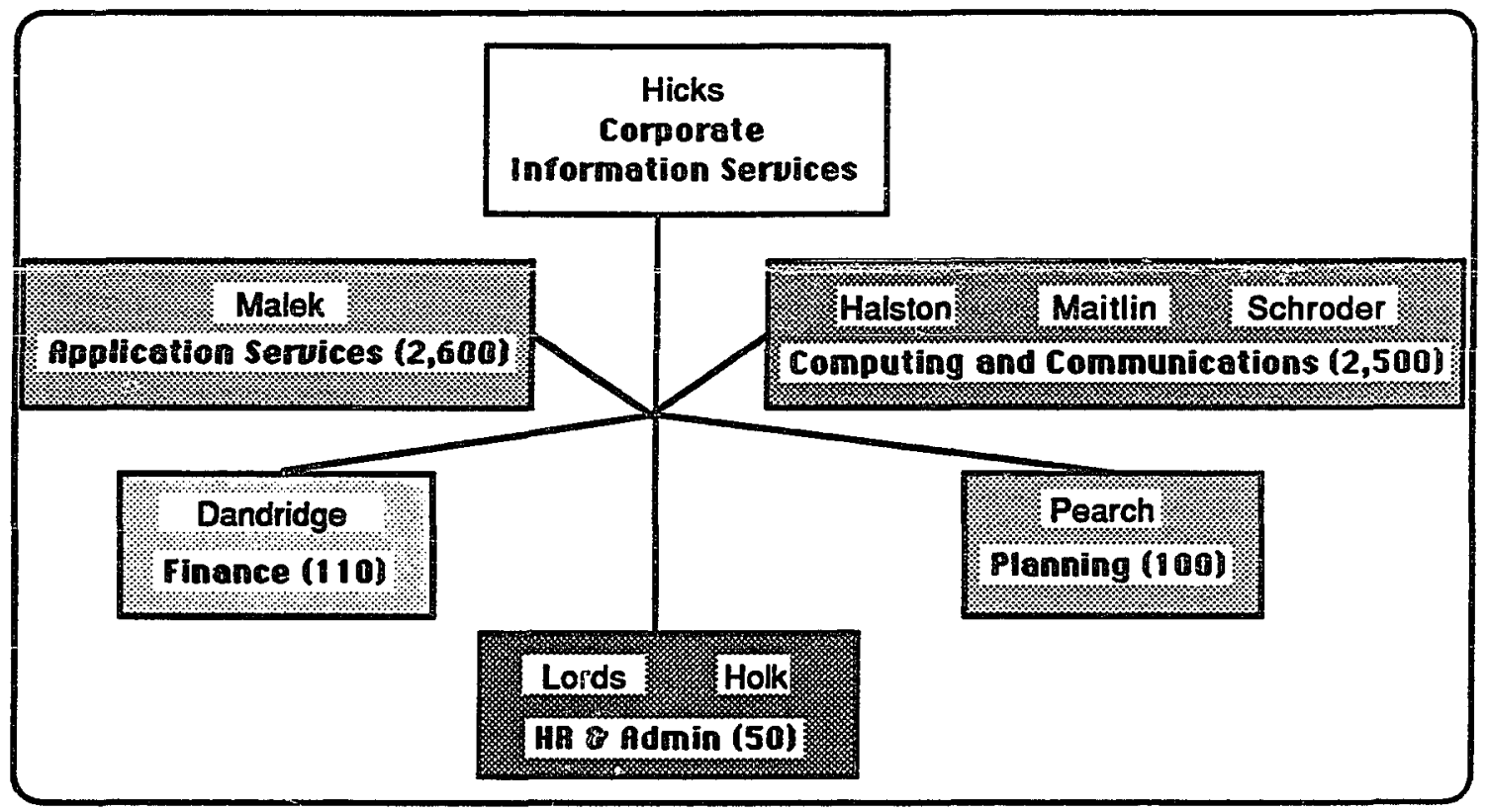

Figure 39. CIS organizational structure.

Each of the primary project sponsors (Medina, Gunter, and Schroder) agreed to provide headcount $(2,1,2$ respectively), and sufficient capital and exper $*$ o money to 1$)$ support the allocated headcount level and 2) to support the general needs of the project, i.e. those costs associated with group functions more than with individuals. In the initial KSTP Memorandum of Agreement ${ }^{42}$ additional resources were agreed to by U S WEST Advanced Technologies, but were not realized during the project. Therefore, from a Tperspective, the most significant impact of the AT group was their complementary, but largely independent technology development efforts. There were no reporting or funding relationships. 


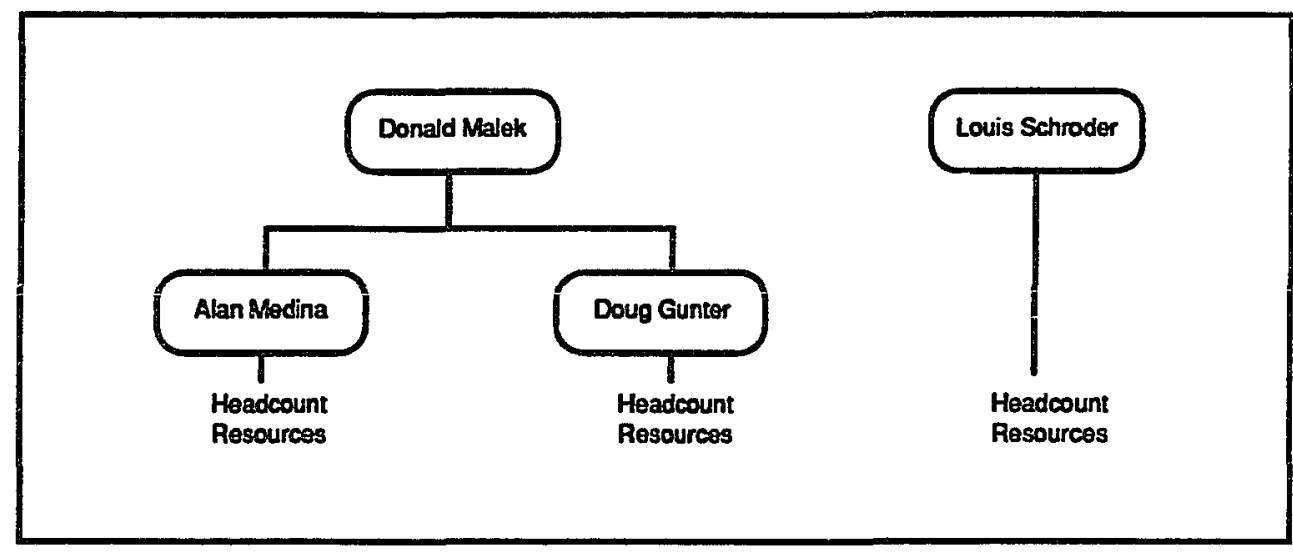

Figure 40. KSTP sponsorship structure

In January of 1989, the Advanced Technologies organization and Corporate Information Services were combined into a single functional organization (although legal identities remained separate). The rationale was to bring the organizations closer together and to foster teamwork. This organization had great impact on the dynamics of KSTP, both positively and negatively. These will be explored in the $\mathrm{O}$ and $\mathrm{P}$ analysis.

The information systems organization was spread across a number of geographic locations, with employees located across the entire 14 state region but primarily in the cities listed in Figure 41. 
Geographic Distribution of Information System Employees

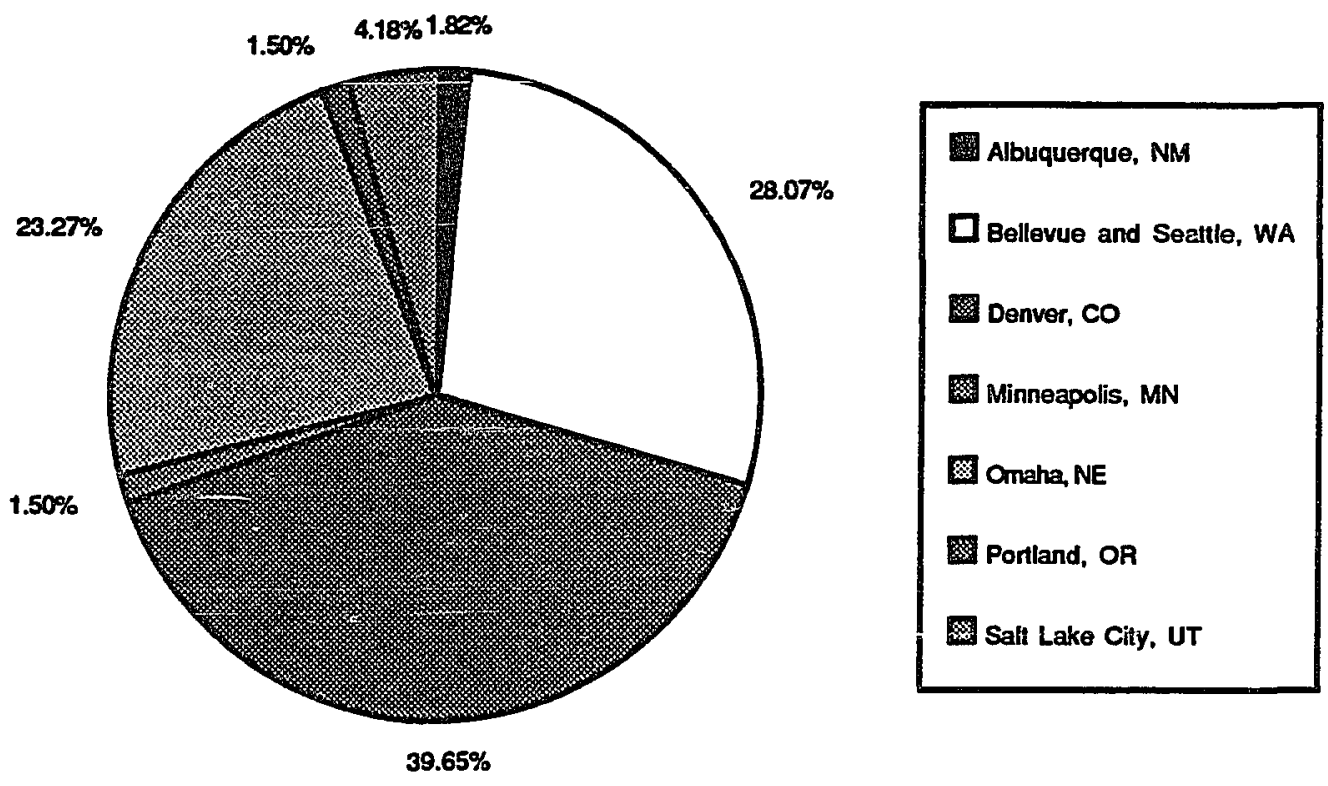

Figure 41. Geographic distribution of IS employees

The effect of regionalization, ongoing organizational realignment, and geographic separation foreshadow significant influences on the efforts to integrated a new technology. Regionalization forces the confrontation of different cultures and operating practices, which are seen in the $\mathbf{O}$ and $P$ perspectives. Ongoing organizational realignment adds to the dynamics, as people no longer remain in one organization to stabilize and no organization remains intact long enough to develop its own identity. This requires a deep look into the $\mathrm{O}$ and $\mathrm{P}$ dimensions to provide insight beyond the $\mathrm{T}$ orientation of the organization chart. Geographic separation causes severe communications problems, as discussed in previous sections. Dealing with these forces was a major component of KSTP work plans. 


\section{PROJECT MEASUREMENT}

As discussed in the literature review on technology transfer, one of the difficult issues is knowing when technology transfer has cccurred. One part of the difficulty is defining what is to be measured; a second part is how it will be measured; and a third part is establishing an acceptable value for the measurement.

For KSTP, the research committee report implies some potential measurements:

- Training courses should be developed, at some quality level

- One large expert system with important financial rewards should be developed

- Financial constraints are stated, enabling variance measurements

To actually manage the project, the KSTP team developed a rather quantitative spreadsheet tracking tool and a more qualitative Macintosh ${ }^{\mathrm{TM}}$ HyperCard tracking tool.

\section{Contact Log}

The HyperCard tool was used by all team members to maintain a Contact Log, keeping a record of client and vendor contacts which had a bearing on the project (index shown in Figure 42, log entry shown in Figure 43). This tool was used as input to the spreadsheet tool which tracked project status within a number of key performance areas, with specific items within each area (Figure 44). At each quarterly checkpoint, the Contact Log, personal calenders, and other documents were reviewed, summarized, and input to the Project Evaluation spreadsheet. Results were analyzed (even if they matched projections) to determine if adequate progress was being made. In some cases, items were deleted or added. In cases of variance from projections, causes were assessed. Depending on the cause, future projections may be adjusted up or down. 


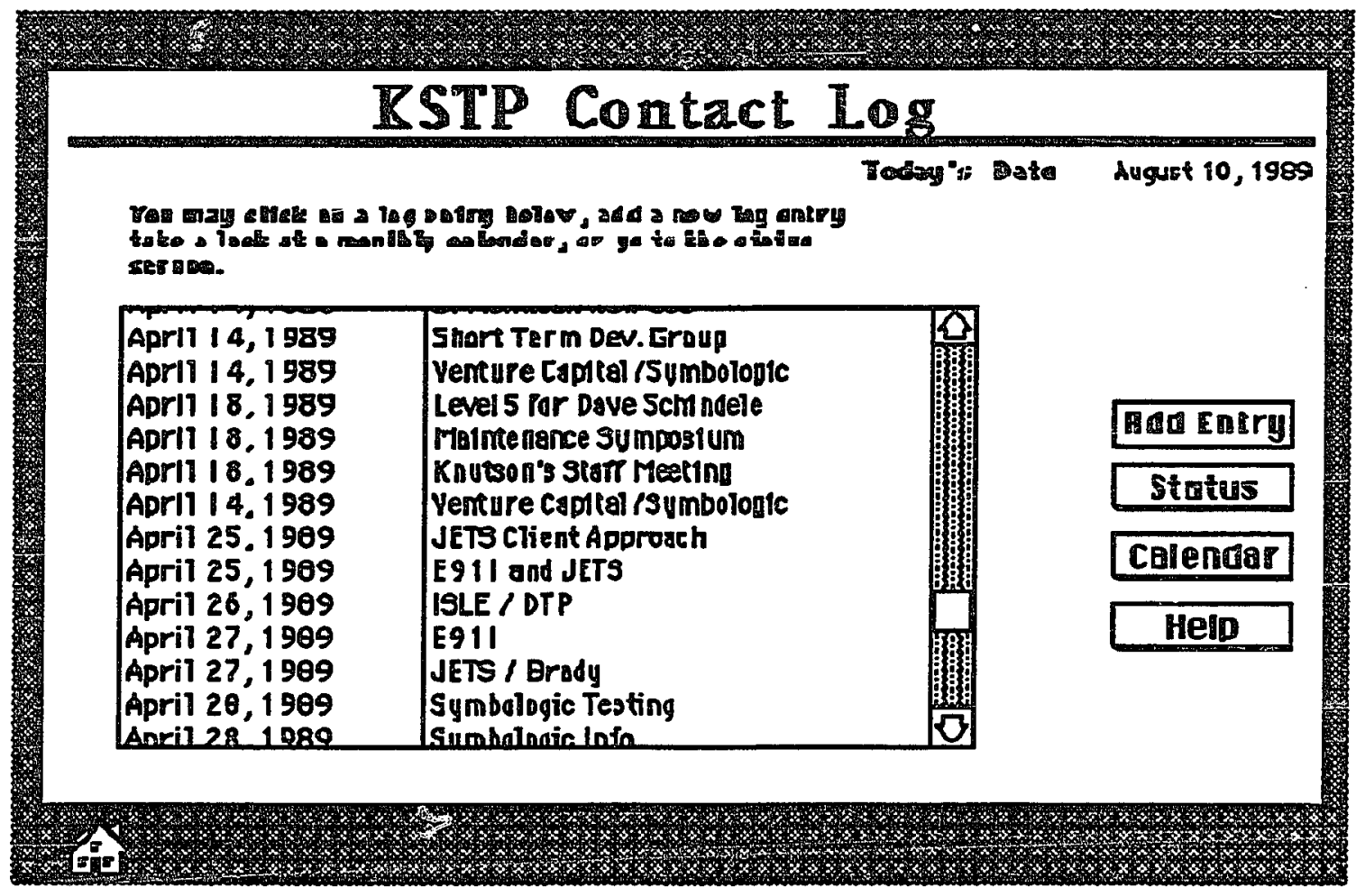

Figure 42. Contact log index. 


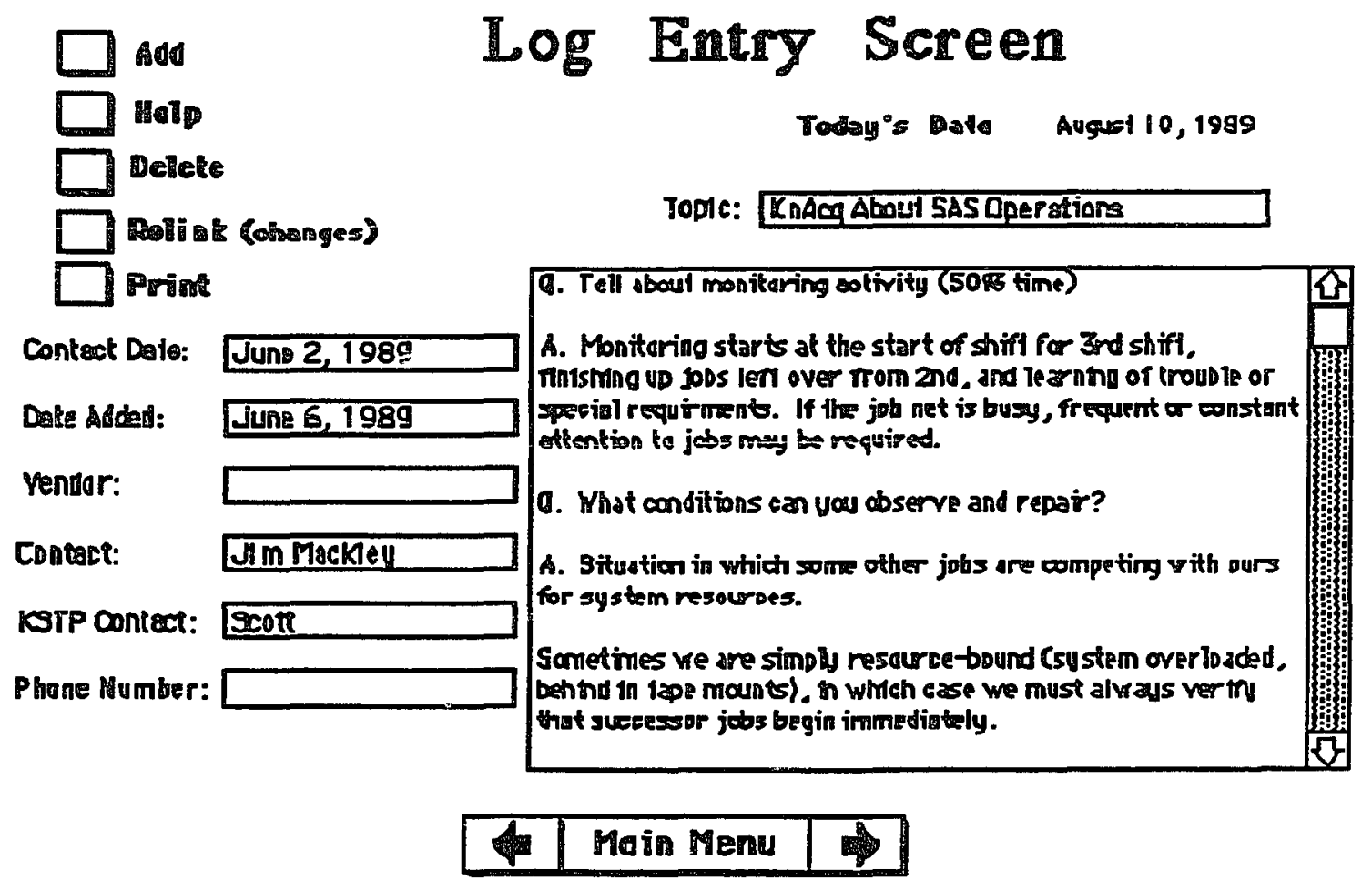

Figure 43. Contact log entry screen.

\section{Spreadsheet Analysis}

Without analyzing the spreadsheets in detail (Figure 44 and Figure 45), it is sufficient to observe the mapping of the key areas to the original project objectives in Appendix C. There is also an automatic projection mechanism built into the spreadsheet which support the assumption that a certain number of consultations will lead to a certain number of exploration and analysis engagements, leading to a number of development projects, and finally resulting in a number of production systems. This was a simple case of working the numbers, assuming that with large enough numbers in the early stages, something would make it through to production. 


\begin{tabular}{|c|c|c|c|c|c|c|c|c|c|c|c|c|}
\hline & \multicolumn{2}{|c|}{ Jul15 88} & \multicolumn{2}{|c|}{ OA15 88} & \multicolumn{2}{|c|}{$\operatorname{Jan} 1589$} & \multicolumn{2}{|c|}{ Aprt5 89} & \multicolumn{2}{|c|}{ Jul 1589} & \multicolumn{2}{|c|}{ Oct15 89} \\
\hline & Exp & Act & Exp & Act & Exp & Act & Exp & Act & Exp & Act & Exp & Act \\
\hline \multicolumn{13}{|l|}{ Tralning } \\
\hline Curriculum Recommendation Done & & & $x$ & & & & & & & & & \\
\hline Curriculum Recommendation Updtd & & & & & $\mathbf{x}$ & & $\mathbf{x}$ & & $x$ & & $x$ & \\
\hline ESAT/KSTP Partnership & & & & & & & $x$ & & & & & \\
\hline \multicolumn{13}{|l|}{ ES Training in Place $(\hat{A})$} \\
\hline Number of People Trained & 0 & 0 & 5 & & 10 & & 30 & & 60 & & 60 & \\
\hline Percentage of Trainees thru KSTP & & & $90 \%$ & & $90 \%$ & & $50 \%$ & & $50 \%$ & & $90 \%$ & \\
\hline Library Updated w/ Training Refs. & $x$ & $x$ & $x$ & & $x$ & & $x$ & & $x$ & & $x$ & \\
\hline \multicolumn{13}{|l|}{ Tools } \\
\hline Maintrame Tool Selected & & & & & $\mathbf{x}$ & & & & & & & \\
\hline \multicolumn{13}{|l|}{ Mainframe Tools Installed } \\
\hline Recommended PC Tools Identified & & & $x$ & & $x$ & & $x$ & & $x$ & & $x$ & \\
\hline Library Updated w/ Tool Rels. & $x$ & $x$ & $x$ & & $x$ & & $x$ & & $x$ & & $x$ & \\
\hline \multicolumn{13}{|l|}{ Formal Communications } \\
\hline Number of ESIGKSUG & 1 & 1 & 1 & 1 & 1 & & 1 & & 1 & & 1 & \\
\hline Participation in Al Team & 0 & 0 & 1 & 1 & 0 & & 1 & & 0 & & 1 & \\
\hline Epistemological Flyers & & & 1 & & 2 & & 2 & & 2 & & 2 & \\
\hline Executive Briefings & 5 & 5 & 0 & & 5 & & 0 & & 5 & & 0 & \\
\hline & & & & & & & & & & & & \\
\hline \multicolumn{13}{|l|}{ Industry/Acadomic Liaisons } \\
\hline Carnegie Group Project & & & $x$ & & $x$ & & $x$ & & $x$ & & $x$ & \\
\hline Bollcore & & & & & $x$ & & & & $x$ & & & \\
\hline ES Implementation Group & & & $x$ & $x$ & $x$ & & $x$ & & $x$ & & $\mathbf{x}$ & \\
\hline University Contacts & 2 & 2 & 3 & & 2 & & 2 & & 2 & & 2 & \\
\hline GUIDESHARE & & & $x$ & $x$ & $x$ & & $x$ & & $x$ & & $x$ & \\
\hline \multicolumn{13}{|l|}{ Consultations } \\
\hline General & 5 & 5 & 15 & & 15 & & 20 & & 20 & & 20 & \\
\hline Training & 5 & 2 & 5 & & 20 & & 40 & & 40 & & 40 & \\
\hline Tool & 5 & $?$ & 4 & & 10 & & 20 & & 20 & & 20 & \\
\hline \multicolumn{13}{|l|}{ Total } \\
\hline Fieiereñice Library Established & & & & & $x$ & & & & & & & \\
\hline Reference Malerial Maintained & $x$ & $x$ & $\mathbf{x}$ & & $x$ & & $x$ & & $x$ & & $x$ & \\
\hline \multicolumn{13}{|l|}{ Exploration and Analysis } \\
\hline Number of Engagements & 3 & 3 & 6 & 7 & 10 & & 12 & & 20 & & 25 & \\
\hline \multicolumn{13}{|l|}{ Costs of E\&A Engagements } \\
\hline Prob Selection Techniques 10'd & & & $x$ & & & & & & & & & \\
\hline Prob Selection Techniques updid & & & & & $x$ & & $x$ & & $x$ & & $x$ & \\
\hline Establish HyperCard Contact Log & $x$ & $x$ & & & & & & & & & & \\
\hline Maintain HyperCard Contact Log & $x$ & $x$ & $x$ & $x$ & $x$ & & $x$ & & $x$ & & $x$ & \\
\hline Number of Small Tools Distributed & & & & & 5 & & 5 & & 5 & & 5 & \\
\hline Percentage on Permanent Loan & & & & & $20 \%$ & & $60 \%$ & & $60 \%$ & & $60 \%$ & \\
\hline
\end{tabular}

Figure 44. Project activity measurment. 


\begin{tabular}{|c|c|c|c|c|c|c|c|c|c|c|c|c|}
\hline & \multicolumn{2}{|c|}{ Jul15 88} & \multicolumn{2}{|c|}{ Oct15 88 } & \multicolumn{2}{|c|}{ Jan15 89} & \multicolumn{2}{|c|}{ Apr15 89} & \multicolumn{2}{|c|}{ Jul 1589} & \multicolumn{2}{|c|}{ Oct15 89} \\
\hline & Exp & Act & Exp & Act & Exp & Act & Exp & Act & $\operatorname{Exp}$ & Act & Exp & Act \\
\hline \multicolumn{13}{|l|}{ Dovelopmont } \\
\hline Number of Engagements & 2 & 3 & 3 & & 6 & & 8 & & 12 & & 14 & \\
\hline Ñumber of Cis Centers invoived & $i$ & 2 & 2 & & 3 & & 3 & & 3 & & 3 & \\
\hline \multicolumn{13}{|l|}{ Costs of Dev Engagements } \\
\hline Demo Prototype & 2 & 3) & 3 & & 41 & & 5 & & 6 & & 6 & \\
\hline Fiold Protolype & 0 & 0 & 0 & & 21 & & 3 & & 4 & & 4 & \\
\hline Production Systems & o] & 0] & 0 & & 0 & & 0 & & 2 & & 4 & \\
\hline Value- of Product to Client (C) & & & 25 & & 2.5 & & 2.5 & & 25 & & 2.5 & \\
\hline Valuen of Process to Client (C) & & & 25 & & 2.5 & & 2.5 & & 2.5 & & 2.5 & \\
\hline \multicolumn{13}{|l|}{ Hainframe Production Systems } \\
\hline Number & 0) & & 0 & & 0 & & 0 & & 1 & & 2 & \\
\hline \multicolumn{13}{|l|}{ Devalopment costs (Smillions) } \\
\hline \multicolumn{13}{|l|}{ Annual doltar benefils } \\
\hline \multicolumn{13}{|l|}{ Annual dollar costs } \\
\hline \multicolumn{13}{|l|}{ Net annual value } \\
\hline \multicolumn{13}{|l|}{ All Other Production Systems } \\
\hline Number & & & 0 & & $\mathbf{0}$ & & o) & & 1 & & 2 & \\
\hline \multicolumn{13}{|l|}{ Development costs (Smillions) } \\
\hline \multicolumn{13}{|l|}{ Annual dollar benelits } \\
\hline \multicolumn{13}{|l|}{ Annual dollar costs } \\
\hline \multicolumn{13}{|l|}{ Net annual value } \\
\hline \multicolumn{13}{|l|}{$\begin{array}{l}\text { Contribution to Corporate } \\
\text { Goals }\end{array}$} \\
\hline \multicolumn{13}{|l|}{ Technical \% (D) } \\
\hline \multicolumn{13}{|l|}{ Organizalional @ (E) } \\
\hline \multicolumn{13}{|l|}{ Personal ^ (F) } \\
\hline & & & & & & & & & & & & \\
\hline \multicolumn{13}{|l|}{ Personal Development } \\
\hline Job Satisfaction (avg, scale 0-5) & 4 & & 4 & & 4 & & 4 & & 4 & & 4 & \\
\hline Educational (ATEP Participants) & 1 & & 3 & & 3 & & 3 & & 2 & & 2 & \\
\hline Hours Training/person & 20 & & 20 & & 20 & & 20 & & 20 & & 20 & \\
\hline Promotions & 0 & & 0 & & 2 & & 0 & & 0 & & 0 & \\
\hline Career Growth (B) & & & & & & & & & & & & \\
\hline & & & & & & & & & & & & \\
\hline -Average values of on 0.3 scale, & orted & by doll & ars wh & re po & & & & & & & & \\
\hline \# Inyestment spreadsheet analys & attachec & & & & & & & & & & & \\
\hline $\begin{array}{l}\text { \% Technology characteristics ano } \\
\text { adoption and deployment; evolut }\end{array}$ & $\begin{array}{l}\text { hnologi } \\
\text { y cons }\end{array}$ & $\begin{array}{l}\text { cal en } \\
\text { ideratic }\end{array}$ & ironme & & & & & & & & & \\
\hline $\begin{array}{l}\text { @ Upper management, middle m } \\
\text { technology transfer: linkage with }\end{array}$ & pany $\mathrm{p}$ & $\begin{array}{l}\text { lower } \\
\text { rogram }\end{array}$ & manag & & & & & & & & & \\
\hline $\begin{array}{l}\text { A Description of individual bohav } \\
\text { tochnology transfer; human resou }\end{array}$ & ranag & $\begin{array}{l}\text { the } \\
\text { ent }\end{array}$ & & & & & & & & & & \\
\hline
\end{tabular}

Figure 45. Development activity measurement. 
These are internal KSTP measurements. External to the project, no one had stated requirements nor expectations for KSTP performance.

An additional measurement was client feedback. Each month, more or less, clients were asked to rate the level of service which they received from KSTP (poor, fair, good, excellent), to provide suggestions for improving service, and to offer ideas for other potential knowledge systems applications in U S WEST. 


\section{CHAPTER VI}

\section{THE ORGANIZATIONAL PERSPECTIVE}

The organizational $(0)$ perspective dominates the inquiry methods within organizational settings such as companies, government agencies, and volunteer groups. But further than these, the O-perspective also includes informal groups that may not have a name, may not be readily identifiable, and whose members may not recognize the existence of a group. People in organizations do not deal with their environment from an abstract view. Practical necessities and needs mold their perceptions of their organizational interactions and what they must do to survive and to prosper. The O-perspective is both subjective and objective in that it views the world according to a mix of uncertainties and standard operating procedures, with satisfaction rather than optimization as a goal. Planning, and action on those plans, tends to be incremental and representative of the status quo method of doing business.

At it matures, an organization becomes a system with a logic of its own and the weight of tradition and inertia. The deck is stacked in favor of the tried and proven way of doing things and against the taking of risks and striking out in new directions.

\section{IDENTIFICATION OF THE ORGANIZATIONS}

To analyze the organizational entities in this study, major units having impact on the integration of knowledge systems technology were identified and grouped into the following categories: 
- Internal formal - A U S WEST unit whose members mutually identify and whose members can be readily identified by non-members due to official U S WEST sponsorship.

- Internal informal - A U S WEST unit whose members may or may not mutually identify and whose members may or may not be readily identified by non-members. No official U S WEST sponsorship exists.

- Extermal formal - A non-U S WEST unit whose members mutuaily identify and whose members can be readily identified by non-members due to some type of official sponsorship.

- External informal - A non-U S WEST unit whose members may or may not mutually identify and whose members may or may not be readily identified by non-members. No official sponsorship exists.

The organizations included in each of these four categories were investigated while looking at the following areas:

- members and size

- official goals of the organization

- unstated goals

- technology view (benefit or victim of new technology, hire/fire due to new technology)

- physical environment

- peoples perceptions of stability and vulnerability to influence

- Clarity of how to achieve objectives and stability of environment

- tasks

- division of tasks

- responsibility for task completion

- environmental linkages 
- operational structure (as opposed to formal)

- power over knowledge systems development

- resources

- resource division between DOING WORK and CONTROL, real power (policy control)

- resilience in unpredictable situations

- uncertainty coping behavior: communications, task coordination, developing routines and rules

- programmed responses (SOP's ), unwritten rules and how they are circumvented

- non-programmed responses

- incentives and reward system, explicit and implicit

- information flow within the organization

Each of these areas were not necessarily found within each organization and, in many cases the information about that area was not essential for the analysis of the technology integration process. Therefore, in the sections that follow, only the factors that bear on the research topic are discussed.

Before analyzing the organizational perspective of KSTP itself, there are some contextual pieces that must be described. These are the relevant organizational views of $U$ S WEST and Corporate Information Services.

\section{U S WEST}

As described in Chapter II, U S WEST is largely composed of Mountain Bell, Northwestem Bell, and Pacific Northwest Bell. The attempts to merge these companies into one amalgamation have proceeded slowly. Slow speed is not, of itself, a negative factor because the significant differences in company cultures cannot be forced together by 
ultimatum. US WEST faces unique problems not faced by any of the other six regional telecommunications companies, such as a 14 state operating region (which means 14 public utility commissions to interact with), wide geographic reaches (from the Great Lakes to the Pacific Ocean, from Canada to Mexico), and the resulting social and cultural differences crossing such a vast region. The company is addressing these issues by actively pursuing deregulation from the utility commissions, investing in internal communications networks, and heightening individual awareness of pluralism as a fundamental part of the business.

With a history of service orientation, pre-divestiture market responsiveness had been minimal, essentially in the mode of telling customers, "Here is what we sell." Now sre is a strong move towards market orientation, with a realignment of the company into market units which are focused on serving the unique needs of their customers. In turn, the market units tell the U S WEST support organizations, including information system, what they must have to serve their customers. In this way, the market units define what the priorities are for software development.

While these efforts are unfolding, there are limitations to the way the business can operate, such as the inability to transfer internal budget dollars across company lines. This is due to a combination of regulations, accounting system limitations, and the fact that the three telecommunications companies are still legal corporate entities. There are also unregulated subsidiaries of U S WEST that must not be subsidized by the regulated companies. For example, when a U S WEST knowledge systems training class was held, it was permissible for employees of regulated and unregulated companies to attend. Those from the unregulated subsidiaries had to pay their fair share and the FCC dictates a specific, rather involved procedure for this.

Operationally, U S WEST is a systems-oriented and systems-dependent company in the fullest sense. The telecommunications network operates as a very large, complex system and the management of such a network requires a workforce that reflects the system 
in terms of complexity and communications needs. One vendor viewed the company with amazement, saying, "The more we look at U S WEST, the more complicated the picture becomes in terms of a giant and complex network of systems that need to communicate."

As a large organization, U S WEST is less able to implement timely change. Because it takes a fair amount of time to see results, the company, if it wishes to survive in a competitive world, must have a long time horizon with less discounting than many other businesses.

A rapidly fading remnant of the old Bell System is the maternalistic relationship between the company and the employees, as was evidenced by lifetime employment, good benefits, good working conditions, high integrity, and high regards for the individual. With market pressures and the incessant demand for short-term financial performance (which is not unique to U S WEST), the maternalistic qualities that attracted the current workforce are becoming memories.

Promotion from within is an enduring company value that has served as a stability factor in the past but shows some signs of weakening when business needs necessitate incorporation of new talent. Key players are being lured from other companies to fill new world voids that cannot be filled by experienced old-school managers, many of whom say they've changed, but act in accordance with a career of organizational conditioning.

As with most stable bureaucracies, there has been an historical resistance to change. By necessity, this resistance has been diminishing since the day AT\&T and the U.S. Department of Justice announced divestiture as the solution to the government's anti-trust suit. However, the entire corporation and its standard operating procedures were established in a different era. With these legacies, rapid change is not possible even when it is needed. This is very visible with large software systems that were designed to incorporate approved utility rate changes once a year, and are now faced with weekly or daily change demands to keep up with market demands. 
Consistently strong financial performance is another organizational trait which plays a prominent role when considering the time and money costs of change. The old AT\&T "blue chip" stock for widows and orphans is a difficuitt legacy to maintain. While U S WEST stock has risen in value and continues to issue respectable dividends, the uncertain future of telecommunications during the transition from regulated to unregulated causes new efforts to be viewed as strategic investments in the future, at the expense of short-term payoff.

\section{CORPORATE INFORMATION SYSTEMS}

CIS has some inherited (from U S WEST) and some of its own organizational factors which influenced KSTP. The three company cultural issue is manifested to an extreme within the organization. The resolution of cultural differences are met without decisiveness. Turf battles go on for prolonged periods without progress towards resolution. In early 1989, a number of burning issues faced CIS and Advanced Technologies:

- A significant morale problem which required attention from U S WEST senior management, calling attention to the corporation's values toward people

- Employee fears about redeployment and job security due to constant cost-reduction efforts

- CIS employee concerns about possible pay and benefit cuts if transferred to an unregulated subsidiary

- Regulator concerns about cross-subsidization between CIS and AT

- Union leaders' concerns about pay, benefits, job security, and union representation of certain CIS employees

- The lack of market unit understanding of the role of AT 
- The negative image of CIS in many parts of the corporation

- Confusion between CIS and AT over roles and work division, with resulting turf problems

Contention between the two organizations was apparent for nearly a year, when action was finally taken to put them under one name, the Information Technologies Group.

CIS has a number of organizational attributes which affect its ability to adopt new technologies. The most significant of these are the existence of well developed rules and procedures, limited knowledge of new technologies, immature technical skills assessment organizations, uncertain recruiting practices, and a focus on budget management as a primary activity.

\section{Rules and Procedures}

As with the corporation, CIS standard operating procedures were established in a different era. While documented procedures can be easily rewritten by staff groups, the actual practice takes much longer. In other cases, the unwritten rules have even greater effect, such as the mid-managers who are not comfortable with employee communications outside of the chain of command and the programmers who are on such a tight leash that they must ssion to attend a two-hour meeting on a new technology.

ise strength in having well-developed rules and procedures is that, in many cases, there are insertion points for new procedures within existing structures. The limited resources of a new technology effort prevents reinventing the wheel. It is not only attractive, but imperative that the new technology processes be integrated into the mainstream procedures.

\section{Limited Knowledge of New Technologies}

The CIS organization's traditional operating environment can be generally characterized as IBM or Amdahl mainframes with most applications written in COBOL 
using flat files or commercial database systems. With the large workloads imposed due to market unit needs, CIS staff works with existing tools because they simply do not have the time to learn about new technologies. So they are not in a position to determine if or when a different approach would be beneficial.

There are three groups of people that can be disguised for the purposes of technical preparedness: technical employees who directly perform technical IS tasks, managars of the technical employees, and directors who manage groups of managers.

The senior technical employees have made these observations on the capabilities of theses three groups to deal with new technology:

- The technical employees who have an interest in new technologies simply do not have enough hours in the day to meet their existing job responsibilities and invest time in learning about the new

- The managers of technical groups are concerned with their own loss of technical competence because their job responsibilities include many administrative tasks. In many cases, managers do not have any technical background

- The directors have lost their technical knowledge in the same fashion as the managers, usually to a greater degree

A major reason for knowledge loss at the manager and director levels is that the organization culture does not support or encourage technical literacy, leaving it to the choice of the individual. Some people in these groups have specifically chosen to leave the technical ranks because they were no longer interested in it. They do not accept technical leadership as their role.

There is also an understandable reluctance to take on any new responsibilities because these people are very busy running their area of the business. A large part of their work concerns budget management, which is discussed below. 
It is also interesting to viev he need for technical literacy from the CIS client perspective. The following passage captures the essence of this.

Account managers are the peopie who represent the client interests to CIS:

"I met with the Seattle Account Management Team to talk about ways in which KSTP and the Account Managers might work together.

To start off, they were unfamiliar with KSTP. After a brief introduction to KSTP, I suggested that we could be one more trick in their bag of tricks to serve their Accounts (Federal Services, Government and Education, Network Facilities-Services-Switching, Business Resources, and a large chunk of legal entity Pacific Northwest Bell (Treasury, Tax, Separations, Security, Legal).

They have had a particular problem with CIS response to their client needs. For example, they will match a client information need to an application area in CIS, then spend too much of their time getting the application area to commit resources to work on satisfying the client needs. Also, the application solution proposals are very narrow, in that they only consider tools and techniques familiar to the IMTS's, which may not address the client needs.

I said that we too must work with gaining application area support for ES projects, so if they came to us with a client we could help each other. They agreed. I also said matching the technology and problem was part of our job, so they would not be stuck there either.

I proposed that they use the "what are your three biggest information-related headaches" approach with clients and we would help apply the selection and filtering process. They agreed.

The group manager agreed to take the information to her boss' staff meeting for dissemination throughout all CIS account manager locations. If warranted, they will meet with me in the future.

One account manager was very enthusiastic and said she would call me within the week to follow-up on some ideas.

Final note: The account managers are very interested in getting some training and want the training package from us as soon as possible."

From this very encouraging beginning with one small group, the overtones of CIS organizational problems overshadow the potential benefits of trying a new technology.

Because of this, nothing further developed with the account management group. 


\section{Technical Skills Assessment Organizations}

As the traditional data processing and engineering functions have progressed from the Bell System environment to the more demanding environment of today, a number of groups of managers and technical personnel have been formed to address technical skill rating and classification schemes. These groups are more like task forces rather than formal organizations, but when considered in total give an impression of a fairly substantial movement. The goals of one group provide a flavor for the $\mathrm{O}$ perspective:

- Provide an emphasis for establishing and maintaining a professional organization which emphasizes technical proficiency and performance

- Aid in retaining a skilled force essential for maintaining current systems and planning for and implementing future technology

- Ensure uniform communication and administration of the requirements to enter, advance through, and exit specific levels of technical proficiency

- Achieve skill alignment among the various US WEST companies

- Facilitate a means for rewarding individuals for technical expertise

In addition to the large number of these groups addressing technical skills, nearly every report or study in business planning areas includes a section on improving skills, recruiting and retaining "superstars", and developing training programs for the future.

In spite of the reorganization described previously, the Technical Career Structure (TCS) ${ }^{43}$ process has not been reviewed for possible application in Advanced Technologies. Not only are the technical people evaluated much differently, but group managers (i.e., managers having only one layer of technical employees reporting to them)

${ }^{43} \mathrm{TCS}$ is used for technical personnel assessment and development. Ir consists primarily of skill areas, ratings, and a periodic review process between the technical person and their manager. 
are classified higher than equivalent jobs in CIS. The conflict in messages (work as one : get treated differently) is obvious.

A significant problem with current skill definitions of the TCS is that they do not include future skill sets, relying on what was important instead of what is and what will be important. This has implications for people working with new technologies which are by nature oriented towards the future. In this context, the TCS process is also used as part of the promotion process for the technical levels. There are organizationally imposed limitations on the perceptions of promotion review committees as to what skill areas are important and how people are reviewed.

In one instance of a promotion review committee getting its first non-traditional type of request for promotion, they (upon later admission) did not know how to deal with it. The request was initially denied, but one month later it was approved with the comment, "Some of the documentation and supporting interviews exceed the newly promoted to level." This low-key superlative indicated a significant shift in the committee's position, because it is clear that the employee did not gain significant new skills in one month. Indeed, a committee member explained, "It was nothing $\bar{p}$ ersonal, it was simply a matter of the committee getting the first non-traditional type of application for reclassification and not knowing how to deal with it."

The process was a learning experience for mànageis (plan ăhead, "grease the skids" more), committee members (open your eyes), and technologists (start work on promotion early, keep expectations under control, work towards productive results).

The evaluations committee's role is difficult, with few black or white cases and many in varying shades of gray. The committee tries hard to understand job roles in new technology, but they cannot truly understand it because they have not experienced it. It is understandably biased from years of conditioning and the present job roles performed by its members. Therefore, the burden is on new technologists to plan in advance for 
promotions, knowing that their contributions to the company, no matter how valuable, are will not initially be judged by appropriate measures. New technologists must be willing to take their lumps in the early stages.

When changing jobs, most employees step into an existing position (or at least a well defined position), with well defined roles. Their job is to fit in and make modest changes as warranted. New technology employees step into newly created positions with no support structures, no defined roles, preliminarily defined tasks. Their job is to create a client base, market the technology, identify applications of the technology, select the projects, develop the projects (with clients), integrate the technology into existing organizations, and develop new talent. In CIS, there is little organizational accommodation for these differences, again pointing out the need to get the technology into the mainstream environment as scon as possible.

While this demonstrates some of the complexities of working with new technologies, it is also very revealing about the strengths of the review committees to rethink, analyze, and adapt to such situations. This beneficial characteristic is illustrative of how committee process can work within CIS, providing an entry mechanism for new techinology.

\section{Recruiting}

The recruiting staff is primarily responsible for relations with colleges and universities as sources for prospective employees. There are three factors which have been significant in the effectiveness of recruiting programs. First is the competition for qualified graduates in high demand fields such as computer science and engineering. Second is the downsizing of the company which has reduced the need for employees, resulting in a cutback of recruiting presence on campus. Third is the practice of sending managers who are not conversant in the disciplines for which they are recruiting. 
The intense competition for graduates would logically guide an organization to increase the quality and effort of the recruitment program. Accepting this premise, it seems that a campus recruiting presence must be maintained even in slow hiring periods in order to retain the good name and relationships that are needed in high demand periods. With the stature of the company dependent largely on the impact of the on-campus recruiters, it is imperative that the recruiters know the subject areas of the interviewees. Student groups form opinions about companies based on interview experiences that are handed down from graduating class to graduating class. These perceptions endure, much like interviewer opinions of schools providing quality graduates. While the company interviewers can make use of the track record of employees hired from various schools, college students depend much on grapevine company reputation, placing high value on the views of their peers. The company has not maintained a high profile because of recent lean business years, and this further aggravates its ability to compect for an already scarce resource. Furthermore, reduct $d$ recruiting puts additional importance on the development of existing staff.

\section{Budget management}

Yearly budget crises have caused budget management to become the primary activity of managers and directors. There are four major effects on new technology development:

1. Productive time is lost dealing with budget issues

2. Planning becomes a futile exercise

3. Suboptimization is encouraged

4. Accumulated experience is in dealing with budgets

On the first point, current budget administration includes an annual budget crisis accompanied by across-the-board budget cuts. It is short-term focused but practiced for months at a time, usually from June, July, or August through December 31. During these 
periods, but especially near their beginning, making budget cuts is the primary work activity of managers, directors, and technical employees. Extensive effort is made to question every activity and justify its continuance.

KSTP was the subject of repeated questions including reducing staff, reducing expenses, delaying the project, and full cancellation. Every time it happened, effort was diverted from knowledge systems deployment to formulating response to questions. Interestingly, the questions are often asked only a few months apart, which causes significant work interruption.

Secondly, budget crises in mid-year cause a major disruption in the work flow underway. A work flow is the actualization of a work plan developed mid-way through the previous year. Continual budget problems naturally lead people to question why they should spend so much time planning and preparing a budget to execute that plan, when their resources will be cut anyhow. A manager in the budget process commented on one budget submittal by saying,

"While I will forward your budget on for the ' 90 budget collection, you ought to be aware that it is pretty much meaningless because there will be no formal planning process for the budget."

A serious side effect of budget chaos is that managers cannot be accountable for their work nor their expenditures because they lose controi of their resources, and work plans are greatly reduced.

The third point, suboptimization, is a common systems phenomena which is aggravated in budget crises. Managers look to minimize their costs in any way possible, including shifting costs to other organizational units. This does nothing for the corporation, and wastes management time by playing the game. When managers are reluctant to step up to the problem, the issues are simply escalated to the next higher level in the hierarchy for another round of suboptimization, until someone finally makes a decision. 
This phenomena also leads to the McNamara style of results reporting. Significant "savings" are reported as organizational successes which are of dubious value when examined closely. Examples are saving a half million dollars of staff time by cancelling a project (no real money saved, just time reallocated to other efforts), saving thousands of dollars by reducing logon wait times to centralized computers (calculated by annual hours of staff time not spent waiting), and using CIS employees instead of contractors to perform work (it saves the contractor fees, but what about the CIS salaries?). As was said when McNamara was at Ford, "There haven't been any honest answers around here because there haven't been any honest questions."

The fourth issue is most serious. Over the years, CIS employees have spent a significant amount of time on budget issues. Not the issues that are necessary for managing and controlling expenditures, but time consuming chuming that results in the previous three points. CIS is an organization that is building a high level of experience with budgets, to the neglect of its business of providing information service to the corporation. Time spent on these excessive budget crises is time taken away from project management, client and partner relationships, employee development, software development, new technology adoption, and all the other pieces so important to the information systems function.

A piciure of the state of CIS rudgeting is given by a senior director:

"People are frustrated with the bidget process. There is the perception that it is bad to overrun, but when we underrun, the money just gets taken away anyhow (for both this year and next year). People are not clear on what sort of behavior the organization is trying to encourage."

\section{Summing up the CIS Organizational View}

Two things. First, is that CIS became ITS, or Information Technologies - Services in January of 1989. In addition to the new name, the change came wiih yet another organizational realignment. This illustrates the change that has been ongoing since 
divestiture, change that has become so commonplace that it has diminishing importance to employees. In fact CIS 1988 results listed significant change as one item causing employee concern. Coupled with increasing customer expectations and severe limits on resources, employee concern about change casts an interesting light on how the introduction of new technologies might be received.

Second is the quote below, from a senior technical professional:

"One thing I think your group should do is decide on how to spread ES involvement in CIS when they're ccnstantly harping about personnel shortages and not being able to break anyone away from the "critical" jobs to mess with as yet totally unproven (here) technologies. You know the mentality... there is a built in failure if you cannot convince the operational staffs that you are doing "real work"...more than just playing. Until it becomes a part of every group's operating environment (like COBOL or Cor methods writing) they will see it as a toy. The emphasis has to be on the people problem more than the technology problem. Visualize this...some egghead with a Ph.D. telling us how to put out bills HUMPH!! You get the point."

\section{THE KNOWLEDGE SYSTEMS TRANSFER PROJECT}

KSTP was formed as a result of the findings of the Research Committee on Expert Systems. 44 The committee found that Corporate Information Services activities encompassed three types of groups:

1. Those with a technology focus

2. Those with an application focus

3. Those providing access to consultation, training, and tools

While these activities were being performed, only a few prototype expert systems had been built and no industrial strength, production systems had been fielded. This was seen as an incoherent organizational response to a promising technology.

To remedy this, the committee considered three alternatives to providing support to the CIS organization's burgeoning demand for consultation, training, and tool evaluations.

${ }^{44}$ The text of the committee's report is in Appendix D. 
Continuing in the current uncoordinated fashion would not have prevented CIS groups from adopting expert systems technology; but it would not have leveraged the expertise being developed across the region to the corporation's maximum advantage. In the worst case, it might have resulted in duplicate efforts or even costly mistakes in training or tool selection. A logical approach might have been for U S WEST Advanced Technologies to provide support activities in addition to its functions of project development and Carnegie services management. Two problems were seen with this approach. First, the AT staffs would potentially need to be enlarged to manage these functions in addition to their missions of developing systems for clients in the $\mathrm{IDCs}^{45}$ and the unregulated subsidiaries. Secondly, the AT staff consisted of very qualified technologists, largely hired from outside of the corporation; as such they were somewhat removed from many CIS issues and concerns. The third and recommended approach utilized existing CIS employees with expertise in expert systems development to supplement U S WEST AT's larger corporate mission with support tailored to the CIS organization and its clients in the IDCs.

The operational charter of KSTP was to facilitate the transfer of expert systems technologies into CIS application, development, and maintenance groups. This would provide mainstream information systems technicians and managers with the knowledge, skills, and tools which would enable them to apply expert systems technology when appropriate to their application development efforts. In its implementation, the KSTP provided the six functions shown in Figure 46.

45Information Distribution Companies, which included Mountain Bell, Northwestern Bell, and Pacific Northwest Bell 


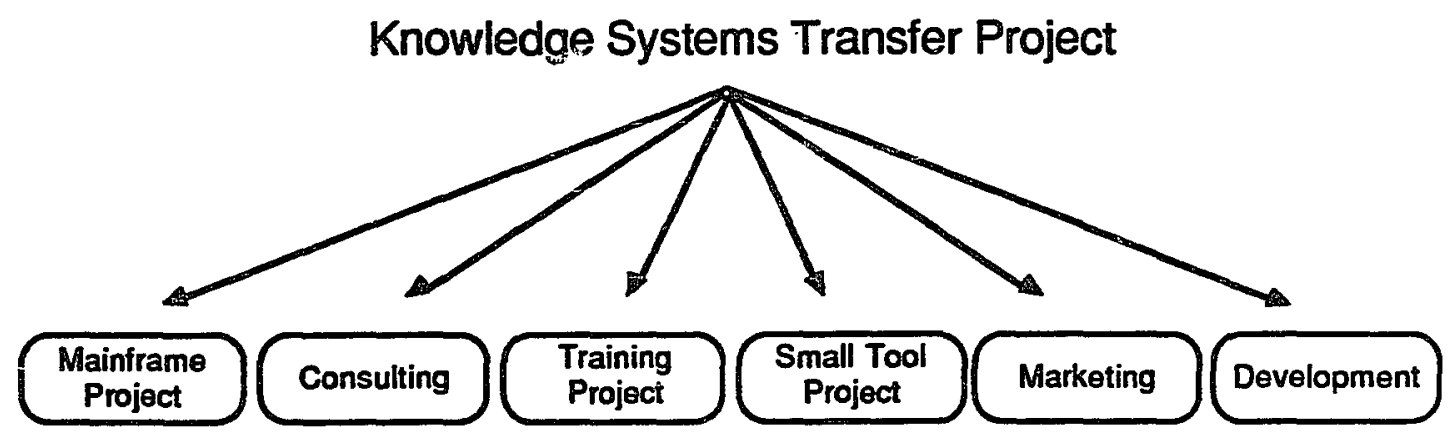

Figure 46. KSTP Subprojects.

With this division of tasks, the KSTP became the primary expert systems development force within CIS. Each of these functional areas establish boundaries in which to examine the organizational interactions, both internal and external to U S WEST.

\section{Mainframe Projeci}

When KSTG was initiated, it was staffed by people with strong computer science and mathematics backgrounds, befitting the then current domain of artificial intelligence. The desired hardware platforms were Unix workstations and LISP machines, with $\$ 50,000$ expert systems shells running on them. KSTP was aligned with this in its early equipment acquisitions.

Soon after formation of the project, KSTP staffers went out into CIS to look for expert system opportunities. When they spoke of the hardware and software used for AI, people in the CIS mainstream were not impressed. In fact they were not interested in buying into anything that cost as much as that, especially if it were unproven.

They were interested in software that would run on their embedded hardware base, primarily IBM and Amdahl mainframes and IBM PC's. Their current projects used very large databases with very high on-line transaction volumes. This was where the real work was done, so even expert systems on stand-alone PC's were not to be taken seriously. 
In near parallel with this enlightenment, another group at U S WEST headquarters became interested in using a mainframe expert system tool in an executive decision support application. The tool they chose was not held in high esteem by the expert system community, which prompted an AI Center evaluation of it specifically as a defensive maneuver. The evaluation pointed out the need for a mainframe tool that was robust enough for industrial strength applications and had enough features to satisfy diverse IS needs.

Having the primary linkage with CIS, KSTP initiated a U S WEST task force for the purpose of evaluating, recommending, and acquiring a mainframe expert system tool. It was clear that this would provide a wide accessibility to CIS developers and would serve as a legitimizing action for expert systems technology:

\footnotetext{
"As the salesman moved through the introduction to expert systems slides, the COBOL programmers noticeably lost interest, looking around the room, doodling, or trying to keep their eyes open. Then the salesman dialed into a mainframe computer, projecting a full screen image on the wall. He showed the expert system linkages to COBOL and they looked much like calls to a database. The COBOL programmers were attentive now, and actually started talking about where they could put such a tool to use."
}

With the risk of acceptance or rejection of expert system tools by the mainstream CIS staff people, the U S WEST team decided that it would be necessary to make detailed evaluation of the mainframe tools, including installation and database interaction testing on U S WEST computers.

From application programming areas, there were many volunteers to work on the trial. One group said they could put a mainframe tool to immediate use, if one were available. This enthusiasm endured until it was time for people to make specific work commitments. Only the billing organization was willing to participate, because they had experienced people who knew the potential of the technology. Other organizations had not 
made the á priori investment that the billing people had, so lacked the understanding needed to commit.

Other significant applications were identified during the course of the tool evaluation. In one notable case, a project team was formed, resources obtained, and timelines prepared for an effort that would have significant impact on company business. This effort was suddenly cancelled, for a multitude of reasons which are described in the cross-cuing section. For now, it is sufficient to observe that significant applications existed within the CIS environment.

\section{Consulting}

KSTP consulting activities provided extensive contact with a large number of organizational subunits. From a technology integration perspective, the intents were to:

- Provide information on expert systems technology

- Assess the feasibility of applying the technology to specific applications areas

- Provide the resources for the client to continue expert systems exploration. This included reading lists, books, journals, training recommendations and development alternatives

- Discover high potential application areas that could be developed by the CIS analyst alone or in partnership with KSTP, the Expert Systems Development Group in Advanced Technologies, or the Carnegie Group 46

These consulting activities consumed a significant amount of KSTP resources through the actions of two informal groups whom are identified as lookers and as talkers.

46 These last two groups are described below. 
The lookers only look at expert systems, not progressing to the point of talking seriously about using the technology. In some cases, lookers attended two hour demonstrations of a PC-based tool. They were usually motivated by curiosity and the desire to gain a small amount of exposure to the technology. Time was the most valuable resource consumed from KSTP, which was reduced by scheduling group meetings. Even when working with individuals, the amount of time spent was small for each case, but the large number of cases had a significant impact on KSTP. Many of the lookers were intimidated by the technology.

The talkers were more serious about the technology, but in varying degrees. Some described applications and did everything except start work on it. Others actually started work and never finished, sometimes on a small scale and sometimes on a large scale. Small scale talkers used moderate amounts of consulting time while the extreme large scale talker consumed a half-person year.

\section{Training Project}

The Research Committee on Expert Systems recommended the development and delivery of expert systems courses by the staff of KSTP. Initially, the KSTP followed the recommendation set forth by the committee, but it soon became clear that the development and delivery of training courses was very resource intensive. US WEST has had an Information Systems training group for many years. They provided the bulk of training needs to the corporation in basic areas needed for the operations role of the company. In the new corporate environment, a key distinction is made between training and education, where the former provides the means for an employee to perform a specific job function and the latter provides general knowledge that an employee can apply in changing, diverse situations. These different intents have resulted in two different organizations to address 
each aspect: one is a formal training group dedicated to providing on-the-job skills and the other is a coalition of advanced education proponents operating under the ATEP47 banner.

ATEP students were not pursuing AI options, and would not be available within the two-year limitations of KSTP. In order to provide fundamental training for the IS staff, the U S WEST training group was the best alternative. Two of the three major IS training groups told KSTP that there was no demand for courses in expert systems and therefore no plans to develop training. What ever demand might surface could be satisfied with vendor offered courses.

The third center, however, was already at work developing two introductory courses, forecasting a demand of 500 to 600 students over three years. Forging the partnership between that center and KSTP evolved over an extended period of time, with a persistent effort by both parties. It resulted in an effective way to offer the high demand courses, with vendor offerings available for more in-depth topics. When demand was warranted, vendor courses were brought to U S WEST facilities. The coordination of these courses were managed by the training organization, reducing the resource demands on KSTP.

A major problem working with the training organization was geographic separation. Many months of working via telephone, electronic mail, and physical mail transpired before the primary training people from the two organizations met for the first time. Until that meeting (and subsequent meetings) both parties were unsure of the strength of their working relationship and the basic temperament of each other. Both were less than satisfied with the communications limitations imposed by geographic separation.

47The Advanced Technical Education Program, which provides company sponsorship of formal technical education through on-site courses and partial and full fellowships. 


\section{Small Tool Project}

Many clients were attracted by the KSTP Loaner Tool Program. This program was developed to provide a low entry path for potential developers who were uncertain about either their domain or the technology. In either case, they did not want to invest money for contract work, hardware, or software. The tool ran on a PC and was rule-based. It provided the exploratory capabilities, and was capable of being used for fielding applications.

To make the program effective, an agreement existed between KSTP and the developer. 48 The limited amount of software available necessitated a screening process, which provided a rudimentary control point which encouraged developers to articulate their plans.

By reducing the barrier to use the technology, both good and bad things happened. First, a larger number of people were willing to try the tool because they didn't need to make a financial investment. However, by not making a financial investment, there was, in some cases, less commitment to developing a prototype. It was easy enough to articulate your needs and get a tool, without getting the management commitment to work on the project.

\section{Marketing}

All KSTP activities provided an opportunity to expose people to the technology and its appropriate uses, but there were specific activities designed to inform people. Many of the ideas were generated by the KSTP staff and the entire marketing plan was reviewed with corporate public relations to ensure effective coverage.

One of the most important was The Standard Presentation, which zonsisted of a one to three hour briefing which covered such topics as:

\footnotetext{
${ }^{48}$ See Appendix E.
} 
- A Description of Expert Systems Technology

- How Expert Systems Help People Work

- Examples of Working Systems

- Current Projects within U S WEST

- Tools to Build Expert Systems

- Services and Support in U S WEST

- What to Do Next

The goals were to provide a simple background to the technology, ideas on using it, how expert systems are built, and what action could be taken. These presentations were delivered upon request or by KSTP offering to application group staff meetings. Publicity materials were handed out including guideline handouts, demonstration software, KSTP calendars, and, in certain meetings, hardbound expert system books.

A second major mechanism was to write articles for publication in company and departmental newspapers. A much larger audience was reached and the editorial staff were instrumental in setting the correct technical level for such articles.

An early variant of using the prine medium for publicity was a document called "The Epistemological Flyer," which contained "all the news that can fit on a page." The events that transpired around this document are illustrative of the constraints of a large company.

The first issue of controversy was the name of the document. Mixed reactions ranged from "It's great" to "I can't even say it, let alone what it is." It had the potential to alienate many people, but that turned out to be a small matter compared to what was brewing. This is shown by this excerpt from the KSTP Contact Log:

"Sally Smith called with some questions (initially) about the Flyer. Sally works for Regional Public Relations, and has CIS as one of her clients. Sally and I spoke 3 times today about this matter. This entry will capture all 3 conversations.

Her initial questions were about details of the distribution of the Flyer: how many copies, and at what cost. I replied 3800 copies and that I didn't have a cost figure. 
She told me that there is a policy that internal company organizations are not to distribute newsletters, except for the single exception U S WEST Today. Employee communications are supposed to be in memo format.

The policy originated with U S WEST Inc., and Sally stressed that Jim Hicks supports it strongly.

I responded that I would talk about the matter with Sid and give her a call back. Sid and I agreed to ask Sally 3 questions:

(1) how can we work with Sally to get our message out?

(2) what distinguishes memo format from a newsletter?

(3) could we send Flyers inside U S WEST Today?

Sally's responses:

(1) Sally would be happy to work with us to produce a better memo. She objected to several attributes of the Flyer: the title, inaccessible language, no clear motivation for the information, no call back number (I put my e-mail address).

(2) A newsletter has a masthead. A memo does not (she saw right thru me when I asked about multiple fonts or multiple columns). More below....

(3) We could be featured in a special U S WEST Today Bulletin, but the content would be in Sally's control, and this could only happen once.

The goal of the policy is to cut back on junk mail in in-baskets.

The last point stimulated my third call with this question: if the goal is cutting back on junk mail, why write a policy about the format of communications?

Sally agreed that the target is somewhat off the mark of the real target. But there are no facilities for generating specialized mass mailings. Sally recommends: specialized mailings to those who "want and need to know", or using e-mail heavier.

Sally promised to send me a copy of the guidelines as soon as a CIS version is completed.

Sally ended, by waffling a bit. She pointed out that the policy is a guideline, that no one would get "their paycheck taken away" by publishing a newsletter. (See entry for George Swanson for follow up on that point)."

The following quote captures the related conversation with George Swanson, Director of Employee Communications: 
He was very cordial, said he recognized that my group had some information to disseminate, but that he had gotten complaints about the Flyer from the VP of PR. Did I know about the policy on newsletters.

I discussed the two problems I have had with the Flyer: its improper distribution by CDC and the variance with the guideline. George was glad to hear that I had already been in contact with Sally Smith, and said he would report that fact to the VP.

I stated to him that the Flyer would not go out to all managers in the future, that its format would probably undergo some change, and that the first issue was still in the process of going out (to eastern and central regions) in the original format.

I made reference to Sally's statement that the guideline was just that, and he corrected me, using statements like "firm policy" and "Tim Moore doesn't like newsletters." I reassured him that Sid would check out the matter with Hicks and that we would work with Sally for the next edition."

Next came the official word about the memorandum versus newsletter incident, coming through the formal chain of command:

"FROM: Bill

\section{SUBJECT: Epistemological Flyer}

I underestimated the impact the flyer would have. It would seem there is some type of ban on newsletters and this looks like a newsletter. Someone gigged Hicks for allowing it and he reminded Medina that we should not be issuing newsletters. Please prepare a memo (be sure it looks like a memo) explaining the purpose and audience that these go to and why we are using paper rather than E-Mail or another form. I would like to send that back in response to the issue. Also, please hold up on the next issue until we get this resolved. Thanks"

By now, the KSTP staff figured that this was considered a very important matter by

some people. Here is the KSTP response:

"The purpose of the newsletter is to provide broad advertisement of the KSTP mission targeted to our entire client base, CIS managers and MTSs. The kind of information to be conveyed is entry-level for that intended audience. The newsletter, a technology transfer medium with a marketing flavor, sits at one extreme of the continuum of KSTP's suite of client identification initiatives. Other initiatives on that continuum range from broad to narrow in focus:

- $\quad$ TI Satellite Symposium sponsorship

- $\quad$ Expert System Interest Group meetings

- USWEST AI Team activity 
- Presentations at staff meetings

- Contact with targeted individual managers and MTSs

- Specific consulting engagements

The decision to use a paper-based medium for distributing the newsletter's message was based on two factors. First, due to the marketing focus of the information, our intent was to stimulate interest with graphics and an interesting format, rather than just convey information dryly. Secondly, coverage of all CIS management employees requires mailing labels, but the mechanism to generate labels is limited to broad categories of employees, not to individuals, and certainly not to CIS employees except those served by e-mail."

\section{Development}

Once a potential application matures past the consulting phase, prototyping and development services were offered. Because KSTP's mission was to transfer the technology into the CIS organization, sponsorship and development resources were to be provided by the application group which proposed the work. It was found that a rare individual is needed in the application group in order for development to proceed unassisted. In most cases, the strongest arrangement was a partnership between the KSTP staff and the application staff. This provided the synergy of technology and domain knowledge , and was particularly effective if the application staff had been through at least knowledge acquisition and knowledge engineering training.

After a certain point in the development process, it was necessary to obtain formal funding and sponsorship. This satisfied the commitment deficiency described previously and the projects went successfully on to the next stages.

A significant factor is the role of organizational non-participants. The issues of how to manage new technology within the application work group are difficult and were not adequately addressed: Training? Support? Time in project schedule? Managers said it was difficult to step back examine requirements, scope, and feasibility of new technologies because they have a job to get done. It is made more difficuit because no one provides this service for them nor is any training offered to help. The managers want training set-up for 
them and plans made so they can effectively implement the plans within their group. They said that their jobs were much too complex for them to take on new, ill-defined responsibilities.

\section{Qther KSTP Organizational Issues}

An unusual aspect of KSTP was the reporting structure and resource providers as reported in the T-perspective. Having three organizational sponsors had the benefit of providing protection from suboptimization. In the cases when a sponsor wanted to reclaim their resources from KSTP because other priorities came up, they had to receive concurrence from the other two sponsors. When budget money was not ayailable from one source, it was always found in another. This had a powerfully positive effect on the technology transfer process, allowing it to survive many more potential disruptions than would have been possible under ^ straight-line organizational structure. A very real negative aspect of this was the perception in other CIS organizations that KSTP was not held to budget cuts like everyone else. They were, of course, unaware of the periodic management challenges to the project.

In order to effectively use three organizational sponsors, it was necessary to we with the entire command chains in each of them, to keep them informed. This require extra effort, but resulted in the previously mentioned benefits. A more time consuming burden was the three separate budgeting processes that were managed, although they were often rendered irrelevant by budget crises. Also, for personnel issues including salaries and bonuses, three organizational relationships were required.

\section{THE ARTIFICIAL INTELLIGENCE CENTER}

In late 1985, the Advanced Technologies organization identified and prioritized leading technologies which had strategic importance to US WEST. Artificial intelligence was one of the key technologies, which led to the development of an AI Center concept. 
This concept was not specifically tied to one organization, nor was it a formally unified organization itself. The primary organizational components of the center concept were one group from advanced systems research and another from expert systems development. This arrangement provided for numerous technology entry points into U S WEST, from both the early scientific stage through the applied development stage. The center concept was intended to provide specific products and services:

- Product assessment and recommendations regarding existing AI systems and offerings.

- Application analysis and development of AI systems, concentrating on expert systems requested by U S WEST companies.

- Technology transfer, including the management of strategic alliances with leads in the field of AI, the acquisition of AI expertise, and the development of in-house expertise.

- Applied research in knowledge-based systems, speech processing, and natural language processing, including liaisons with universities and industry.

- U S WEST-wide consultation and coordination of AI projects to ensure that strategic goals are met.

The relationships among these various organizations and activities is shown in Figure 47, centered around the AI Center concept. 


\section{U S WEST ADVANCED TECHNOLOGIES}

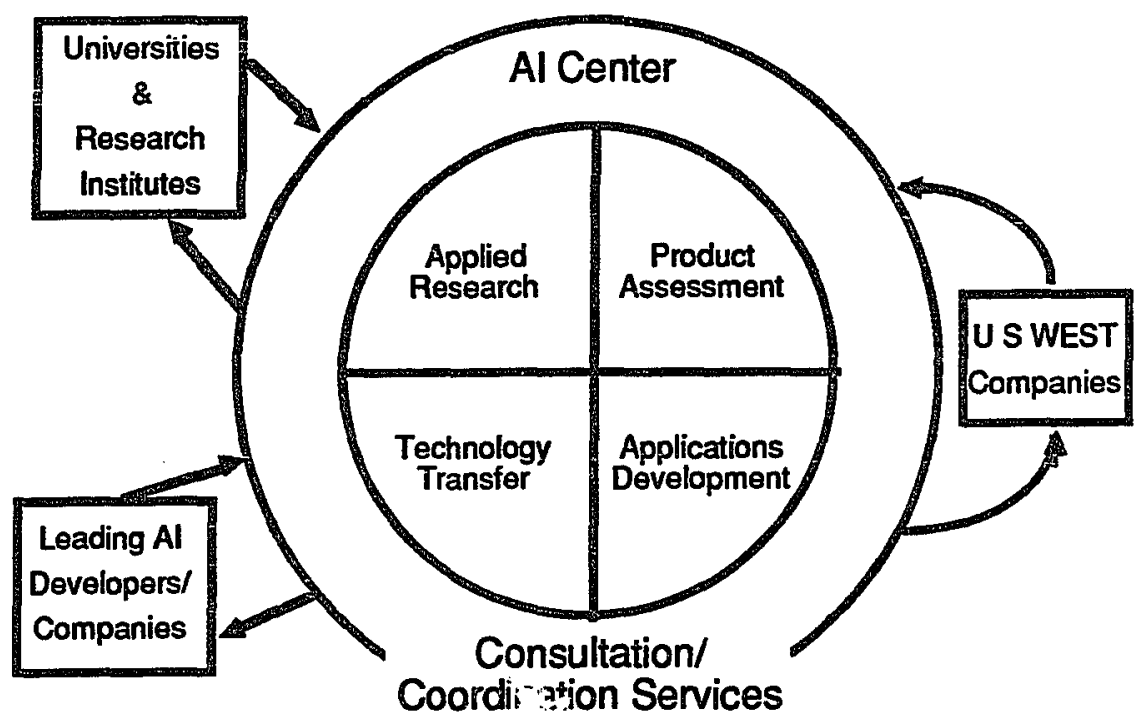

Figure 47. The AI center concept activities and relationships

An early role of the Expert Systems Development Group (ESDG) was to provide training for other U S WEST employees, as part of its technology transfer objective. In 1988, they arranged vendor courses which were taught at U S WEST locations and they announced plans for other training classes, with detailed course information and schedules to be available by February 1. Much work was put into course development, but the course offerings never reached the anticipated levels because of an executive decision that Advanced Technologies was not going to be in the training business.

The ESDG filled a primary role of working independently and with liaison organizations to find expert systems applications throughout U S WEST and develop the most promising systems. In late 1988, a major part of the selection criteria was if the client organization was willing to commit to specific funding of the development work. Staffing levels in the ESDG were defined as a function of the specific funding dollars available for 
salary and overhead support. This put additional emphasis on the activities required to attract clients, especially for large development projects.

\section{BELL COMMUNICATIONS RESEARCH}

In recognition of the $R \& D$ needs of the nation's operating companies at divestiture, part of Bell Labs and part of AT\&T were combined to form a new organization, Bell Communications Research (Bellcore). Prior to divestiture, AT\&T owned the 21 operating companies, Bell Labs, and Western Electric. As an integrated top-down corporation, the goals and conduct of these corporations were orchestrated by central management. But when the courts created Bellcore, this central R\&D corporation was owned by the regional Baby Bells, each with a one-seventh share.

Bellcore has a Expert Systems Development District which was created to work with the seven regional companies in developing prototype and advance expert systems. The district is also concerned with enhancing and maintaining existing expert systems, primarily in the areas of telecommunications systems support.

Relative to the Knowledge Systems Transfer Project, Bellcore did not play a significant role. KSTP staff members met with members of the Expert Systems Development District on two occasions and shared ideas, but a substantive working relationship was not established.

\section{VENDORS}

Because most of the external organizations affecting KSTP are vendors, there is a tendency to categorize theri by easily identifiable technical criteria such as hardware platform or tool capabilities. But to do so in a rote fashion would be misleading because of additional organizational issues of each vendor. To guard against oversimplification, the vendors are classified according to their impact on the technology transfer process. 


\section{The Carnegie Group}

The Carnegie Group and U S WEST formed a strategic partnership which influenced KSTP. In essence, this agreement provided for U S WEST to receive systems and technology, while Carnegie was provided a fertile domain for system development. In this way, both companies would benefit. The primary interest of KSTP was to provide knowledge systems capability to the IS organization.

Carnegie had created a high performance development environment which operated on LISP workstations, and eventually Unix-based workstations. The company also had outstanding technical people, resulting from direct relationships with academic departments at Carnegie-Mellon University.

In addition, their business development staff, which identified candidate projects, were of exemplary qualifications. They knew (as KSTP knew) that their historical strengths were not addressing mainstream IS needs because of the mainframe/PC orientation. One instance of this was a workforce scheduling system which was needed by the telephone operator division. A U S WEST account manager reported that Carnegie was interested only in the AI engine of such a scheduler. This left the delivery system issues open, i.e. networks, large scale implementation, etc. Even though the financials of this project were also against Carnegie development, the episode pointed to the need for system solutions instead of just one part. In another situation, the lesson learned was well demonstrated. A fully functional expert system was developed on a workstation, which was an unacceptable delivery environment for the client. Carnegie (with U S WEST funding) ported the system to the Macintosh ${ }^{\mathrm{TM}}$ environment and developed a HyperCard ${ }^{\mathrm{TM}}$ interface. This system became a showcase of the value of the partnership arrangement to mainstream knowledge systems.

Internally to Carnegie, there was honest recognition that they were not where they needed to be to serve mainstream markets. When attending a training class in Pittsburg, 
one student observed, "The tool actually looks pretty interesting, although very pricey. It is a diagnosis shell, very well suited to the mechanization of failure trees. The interface is a bit funky, but this is no surprise once you realized that this product is built on top of their other tool. Parts of the new tool can be ported to a PC, but their inexperience showed when the instructors could barely find their way around DOS. They said they were just learning about PC's and knew they had a long way to go. No matter, they were sharp and amazingly dedicated."

This inexperience with PC's combined with little experience in mainframes meant that KSTP could not directly use Carnegie's talents to address the knowledge systems issues of the IS organization.

$\underline{\text { IBM }}$

IBM is another vendor with an unusual relationship with U S WEST. IBM has been the primary supplier of IS hardware and system software for many years and has built strong organizational ties. Because they service and maintain so many of the CIS systems, they have staff on U S WEST premises with fairly unrestricted access to CIS employees. This closeness helps them serve CIS as a customer and also allows them insight into current operational problems.

There are occasions when a system performance problem turns into a marketing opportunity. IBM is very good at this and they have done this well with expert systems, as the following scenario indicates.

A particular performance problem existed on a U S WEST production system. A job was taking four hours to process, which exceeded the alloted time. IBM was called in to look at tuning the underlying relational database and found that the database records were actually in rule format. They suggested recoding the application into a rule-based expert system, using one of their software tools. 
The character of the IBM organization came into view when they contacted KSTP to tell what was being considered. IBM krew that KSTP was the CIS expert systems group and thus followed protsiol by contacting them.

The performance problem was finally resolved, at least temporarily, by the purchase of more hardware. But the salient point is one of IBM discovering customer needs by maintaining a constant, heipŕul presence.

IBM also established a Customer Advisory Board, which brings a number of large IBM customers together to discuss IBM tools and what the customers would like to see. The participating companies are from around the world and provide IBM with a view of the market. In an unusual move, IBM invited U S WEST to participate on this board. U S WEST did not use any mainframe expert systems tools, let alone a tool developed and sold by IBM. This was a particularly smart move because it provide a chance for IBM to hear why a large customer of theirs did not have an expert system tool installed on a mainframe, instead of hearing only from those who did.

The characteristic of IBM as a legitimizing force can be seen in their marketing efforts. A number of CIS meetings on expert systems were only moderately attended, even though there had been extensive publicity. By contrast, when IBM scheduled an introductory meeting on one of its expert systems tools, the session was well attended through mostly word of mouth advertising. The message to one observer was clear: if IBM is doing it, then it must be for real:

"Here was big blue talking to customers about a technology/product that they used internally, were excited about, and supported. They can hardly be accused of living on the leading edge. To my mind, the presentation symbolized the fact that rule-based systems are only a step away from being mainstream." 


\section{Qther Mainframe Tool Vendors}

The other vendors offering mainframe tools which were considered included Intellicorp, AICorp, and AION. All of these organizations lack the infiltrative capabilities of IBM, but offered some technical benefits.

Intellicorp offered their development environment, KEE, for IBM mainframes through a joint marketing agreement with IBM. KEE was regarded by KSTP as one of the best tools available on its original workstation platform, but was questionable in the mainframe world. Indeed the workstation version of KEE which resided with KSTP had been relegated to disuse for two primary reasons: 1 ) KSTP clients did not want workstation based tools and 2) KEE was a direct competitor of the Carnegie Group workstation product.

AION and AICorp products were both strong technical performers, having been formed and developed by ex-IBM employees. But as one U S WEST employee said, "I'm concerned about their even being in business a couple years from now. We carit afford to be left with marginally supported tools once we get them integrated into our production systems." In spite of those concerns, the performance of the tools and the willingness of the companies to provide access to their products for testing were an important part of the KSTP mainframe tool project.

\section{OTHER GROUPS}

A number of other groups had an effect on the technology integration effort, either through their active role or by their absence.

\section{The Media}

As with all other segments of the general population, CIS staff has been exposed to significant numbers of the popular press articles discussing the "wonder" of $\mathrm{AI}_{5}$ "thinking 
machines", seemingly magic solutions, and the ability to displace workers. Many of these articles are intended to grab the readers attention, which sells newspapers and magazines. But while doing so, these articles prey on the misbeliefs about machine intelligence, as was discussed in Chapter III.

In a media example specifically concerning U S WEST, one commercial report covering AI in telecommunications told about its expectations of "the company to be one of the top two [regional companies] in the area of internally deployed systems." The report talks of work-in-progress and describe expert systems applications as "actual or soon-tobe-actual," at a time when almost all applications were in the latter category. U S WEST internal media representation of work also reflected this optimism. Company publications were very good at taking raw material provided by the knowledge systems groups, transforming it into a consumable form, and effectively delivering it to U S WEST employees.

\section{Al Teams}

About every six months, either the KSTP or the ESDG sponsored a U S WEST AI Team conference, which took the form of two days of panel discussions, presentations, and demonstrations. The intent of the conferences was to provide information sharing on tools, applications, techniques, and such things as sponsor support. By all measures, the conferences met or excseded the expectations of the attendees.

However, the AI Team conferences did not have the organizational impact that was possible. The attendance at these meetings were about 30 to 40 people for a company of 65,000 employees. Contrast this with Boeing conferences which have attendance of 600 for an employee body of about 140,000 , which is about 10 times the attendance. The reasons for some of this disparity will become clear in the cross-cuing analysis. 


\section{Lookers and Talkers}

Recall the effect of these two groups on KSTP consulting activities, which hinted about the large effect these groups had on the technology integration process. The lookers consisted of people who repeatedly inquired about the technology but did not proceed past this point. For the technology integration staff (KSTP in this case), these people were required to have been viewed as legitimate potential users of knowledge systems. As such they were given the consultations, training, reading material, etc. that they might need. It was only after extended resource expenditure by KSTP that these people were seen for what they were: lookers.

Talkers were one step better. They were often, but not always, people who had passed through the looker behavior class. These people proposed some type of prototype and acquired the tools and training to begin work. In some cases, the work did not begin, with the person always having something else higher on the work priority stack. It was common to hear, "My boss won't let me get to it." In other cases, prototype development did commence, but follow through was lacking. The causes for both types of talkers were often the work priority issue, but occasionally were issues of training and lacking of fundamental understanding of the technology. When any delay situation occurred with the talkers, the minimum impact on KSTP was resource diversion for monitoring the prototype effort. More frequently, the impact was more severe, including direct consultation on knowledge representation, tool features, knowledge acquisition, and project management.

In both the looker and talker situations, the common point was KSTP resource consumption which produced no benefit for the CIS or U S WEST organizations.

\section{Technopromoters, Blue-Skyers. Turf Protectors}

A technopromoter is not a particularly helpful person because of the focus on the technology, rather than the contributions to the business. This behavior is often 
characterized as "a technology looking for a problem." Technopromoters are very interested in the technology, and therefore tend to imbalance the technology-push, marketpull process with all push, no pull.

Closely related to the technopromoters are the blue-skyers. The major difference is that the blue-skyers are much more oriented towards science fiction applications of the technology, and do not do anything toward actually working with their ideas. Recalling Ed Roberts' critical functions staffing model, it is clear that an idea generator is an essential part of the technology integration process, which is a role that could be played by the blueskyers. However, there must be a link with the entrepreneur in order for the idea to have some benefit. Blue-skyers do not even attempt to make this link. The bottom line is that their relationship with the technology is viewed by others as "hot air" and superficial. This can damage the reputation of the technology.

Turf-protectors react to a new technology in the same fashion as any other threat to their turf, doing anything they can to minimize the danger.

Interestingly, there were very few members of any of these groups found during the course of the technology integration project. This was a very positive aspect for KSTP, CIS, and U S WEST. 


\section{CHAPTER 7}

\section{THE PERSONAL PERSPECTIVE}

The personal (P) perspective is the most difficult perspective to obtain. A major question an investigator faces is the distinction between a person making a statement that reflects either the organizational or the personal view. How does one know which is which? Personal motivations and aspirations play a major part of the P-perspective. Elusive qualities such as leadership, charisma, personality, power, and strength come into play.

P-perspective actors shape the use of new technology to a great degree. What does this offer to the total analysis? First, is that it can serve as a precursor to the organizational perspective, in that organizations are composed of individuals. Second, some individuals exhibit such strong behavior that they dominate a situation, dwarfing the role of the T-perspective and the O-perspective. Third, the communication of complex issues may be more effective from the P-perspective, such as brief stories or quotes. Finally, at a minimum, the personal actors are participants in the adoption of new technology and can therefore add to the understanding of the entire process.

Each of the individuals who were identified as key figures in the technology integration process had their distinct impact on KSTP. The following list provides some examples of what was looked for:

- The degree of personal stake in the project or the technology

- How much power the person had over the project

- The effect of the project or technology on one's career 
- The change in a person's work due to the project or technology, e.g. was it made harder/easier

- What changes occured in the way decisions were made

- Did the person take a visible stand on the project or technology

- How was a person's career objectives affected

- What personality traits influenced the project

- A persor's risk inclinations

- Type of time discounting profile

- How much was the person affected by sunk costs

- A person's vulnerability to influence from others

- The use of decision avoidance strategies, if any

These factors, and perhaps others, contribute to the attempt to understand key behaviors and elusive qualities such as leadership ability, charisma, and intuition.

\section{IDENTIFYING THE PLAYERS}

A logical place to look for individuals to investigate for the P-perspective is the organization chart. Figures 39 and 40 (Chapter V) provide the names and organizational positions of 6 executives who had important roles in the KSTP process. They are:

- Louis Schroder, Department Head of Computing \& Communications

- Alan Medina, Director of Application Support Services

- Doug Gunter, Director of Marketing Applications

- Donald Malek, Department Head of Application Services

- Jim Hicks, Vice-President of CIS

- Tony Pearch, Department Head of Planning

While these people were easy to identify due to their formal position, there were a number of people who emerged over time from less obvious formal positions. Their 
emergence was due to other critical roles they played, in situations that greatly affected the technology integration process for better or for worse. These people included:

- Bob Haberman, Vice-President of Advanced Technologies

- John Fitzpatrick, industrial external consultant

- Bill Hoyt, Training Director

- Kathy Dobbs, Director of Billing Applications

- Ron Garcia, Manager of the Information Systems Technology Group

- Glen Dillon, Head of the Expert Systems Development Group

- Alvin Vail, also Head of the Expert Systems Development Group

- Sid Thompson, Head of the Knowledge Systems Transfer Project

- Mike Janzen, Training Instructor

- Mark Tyson, a knowledge engineer

- Gary Ashley, CIS programmer/analyst

- Andy Shuler, an IBM marketing person

Each of these individuals had a significant impact on the technology integration process within CIS, either through their actions or lack of them. The items described have been selected to provide the basis for examining the dynamics of KSTP in the cross-cuing analysis that follows in Chapter VIII.

\section{Louis Schroder. Department Head of Computing \& Communications}

Louis was, in the U S WEST environment, a very unusual person because he did his day-to-day job and was also a very forward, long-term thinker.

He was a strong supporter of KSTP from the idea stage, thus had a high degree of personal stake in its success. This didn't prevent him from making good business decisions, such as in the case of one major project that had wavering support from those who would benefit most: 
"Louis was most interested in the project, whether we were going to go forward with it. He was unaware of the project management problems and the lukewarm interest from the client, but did know some decisions had to be made about future work on it. We agreed that if Young et al, didn't want to do it we were not going to waste our time and money on it. Instead, he found the other projects very interesting, seemed quite pleased that we are finding such diversity in application of the technology."

Of course in the project in question, a significant amount of money had already been spent, but the sunk costs did not affect Louis from making the prudent decision.

As one of the original formal sponsors, Louis had a large amount of power over the project, but always used it in support of making the project successful. A number of times, KSTP was challenged by executives needing money and personnel. Louis would say, "What would they do with such highly trained people?" He became the hidden executive champion for KSTP, the one who was privy to all of the major issues throughout the process.

When project decisions needed to be made he let the project staff make them, then backed them up. He was able to do this because he made efforts to get to know the people on the project. By doing this, he had personal confidence in what they were doing. He also believed in allowing people to use their own judgement, and accepting the responsibility and the consequences that resulted.

Being towards the end of his career, he did not have to concern himself with the effect of the project on his future. This situation also made it possible for him to perceive KSTP and the technology as having little impact on his workload; it was simply another facet of his job that needed the same type of attention he gave to other facets. So his decision style remained constant for the duration of the project.

He had the years of experience to skillfully balance short-mid-long term needs and was not afraid to take risks. These traits were most unusual because of the existing corporate culture and the fact that Louis had nearly 40 years of Bell System experience. 
Most managers become assimilated into the risk averse, short-term, conservative roles encouraged by years of regulated business. Somehow, Louis bucked this phenomena.

With his strong sense of how to do business, it follows quite logically that Louis was invulnerable to outside influences on the course of KSTP. He had his own monitoring capabilities and was fully prepared to hold his position when necessary. With great knowledge of the CIS organization, he did not need to avoid decisions. When KSTP status reports were issued periodically, he was the only executive who, on his own initiative, sent a response saying, "Leave me on the distribution list. I want to know about KSTP status."

\section{Alan Medina, Director of Application Support Services}

Another of KSTP founding sponsors, Alan was rather removed from the issues, not seeming to understand the technology nor the issues about the technology integration.

He was most comfortable in the old management style and retreated to Bell System style SOP's in most situations, or relied on a fellow executive to lead the way. In this mode, he was willing to listen to employee concerns and pass them up the rank.

He had a fair amount of power over the project in a formal sense, but caid not exercise it any further than letting KSTP function independently.

When decisions had to be made, he relied entirely on information provided to him in direct response to a request. He did not have the general monitoring skills to learn about the organization, did not practice MBWA, and was not technically proficient.

He was a proponent of the project primarily as one who already had software tool support in his organization, so this was a reasonable fit. In the face of budget cuts, however, he did not have the personal understanding of the project to take his own stand. Instead, he relied on subordinates to prepare background data and tell him what his position was. 
Without personal understanding, he was risk averse in almost all situations. When strategic decisions had to be made, he displayed uncomfortable behavior, but would say to himself out loud, "We just can't go on cutting out the future forever." Lack of understanding also made him very receptive to influence from others. One manager gave the advice, "Go tell Schroder what you need, ask him to tell Medina, and Medina will do it, just because Schroder said so."

Alan retired 16 months into the project so he had no personal stake or career effects from the degree of success of KSTP.

\section{Doug Gunter, Director of Marketing Applications}

Doug was a founding sponsor of KSTP, but was the most difficult to arrange meetings with. A clue to his modus operandi can be found in that he was one of the few executives who maintained control of their meeting calendar. He liked to be in control of things.

His positive effect on KSTP was minimal and most of the significant effect was negative, as a result of resource issues.

Doug provided one technical employee (including salary) to the project. All sponsors supposedly agreed to funding the expenses of their sponsored employees, but Doug said he wasn't going to, that it wasn't what he'd agreed to. Budget contention for these expenses lasted throughout the project, which was yet another drain on KSTP resources in both time spent and expenses covered from other budget sources. At one point, Doug agreed to 1989 expense funding for the staff person, but this was not communicated down the chain of command.

There was speculation from the beginning that people in Gunter's organization were miffed because KSTP did not reside in their organization. The problems were so extensive that Gunter was asked if this was an issue. He denied that it was. Indeed, on all issues 
other than personnel and budgets, Doug was very helpful and a source of many good ideas.

KSTP issues did not have an effect on Doug's career. He retired 14 months into the project.

\section{Donald Malek, Department Head of Application Services}

Don Malek was hired from IBM just before KSTP was initiated. He was a very outgoing person, sincerely interested and eager to help people achieve.

Concerned about the lack of use of new technologies in his organization, he saw knowledge systems as an important one. From this angle, he had a personal interest in its success. He took a visible stand advocating not only the use of knowledge systems, but development of the infrastructure to support the technology.

Don had formal budget control over part of the project but deferred to his subordinates for project control. He actually exerted more influence by asking traditional IS project teams to consider the use of knowledge systems as part of their project.

He viewed his subordinates' successes as his successes, so he worked to help people attain goals. It was in this way that the project had an effect on his career. He took the professional evolution of his organization, and the individuals within it, as a top priority objective. As such, his career was dependent on the degree of evolutionary success. Knowledge systems was one small part of his responsibilities and as such, contributed to the attainment of his personal career objectives.

His job had been made a little harder by the technology integration process due to issues on which he had to make decisions and the time it tcok for him to understand those issues. To manage this, he trusted his subordinates to make many decisions. In situations where significant financial or organizational issues had to be decided, the subordinates provided him with the alternatives and he made clear-cut decisions in a timely fashion. 
He was willing to take risks because he saw risk as a way to make progress. His willingness was greatest in people and technical areas, but was constrained in financial areas by corporate budget churning. This affected his time discounting profile because he was short-mid-long range balanced on his own, but forced towards the short term by short term corporate finance problems.

Other than such large impacts, Don was fairly invulnerable to influence from others on issues that he has good command. This is not to be confused with stubbomness or other negative characteristics. If he knows what he's doing, he'll do it. If he needs input from others, he'll get it. He does not avoid decisions unless he sees benefit in letting more information come in as time passes, if he sees a half-baked situation, or if there is no compelling reason for a quick decision.

\section{Iim Hicks. Vice-President of CIS}

Jim Hicks rose up from the IS ranks to assume the vice-presidency. His behavior is very pleasant and non-confrontive, so KSTP interactions with him were enjoyable but not always beneficial.

As manager of a large organization that has experienced much turmoil (see Chapter VI), Jim was very overloaded and had developed a support staff and coping strategies to deal with the extreme dynamics of CIS.

One strategy is management by consensus, which was a difficult task given the amalgamation of companies that had been forced into one by divestiture. At times it appeared that CIS just needed some tough decisions to be made, to end the warring factions. Sometimes the search for consensus was viewed as a decision-avoidance strategy.

It was within the context of this extremely busy executive that KSTP was operating, but it was a satisfactory relationship because Jim was very supportive whenever support was requested. However, he had little personal initiative to find out how the 
project was progressing, unless there were occasions when a vendor or other company executives wanted to know what CIS was doing with expert systems.

He did not practice "management by wandering around," and therefore did not receive the informal information that he could have. But in the context of KSTP, this did not matter because he had little personal stake in the project or the technology, specifically. Generally, though, he wanted to see people succeed and, of course, his organization perform well, so he did care about both the people and the project.

He had little power over the project due to non-involvement. His major contribution to the project was to encourage relationships with other companies, primarily telephone companies. "What are the other regionals doing?" he would ask. He perceived the telephone companies to have much to share because of the common aspects of our business.

KSTP nor knowledge systems were perceived by Hicks to have an impact on his work, due to his short time horizon, dealing with operational issues. He couldn't see the long range impact of knowledge systems, because of the level of detail that was required to understand the technology. But even without knowing this, his intuition told him that the technology was important and we had to have some effort underway to put expert systems to work in CIS. Even without specific understanding, he had the ability to see when something just seemed right, provided he was given a sufficient amount of information.

Without the information, he appeared risk averse, especially in technological areas, less so in financial areas. He did not have assistants with technological strengths, but had good support in the financial areas, which promoted his involvement in the that arena.

\section{Tony Pearch. Department Head of Planning}

Tony Pearch was interviewed only once for this research and did not have a formal role that was directly relevant to KSTP. In that one interview, however, he articulated some very insightful personal views. 
The first was that he was pleased that CIS was integrating a news technology in such a coherent, organized manner. He felt that all too often, the organization dabbles in new technology with no plan and no goals.

Second was the two year time limit in the KSTP charter. He stated that two years is plenty of time to find out if a technology has applications in our organization.

Third and last was his strong, emphasized statement that CIS is nothing more that a production system, like a factory, that has a difficult job to do to meet its production goals. With this model of the business, he said there was no time for dawdling with anything. We must identify a new technology, plan how to test it, decide what to do with it, then $\mathrm{l}_{\mathrm{e}}$ it.

These were some of the most precise views on what CIS did and how it should be done that was reported by any executives. He had his convictions on how things should be run and they were well-reasoned.

\section{Bob Haberman, Vice-President of Advanced Technologies}

As VP of Advanced Technologies, Bob's effect on KSTP were indirect, primarily through the views he communicated throughout other organizations (including CIS) and the Expert Systems Development Group which was within his span of control.

In a presentation to a large group of managers, he listed his choices for strategic technologies for U S WEST, emphasizing that they were his opinion. He listed:

- Relational, object-oriented, and semantic model databases

- Database machines

- Distributed processing

- Yoice response systems

- Network management technology

When someone asked him where expert systems came in, he somewhat grudgingly said, 
"Yeah, I guess should have mentioned that. It has been so isolated, but now it is being integrated. This is good for distributed processing."

Conversations with the ESDG staff told of their feeling of lack of support for the tecinology from Haberman. So they invited him to a staff meeting to see where he stood, and he told them he was not a strong supporter of the work they were trying to do.

It is curious that he was able to list any teshnologies because of his views on how CIS was helping U S WEST to compete in the telecommunications industry:

"All RBOC's 49 are copying each other and we are not competitive for most revenue streams. We differentiate ourselves on cost control, not product difference. We are more concerned with existence than with revenues."

This view immediately reduces the attraction to new technologies because of the short-term costs involved. 50

\section{John Fitzpatrick, Industrial External Consultant}

John Fitzpatrick played an interesting role in KSTP because he served as a consultant to U S WEST while employed in industry. His consulting role was to help CIS define their strategy to develop expert systems. As he was working with the CIS Research Committee on Expert Systems (RCES), U S WEST was considering hiring John to lead what eventually was called KSTP.

Due to this situation, he had a high degree of personal stake in both the technology and the early phases of the project. As an external consultant with experience in expert systems development, he also had influence on the recommendations made by the RCES. And if employment negotiations would have worked out, the project would have been critical to John's career.

His industrial experience was within a huge organization where work was distributed among various subunits, which resulted in local organizational support for AI.

${ }^{49}$ Regional Bell Operating Companies

50Months later, Haberman had reversed his position, but this was to too late to affect KSTP. 
In his opinion, there was lots of replication of work and little coordination of activities. The various groups competed for money for startup and research funding.

John was very high on his company's training program, saying that it was so strong that they had large contracts with other major companies to provide AI technical training services.

John's company also had experience with a training program in which an employee would come from another department with an AI problem to work on, do six months of course work and then six months of work on their project. They would return to their home office and complete the project. There turned out to be problems with this approach to use John's borrowed phrase - "seeds need nurturing." When a person got back to their jơt wisth a prototype written in a high-priced shell which ran on a high-priced workstation, they found that few organizations were likely to spend the money needed to acquire such an environment. With little home department support for the trainees, many projects did not proceed into production.

So if John had total control of an expert systems organization he would use:

1. A small research group, to collect useful things in the literature, do experiments, explore.

2. A support group, to do tool evaluation, identify directions, and take needs to vendors.

3. A project support group, to identify successful candidate applications for development, get projects started, possibly do some development, and facilitate integration with existing software.

One of John's major issues was that it was extremely important for these groups to fit in with existing groups and organizations, so that people would know where to go for the services they needed and so that turf issues were minimized. 


\section{Bill Hovt Training Director}

The CIS training organizations were located in the cities of Omaha, Nebraska, Denver, Colorado, and Bellevue, Washington, corresponding to the old Northwestern Bell, Mountain Bell, and Pacific Northwest Bell telephone companies. When the consolidation moves came, the transformation for the training groups was more significant than for most groups. The groups were excised from CIS, placed in another U S WEST organization called Learning Systems, which provided technical and non-technical training for all U S WEST departments.

Bill Hoyt was the director of the Bellevue training group and was selected to lead the entire computer-related training organization for Learning Systems.

He was a manager in the tradition of the Bell System, excellent at controlling costs, but occasionally at a superficial level. This was sometimes at the expense of important work and sometimes at the expense of employee morale. On one occasion, an instructor was scheduled to teach a number of courses in another city over a two week period. She decided to stay over the weekend because flying half-way across the country (with hub stops) would take too much time. Bill told her if she wanted to do that, she would have to pay for the weekend's hotel bills out of her own pocket. Never mind the fact that two nights of hotel was less than the cost of an additional round-rip air fare. There was speculation that the "misunderstanding" about the travel options was because the instructor was from a city different that Hoyt. Therefore, he didn't know her, didn't know her boss, and didn't have the personal basis on which to make a decision.

Bill was very loyal to those with whom he had rapport and were loyal to him. For these people, he would see to it that there needs were satisfied. He knew that they could be trusted because they had earned his trust.

He operated heavily on personal relationships because he did not have a good understanding of the technology about which his organization was training. Years ago, he 
very seriously asked Sid Thompson, "What does math have to do with computers anyhow? It seems like people just try to get fancy with what there doing, and make problems harder than they really are."

Bill's stake in knowledge systems technology was very low. He knew he had to provide the training services needed, but to him it was just another part of the training regimen. He knew the capabilities and role of his organization and offered to provide all of the infrastructure needed to deliver internal training courses and to work with external training vendors.

He did not have any career aspirations tied to knowledge systems nor to any other technology, organization, or person. This was made obvious by his retirement 15 months into the project.

\section{Kathy Dobbs. Director of Billing Applications}

Kathy Dobbs had spent a number of years in non-technical management positions with a number of Bell System companies. In early 1988 , she returned to a Director position in CIS and had responsibility for certain telephone bill operations which showed great potential for the application of expert system technology.

The significant effect Kathy had on KSTP was sincere enthusiasm for working with any technology or procedure that would help her organization perform better. The first hint of her behavior is captured in this email note to Sid Thompson, after he had given an overview of expert systems and KSTP to Kathy's staff managers:

"You were great! Thank-you for the presentation and the support. Folks are already preparing their ideas and forms. I hope you're ready for this group. We would also like to stay close to the work you are doing for [other operations groups] since our [operations group] is comparable."

Shortly after this, another KSTP staff member had this observation about Kathy's aggressive ideas:

"Kathy is very excited about building an ES application that will actually mechanize some part of their duties. She is not interested in merely some 
sort of advisor or help-desk kind of application. They see that as merely documentation."

She was one of the few directors who saw the value of the technology and followed through with it. She ensured that her staff made time to talk with KSTP knowledge engineers. When one of her technical employees created a prototype of a very important system, two KSTP staff members met with her. Further applications in her group were discussed and she asked a question that had never been asked by any other client of KSTP. "With all that you are doing for us, what can we do to help you succeed in your mission?" The KSTP staffers were shocked and pleased at the same time, and responded that the best way was to make sure her people had the time and priority to develop a production system. She agreed and within two months, that prototype was in production.

\section{Ron Garcia. Manager of the Information Systems Technology Group}

Ron Garcia was one of the original visionaries behind the Knowledge Systems Transfer Project. He was manager of a new technology group whose mission was to identify and exercise new technologies, then spin off sub-groups or individual people into other organizations for further technology integration. He had a high degree of personal stake in the project because expert systems work had been performed in his group, and was being spun off.

Because he was managing the people who were using expert systems, he was in a powerful position to influence the course the technology was to take. For example, it was primarily Ron who tried to lure John Fitzpatrick into U S WEST and Ron was the focal point on the Research Committee on Expert Systems.

His influence was not limited to the early stages because, as a spin-off from his group, the degree of success of KSTP would have some impact on his career. It was his responsibility to spin off a technology when he felt it was ready and to provide the organizational setting for the spin-off that would help its likelihood of success. 
In the planning stages, expert systems were clearly an additional burden to Ron's workload, but he realized that a successful spin off would reduce his workload and increase the chances of expert system deployment in CIS. Driven by both personal and professional desire to perform well, he spent much of his time creating a strong organizational coalition that would nurture the technology integration process. The charter and its multiple sponsor structure (Appendix C) is the result of his efforts, and showed his keen understanding of organizational dynamics and his practical sense about what would and wouldn't work.

A final key point about Ron Garcia was his predisposition towards significant formal education. He held a doctorate, which led many people to believe that his bias originated from his own accomplishments. Deeper inspection showed this not to be true. His own formal education simply raised his awareness about the benefits of having a solid understanding of computer science disciplines. With a strong foundation, the changing technologies manifested in vendor products are much more coherent and better choices can be made for CIS. So while Ron was biased towards formal education, it was rooted in his belief in the functional benefit of having knowledge. He was able to promote formal Eưucation in his role of administrator of U S WEST's Advanced Technical Education Program.

\section{Glen Dillon. Head of the Expert Systems Development Group}

The AI Center concept discussed in Chapter VI included the Expert Systems Development Group as a major component. Glen was head of this group during the first part of KSTP's existence and had a major role in the partnership between the two groups.

In the initial charter of KSTP, Glen was one of the founding sponsors, in which he agreed to contribute expense dollars, head count, and/or equipment. Also, the Memorandum of Agreement (Appendix C) stated that Glen's group was to provide strategic 
direction. This did not occur. When asked about his funding of worthy tasks in CIS, his response was, "The emphasis is on worthy."

Glen had the opportunity to provide guidance to KSTP in its early stages because ESDG had been operating for over a year, giving him a fairly good base of experience. When explicitly asked for ideas, none were offered. Why was this?

The first clues surfaced at a large industry conference in August, 1988. Twice members of the KSTP staff crossed paths with Glen, with no other people in sight. He did not even acknowledge their presence.

Suddenly, in August, he began questioning what KSTP's measurements and deliverables were. In response to his inquiry about this, he was asked by KSTP to provide some guidance:

"We'd welcome input from ESTG's measurements and deliverables to make our's compatible and complementarily effective. Let's send each other copies of ours, look them over, and see if we are light-years apart. We like the idea of helping each other out."

No response, but Glen agreed to meet in September to discuss the issues. Prior to meeting, Glen's behavior was very icy, so he was asked if something was wrong:

"Glen also admitted that he is bugged about something, and was somewhat surprised that it was showing in his email. However he said he didn't want to talk about it until he had a chance to think about it, fearing that he would give an incorrect impression of his concerns. He agreed to call today or tomorrow."

He never called. Concern over this prompted discussions in CIS on what should be done and how strong the relationship between the two groups should be:

"Continuing problems communicating with Glen. He does not answer direct email questions, has not returned phone calls, and, when confronted, says something is bothering him, but he's not ready to talk about it. This has gone on since the second week in August. We scheduled a meeting on Sept 26 to talk about goals, success factors, etc. but this does not address the behavior of late. Or maybe the substantive issues ARE the problem.

At any rate, not talking about these problems is causing problems for ESTG, thus indirectly KSTP. However, we are charging ahead full speed with our work so we are not directly suffering. 
We're hoping Glen will open up before 9/26 so we can get this distraction behind us and make some headway in the meeting.

Bill did SPECULATE that possible problems could be 1) viewing KSTP as competition, 2) inferiority perceptions, 3 ) unknown (to us) top-down directives within AT, 4) uncomfortable with relaxed management style, 5) desire for more control. This is just general speculation about what would cause someone to behave as such, and Bill emphasized that he doesn't know what's going on either.

On the control issue, Bill specifically stated that KSTP is an autonomous CIS project and will remain so. Glen's role is advisory at most."

When the meeting finally occurred, the issues were rather trivial and were resolved within two hours. One issue was an expert system client who had told Glen that they didn't like the service they had received from KSTP. Interestingly enough, this same client had asked KSTP for help, saying they were dissatisfied with the service they had received form ESTG. The major point with this was that the issue was small, but the way it was handle was detrimental to both ESTG and KSTP. To loosen up, Sid Thompson, head of KSTP, suggested they go play golf. While waiting in the clubhouse to tee off, Sid frankly told Glen that: if such issues arose in the future, just pick up the phone and air them, for all of our benefit. Glen did not respond and would not make eye contact.

Some month later, one of the ESTG staff members was chatting with the KSTP staff and revealed some startling insight into Glen's role as leader of ESTG. She said he was so insecure with expert systems that he spent his first few months in the job learning the technology instead of fulfilling his management role. She felt that the group lost its momentum and languished for these months, suffering lost leadership and a delay from which it would never recover. Further investigation resulted in comments of this tone:

"He is the sort of guy that you can't really get to know because he doesn't open up to you. He is certainly not easy and comfortable to talk with."

"Glen was a charlatan. It was clear to me that he never new what was going on but was able to create the façade of being knowledgeable. When he was put in the position of having to perform, he didn't have the real knowledge to pull it off." 
"He may have technical abilities, but I would never be able to respect him as a manager."

With these underlying currents, it wasn't long until an ESTG staff person contacted KSTF and told of Glen's imminent departure. Sid Thompson was understandably upset. Here was a leadership change in the partner group and he was totally unaware of it, let alone having any input into a successor. Numerous calls to Glen and attempts to set up a lunch meeting fell on deaf ears. Electronic mail exchange was all that happened, and it is interesting to see in the following email the overoptimism relating to Haberman (recall he wasn't enamored with expert systems), CGI (they were having a tough time figuring out $U$ S WEST), and the EPX project (it did not go forward):

"Glen,

Congrats on your new job! Sounds like a good opportunity and hopefully more realistic working conditions.

What are your thoughts on the status of ESTG with the specific funding constraints? What's the future?

I think we (KSTP) can feed ESTG clients. We've got too many right now and growing, so some relief would be good. I'll pursue this with your successor.

Also, I've met with all KSTP sponsors and Malek, and got great support. I talked with Don about support for ESTG projects at maintenance time, especially about DDAS.

That was one of the meetings I had in Denver, too bad we didn't connect.

Could you jot down your thoughts on the good and bad things that happened with ESTG during and before your tenure? It would sure help me figure out some of our future directions. Thanks much.

$* * * * * * * * * * *$

>From Glen Mon Feb 27 18:25 PST 1989 remote from uswest To: Sid Subject: Who's Next?

Date: 02/27/89 Time: 18:23:32 PST

*** Reply to note of $02 / 24 / 8912: 11$

From: Glen Dillon 
Subject: Who's Next?

I got the funding problem resolved. ESTG is in no danger for the rest of 89. We have high level visible support from Haberman right now. It is due primarily to the success of the CGI relationship and the success of the EPX, both of which are being presented to [the U S WEST president and chairman] in the near future.

If you have too much work talk to Chuck. He is acting group leader until they find a replacement for me. I don't really believe there are that many clients with viable system ideas and money but if there is we would like to help. I think even more important is to find a good application for CGI within ITS. The CGI relationship is making news at high levels. It would be a good deal all the way around if you could get something going with them in ITS.

I don't really understand the question about good and bad things with ESTG. How about restating the question?

At some point I want to give you my impressions about how well KSTP has worked out the first year (even though they are unsolicited). Maybe we can get together or something sometime."

An interesting footnote to Glen's involvement with expert systems happened when he moved on to his next job. He and one of his co-workers saw a potential expert systems application in his new domain and contacted KSTP to participate in the Loaner Program, indicating that Glen still saw some potential in the technology. However the KSTP analyst in charge of the Loaner Program noted:

"Given the fact that I have tools idle right now and Glen should have picked up enough during his stay with ESDG to have some sort of idea of whether or not the technology is appropriate, I am sending them a tool. But my expectations are fairly low that anything will really come of it."

Four months later, nothing had.

\section{Alvin Vail, Head of the Expert Systems Development Group}

Alvin Vail was the originator of the AI Center idea at U S WEST and both preceded and followed Glen Dillon as the head of the ESTG. He was also the architect of the agreement with the Carnegie Group, and relations with them were his primary responsibility during the time he was not head of ESTG. 
He gave cursory advice during the formation of KSTP but was not deeply involved. Once KSTP was formed, he paid very little attention to the group. When Sid Thompson asked Glen Dillon why Alvin did not respond to phone calls or email, Gien replied, "I don't think he takes you guys very seriously." Alvin appeared to be focussed only on the Carnegie Group and large U S WEST issues, which was understandable given the superb credentials of the Carnegie Group.

At one point, when KSTP was (unsuccessfully) trying to work through Alvin to contact the Carnegie Group, Brent Larson in KSTP contacted the Carnegie Group's principal U S WEST account manager directly. After the conversation with the manager, Lamar Jones, Brent reported:

"I feel that Lamar is a valuable resource to us in that I can pick up the phone and get help ur answers in regard to CGI and their activities, something that was not really available from you know who (nickname /dev/null ${ }^{51}$ ). Lamar was aware of the problem to which I allude above."

/dev/null was Alvin Vail and it was interesting to see that people at the Carnegie Group had similar impressions. As Brent put it, "At least we know it wasn't just us!"

Putting this in perspective, Alvin had a lot at stake for his career, both in managing the Carnegie relations and in managing the ESTG. He was very helpful and sincere, if you could get his attention. He frequently said he would do things and then would not. Initially, this caused problems for KSTP work flow, until the unresponsive pattern became clear. Then, after waiting a short while, the KSTP staff would contact someone else in ESTG who should have been working on the issue. Which they would have been, except they had never heard of it!

In addition to personal style, much was revealed at a meeting when Alvin divulged his feelings about pushing expert systems technology:

$51 / \mathrm{dev} /$ null is the pathname for the null device in Unix ${ }^{\mathrm{TM}}$ systems, also known as "the bit bucket" and "a black hole." Nothing ever comes out of it. 
"I can't totally commit myself to plans anymore, and push for what I think should happen. I used to and thought it would payoff, but it doesn't, not only in what I've worked on but everything else I've seen. So I'll pull things together, submit my plan, and see what they want me to do. It just takes too much out of me to devote myself to this."

\section{Sid Thompson. Head of KSTP}

Sid Thompson had a fairly high degree of personal stake in KSTP, due to his formal position as leader of KSTP. His leadership position came about in an unusual fashion, in that he was, at best, second choice for the role. The first choice was John Fitzpatrick, and when negotiations with him broke down, the architects of KSTP (lead by Ron Garcia), were put in a pressing situation. The entire project team had already been assembled, executive support had been attained, and computing resources had been acquired. All that was needed was someone to lead the project team. It was in this urgent context that Sid was selected.

Most of the project's structure and all of its tasks had been defined by the time Sid began work on KSTP. On the surface, it appeared as though there would be little chance to deviate from previous decisions. However, Sid asked for and received complete decisionmaking and budget control. This proved to be the flexibility factor that allowed later changes in KSTP directions.

One of the first things Sid realized was that there was a lot of work to be done on many facets of the technology integration process, and he had a small staff and small budget to work with. This made necessary the prudent selection of tasks and the extent to which these tasks could be carried out.

On the subject matter of knowledge systems, Sid could not have been more pleased. In previous years, he had proposed AI applications within the company and the ideas had not been acted upon for a number of reasonable company, personal, and maiurity-of-technology reasons. The opportunity to lead a significant knowledge systems project for a major corporation was very appealing. 
As such, he took his job very seriousily and worked hard to plan and execute the technology integration process. In doing so, his work was made harder, but because he felt the work was so important, the burden was not great. In fact, he perceived the work as easier because it was contributing to technological growth in such a big way.

One of the more difficult tasks for Sid was to ask the technicians in KSTP to hit the road and sell knowledge systems concepts to CIS employees. The technicians were technical experts by career choice and by formal education. Giving presentations, popularizing knowledge systems was not what they wanted to do. In fact, one technician declined to participate in this phase of the project. It put stress on them, which in turm, put stress on Sid. They all knew the PR-type tasks had to be done, and Sid knew they were not the right people to be doing it.

He looked to his partner group, ESTG, for help in this area and found great willingness to share the responsibilities. He looked to vendors to give controlled 52 presentations, and they were obviously willing, even though a few of them got out of control. He took much of the burden of the PR-type tasks himself, in order to free the technicians to do the tasks for which they were better.

This resourcefulness was a trait that resurfaced time and time again. He was constantly looking for a better way to accomplish a task, looking for opportunities and being prepared to use thern. On his desk hung a quote from Julius Erving, the legendary Dr. J of basketball fame:

"You play to daylight. Sometimes its there and you take it."

Sid believed in a low key approach that characterizes long term, consistent progress.

"You don't always make the big splash or spend your resources preparing to. You keep your mind open, ready to seize the chance, because in a moment, the door slams shut."

52Meaning high knowledge systems content, low sales pitch. 
As an independent thinker, Sid always had ideas on how things should have been done. On occasion, he had to force himself to ask for input to decisions because he knew what he wanted to do. While he tried to keep in mind that it was important to build consensus on certain decisions, he was also bull-headed enough to keep it to himself at times, which undoubtedly caused some communication problems.

Sid was inclined to take large risks when he knew he had good people and solid te-hnology on his side. The IS organization was the most uncertain part, and he would require a significant advantage before pitting risky situations against the entrenched bureaucracy.

He understood technological maturity phases, which enabled him to view knowledge systems with a long time horizon. He knew it would take time for the technology to mature, and it would take longer yet for U S WEST to fully integrate it. As such, he advocated strict adherence to the two year role of KSTP, believing that a specialized task-oriented, transient organization must have a limited existence. Driving the technology into the mainstream was paramount.

\section{Mike Janzen. Training Instructor}

Mike Janzen was one of the training instructors who developed the internal U S WEET expert systems training courses. He was selected for study due to his personal dynamics which had a significant effect on the integration of expert systems technology.

To set up the exchange that follows, Mike worked in Omaha, a city that suffered from its own economic and image problems. Contributing to this was CIS force reduction and consolidation activities which removed all new IS development from Omaha. Employees in that city were rightfully feeling downtrodden, wondering when their job would be eliminated. CIS executive efforts to lessen the impacts did not calm the employees. 
Knowing the sensitivity of Omaha employees, Sid Thompson took extra precautions before his first meeting with Mike and other instructors. He told them he wanted to make sure that they understood the teamwork needed to integrate expert systems technology, that the instructors were an essential part of the team, and that he was not coming to Omaha to impose anything on them. Mike responded:

"On your note of Dec 1: I don't view you as coming in to mess up our thing. On the contrary, I feel that unless the people we have given the intro to are encouraged by your organization then we are wasting our time. The majority of the people have been interested and seem to feel there is potential, but are unsure as to how or where to proceed.

We do not do on-line support. Personal interest makes it enticing, but that is not our charge. We would love to provide additional training, but on-going consultation is not feasible.

I perceive no need to talk prior to Thurs, however many thanks for your concern.

See you soon."

The mevting went well for all parties and no further KSTP and training interaction took place for six weeks. At that time, the KSTP training coordinator and Mike agreed to co-sign a memo on training, to be sent to all CIS directors. In the meantime, the KSTP training coordinator issued a memo to all CIS employees about current KSTP activities. In it he described training availabilities:

"MTS's, managers, and directors seeking limited knowledge of terminology and concepts can meet those needs via an overview course. Omaha is the only U S WEST city with in-house courses, a half day $A I$ Overview and a two day Introduction to Expert Systems. Employees in other cities interested in an overview must use courses from outside vendors, until equivalent courses are available locally."

The intent was to give positive exposure to the Omaha training staff, while pointing out the inaction of Denver and Bellevue staffs. Mike did not read it this way:

"TO: Loren Sanderson, KSTP training coordinator

FROM: Mike Janzen

RE: Training memo of $1-25-89$ 
I sure hope this is not the memo we were supposed to be co-authoring, as I am very upset and disappointed by the implications of it. I thought we had an honest, working relationship, but now I'm not so sure.

In a nutshell, the wording and sequencing used in the memo presents an attitude that says, "Omaha has a couple of courses which are okay for THEM, but if YOU want something, call an outside vendor or contact me. If we can't work out something else, Iil set up the Omaha class for you.".

Computer Technology Education of Learning Systems is, by contract, the vendor of first choice for US WEST CIS (now ITS). I believe it has been made perfectly clear from the beginning that we are willing to travel to all locations in order to deliver the courses. Re-issuing your memo to clarify this would be best.

Mary and I are both professional educators and hold Masters degrees in mathematics, plus further course work in other fields. In evaluating, courses and intended audience, we are both full-time, objective, qualified professionals. We believe the courses developed in the Eastern Region are of equal or better quality than anything on the market.

We have tried to be team players in helping to support AI and expert system technologies within US WEST. The technology has a great future in the world, but if we spend all of our time playing political games, it has no future here. We looked to KSTP for the leadership that was inherent in its charge. It was not forthcoming. On the contrary, with regard to training, we feel we have been leading the way.

We, as the training group, are going to go ahead through our training organizations and schedule the classes in all applicable locations. I intend to send a memo to all training group managers and personnel responsible for registrations relative to this scheduling."

Mike proceeded to send the following memo to all of the training coordinators and directors across U S WEST:

\section{"TO: All U S WEST Training Managers}

FROM: Mike Janzen

RE: KSTP training memo of Jan 25, 1989

The KSTP training memo that was issued conveys some inaccurate ideas sbout availability of $\mathrm{A} I$ and expert systems training.

The memo says that non-Omaha personnel must go to outside vendors to get this training. This is incorrect. We have repeatedly stated that we are willing to deliver the courses where needed. This is still true.

We held off on scheduling the courses outside of Omaha because we sished to be team players and not infringe upon KSTP's role. 
The memo also states that anyone who wants expert systems training needs to contact Loren Sanderson. While this is a viable avenue, it is not the only one that can be followed. Computer Technology Education/Learning Systems is an organization that is also capable of providing options on all phases of expert systems training, including delivery.

As Computer Technology Education, we are the CIS vendor of first choice by contractual agreement. However, we are not the only vendor to choose from, thus we intend to start offering CTE's AI and expert systems courses throughout the entire region.

If you have any questions or comments please call me."

In an effort to defuse the situation, Sid Thompson sent email to Mike:

"Loren showed me your note to him about the latest E-memo and I'm concerned about your perception. The note just doesn't seem liike it was written by the Mike I've worked with. We have been portraying your efforts as exemplary for all of the CTE centers. This includes prominent mention in our formal presentations in all cities, to director groups, and in my meetings with KSTP executive sponsors.

You folks are the leaders and we consider you strong partners.

Your reaction certainly caught us by surprise and we are eager to get to the bottom of this. I know Loren has a call in to you, but if I can be of help, call me."

Loren did talk with Mike and they cleared up the misunderstanding. KSTP was completely caught by surprise by Mike's reaction, but it did provide a good outcome: Mike was so maddened by his thoughts that CIS employees in other cities would go to external vendors, that he scheduled his own courses in those cities for the first time. KSTP had been trying to get him to do it for months, but was always turned down because they didn't have travel money.

This remarkable sequence of events, predicated on self-perceptions of inferiority, resulted in the teaching of expert systems courses across U S WEST and a very strong relationship between KSTP and the training group in Omaha. 


\section{Mark Tyson. Knowledge Engineer}

A critical part of the technology integration process is to have demonstrated success in the application of the technology. With KSTP, there were two individuals who played these important roles.

First is Mark Tyson, a knowledge engineer in an application programming group. Mark developed a major prototype on a PC platform and followed through to developing another on a mainframe test system. It was his follow through that separated his efforts from many other expert systems practitioners.

One reason he succeeded with his projects is that he truly enjoyed his work, simply for the challenge of taking this promising technology and really putting it to work. He did not seem to have significant fear-of-failure thoughts and did not appear to be particularly concerned about the impact of his work on his career.

In his practice of the technology, Mark was really a functional part of KSTP, and in this sense, he had a significant impact on the course of the project. Sid Thompson had no formal authority over Mark's work and this independence allowed Mark to do the work as he saw necessary. This was very beneficial to the technology integration process because it was the application of expert systems in mainstream IS that KSTP needed.

Fortunately, Mark was very good at his work. His mainframe expert system prototype was used as a benchmark with which to test other mainframe tools. It was also noteworthy that this prototype located an error in a production database, the first time it was tested. This error had gone undetected by the human experts for over a year.

\section{Gary Ashley, CIS Programmer/Analyst}

Gary Ashley is the second key person who put expert systems technology to work. His story is very simple because he is a rather quiet person, preferring to get down to work instead of a lot of talk and planning. 
This personal bias is what made Gary successful in the use of the Loaner Program

PC tool. The tool gave Gary independence from the trap of complexity and bureaucratic

overhead. He applied for the tool loan and quietly went to work. Brent Larson was the

KSTP consultant working with Gary, and after two months of work, Brent reported:

"Gary and I met today, as we had scheduled about a week and a half ago. When we last spoke, Gary had not had enough time to look at the tool yet, and had only gathered rough documentation about the process. The last time we met, I pointed him to an example of rule control by way of the set of rules that I had earlier written for Sandi Roberts. He seemed to be mostly following it, but I was a bit disappointed then with how little time he had managed to make for the project.

I went into the meeting today with Gary sort of expecting to see more of the same that I have been getting from folks. "Well, I am really excited about it, but I just haven't been able to find the time to do anything." My general plan was to get directly involved with Gary in this project, perhaps doing almost all of the work.

What I did see was a pleasant surprise. Gary had put together some rules as a cross between a demo and a prototype. He used as a case the situation that occurred last December. I guess that some rework had besn necessary, and some expensive and time consuming mistakes were made. Gary's demo asked the user a few questions up front, while printing a report of advice to the printer. Some of the printed information would be printed every time, and some was specific to the answers that were given during the consultation.

I was impressed with how quickly Gary had caught on to the rule based paradigm. In the first several hours he was using rules that accessed external text files and dumped info to the user, based on the flow of answers. He was also taking advantage of backward chaining to get things done, which I have found to typically take a person a while to catch on to. All and all, Gary's initial work is excellent, and it is encouraging to me to see it happen.

I told Gary that Sid and I would be meeting with Kathy Dobbs later that day, and Gary said that he would try to get a hold of Kathy before that and show her his demo. He said that if he was not able to show her before the meeting, we should feel free to come grab him during our meeting and he would show her then."

A month later Gary's systems was finished and put into production. His

contribution to the project was unique because of his independent work to develop the application for his work group. 


\section{Andy Shuler, IBM Marketing Person}

In Chapter VI, IBM was described as an important organizational actor in technology integration. Within the IBM workforce, Andy Shuler was one individual who contributed to KSTP through hard work and persistence.

Quite clearly, Andy was motivated by making sales for IBM, and as a part of that company, he had fairly unrestricted access to certain CIS offices. He used this access to look for opportunities for knowledge systems application within U S WEST, and when he found them, he heavily promoted IBM solutions.

For one knowledge system prototype, he incessantly was pulling pieces of the project together, getting help from his research labs, talking to the project team, trying IBM tcols, and presenting the project to senior CIS management.

For a U S WEST trial of one of IBM's knowledge systems tools, Andy was actively involved in resolving everything from contractual issues to product support issues. His helpfulness was to the degree that he would sometimes be perceived as a useful resource for KSTP, instead of a vendor trying to sell something.

Then IBM was setting up an international advisory board for its knowledge systems products, and was selecting major customers who currently used at least one IBM mainframe knowledge systems tool. Andy fought long and hard within IBM to get U S WEST a seat on the board, even though U S WEST did not own any IBM knowledge systems tools and had no immediate plans to acquire any. Andy's work was clearly to IBM's benefit because what better source is there for product improvement ideas, than a major customer who has substantive reasons for not buying into one of your product lines? Now all of this can simply be attributed to marketing tactics and dismissed. Or it can be seen as an important part of the technology integration process, in which a marketing employee of a vendor becomes an active agent in advancing the use of the technology. In 
Andy's case, it is the latter, even to the extent of taking on his own company in order to imate înings happen. 


\section{CHAPTER VIII}

\section{INTEGRATION AND CROSS-CUING}

Each of the technical, organizational, and personal perspectives provide information about the integration of knowledge systems technology into CIS. While a reader might recall an occasional T-perspective item when reading the P-perspective, the complexity of the study makes it difficult to recognize and retain connections between the various perspectives.

While the capability of the human mind to store and recall disjoint pieces of information sometimes limits understanding, it is precisely through such mental processes that one gains understanding of a system such as KSTP. This chapter focuses on the integration of the three perspectives in order to explicitly document major interactions. The cross-cuing relationships are sometimes reinforcing and sometimes inhibiting, but always provide enlightening insights into the technology integration process that would have been otherwise unobtainable.

By documenting the major interactions in a graphical form, the full system view can be attained. Supporting the graphical view with narrative explanation provides the detail necessary for understanding. Finally, summarizing the detail with a list of conclusions provides a concise view of the major points.

\section{CROSS-CUE CHART OF THE KNOWLEDGE SYSTEMS TRANSFER PROJECT}

In the technical, organizational, and personal perspective chapters, effort was made to investigate each dimension independently. This separation was intended to facilitate thorough investigation of each perspective and to permit clear presentation of the findings. 
Cross-cuing these perspectives into a meaningful whole must not be mistaken as being a simplification of KSTP into a common denominator, which would greatly limit the utility of multiple perspectives. Instead, cross-cuing shows how certain parts of the different views conflict or support other views, thus conveying a deeper understanding of the research topic. Such activity routinely takes place in certain areas of society [Linstone, p. 82]:

"Consider a corporate executive faced with a complex sociotechnical decision. He obtains a T perspective from his engineers and systems analysts, an $\mathrm{O}$ perspective from his department heads, and a $P$ perspective from workers and staff whom he informally queries. He may receive conflicting input as well as reinforcement. Similarly, the various witnesses at a trial provide different perspectives to the jury. The process of integration is not merely one of assembling a composite picture from jigsaw puzzle pieces, nor ironing out contradictions by some rules of thumb, nor arranging the information hierarchically. Integration resembles the task of concepiualizing a threedimensional object from a series of one-dimensional descriptions and twodimensional drawings."

Cross-cuing is the culmination of the study, where reasons for results are revealed and a foundation for progress through understanding is laid.

\section{Instructions for Using Cross-cuing Analysis, and Conclusions}

To begin the process, Figure 48 shows the cross-cuing of the three perspectives. All of the $T$ elements are in one band, as are the $O$ and $P$ elements. For cohesion, most of the element labels map to corresponding sections or subsections in the $\mathrm{T}, \mathrm{O}$, and $\mathrm{P}$ chapters. The cross-cuing explanations following Figure 48 describe the dynamics of their interactious. The time scale shows the temporal relations, within certain approximations which are described in the cross-cuing analysis following the chart. All items lined up at the beginning of the time scale existed before the Knowledge Systems Transfer Project was initiated. Some of these were relatively recent, such as the Advanced Technical Education Program which began in 1985 . Others, such as Computer Operating Environments, have been evolving over many years. Where cross-cuing lines intersect and it is not clear which 
path an arrow follows, one or more of the arrows have been shaded to make the paths easier to distinguish. The symbols serve as flow chart connectors from page to page. 


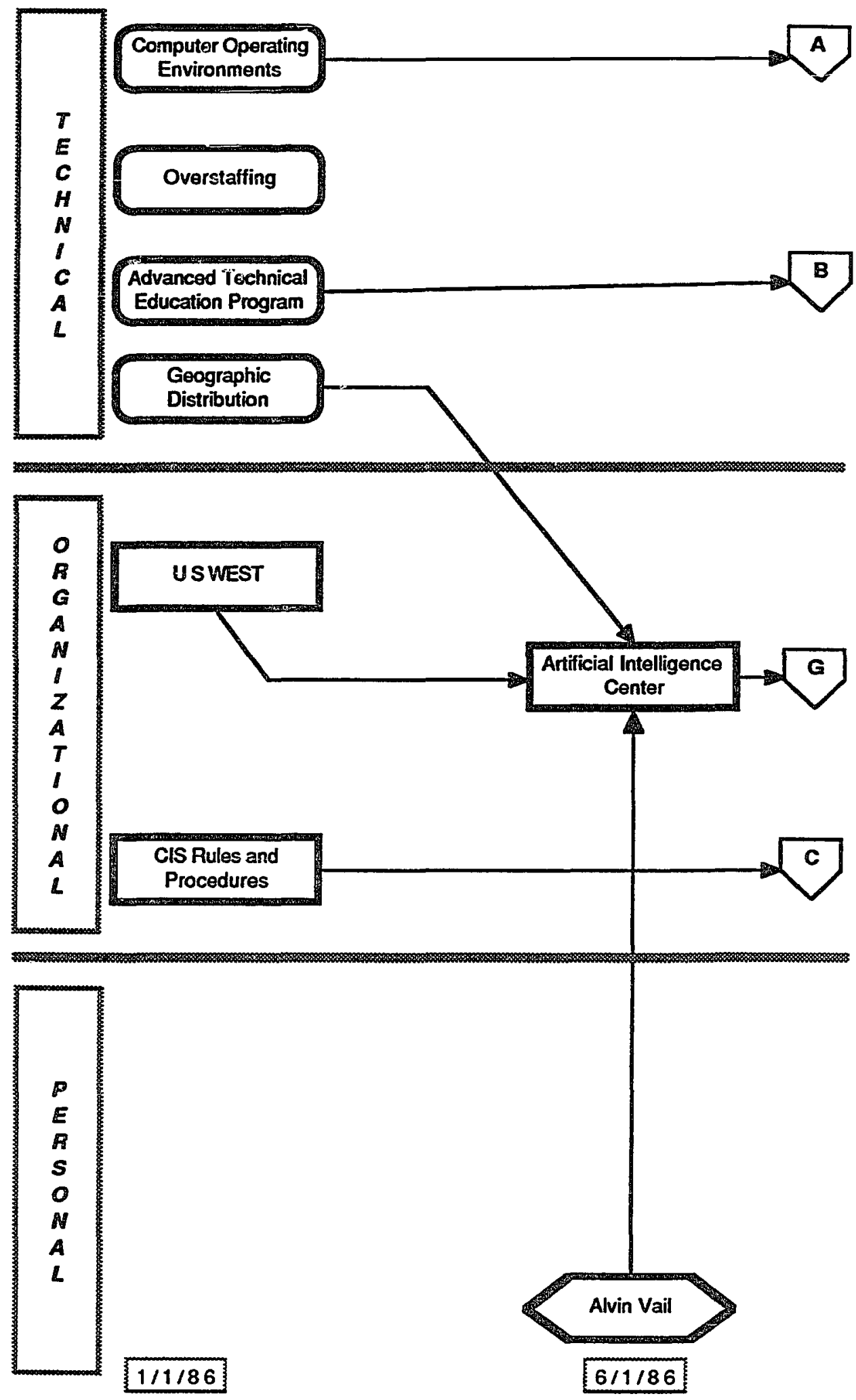

Figure 48. Cross-cue chart. 

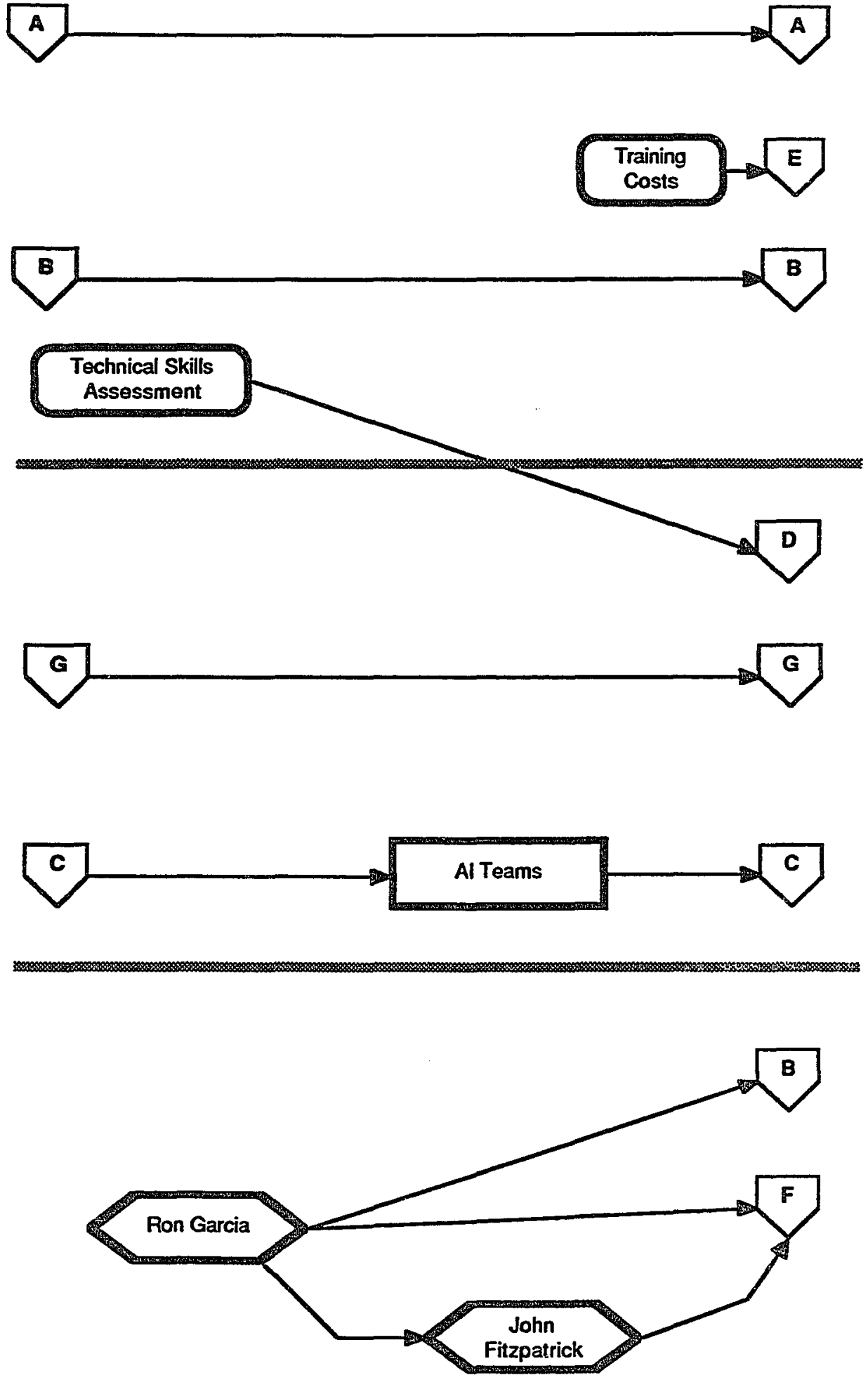

$6 / 1 / 87$

Figure 48. Cross-cue chart (continued). 


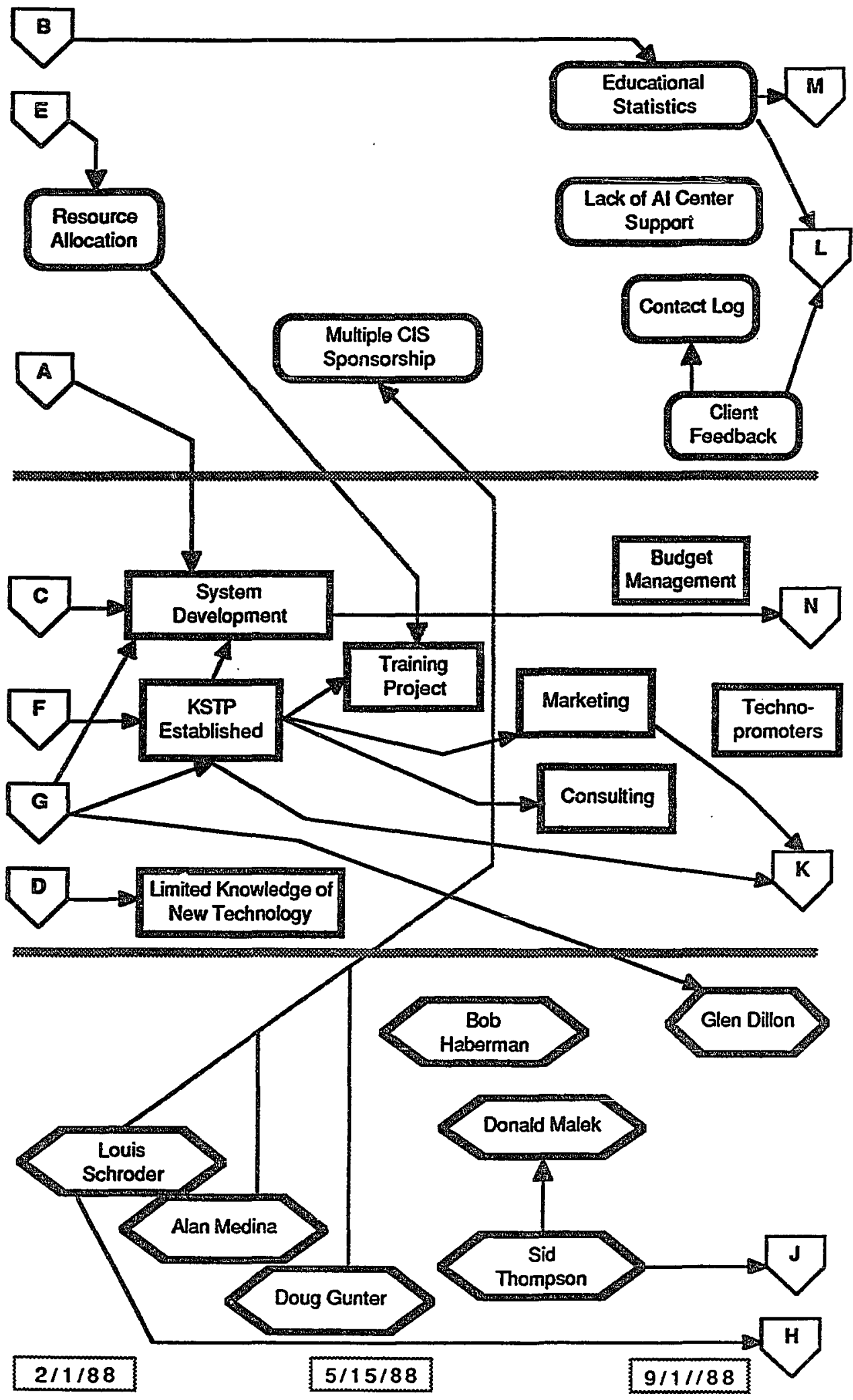

Figure 48. Cross-cue chart (continued). 


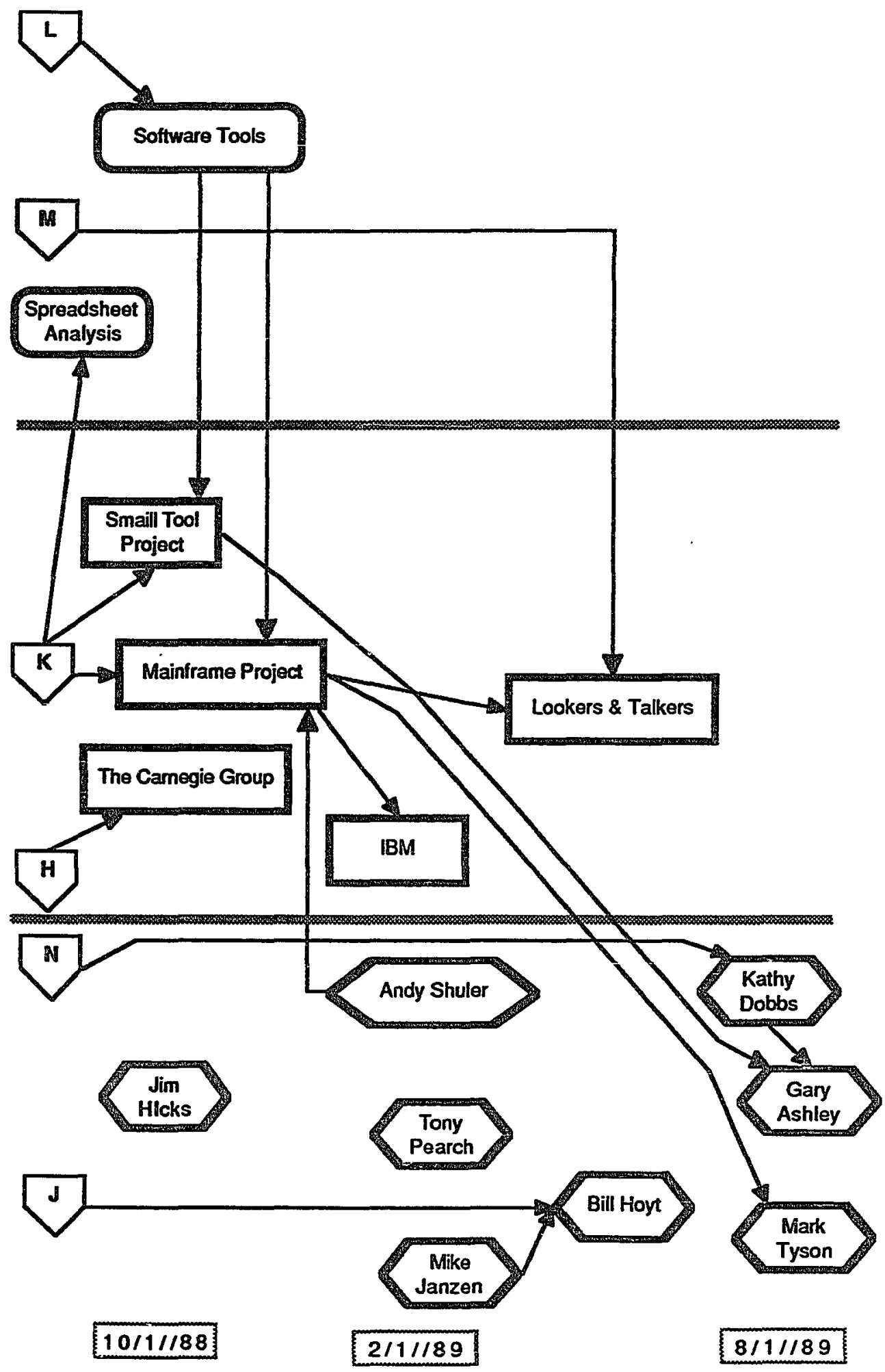

Figure 48. Cross-cue chart (continued). 
In the description of the cross-cuing chart which follows, the element labels are distinguished by italics and underline, such as Computer Operating Environment which will enable the reader to follow the diagram discussion. At the end of the analysis, the conclusions are listed with 1) the primary perspective which enabled the conclusion to be made and 2) the page number in the discussion which can be referenced for detail. Further detail can be obtained by reading Chapters V, VI, and VII under the heading corresponding with the element label, as shown in Figure 49.

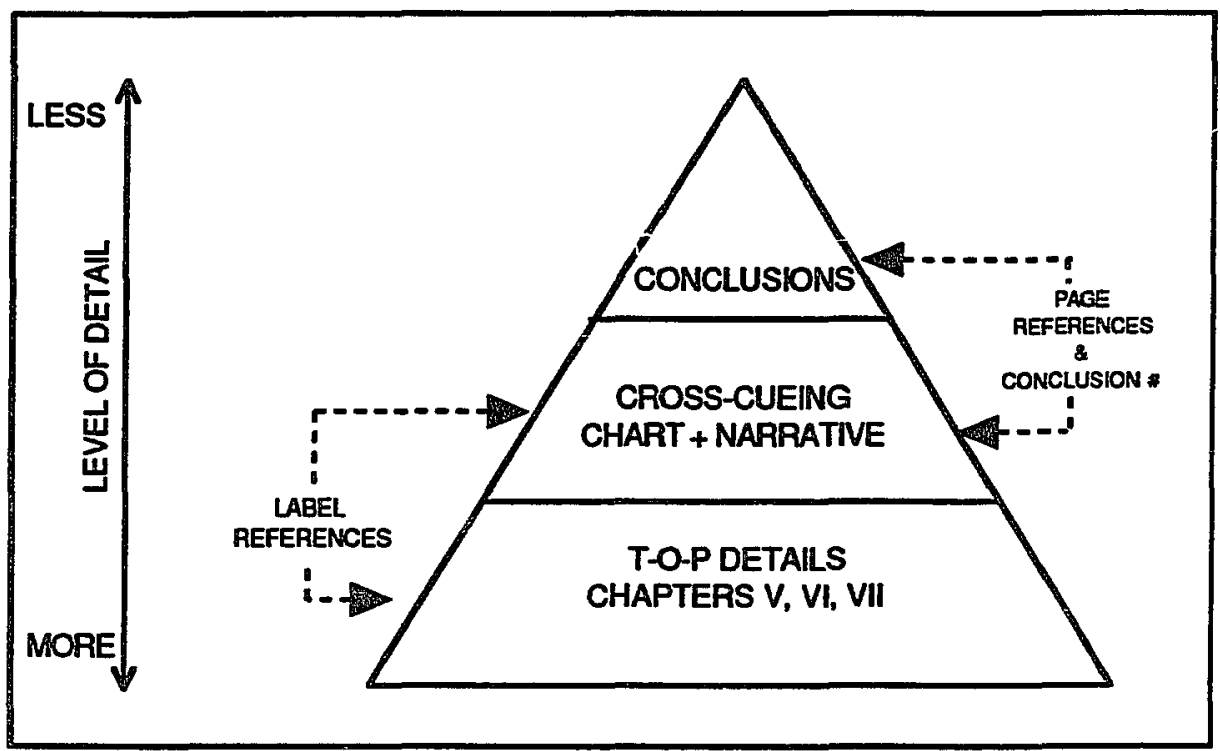

Figure 49. Navigating the conclusions, cross-cuing, and T-O-P detail.

Using this diagram, the conclusions can be traced back to an intermediate level of detail in the cross-cuing narrative using page number references. In the text, conclusions are noted in parentheses, e.g. (4) corresponds to conclusion number 4. The cross-cuing chart and narrative can be traced back to the great amount of detail in the T-O-P chapters via the label references used in the chart and in the chapter headings. 


\section{Description of the Cross-Cue Chart}

The Computer Operating Environment (3) of U S WEST information systems, as described from a technical perspective, was primarily composed of large scale IBM or compatible mainframes. A growing number of PC's were primarily used for personal productivity, not corporate information processing. A review of the technology of knowledge systems shows that large, industrial strength expert system shells had existed primarily on high-performance workstation machines. This technical gap had a direct impact on System.Development in a way which was not anticipated during the planning stages of KSTP (12).

Development of production systems ${ }^{53}$ was seen as a very important part of KSTP from its inception, primarily because it was clear that successful implementation of a new technology required that someone had done something useful with it.

The disparity between the environment of successful expert systems in 1986-88 and the Computer Operating Environments of U S WEST inhibited System Development.

Although Qverstaffing was a problem that had existed for many years in U S WEST and, prior to that, the Bell System, one would be hard-pressed to prove it using historical data. Some of the recent data from the $\mathrm{T}$ perspective shows U S WEST relative to the other seven regional companies, but this does not give an indication of IS staff sizes relative to other industries. Even within the seven regionals, the data shows that U S WEST had about 1600 more people on its IS staff than one would expect (using the number of access lines for the core telecommunications business as the measure). Debate raged over the reasons for this excess or whether this was really an excess at all.

$53 \mathrm{~A}$ production system is defined as a software which is used in performing activities supporting U $S$ WEST business activities. 
Part of the Qverstaffing was because U S WEST's origin was much different than the other seven companies. Some regionals were composed of exactly the telephone companies which existed prior to divestiture (e.g. Pacific Bell $\rightarrow$ Pacific Telesis; Southwestern Bell $\rightarrow$ Southwestern Bell) and others had fairly similar companies, culturally and geographically, joined together (e.g. Southern Bell + South Central Bell $\rightarrow$ BellSouth; Illinois Bell + Michigan Bell + Indiana Bell + Ohio Bell + Wisconsin Bell $\rightarrow$ Ameritech). U S WEST was composed of three companies, Mountain Bell, Northwestern Bell, and Pacific Northwest Bell, each of which had very different cultures and great geographic diversity, stretching across 14 states from the Pacific Ocean to the Great Lakes and from Canada to Mexico (8). The IS organizations differed in that Northwestern had much Honeywell mainframe equipment, while Mountain and Pacific Northwest were mostly IBM.

Accepting this "great diversity" argument as a reason for more staff than other regional companies is plausible, but it would be difficult to rationalize 1600 more. Some have even argued that the quality of information provided to the market units was much better than the quality in other regionals, but there has been no work to substantiate that.

The effect of Overstaffing on the integration of new technology is great because there are too many people competing for too little work. At first this doesn't make sense, because it would seem that there are "extra" people who can be devoted to the new technology. However, all of these people are committed to existing work which is very much aligned along the old company boundaries (8). When examined at a group level, these functions indeed appear to be necessary, but looking at it from the company organization level, 1600 "excess" people are seen.

This dilemma leaves organizations and people working hard at their job, knowing that the cleaver is hovering, uncertain as to where it may fall. To ensure survival, the safe 
route is to be as productive as possible within the existing performance boundaries. Organizational churning prevented people from taking risks.

Just after divestiture, the Advanced Technical Education Program (ATEP) was started with the primary goal of upgrading the technical capabilities of CIS staff (4). Clearly knowledge-based systems was an important area in which to invest in 1985 and 1986, but little was done until 1987, when the first person in IS went to graduate school to specialize in the technology. Looking at the timeline, one can see that this is not particularly odd because there was very little serious movement towards strategic use of knowledge systems.

What was hoped for, and what is a traditional Bell System approach, is to reshape high performers with the skills that are needed. Reduced levels of recruiting also put an additional importance on the development of existing staff. The reshaping approach worked well during the pre-divestiture days when nearly all new technology was provided by Bell Labs, Westem Electric, or major external vendors such as IBM. The shallow skill set was easily changed and the depth was provided by the technology source through their support organizations.

Post-divestiture, nearly everyone in the remnants of the Bell System were uncertain about the work that should be done. This was evident at the juncture of new IS applications and knowledge systems technology: none were delivered. In the past, IS applications were delivered in run-time form so the receiving company simply installed the software.

With the depth of technology expertise residing primarily at Bellcore and the drive for independence at U S WEST, $\underline{A T E P}$ was an idea whose time had come. A review of Figure 32 shows the position of artificial intelligence as part of the post-divestiture technical needs. The data from Chapter $\mathrm{V}$ shows that CIS did not have a strong base on which to 
build, in that a majority of the staff did not have a college degree and less that 1 in 10 had a degree in computer science.

At the time of $A T E P$ 's beginning and prior to the inception of KSTP, artificial intelligence topies were primarily in the graduate student curricula. But here it is seen that the educational foundation of existing CIS staff is largely inadequate for technical graduate work, and that the actual matriculation of a graduate student in AI did not occur until 1987.

Geographic Distribution, a result of the immense U S WEST regulated territory, would have been a negative influence on the integration of knowledge systems even in company that had a stable culture (5). From a simple geographic separation view, it is difficult to work as a team with people who do not know each other (8). Travel expenses are high because of the distance between the major cities listed in Figure 41. The studies of Allen document the severe impact of geographic separation on communications (6). Once two people are separated by more than 100 meters, they have a .03 probability of communicating at least once a week. Within U S WEST, explicit pleas and directives to work creatively, use alternate methods of communications such as electronic mail, telephones, fax, and conference calls all ignore the research data that has been compiled.

The effect of the geographic separation on the Artificial infeliligence Center was much the same. The result has been knowledge systems practitioners that have no particular alliance with one another, making it very difficult to build a critical mass of people to support and encourage further use of the technology. This underscores the need for good communications facilities between disjoint groups and individuals for effective changes to occur.

Part of the inherited USWEST culture said that new projects would be done on a large scale, or they wouldn't be done at all. The plans for the AI Center, which indicated that it was really a loose association of work groups active in artificial intelligence subdisciplines, were on a large scale. At the time of its proposal, it was forecasted to have 
a total staff of 48 people dedicated to knowledge systems work by 1989 when in fact it had 8, or just a few more counting its associates in other work areas. The environment of $\underline{U S}$ WEST had much to do with this, lacking the sirong commitment to the AI Center concept.

One person's view of the $U S W E S T$ impact on the ability to engage in technological development (9):

"The organization is staffed by a group of senior managers in the Bell System mold, primarily Northwestern Bell and Bell Labs. They don't know how to run a research organization. Every year they point to what dollar value they returned to the company when they really haven't been in business long enough to have results. Specific funding from clients for technology development efforts doesn't make sense. Glen Dillon was in the crunch with the rest of them, how could anything get done in such an environment. Good work sat on people's desk because they feared letting people know about it, just in case it was not politically acceptable for them to be doing that type of work."

Part of this was caused by inadequate role definitions and the resulting competition for desirable work, often as related to the needs of the market units.

One of the facts established by the Research Committee on Expert Systems was that there was a market-driven need to take advantage of the technology in order to drive expert knowledge down to lower levels of a company. From a U S WEST company view, this is a desirable action. But from the view of the excess staff personnel, their knowledge is what makes them valuable to the corporation. With too many people and a residual culture that values life-time employment, there is very little incentive to encourage the use of technology that reduces dependence upon personal knowledge.

U S WEST has had a large number of changes to make in order to adjust to the competitive arena.

One of the most significant areas of change was towards market orientation. In the past, telephone companies served customers by offering limited services, take it or leave it. In the new era, there is a concerted effort to practice the "excellence" principles of being close to the customer, listening, and providing customized service to meet customer needs. 
At the same time the evidence clearly shows the need for increased technical capabilities to deliver the needed prodticts and services. The question is, can an organization make such large, fundamental shifts simultaneously (8)? And if not, which one should come first?

It appears that the answer at U S WEST was market orientation, which would be the precursor to driving demand for technological solutions. This is the classic case of technology-push or market-pull.

Another severe impact on the development of knowledge systems was the method for funding new technological development. General funding works well in some companies. Few customers question it because they don't see it. They simply pay the price for whatever you are selling, if they perceive $\mathrm{i}^{\dagger}$ to be a reasonable buy. For example, when buying a car, few purchasers care how much the manufacturer spends on R\&D. They only care if the cost is acceptable for what they are buying.

However, within one large centralized company, other subsidiaries or departments know what gets diverted to R\&D projects and either won't pay for it or does everything possible to put a stop to the projects. Prior to KSTP, this is precisely what happened with knowledge systems technology in CIS, causing organizational rifts. This was partly responsible for the decision to establish the Knowledge Systems Transfer Project.

As a long established organization, CIS Rules and Procedures had evolved over many years. The existence of standard rules and procedures are sometimes inhibiting to progress, especially if they are imposed prematurely. On the other hand, standards allow rapid processing of routine work so time and effort can be applied to tasks outside of standard areas (11).

In the case of KSTP, it was the beneficial use of existing standards that was most noteworthy. The rules and procedures provided convenient insertion points for the technology into guidelines which were already being used. As with most bureaucratic 
organizations, CIS had a full complement of standards. No one, save the truly incorrigible, would ask for more, so it was clear that the ALTeams would not be able to push the technology as something different and special which needed its own rules.

The key to successful integration was to adapt the technologically based methods and procedures into existing CIS Rules and Procedures. An example of this was the standard development methodology for all information systems projects. The KSTP staff decided, with Donald Malek's encouragement, to insert knowledge-systems-specific information into appropriate places of the standard methodology.

The logic of this was clear. In a work environment which was already overloaded with change and information (often data, making the distinction of meaning versus no meaning, respectively), no one needed yet another document saying how they should do something.

Actual implementation of this was nearly another document, but packaging it as part of the standard methodology made it more palatable.

As the creative force behind the Artificial Intelligence Center, $\underline{\text { Alvin Vail developed }}$ a strong vision of the future of AI within U S WEST (13). Because KSTP was not in existence in 1986, Vail's effect on the project was indirect, through his work on the AI Center. Recall that Vail then became head of the Expert Systems Development Group, was replaced by Glen Dillon, and then replaced Dillon in 1989. During Dillon's tenure, Vail was the primary liaison with the Carnegie Group. In this role, Vail had tremendous opportunity to involve the mainstream of U S WEST Corporate Information Services through active involvement with KSTP. He chose not to take such a path, which reduced KSTP access to the consulting skills of the Carnegie Group.

Part of the reason can be seen in Dillon's comment that Vail did not take KSTP very seriously. The Carnegie Group's reputation was so high that it took precedent over all. 
Examining this in the context of the Computer Operating Environments provides a bit more information. The Carnegie Group was a traditional AI vendor with much invested into academic-type AI, with software that ran on the workstations. There experience with commercial information systems, mainframes, and PC's was minimal, so they had very little to offer. It seemed more reasonable, at the time, for them to pursue applications within their hardware and software comfort zone, in spite of their fairly strong general knowledge systems skills.

Vail, a product of Mountain Bell information systems, had clearly decided to move U S WEST into the AI forefront with a radical departure from the entrenched information systems.

A point from Chapter VII worth repeating is Vail's failure to communicate. As the research of Allen has shown, communication is vital to the technology integration process (6).

While temporally disjoint at this point, please note the reappearance of Vail at the end of the timeline. His feelings about pushing expert systems technology:

"I can't totally commit myself to plans anymore, and push for what I think should happen. I used to and thought it would payoff, but it doesn't, not only in what I've worked on but everything else I've seen. So I'll pull things together, submit my plan, and see what they want me to do. It just takes too much out of me to devote myself to this."

The Artificial Intelligence Center provided a focal point for knowledge systems work in all of U S WEST. During the time of its inception, a fair amount of excitement was generated, and its eventual acceptance would have led one to conclude that AI would inevitably be thoroughly applied within U S WEST.

As part of the AI Center umbrella, the Expert Systems Development Group (ESDG) played a central role in development efforts. One of their projects became a joint venture with ESDG and KSTP, which was also the first significant project for KSTP in April 1988. ESDG had hired a number of people to develop knowledge systems within iheir 
owrs group, which should have been a warning to those who participated in the planning of KSTF. The Research Committee on Expert Systems found that to be successful "formal expert systems groups should not centralize development, but act as a point of technical transfer."

By chance, both leaders of ESDG did not communicate well with KSTP, which compromised the potential of the AI Center (6). Regardless of the individuals involved, the head of the AI Center (even if it was just an umbrella organization) had important responsibilities as direction setters. Because the AI Center lacked this leadership from the beginning and through the end of KSTP, it was not able to provide the cohesiveness to company-wide efforts. In addition to lack of guidance, the KSTP staff had to reinvent measurements, processes, and procedures, which impacted their effectiveness. The ESDG staff also asked to be designated as the group to set U S WEST knowledge systems tool standards, in spite of having a work orientation which was not aligned with mainstream I

Members of the AI Center staff also participated in the planning meetings leading to the establishment of KSTP. Alvin Vail was one of the major contributors, through his role in the AI Center.

Stepping back from what can be seen at this point reveals a cross-cuing precursor to events to come:

- The mainframe-PC information systems environment

- Alvin Vail's involvement with the Carnegie Group

- The Carnegie Group's expertise in academic AI

- Vail's central role in setting AI directions at U S WEST

From these facts it is clear that the main thrust of U S WEST efforts in AI were away from its information systems base. It was within this IS base that KSTP was to focus its efforts. So it is rather obvious why the AI Center did little to support the mainstream use of knowledge systems technology. 
In mid-1987 there began a major effort to formalize the Technical Skills Assessment processes. The major impact of this was the reaffirmation, from yet another perspective, that there was Limited Knowledge of New Technology (4) which severely impacted the use of knowledge systems.

One part of the skills assessment required general knowledge of AI for certain technical levels. This stimulated demand for rudimentary courses in AI (such as one or two day overviews) but nothing further, indicating the interest was in fulfilling the skill requirement, not in learning about and applying the technology. So Technical Skills Assessment did not have a positive impact in the efforts to apply knowledge systems.

On another dimension, those people working with knowledge systems encountered barriers to well-deserved promotions because people and organizations were not prepared to deal with new technologies.

Most new employees step into an existing position (or at least a well defined position), with well defined roles. Their job is to fit in and make modest changes as warranted. New technology employees step into newly created positions with no support structures, no defined roles, preliminarily defined tasks. Their job is to create a client base, market the technology, identify applications of the technology, select the projects, develop the projects (with clients), integrate the technology into existing organizations, and develop new talent (5). In CIS, their is little organizational accommodation for these differences, again pointing out the need to get the technology into the mainstream environment as soon as possible.

Also in mid-1987, the early stages of KSTP planning were underway. Ron Garcia was the manager of a work group that was responsible for knowledge systems prior to KSTP. There were three major impacts Garcia had on KSTP.

First, he uas determined to push knowledge systems into its own existence. The Research Committee on Expert Systems and the organizational maneuvering to build strong 
support for KSTP were instrumental for the success of the project. A testimonial to this was the ability of KSTP to exist intact throughout its entire planned existence.

Second, he had responsibility for ATEP, which affected the Educational Statistics (4) within CIS. He was dedicated to improving the quality of the educational foundation through formal advanced schooling. Recall from Chapter VII his belief that with a strong knowledge of technology fundamentals, the changing technologies in vendor products and U S WEST development would be much easier to manage.

Third, Garcia searched for the best person he could find to head the KSTP. His choice was John Fitzpatrick, a consultant who was a technical instructor as well as a fulltime worker on industrial knowledge systems. Recognizing the importance of knowledge systems training, Garcia felt that Fitzpatrick's teaching experience and technical knowledge would be invaluable for building a knowledge systems training curriculum. Here again, company recruiting practices had significant impact on KSTP.

Garcia decided that it would greatly benefit U S WEST knowledge systems development to have Fitzpatrick on the staff. Since Fitzpatrick was a highly educated and experienced professional, Garcia attempted to offer Fitzpatrick an inducement package commensurate with Fitzpatrick's abilities. However when the human resources department got involved, they imposed standard recruiting procedures which, in this case, meant a woefully inadequate offer. Negotiations carried on for three months, and finally human resources came close to what the original offer should have been. By this time, Fitzpatrick was hesitant about working for a company with such personnel procedures and he finally declined the offer (4).

These events permanently changed the course of KSTP's training programs and development efforts.

In late 1987, the first meeting of the U S WEST AI Team meeting was held. The Al Team concept was similar to that of the AI Center because it was composed of a number 
of organizationally independent groups and interested individuals without organizational sponsorship. The primary linkage among these entities were conferences which were held about once every six months.

AlTeam conferences did not have the organizational impact that was possible. The attendance at these meetings were about 30 to 40 people for a company of 65,000 employees. Contrast this with Boeing conferences which have attendance of 600 for an employee body of about 140,000 , which is about 8 to 10 times the attendance for equivalent workforce sizes. Why the disparity?

First is the limited charter of KSTP as focussedi on the Corporate Information Services organization (9). CIS is the information provider to most of U S WEST and the belief was that integrating the technology into the IS organization would make it available to most of the company. So the target audience for team meetings was much smaller.

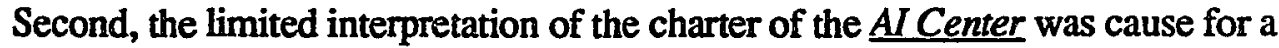
reduced audience for the technology (9). Primarily this was the search for large-scale, high-payoff System Development which required a narrow concentrated publicity program.

Third, the workforce of U S WEST, as described previously, was not highly educated in technological areas $(4,9)$. The beginning phases of the use of new technologies are inherently high in technical content, and U S WEST did not have the population characteristics to capitalize on this. Exacerbating this was the early hype about AI which has characterized the technology as complex and difficult to apply. Even with the introduction of easier-to-use tools, the initial impressions held fast.

The last major factor relates directly to the geographic separation of the major work centers. It is simply too costly and logistically difficult to get a large number of employees to a single site for such a forum. The mechanism chosen by KSTP and ESDG was to rotate the site among major cities, but this still had a significant impact on the formation of a large user community. Without this ongoing sharing of experiences with knowledge 
acquisition, knowledge representation, tools, project management, etc., System Development was also impacted. In specific cases, users of the same tools reinvented certain problem solving techniques and in other cases ideas among people in the same domains were not communicated.

What is revealed by these cross-cues is the large void in the extent of U S WEST'S knowledge systems efforts (9). Neither KSTP nor ESDG had a large breadth of coverage, so it is understandable that few people would be interested in the AI Team meeting. The demographic data would also indicate limited interest in what was viewed as a highly technical area. In fact the name "AI Team" itself could have been a negative factor in that it is technologically rather than business problem oriented, thus alienating more people.

Even though he did not come to work at U S WEST, Lohn Fitzpatrick had a large impact on the course of the Knowledge Systems Transfer Project through his role as consultant to the Research Committee on Expert Systems (7). He contributed a conceptual structure around which he thought the knowledge systems effort should have been organized: the small research group, the support group, and the project group described in Chapter VII.

Connecting his thoughts to the structure of the AI Center explains part of the final form of KSTP (KSTP Established). The AI Center concept contained the small research group and a project group, but not the support group. It was primarily the latter role that KSTP played, complemented by project-related activities specific to the information systems organization.

The rapid increase in Training Costs was a motivator for the establishment of KSTP (10). As part of the Research Committee on Expert Systems work, it was decided that internal course development would be beneficial because such training costs were only going to increase (7). In a formal sense, this increased the Resource Allocation to Knowledge Systems by specifically designating money and people to the training tasks. 
Overall to the CIS organization, there was the potential for a reduction in resource allocation to expert systems because the distributed (and therefore untracked) expenditures on training could be decreased. It was Donald Malek's hope that the distributed training costs could be reduced to near zero and he pushed for the training initiative in KSTP.

In April of 1988, KSTP was formally established (KSTP Established). As can be seen on the chart, a number of technical, organizational, and personal factors were in play at this point.

The Al Center was was not designed to deal with the integration of knowledge systems technology into a department as large as CIS, nor was it appropriate for them to undertake the integration activities. It became clear to existing CIS knowledge systems developers, led by Ron Garcia, that there was a need to establish a group to implement the recommendations of the research committee, the ideas of John Fitzpatrick, and the experiences of the AI Center.

Over time, a key to the CIS organizational acceptance of the KSTP concept was Multiple CIS Sponsorship (2). Many believed that no one subunit of CIS had the resources to support the technology. Furthermore, it was not appropriate for any single organization to have control of the project because the technology was capable of being applied across all parts of CIS. The idea of multiple sponsorship had appeal from both a resource perspective and a technology application perspective.

With the current CIS knowledge systems developers in Garcia's group, their management chain was most knowledgeable about the technology and therefore supportive of its integration into CIS.

Louis Schroder (2) was Garcia's superior and was strongly in favor of the formation of KSTP. He was unusual among U S WEST managers because he had a healthy concern about investments in the future of the company and was willing and able to 
make resource allocation decisions to back up his beliefs. It was through his influence that KSTP was formed, and sustained through various budget and organizational crises.

The second sponsor of KSTP was Alan Medina (2) who played an obedient role in the formation of KSTP. A piece of advice given to Sid Thompson was, "If you want Alan to do something, tell Lou Schroder to mention it to Alan, and it will happen." On the other hand, if Alan got suggestions or advice from other sources, he would be as easily influenced by them as he would be Schroder. So Medina was not a champion of KSTP's formation but he was a willing sponsor.

Doug Gunter (2) was the third sponsor and the circumstance of KSTP's planning seemed to leave him somewhat dissatisfied (although he personally denied it). His attitude about KSTP was invisible acceptance, sometimes leaning towards withdrawal of support. This was first demonstrated by the "misunderstanding" about expense money support for KSTP, which, out of 5 people in a meeting, was only misunderstood by Gunter.

Looking at these three sponsors (Schroder, Medina, Gunter) together provides insight into the strength of the KSTP organizational alignment. With three sponsors, no one could unilaterally change the support or charter of KSTP unless the other two agreed. There was nothing in the original agreement that specifically stated that there must have been unanimous agreement on changes, but the political battles that would have been necessary were sufficient to protect KSTP. Twice Doug Gunter's organization tried to stop supporting KSTP, and both times Sid Thompson was able to resist, reminding them that they would have to discuss it with all stakeholders before changes could be made. In each case, Thompson notified Schroder when the trouble first surfaced so Schroder could be prepared for the issues. The unwavering support of Schroder was enough to convince Gunter that the challenge to KSTP was futile.

It was shortly after KSTP was established that Sid Thompson realized that they were terribly out of synch with their client base. The KSTP staff and the staff of the AI 
Center were both products of the state of AI technology, the workstations and expensive software (12).

Through the Marketing and Consulting activities of KSTP, the KSTP staff learned that the CIS client base was not interested in special purpose hardware and software, especially when it was disjoint from their normal work environments. They wanted mainframe software, with a small amount of interest in PC software (1).

Since Thompson was very sensitive to the importance of client feedback, the early Marketing findings became the seeds of the Small Tool Project and the Mainframe Project (6).

It was also in these early days of KSTP that the internal training issue was being examined. The original charter had described KSTP developed training and discussions with the traditional CIS training organizations indicated that development of a course was very expensive in both time and resources. Looking at the work ahead for KSTP, Thompson decided that KSTP could not afford to spend so much on building courses. He suggested to his staff that the training people develop introductory courses and then recommend outside training for advanced courses. This would effectively increase the size of KSTP by leveraging the training organization to do part of KSTP's charter. As the official training body, they had anticipated the rising demand for expert systems courses and eagerly joined in partmership with KSTP.

Directly and indirectly, the Training Project was subject to a number of forces over the duration of KSTP. Recall that the negotiations for John Fitzpatrick's services were made difficult by human resource practices, eventually leading to his refusal of U S WEST's offer for employment. One of the major reasons Ron Garcia wanted Fitzpatrick was because Fitzpatrick had extensive training development experience. Without Fitzpatrick, the course of KSTP was destined to change, but perhaps nowhere as dramatically as in this training area. 
It would be inconceivable that delegation of training course development would have occurred under Fitzpatrick. Thus KSTP Resource Allocation would have been directed toward training, and the other major subprojects would have been reduced accordingly.

As it turned out, the ESDG method of internal development and the KSTP method of distributed development had the potential of a very strong combination. Between the two groups, all development platforms from PC's through workstations to mainframes were covered $(9,12)$. The difficulty with this was the breadth of training which was required for these environments. Internal classes could not cover so much so the needs were satisfied through vendor courses.

The relationship between new and current IS technology is captured most succinctly by the views of Bob Haberman. As an executive who had responsibility for the AI Center, he did not seriously support the development of expert systems because they were so isolated from U S WEST's mainstream computing (9). His financial views showed that he clearly was not willing to support a new technology until it could help with significant portions of the business. In his view, stand-alone expert systems could not.

Haberman's views had powerful implications about the AI Center, the Carnegie Group, and the directions of KSTP. The AI Center and the Carnegie Group both operated in the specialized environments, what would be called the new technology area. This technology did not easily mesh with U S WEST current technology. Furthermore, other industrial efforts to integrate workstation-based expert systems with traditional information systems 54 were complex and risky. With a Bell System background and working within tight budget constraints, Haberman was not about to endorse such work. His views were partially responsible for the reduced enthusiasm of Alvin Vail, as evidenced by his "it takes too much out of me to devote myself" statement.

${ }^{54}$ Such as the American Express Authorizer's Assistant. 
The implication is that a bridging strategy was necessary for the mainstream success of knowledge systems, a strategy that could work until the more sophisticated expert systems could show results. This is the route that the KSTF staff chose as a result of their client feedback.

Because DonaldMalek ( 2) was a new employee of U S WEST, he did not participate in the planning for KSTP. However, had he been on the staff he would have been an important figure in KSTP's formation. In recognition of this, Sid Thompson gave Malek a briefing on KSTP in June, 1988. During that meeting, Malek showed deep interest in the application of new technologies, but clearly lacked the organizational knowledge to participate in guiding the project. Nevertheless, he offered his support to whatever needed to be done to help the project.

Because of his broad offer of support, Malek grew into one of the most dependable allies of the project. Unlike most senior executives, he seemed to understand the technology of knowledge systems and need for us to apply it effectively.

His actions affected most parts of the project. For example, he encouraged his staff to think creatively on how to use knowledge systems and in one case, actually sent a major IS project back to the mid-level managers with the explicit instruction to reconsider the project and its potential use of knowledge-based systems technology.

On the training project, SidThompson asked him to sponsor mandatory training for at least one person in every functional work group and Malek immediately agreed.

The relationship between Thompson and Malek was such that everything Thompson requested, Malek granted, resulting in a supportive environment for the integration of the technology.

Previous discussion has covered the gap between the new technologies and the current CIS technologies (9). When looking at the Software Tools, a variety are listed as 
acceptable products (Chapter V). Looking at these and their usage by the KSTP would find

- Three PC based tools (Personal Consultant ${ }^{\mathrm{TM}}$, EXSYS $^{\mathrm{TM}}$, and VPExpert ${ }^{\mathrm{TM}}$ )

- One large, specialized hardware PC tool (Goldworks ${ }^{\mathrm{TM}}$ )

While KnowledgeCraft ${ }^{\mathrm{TM}}$ was once installed on the KSTP workstation, it was not used for any development. This was foreseeable because KSTP already had been using $\mathrm{KEE}^{\mathrm{TM}}$, and had discontinued those development efforts when Client Feedback showed that their client base did not have such interests.

While the Client Feedback drove the decision, the ability to make the decision was facilitated by the use of the KSTP Contaci Log (6). Nearly all KSTP communications with cilients and associates were recorded in a database from which data could be analyzed giving rise to decision making information. This drove the Software Tools decisions which resulted in the establishment of the Small Tool Project and the Mainframe Project (12).

Also related to the preceding scenario, but involved with the entire project, was the Spreadsheet Analysis. This was the central project tracking mechanism, which was created from project goals and KSTP staff input. Specific items in the measurements varied as functions of changing project demands, the completion: of certain work functions, and the, adoption of certain tasks by traditional IS organizations. An example of this was the goal to have a certain percentage of all knowledge systems training taken under the control of KSTP. Once the traditional training organization began teaching their courses and KSTP became known as the source of advice on advanced training, it was clear that nearly $100 \%$ of the training was naturally being controlled by KSTP. As these training sources became institutionalized, the measurement was relaxed with confidence that control had been achieved. 
Early in the project, KSTP staff was establishing its goals and measurements and there was a clear Lack of ALCenter Support to KSTP (6). It was a period of time when the assistance of the AI Center staff would have been most helpful. Stepping back from the cross-cuing analysis, a number of factors can be seen which explain the lack of support.

- The tool platforms were not in synch with each other

- The client bases were much different

- Camegie Group influence was away from mainstream information systems processing

- Alvin Vail's attitude of not taking KSTP very seriously

- Glen Dillon's poor communications skills and lack of confidence in his capabilities

- Geographic separation

- Bob Haberman's concerns about the value of the technology put great pressure on the AI Center to show some success

Strangely, Glen Dillon made a concerted effort to get measurements from KSTP (Chapter VII). According to Sid Thompson, when they were handed to Dillon, Dillon was visibly taken aback, softly saying that he would get his to Thompson soon. They were never delivered. It was clear to Thompson that no help was forthcoming.

An important piece of the cross-cuing that has been left until this point is the political storm surrounding the Carnegie Group. The technical gaps have already been established, but there were other issues.

Louis Schroder was opposed to The Carnegie Group relationship. Given his unwavering support for KSTP, he was surely not against the technology of knowledge systems. His objection was to the funding mechanism for Carnegie Group work. In 1987, the Carnegie Group was one of the premier AI tool and consulting firms in the United States and perhaps the world. In spite of the fact that these specialized 
companies were fading fast 55 , and Alvin Vail's admission that they were not his first choice, a business arrangement was consummated calling for U S WEST to become a significant equity partner 56 in the Carnegie Group and to commit to many millions of dollars in consulting over a five year period.

What bothered Schroder about this was that this arrangement was going to cost his department a certain amount in overhead coverage and he was going to have to pay additional amounts for specific development projects. On top of this, no one had asked people in CIS about the wisdom 57 of the Camegie agreement, let alone the funding mechanisms (10).

During marketing and consulting engagements, people would ask Sid Thompson what U S WEST was getting from the money invested in Camegie. Thompson always hedged, saying things about the good work in progress because he was not given hard information by the AI Center. The result of this was a perception among employees that AI was still all smoke, look at how much was being dumped into the technology and nothing of value was coming out. KSTP had to battle this perception without the help of the AI Center. Thompson didn't think they were intentionally withholding information, but they did not realize the damage they were causing and the power of KSTP to dispel the negative image.

The absence of Technopromoters, Blue-Skyers, or Turf Protectors was a large part of KSTP success. Untargeted technology-pushing, science-fiction dreaming, or protecting turf can all cause significant damage to the integration of a new technology. Because none

55 Industry newsletters were predicting their short remaining time, national news magazines were asking the question "Can the AI giants survive, and some vendors were dropping their tool products and turning to pure consulting (e.g. Teknowledge).

56 U S WEST was in good company, with Texas Instruments, Boeing, Ford and DEC also equity partners in the Carnegie Group.

57 And it can be revealed here that very few were please with the Carnegie arrangement, especially because people in Ron Garcia's group had ranked KnowledgeCraft ${ }^{\mathrm{TM}}$ as a very distant last when they decided to buy $\mathrm{KEE}^{\mathrm{TM}}$ 
of these were present to damage KSTP, their absence is noteworthy. Since they didn't exist there is no specific cross-cuing. Their absence helped all phases of the project.

The effects of Budget Management $(1,10)$ had a significant impact in all aspects of the Knowledge Systems Transfer Project. With each periodic budget crisis, Sid Thompson had to defend KSTP from loss of money and/or personnel. Secondary effects included the following:

- The CIS technical staff and managers were preoccupied with budget issues and had no time to consider anything new, not just knowledge systems

- If CIS technical staff and managers had had the time, there was no money for tools, training, or travel to other U S WEST locations

- CIS leadership, most critically the three KSTP sponsors and Donald Malek and Jim Hicks could not behave proactively (2). They could only react when Thompson asked for something

- No runtime software of the small tool could be purchased

- The acquisition of a mainframe tool was delayed for months

- Travel restrictions impacted the KSTP mission of integrating the technology into all of CIS

- The Media as used internally by KSTP was rendered ineffective at a direct level. Exposure of successful expert systems through company publications did not stimulate additional substantive interest in the technology

Even with KSTP and the AI Center offering a full spectrum of development avenues (from do-it-yourself to co-development to contract development, and many gradations of these), it was difficult for mainstream development staffs to initiate and 
sustain a project. There is a significant number of projects which were initiated but became inactive due to no organizational support and follow-through (5).

Within the AI Center, their own budget crises required specific project funding for development work (10). But since the rest of the corporation was undergoing similar budget crises, very few had money to spend. General funding for support and investigation activities were very limited, forcing the elimination of training, tool testing and evaluation, and extensive consulting services. The burden of these activities were passed to KSTP.

$\underline{I B M}$ and Andy Shuler (13) played important vendor roles in the technology integration process. IBM's role as a legitimizing agent for knowledge systems technology cannot be underestimated. Because many computing innovations (which are later adopted by IBM) come from small innovative companies, many of the AI personnel were biased against IBM and saw them as irrelevant to their work.

In fact IBM's knowledge systems tools have not compared well to other vendors in many analyses, including that of U S WEST. However because of the great importance of the mainstream Computer Operating Environments, IBM was able to access and influence CIS personnel at all levels of the organization, in a way not possible by the KSTP staff. So an interplay between the Mainframe Project and IBM occurred, with Sid Thompson encouraging the cultivation of a good IBM relationship for the sake of their marketing power.

Given the predisposition of the AI personnel, it would have been conceivable for them to promptly dismiss IBM's products from any serious acquisition decisions. This is precisely where Andy Shuler had his greatest impact on KSTP, by arranging for the use of IBM software on U S WEST mainframes at no direct cost to U S WEST and including training and technical support. The result was additional valuable knowledge for the $U S$ WEST Mainframe Project Team, at the cost of a few months of time and effort. 
As events transpired, it became more evident that Lookers and Talkers represented much of the dynamics of the technology integration process (11).

First, start with the understanding that a number of stand-alone expert systems had been successful, both in the AI Center and with KSTP. However, there had been no great movement towards mainstream use of the technology. A number of factors can be cited that point to possible causes:

- Deemphasis of mainstream computing environments by the AI Center and the Camegie Group

- Difficulty in building a knowledge systems community, partly due to geographic separation

- Bob Haberman's concerns regarding the weaknesses of stand-alone systems

- Devotion of managers to the more pressing demands of budget management and market unit pressure

- The inability of CIS leadership to address technology issues, also because of budget and market unit demands

- Lack of a mainframe tool, primarily due to budget constraints

With these factors, the behaviors of the lookers and talkers become understandable, because they lacked infrastructure support for continuing their work (11). The AI Center, to whom many look to for technological guidance, had not addressed their needs and they were isolated from potential compatriots. When the lookers and talkers were personally motivated to embark on a knowledge systems project, they received little support from their management, not because management did not want to pursue the work but because there were more pressing issues which took priority.

A number of lookers and talkers were also constrained by the absence of a mainframe tool (Mainframe Project). Their work environment was an instantiation of the 
Computer Operating Enviromment (3) previously described and the corporate data they manipulated was accessible on the mainframe computers.

A minor cross-cue is the effect of the Technical Skills Assessment on Lookers and Talkers. With the technical skills requirement of at least a general understanding of AI, it is certain that some technicians toyed with the technology enough to gain subject matter certification and no more. Because this was their only intent, their failure to proceed does not fall into the infrastructure problem category. However, it does indicate that the Technical Skills Assessment should be reviewed to examine the effect of the skill requirements on the integration of knowledge systems technology.

Bill Hoyt and Mike Janzen were critical players in the knowledge systems training area (13). The transfer of responsibility of the training function from KSTP to the training department was greatly affected by the interactions of these two men with Sid Thompson and the KSTP staff.

In late 1988 , when the training department was beginning to assume responsibility for knowledge systems training, they were also going through major organizational changes. Prior to divestiture and up until late 1988, each of the three U S WEST Bell companies had their own training departments. The transition to one U S WEST department meant major organizational changes, turf battles, and the accompanying trauma. Janzen was the primary developer of the knowledge systems courses and, as related in Chapter VII, was quite sensitive about his work. After the KSTP staff had worked so well with Janzen, the irate memo incident threatened to undermine the working relationships and severely impact the ability of KSTP to attain its goals.

Copies of the irate memos were sent by Janzen to Bill Hoyt, who had recently been named the training director as a result of the training reorganization. Hoyt's appointment was not good news for Janzen because Hoyt was based in Seattle and no one in Omaha knew him very well. 
Hoyt's appointment was greeted with enthusiasm by Sid Thompson, because he had worked with Hoyt years before and Thompson felt they had good rapport. With the training alliance in jeopardy, Thompson decided to visit Hoyt and resolve the training issues. When they met, Hoyt only briefly mentioned the irate memos, chuckling as he spoke. He understood the sensitivity of the issue and assured Thompson that not only would everything be fine, but he was willing to have his training organization take full responsibility for the entire knowledge systems training program.

Tonv Pearch was one of the executives who received periodic briefings from Sid Thompson, in which Thompson explained the mission of KSTP and its two year charter. Thompson believed strongly in the time limit on the charter because he felt that a new organization cannot be created every time a new technology is identified for adoption (13).

When Thompson met with Tony Pearch, Pearch made three statements about KSTP:

1. He was pleased that CIS was integrating a new technology in a coherent organized manner

2. He believed that two years was sufficient time to trial a new technology

3. He felt that CIS was a factory and production goals must be met

His views emphasized the appropriateness of the client-based approach that KSTP was taking and convinced Thompson to continue driving towards mainstream integration of the technology.

Kathy Dobbs and Gary Ashley are illustrative of the power of a mutually supportive professional relationship (13). Kathy Dobbs had the sincere enthusiasm for improving her organization and the formal position from which to illocate resources and influence people. In spite of (or perhaps because of) her non-technical background, she was not intimidated by knowledge systems technology, but was motivated by what the technology might do for her work area. 
Simultaneously but independently from Sid Thompson's conversations with Dobbs, Garv Ashley applied for the use of a PC-based tool through the KSTP Small Tool Project. Ashley's personal inclination towards deeds instead of words enabled him to see a problem in his work unit, recognize the value of a knowledge-based approach, get a tool, and build a prototype.

It was the combination of Dobb's dedication and Ashley's determined work that enabled Ashley's prototype to be developed into production-quality software. Either one alone would have been insufficient for this to have happened. Even deeper, without the easy access to a PC tool, Ashley would not have been likely to undertake his work. The existence of KSTP and the Small Tool Project provided the organizational legitimization of knowledge systems technology.

Near the end of the Mainframe Project, a retrospective view showed the importance of Mark Tyson's work to the overall integration effort (13). Because a critical part of technology integration is to have demonstrated success with the technology, Tyson was an important factor. Asking him about his success in the application of the technology, he would modestly say that he contributed little. However, he was an instrumental person on the mainframe project.

It was through Tyson that most of the mainframe tool features were tested, using real applications. His involvement as an extended member of KSTP demonstrated the importance of having a technology proficient person in the mainstream domains instead of in a specialized AI group.

Most importantly, Sid Thompson had no authority over Tyson nor Tyson's work, so what he accomplished is a case in point of the power of the individual. 


\section{CONCLUSIONS FROM CROSS-CUING}

From the cross-cuing analysis, a number of conclusions are stated in Figure 50.

For each of them, the primary perspectives which enabled the conclusion to be reached are

listed in the left column. The conclusions are a result of distilling the cross-cue section into a small number of items. The sources for the conclusions are listed in the right hand column. The Labels found on the page references can be used to find full detail in the T-OP Chapters V, VI, and VII. Conclusions that may have general applicability beyond the KSTP case study (for practitioners in other settings) are noted by the statement (general applicability).

\begin{tabular}{|l|l|l|}
\hline T-O-P & \multicolumn{1}{|c|}{ Conclusion } & Page Reference \\
\hline 0 & $\begin{array}{l}\text { 1. The extent to which knowledge systems will be used is dependent } \\
\text { upon estabiishing an operational level infrastructure (general } \\
\text { applicability). }\end{array}$ & 226,232 \\
\hline P & $\begin{array}{l}\text { 2. The extent to which knowledge systems will be used is dependent } \\
\text { upon executive leadership (general applicability). }\end{array}$ & $224,225,228,232$ \\
\hline T-O-P & $\begin{array}{l}\text { 3. Technology integration requires time for the process to nature in } \\
\text { a dynamic environment due to moving targets. It also takes a long } \\
\text { time in a static environment due to lack of incentives to innovate, } \\
\text { particularly when the organization is overstaffed and the new } \\
\text { technology has the potential to reduce staff needs (general } \\
\text { applicability). }\end{array}$ & 211,235 \\
\hline T-O-P & $\begin{array}{l}\text { 4. An uneducated workforce is not capable of rapidly assimilating } \\
\text { knowledge-based systems (general applicability). }\end{array}$ & $213,220,221,222$ \\
\hline O-P & $\begin{array}{l}\text { 5. Persistence is essential for the technology integration team. } \\
\text { There are many challenges to new work methods, from those who } \\
\text { think it to be unnecessary and those who would allocate resources to } \\
\text { other areas (general applicability). }\end{array}$ & $214,220,232$ \\
\hline
\end{tabular}

Figure 50. Conclusions from cross-cuing. 


\begin{tabular}{|c|c|c|}
\hline T-O-P & Conclusion & Page Refirence \\
\hline T-O-P & $\begin{array}{l}\text { 6. High quality communications is essential for the effective use of } \\
\text { new technology. Similar groups in a company must freely and } \\
\text { openly share their experiences (general applicability). }\end{array}$ & $214,218,219,226,229$ \\
\hline 0 & $\begin{array}{l}\text { 7. The Research Committee on Expert Systems obtained world } \\
\text { views on how to set up an expert systems group, but did not obtain } \\
\text { and utilize the vast literature on technology integration. This was a } \\
\text { component of early KSTP difficulty (specific to U S WEST). }\end{array}$ & 223 \\
\hline T-O & $\begin{array}{l}\text { 8. US WEST does not have a cohesive culture because of lack of } \\
\text { 1) common experiences and 2) group learning. Pushing three very } \\
\text { diverse companies together resulted in the need for different } \\
\text { technology integration techniques in all three company areas. This } \\
\text { tripled the burden on KSTP (specific to US WEST). }\end{array}$ & $212,214,216$ \\
\hline T-O-P & $\begin{array}{l}\text { 9. A continuous program of technology evolution needs to be } \\
\text { planned and implemented (general applicability). One of the single } \\
\text { biggest challenges to U S WEST's ability to transition to new } \\
\text { technology is in the current investment in software. This would } \\
\text { require technical skills evolution for the technical staff, both through } \\
\text { retraining existing staff and hiring new staff with the necessary skills } \\
\text { (example is specific to U S WEST). }\end{array}$ & $215,222,223,227,228$ \\
\hline T-O-P & $\begin{array}{l}\text { 10. Budget crises must be managed. Prioritization of funding must } \\
\text { and should be planned well in advance of "budget crunches." Plans } \\
\text { should be ready to be activated when new budget constraints are } \\
\text { imminent, with associated risks well understood prior to the budget } \\
\text { exercise (general applicability). Requests for immediate or short } \\
\text { term budget analysis during crisis-mode compounded the crisis, } \\
\text { increased the risk, and demoralized the KSTP project team (example } \\
\text { is specific to U S WEST). }\end{array}$ & $223,231,232$ \\
\hline O-P & $\begin{array}{l}\text { 11. The infrastructure is obvious but can be neglected. If no one } \\
\text { takes the system view of technology integration, then only a part is } \\
\text { delivered (general applicability). This was seen in the executive } \\
\text { mandate from Bob Haberman that the AI Center not engaged in } \\
\text { training, a function which is necessary for widespread technology } \\
\text { integration (example is specific to U S WEST). }\end{array}$ & 216,234 \\
\hline$T$ & $\begin{array}{l}\text { 12. Changes in supporting or underlying technologies drive changes } \\
\text { in the use and delivery of a new technology (general applicability). }\end{array}$ & $211,226,227,229$ \\
\hline $\mathbf{P}$ & $\begin{array}{l}\text { 13. Specific individuals make significant contributions to } \\
\text { technology integration, both in making the technology accessible } \\
\text { and in putting the technology to use (general applicability). }\end{array}$ & $217,232,235,236,237$ \\
\hline
\end{tabular}

Figure 50. Conclusions from cross-cuing (continues, 
At this point the cross-cuing has provided a view of KSTP with more insight than any of the perspectives taken alone. A major question can be asked of the validity of this analysis.

The results of the $T$ perspective can be readily verified and validated. The data can be re-evaluated using different coilection and analytical techniques, then compared to the current data. The $O$ and $P$ perspectives are more difficult to repeat and verify in the quest for reproducibility. Two possibilities are to 1) review the $\mathrm{O}$ and $\mathrm{P}$ data, looking for additional factors and 2) conduct independent data gathering including repeat interviews.

What has been presented in the T-O-P chapters and the preceding crüss-cuing analysis is one investigator's interpretation of the evidence which has been collected. This interpretation is definitely subjective. There is no claim made to observer objectivity, nor can the subjective weightings used in analysis be documented for use by another investigator.

The only certain part of this investigation is the data as reported in the various sections. The organizational impacts which are described were those found during the research process. The perceptions of individuals were volunteered by them during interviews, and in many cases substantiated by other individuals. The remaining analysis, the cross-cuing chart, and the cross-cuing narrative is the interpretation of the investigator.

The strength of this research method lies in the ability of reviewers to evaluate the analysis and perform their own interpretation based on the available data.

For the purposes of this investigation, the Knowledge Systems Transfer Project is a case study to be used with the technology transfer literature to construct a first cut technology integration model. This model is presented in the next section. 


\section{A TECHNOLOGY INTEGRATION MODEL}

One of the objectives of the research was to develop a technology integration model, based upon the literature review and the case study. The following technology integration model (Figure 51) assumes characteristics similar to those of KSTP, primarily that the technology assessment has been completed (with a "proceed" decision), that there are sufficient potential resources, and there exists an acceptable level of demand for the technology.

This Technology Integration Model (TIM) proved to be useful for the Knowledge Systems Transfer Project because it included the process phases of Awareness, Motivation, and Functioning Capability (the AMF Process) [Mahler] supported by understanding of the domain infrastructure via multiple perspectives. Explanation of the features of the model follows Figure 51.

In the figure, the central part is the AMF Process which will be described in detail. It is dependent upon the Goal Definition for the technology integration effort and the Infrastructure in which the integration process will operate. This infrastructure is an amalgamation of the Technology, Organizations, and People and is analogous to the complexity of cross-cuing and the T-O-P perspectives. The AMF Process support by the Goal Definition and Infrastructure is the Technology Integration Model (TIM). 


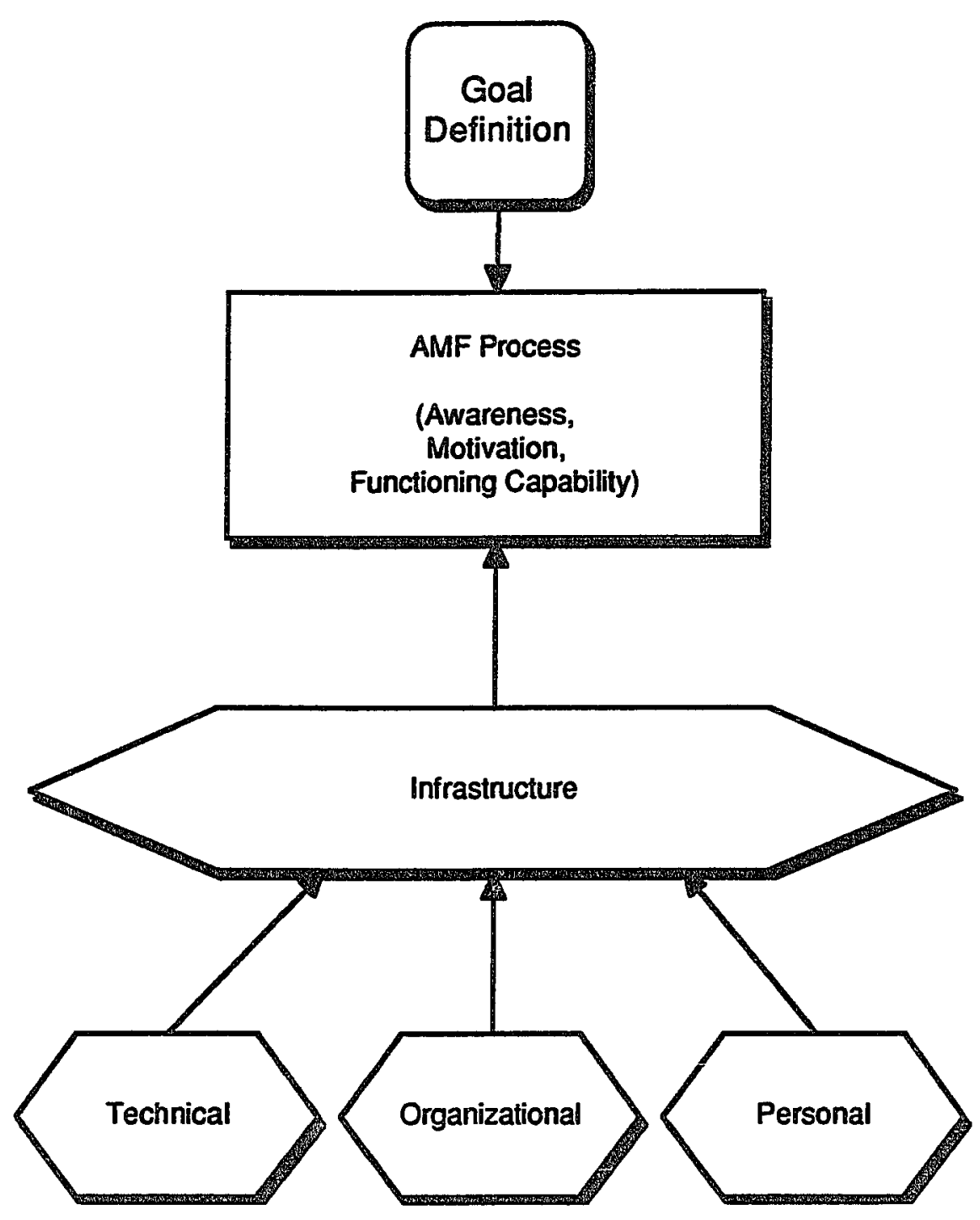

Figure 51. A technology integration model.

The Goal Definition requires the elucidation of the desired results of the technology integration process, which are a function of organizational and personal values. Such goals could take a number of forms. Among the many possibilities, a few examples are:

- A small number of large payoff applications of the technology

- A large number of smaller payoff applications

- Integration of the rechnology inio the mainstream 
- Development of a technology specialist group

Commitment to the desired goal provides the context for understanding the integration situation to be addressed by specific programs in the TIM. If the technology is to be restricted to one or few user sites with few users, then it is possible (and easily practiced) for customized design of programs, a low level of preparedness, and face-to-face informal training.

However if the technology is to be used at many user sites and by many users with varied levels of expertise, then broader program design, a high level of preparedness, formal training courses, and product level documentation are important.

In most technology integration processes, and certainly in the case of KSTP, there is plenty of information available for using the technology but weak methods for delivering the information for effective use. Suggestions for improving this are part of the TIM.

KSTP was established with a pre-existing goal definition, so this part of the model was not used. I have included it because it is a required part of the TIM, and will be performed either implicitly (it just happens) or explicitly (the goal definition process is managed). I suggest that the multiple perspectives methodology would be an effective way to arrive at a goal definition. By examining the T-O-P dimensions and performing the cross-cuing, a good understanding of the goal of technology integration could be obtained.

Moving to the lower part of Figure 51, the Infrastructure is dependent upon the supporting parts for the interactions which would enable a person to characterize the environment in which the technology integration process is to occur. As discussed in the Cross-Cuing section, the specifics of this are a function of the the specific T-O-P perspectives. Given this situational dependence, a number of representative factors are listed with examples. Future use of this model would require a multiple perspective analysis specific to the situation of interest. 
The Technical part of the model includes the obvious factors of the technology itself, the hardware and software, technical environmental factors (such as the mainframe configurations in the KSTP case). Perhaps less obvious are the analytical views of staff characteristics, budget mechanisms, and program measurements. It is clear that these items provide a context for execution of the TIM. Consideration must be given to the effect of these factors on the technology integration process.

In the KSTP case, for example, lack of knowledge about the workforce characteristics would lead a technology integrator in the wrong direction. As previously analyzed, the status of knowledge systems when KSTP began was marked by the workstation, high-performance AI software, and an academic tone of working on "real" AI. Continuing with this view would have been certain failure, given the demographics obtained through employee data analysis.

The Organizational part of the model includes the operating procedures, consulting, training, staffing, budget, and measurements. Each of these are the organizational perspective of factors which may also be represented in other perspectives. For example the Technical perspective will include part of the measurement tools and techniques which will be used and evaluated from an organizational (and personal) perspective. Measurement of results span the perspectives because of the diversity of what must be measured and how it is interpreted: quality, productivity, customer satisfaction, payback, and so on. It is also through the $\mathrm{O}$ and $\mathrm{P}$ perspectives that the ability to take corrective action in these areas surfaces, in line with the goals.

The time commitment to KSTP was about 2 years, which was consistent with its goals. In other goal or infrastructure situations, a very different time frame may be used. In some organizations, a perception of permanence is necessary for success, so an institutional arrangement may be preferred. Organizations have implicit assumptions about the relative importance of the past, present, and future. The time units for tasks are also 
assumed, with some organizations using weeks or months and other organizations using quarters or years. The particulars of these vary from organization to organization, but very short units or very long units may inhibit the integration process. Using a time horizon of the near future, it is conceivable that technology usage could increase as the organization reaches for the "dangling carrot." Short horizons may not allow time for the use of the technology to develop and long horizons may make measurement of progress difficult.

The issues of decentralized or centralized technology integration groups will have an impact on the integration process, depending on the geographic, budgetary, and cultural factors of the target organization. If the goal is to produce a group of specialists or to integrate the technology into one work group, then a case for centralization is possible. Diffusion through many organizations and to many non-specialists may be more effectively achieved with a decentralized approach.

Funding philosophy for integrating new technologies are organizationally dependent. Some view such funding as strategic corporate investments while others budget on a case by case basis, no different than any other tools. There are deeper issues to be aware of because an organization can budget for $R \& D$, to accept the costs of new technology, but this keeps it outside of the mainstream. In the case of KSTP, the mainstream is where the technology needed to be.

For the Personal part, the most critical role is that of leadership. The KSTP case demonstrates the great value of a strong sponsor (Louis Schroder) and the neutral effect of a weak sponsor (Jim Hicks). A very valuable idea is seen in strength of multiple sponsors, which protected KSTP from a number of challenges. But this does not eliminate the need for an individual to stand out as executive sponsor.

The specific people chosen to participate in the technology integration process greatly affect the success level. This can be seen within specific areas as communications abilities where Glen Dillon and Alvin Vail reduced technology integration effectiveness by 
neglecting essential communications. An equally strong but positive action was Sid Thompson's frequent status reports, sent to a large number of interested employees and executive sponsors.

The selection of KSTP individuals from experienced IS professionals enabled KSTP to quickly become tuned to the IS organization and the technical challenges of the mainframe and PC computing environment. Staff selection from outside of the U S WEST IS organization would have significantly delayed the project.

While the IS staff was effective, there could be additional value in utilizing peoplenetworks to select individuals from functional areas that do not overlap. This brings together a broad influence base and different viewpoints from which to evaluate the technology.

I must also point out that the requirements of the TIM will change over time becuase of changes in the technology, the organization, and the people. An example will serve to demonstrate this time element.

When KSTP was established, the knowledge systems computing environment was primarly high-performance workstations and software (often based on LISP). In the two years of KSTP's existence this changed, first to PC's with extra memory and fast processors, then to standard PC's, and also to the maturation of mainframe software tools. The model must incorporate these changes over time. Even if the technology is somewhat stable, organizations and people often change. It seems very unlikely that a technology integration effort would be undertaken in an environment with stabie technology, organizations, and people.

A significant strength of the AMF Process is its flexibility which enables it to be applied to various situations depending upon the goal definition. To explain the model, the matuix headings will first be described using Figure 52, then the contents of the cells will 
be described using Figure 53, and finally two specific knowledge systems projects will be briefly examined to show the model utility.

In Figure 52, the $y$-axis lists the human agents having essential roles in the technology integration process and the $x$-axis lists the major phases through which an agent will progress. The agents are defined as:

- Target - the individual(s) with the problem

- Sponsor - the individual(s) who can supply resources to solve the problem

- Stakeholder - individual(s) who will be affected by changes

- Expert - the source(s) of knowledge to be applied to the problem

- Change agent - individual(s) leading the change process

Consistent with Roberts' Critical Functions Staffing model, these roles do not have to be filled by at least five different people. The sponsor may also be a change agent, and it could be argued that all people involved with a technology integration process are stakeholders. However, the role distinction is made because of the many potential stakeholders who are not actively involved with the process.

The major column headings are arranged in a progressive manner, from the very beginnings of exposure to a technology to the application of the technology. The definitions of these phases are:

- Awareness - Introduction to the technology and a basic understanding of its uses

- Motivation - A matching between the technology and domain problems to which the technology can be applied, resulting in understanding and belief that the work can be done

- Functioning Capability - Assimilation of the skills, tools, and methodologies needed to successfully apply the technology 


\section{Functioning Awareness Motivation Capability}

\begin{tabular}{l|l|l|l|l||}
\hline & when how how \\
\hline
\end{tabular}

Figure 52. Awareness, motivation, and functioning capability

In the Awareness phase it is important to present the technology at a level which is comfortable to the audience. In the case of knowledge systems, for example, awareness activities with a traditional IS staff should not emphasize the academic underpinnings of AI and awareness activities with management should focus on benefits to the business. Great 
care must be taken to present the technology in a non-threatening manner in the context and language of the audience. The criticality of this stage cannot be understated because if an audience is alienated at this time, severe delays in the integration process will occur.

Tailoring of the process continues into the Motivation phase because motivations differ for all players. Motivation is highly dependent on many of the infrastructure factors, such as reward systems for taking risk, leadership handling of innovative activity, and the perceived value of working with emerging technologies.

In the Functioning Capability phase, it is important that there are deliverables to demonstrate the capability. These can take the form of concept papers, work plans, prototypes, etc. As the demands of production and widespread usage are much greater than previous phases, it is most essential to have a good understanding of the infrastructure and to augment that structure as appropriate.

Two subheadings are atop of each column in Figure 52. The "When" indicates the time point within the phase that a specific activity should occur and the "How" describes those specific activities.

Figure 53 shows the completed cells for the Knowledge Systems Transfer Project. The contents are self-explanatory with a few exceptions: 


\begin{tabular}{|c|c|c|c|c|c|c|}
\hline \multirow[b]{3}{*}{ all } & \multicolumn{2}{|c|}{ Awareness } & \multicolumn{2}{|c|}{ Motivation } & \multicolumn{2}{|c|}{$\begin{array}{c}\text { Functioning } \\
\text { Capability }\end{array}$} \\
\hline & when & how & when & how & hen & how \\
\hline & $\begin{array}{l}\text { early } \\
\text { mixed }\end{array}$ & $\begin{array}{l}\text { Presentations } \\
\text { Print }\end{array}$ & $\begin{array}{l}\text { early } \\
\text { mixed }\end{array}$ & $\begin{array}{l}\text { Support application } \\
\text { ID \& selection } \\
\text { Mgt interest \& } \\
\text { commitment, } \\
\text { Spectrum of } \\
\text { development } \\
\text { options, Corporate } \\
\text { payoff, Personal } \\
\text { reward }\end{array}$ & $\begin{array}{l}\text { early } \\
\text { late }\end{array}$ & $\begin{array}{l}\text { Legitimization of } \\
\text { the technology } \\
\text { Sustaining the } \\
\text { motivators }\end{array}$ \\
\hline target & early & $\begin{array}{l}\text { Presentations, } \\
\text { Into the Mainstream }\end{array}$ & mixed & Loaner Pgm & & \\
\hline sponsor & $\begin{array}{l}\text { early } \\
\text { mixed }\end{array}$ & $\begin{array}{l}\text { Presentations, } \\
\text { Print } \\
\text { Into the Mainstream }\end{array}$ & mixed & $\begin{array}{l}\text { Loaner Pgm, } \\
\text { US WEST } \\
\text { "Strategic } \\
\text { Technology", } \\
\text { Tools } \\
\end{array}$ & early & $\begin{array}{l}\text { Technology watch, } \\
\text { Training }\end{array}$ \\
\hline $\begin{array}{l}\text { stake } \\
\text { holder }\end{array}$ & $\begin{array}{l}\text { early } \\
\text { mixed }\end{array}$ & $\begin{array}{l}\text { Presentations } \\
\text { Print, } \\
\text { Into the Mainstream }\end{array}$ & early & Loaner Pgm & early & Technology watch \\
\hline expert & $\begin{array}{l}\text { early } \\
\text { mixed }\end{array}$ & $\begin{array}{l}\text { Presentations, } \\
\text { Print } \\
\text { Into the } \\
\text { Mainstream }\end{array}$ & mixed & Loaner Pgm & & \\
\hline $\begin{array}{l}\text { change } \\
\text { agent }\end{array}$ & $\begin{array}{l}\text { early } \\
\text { mixed }\end{array}$ & $\begin{array}{l}\text { Into the Mainstrearn } \\
\text { Presentations, } \\
\text { Print }\end{array}$ & mixed & $\begin{array}{l}\text { Loaner Pgm, } \\
\text { U S WEST } \\
\text { "Strategic } \\
\text { Technology", Tools }\end{array}$ & mixed & Training \\
\hline
\end{tabular}

Figure 53. Matrix details in the TIM model 
1. Under the "When" columns, mixed means the corresponding "How" was conducted at any time phase (early, mid, late)

2. The specific "How" activities are described in Chapter VI in the section devoted to the Knowledge Systems Transfer Project

3. The U S WEST "Strategic Technology" item at the Sponsor-Motivation cell means that knowledge systems had been identified by corporate technology planners as a strategic technology for the future of the company

4. Legitimization of the technology included the use of the technology by key work groups, the corporate endorsement implied by the existence of work groups (such as KSTP) devoted to the technology, the trend to use PC's and mainframes, and using well-respected external agents, such as IBM, to further the cause

5. Technology watch includes not only the technology but where the technology and applications converge or diverge. This can avoid being blindsided by systems dynamics, such as a change in telephone marketing eliminating the need for a planned knowledge system

Additionally, some general comments are in order:

- When in the Awareness phase, one must recall the point made by Leonard-Barton, that an appropriate amount of technology promotion must be used so the promotional activities are not perceived as hype

- The supreme importance of moving the technology into the mainstream of the organization. This is a realization that the organization will seldom change to match a new technology and the sooner it is in place in the "usual" places, the sooner it will be accepted

- Effective communications facilitate all phases and help all parties 
- People who are not knowledge systems specialists are productive using a TIM approach, but at some point may need more depth

- System development must be viewed as a cradle to grave process, taking into account the need to build maintainable systems

- Simultaneous efforts must be made to provide for short-term, low cost tools and methodology while pursuing longer-term, higher cost tools and methodology

Two cases of knowledge system application are shown in Figure 54 and Figure 55. The check mark " $\checkmark$ " means the "How" item was completed for the case and the $\mathrm{x}$ mark "\&" means it was not.

Many of ways of comparing the two cases are possible. At a gross level, simply counting the number of $X ' s$ shows 16 for Case 4 and 4 for Case 5. 


\begin{tabular}{|c|c|c|c|c|c|c|}
\hline \multirow[b]{3}{*}{$a l l$} & \multicolumn{2}{|c|}{ Awareness } & Moti & vation & \multicolumn{2}{|c|}{$\begin{array}{l}\text { Functioning } \\
\text { Capability }\end{array}$} \\
\hline & when & how & when & how & when & how \\
\hline & $\begin{array}{l}\text { early } \\
\text { mixed }\end{array}$ & $\begin{array}{l}\checkmark \text { Presentations } \\
\checkmark \text { Print }\end{array}$ & $\begin{array}{l}\text { early } \\
\text { mixed }\end{array}$ & $\begin{array}{l}\text { Support } \\
\text { application ID \& } \\
\text { selection } \\
\text { xMgt interest \& } \\
\text { commitment } \\
\text { xSpectrum of devel- } \\
\text { opment options } \\
\text { \&Corporate payoff } \\
\text { \&Personal reward }\end{array}$ & barly & $\begin{array}{l}\checkmark \text { Legitimization of } \\
\text { the technology } \\
\checkmark \text { Sustaining the } \\
\text { motivators }\end{array}$ \\
\hline target & early & $\begin{array}{l}\text { XPresentations, } \\
\text { XInto the } \\
\text { Mainstream }\end{array}$ & mixed & olloaner Pgm & & \\
\hline sponsor & $\begin{array}{l}\text { early } \\
\text { mixed }\end{array}$ & $\begin{array}{l}\text { XPresentations, } \\
\text { XPrint } \\
\text { Into the } \\
\text { Mainstream }\end{array}$ & mixed & $\begin{array}{l}\text { Loaner Pgm, } \\
\text { "US WEST } \\
\text { "Strategic } \\
\text { Technology" } \\
\text { XTools }\end{array}$ & early & $\begin{array}{l}\text { XTechnology watch } \\
\text { XTraining }\end{array}$ \\
\hline $\begin{array}{l}\text { stake } \\
\text { holder }\end{array}$ & $\begin{array}{l}\text { early } \\
\text { mixed }\end{array}$ & $\begin{array}{l}\text { XPresentations } \\
\text { XPrint, } \\
\text { XInto the } \\
\text { Mainstream }\end{array}$ & early & $\sim$ Loaner Pgm & early & XTechnology watch \\
\hline expert & $\begin{array}{l}\text { early } \\
\text { mixed }\end{array}$ & $\begin{array}{l}\text { XPresentations, } \\
\text { XPrint } \\
\text { XInto the } \\
\text { Mainstream }\end{array}$ & mixed & Loaner Pgm & & \\
\hline $\begin{array}{l}\text { change } \\
\text { agent }\end{array}$ & $\begin{array}{l}\text { early } \\
\text { mixed }\end{array}$ & $\begin{array}{l}\text { Into the } \\
\text { Mainstream } \\
\text { Presentations, } \\
\text { Print }\end{array}$ & mixed & $\begin{array}{l}\text { LLoaner Pgm } \\
\sim \text { S WEST } \\
\text { "Strategic } \\
\text { Technology" } \\
\text { Tools }\end{array}$ & mixed & Training \\
\hline
\end{tabular}

Figure 54. Completed matrix for a failed application project. 


\begin{tabular}{|c|c|c|c|c|c|c|}
\hline \multirow[b]{3}{*}{ all } & \multirow{2}{*}{\multicolumn{2}{|c|}{ Awareness }} & \multicolumn{2}{|c|}{$\begin{array}{l}\text { Case } 5 \\
\text { Motivation }\end{array}$} & \multicolumn{2}{|c|}{$\begin{array}{l}\text { Functioning } \\
\text { Capability }\end{array}$} \\
\hline & & & when & how & when & how \\
\hline & $\begin{array}{l}\text { early } \\
\text { mixed }\end{array}$ & $\begin{array}{l}\text { XPresentations } \\
\text { Print }\end{array}$ & $\begin{array}{l}\text { early } \\
\text { mixed }\end{array}$ & $\begin{array}{l}\checkmark \text { Support } \\
\text { application ID \& } \\
\text { selection } \\
\checkmark \text { Mgt interest \& } \\
\text { commitment } \\
\checkmark \text { Specturm of } \\
\text { development } \\
\text { options } \\
\checkmark \text { Corporate payoff } \\
\text { 2Personal reward }\end{array}$ & $\begin{array}{l}\text { early } \\
\text { late }\end{array}$ & $\begin{array}{l}\text { Legitimization of } \\
\text { the technology } \\
\text { Sustaining the } \\
\text { motivators }\end{array}$ \\
\hline target & early & $\begin{array}{l}\text { XPresentations, } \\
\text { Into the } \\
\text { Mainstream }\end{array}$ & mixed & Loaner Pgm & & \\
\hline sponsor & $\begin{array}{l}\text { eariy } \\
\text { mixed }\end{array}$ & $\begin{array}{l}\text { Presentations, } \\
\text { Print } \\
\text { Into the } \\
\text { Mainstream }\end{array}$ & mixed & $\begin{array}{l}\text { Loaner Pgm, } \\
\text { US WEST } \\
\text { "Strategic } \\
\text { Technology" } \\
\text { Tools }\end{array}$ & early & $\begin{array}{l}\text { Technology watch } \\
\text { XTraining }\end{array}$ \\
\hline $\begin{array}{l}\text { stake } \\
\text { holder }\end{array}$ & $\begin{array}{l}\text { early } \\
\text { mixed }\end{array}$ & $\begin{array}{l}\text { XPresentations } \\
\text { XPrint, } \\
\text { Into the } \\
\text { Mainstream }\end{array}$ & early & MLoaner Pgm & early & XTechnology watch \\
\hline expert & $\begin{array}{l}\text { early } \\
\text { mixed }\end{array}$ & $\begin{array}{l}\text { Presentations, } \\
\text { Print } \\
\text { Into the } \\
\text { Mainstream }\end{array}$ & mixed & Loaner Pgm & & \\
\hline $\begin{array}{l}\text { change } \\
\text { aǵent }\end{array}$ & $\begin{array}{l}\text { early } \\
\text { mixed }\end{array}$ & $\begin{array}{l}\text { Into the } \\
\text { Mainstream } \\
\text { Presentations, } \\
\text { Print }\end{array}$ & mixed & $\begin{array}{l}\text { Loaner Pgm } \\
\text { U S WEST } \\
\text { "Strategic } \\
\text { Technology" } \\
\text { Tools } \\
\end{array}$ & mixed & Training \\
\hline
\end{tabular}

Figure 55. Completed matrix for a successful application project. 
These cases are representative of the large number of cases, but obviously were selected to make a point. Case 4 was in progress just as KSTP was forming. It did not have the benefit of a well-organized technology integration process. It failed. Case 5 was undertaken under the guidance and support of KSTP, taking advantage of the technology integration process. It was a success. As a matter of interest, the major reason for failure versus success was identified as the "management interest and commitment" item in the AllMotivation cell. One can speculate that in Case 4, the many missing parts in the Awareness phase contributed to the lack of management support.

From a systems view, perhaps the most significant features of the TIM are its breadth and flexibility. Any system involving humans is highly complex and the TIM provides features to deal with the inherent complexity of the technology integration process.

The breadth and flexibility enables a number of technology integration paths which can be independently or dependently followed. For example, a particular development effort may utilize Path A exclusively while another development effort may utilize Path B exclusively. But in another development effort Path A may be the predecessor to Path B in a complementary fashion, i.e. the work done in Path A supports the work in Path B.

By having multiple paths, failure in one path does not lead to total failure of the technology integration process. Complexity is reduced by keeping the development efforts as small as possible 58 and controlling interactions in a cooperative, peer manner.

Breadth and flexibility also anticipate failure in a robust manner. Chaos theory has demonstrated unpredictability in non-linear systems, to the extent that dramatic system changes can occur when they are not expected. Such events are not foreseeable in a concrete way, but can be anticipated in that they may happen at any time. In these

58 In some cases the size still may be quite large, but size is purposely controlled to remain small relative to the task. 
situations, a single-course technology integration process is highly vulnerable to catastrophic failure. In the case of KSTP, its breadth and flexibility enabled it to progress through multi-company cultural conflict and impactive budget limits. 


\section{CHAPTER IX}

\section{CONCLUSIONS}

In this chapter, I would like to present my conclusions about the four objectives of the research and my observations about the research process. The former will enable you to assess the usefulness of the techniques I have ussd and the latter will give you some insight into what was required to do the research. I have also included some items which may be helpful to someone contemplating a similar research project.

\section{ABOUT THE OBJECTIVES}

Recall that this research intended to examine the appropriateness of using the multiple perspectives methodology to examine events as they occur, in order to guide the technology integration process. The information gained over time could then be used in retrospect to facilitate the development of an intugrati $\eta$ model. My work was divided into academic and industrial objectives:

Academic Objectives:

1. Use multiple perspectives in real-time (for input to decisions as events unfold)

2. Focus on a multiple perspectives view of technology integration into an organization

Industrial Objectives:

1. Improve project effectiveness by increasing understanding of the technology integration process 
2. Establish a model for the integration of a new technology into an organization

The following discussions of each objective will be limited to examinations of each objective in the context of the preceding T-O-P investigation, cross-cuing analysis, and model presentation.

\section{Academic Objectives}

1. Use multiple perspectives in real-time (for input to decisions as events unfold): The search for relevant data in any of the T-O-P domains is usually performed with adequate time for assessment of the breadth and depth of data obtained. As the time from data gathering to cross-cuing and conclusion-making is reduced, the ability to make this assessment is also reduced. Driving the MP methodology to the limits of real-time processing dramatically decreased the confidence I had in the quality of data gathering. However, it dces not follow that MP is unusable in real-time situations. Repeated exercising of MP thought processes is required for such use; in a word, practice. Over time, this training enables the investigator to become increasingly proficient at seeking out the many types of information, quickly cross-cuing, and arriving at some conclusions. The reasonableness of the conclusions are useful determinants for deciding if another iteration of data gathering is appropriate.

Testing the validity of MP thought processes in support of decision making is one potential area for further research on the MP methodology.

2. Focts on a multiple perspectives view of technology integration into an organization: Multiple perspective analysis of the technology integration process proved to be extremely valuable. The dimensions of using a new technology include the technical, organizational, and personal perspectives as discussed in the literature review (Chapter III) and the T-O-P sections (Chapters V, VI, and VII). The information in each of these 
chapters provides very rich descriptions in detail. The key interactions as described in cross-cuing (Chapter VIII) provide a higher level, inter-related view of the information.

Multiple perspectives analysis can provide conclusions from any single perspective, or from the cross-cuing among two or all three perspectives. The number of conclusions derived from the individual perspectives or combinations thereof are as follows:

\begin{tabular}{|c|c|c|c|c|c|c|}
\hline $\mathbf{T}$ & $\mathbf{O}$ & $\mathbf{P}$ & $\mathrm{T}-\mathrm{O}$ & $\mathrm{O}-\mathrm{P}$ & $\mathrm{T}-\mathrm{P}$ & $\mathrm{T}-\mathrm{O}-\mathrm{P}$ \\
\hline 1 & 2 & 2 & 1 & 2 & 0 & 5 \\
\hline
\end{tabular}

Figure 56. Number of conclusions from the various perspectives.

Methodical examination of each of the individual perspectives yielded five $(1+2+2)$ conclusions. Cross-cuing among the perspectives yielded eight $(1+2+0+5)$, some of which would not have been obtained without the formal methodology provided by multiple perspectives. A quick review of the conclusions in Chapter VIII shows that each of the cross-cued conclusions state specific areas which should be addressed during the technology integration process. These include:

- Organizational infrastructure in the technology integration target area

- Executive leadership to visibly and actively advocate the adoption of the new technology

- Timing of the integration effort, to be in harmony with personal and organizational needs

- Workforce capability for assimilation of the new technology, including appropriate education, resources, and infrastructure support

- Persistence, on the part of the technology integrators, to continue with needed work in the face of adversity 
- Communications programs to ensure that the target audience can be effectively informed through the awareness, motivation, and functioning capability phases

- A program of planned technology evolution which describes what will be deployed, by whom, when, and what it will cost

- Budget management which will manage the impact of resource competition on the technology integration team

- Dependencies on related technologies to ensure that changes in the supporting base does not adversely impact technology integration work in progress

- Individual champions, who will work through the preceding issues because they are motivated to use the new technology

Multiple perspectives analysis enabled me to reach these conclusions and I believe that similar studies would be beneficial for comparable projects.

\section{Industrial Objectives}

1. Improve project effectiveness by increasing understanding of the technology integration process: Portions of the conclusions drawn in Chapter VIII were formed at various stages of the technology integration process. Multiple perspectives did make information available which had the potential of improving project effectiveness.

Whether that potential was realized or not depended on the specifics of the situation. For example, Conclusion 6 "High quality communications is essential to the effective use of new technology" was largely realized by installing mechanisms to facilitate the communications process. Many of these mechanisms are in the Awareness part of the TIM model. In the case of Conclusion 10 "Budget crises must be managed," the control was far beyond the domain of KSTP. So while the conclusion was reached, there was no direct 
avenue for resolution of budget crises; thus increased budget understanding did not improve project effectiveness.

This points out an interesting problem. When the power of MP reveals situations that cannot be resolved, a negative impact can result. For KSTP, continued budget pressure reduced team enthusiasm which reduced project effectiveness.

The result is that MP provides the means to learn about the topic of interest. What is learned is not uniformly helpful (nor uniformly harmful) to the goals of the study. So the research goal of improving project effectiveness was only partially achieved. What was achieved was an understanding of the project and its domain of operation. In retrospect, attaining such understanding would have been a more realistic goal, rather than assuming that greater understanding would result in greater effectiveness. Some things are better left unknown, but you never know which ones until you find out about them.

2. Establish a model for the integration of a new technology into an organization: This objective was achieved with the TIM model. In addition to defining the model, it was exercised against a number of U S WEST projects, two of which were presented in Chapter VIII. Working through the Awareness, Motivation, and Functioning Capability processes with the different types of organizations and/or individuals is most beneficial in concert with information provided by the multiple perspective analysis.

The two examples in Chapter VIII showed how specific differences in projects could be the difference between failure and success. The TTM model was used to improve specific projects tested and the model itself was modified as a result of its use. Future research would be appropriate to test the validity of this model or: a broad range of technology integration projects in a broad range of technologies and organizations.

Finally, the organization of the study may be helpful to other multiple perspective practitioners. The conclusions listed with page number references provides easy access to the cross-cuing narrative as shown in Figure 48. The use of clear labels in the cross-cue 
narrative and the cross-cue chart enables the reader to reference the great detail of the T-O-P chapters. Taken together, these feâtures provide a means for tracing through the analysis.

\section{OBSERVATIONS ABOUT THE RESEARCH PROCESS}

If you look at the case study conclusions in Chapter VIII, you can see that the success of a technology integration effort is dependent upon organizational infrastructure, executive leadership, timing, workforce capability for assimilation, persistence, communications, a program of planned technology evolution, budget management, dependencies on related technologies, and individual champions.

This is a rather long list of diverse areas that must be assimilated and I have found that the use of multiple perspectives, as described for the Technology Integration Model, is an effective framework in which to learn about the infrastructure.

To help you get a feeling for what multiple perspectives involves, I would like to describe what I experienced during this process.

Data collection was very time consuming. Total elapsed time was 18 months, and I estimate that about 250 hours was spent on each of the 3 perspectives. I attribute this to a number of things:

- The multiple perspectives methodology does not tell you exactly what to look for nor does it tell you when you have found what you need. You have to know your domain to make these decisions. Skills required to perform this type of research are much like those of an investigative reporter, who must have a sharp sense of what is relevant and what is irrelevant to a given case.

- Access to a large amount of data was important because I did not know precisely what I was looking for. 
- It helped tremendously to be working inside the organization in order to gain access to information. Some information simply would have been unobtainable to an outsider attempting to do such a study.

- Finding the data which can be used to realistically portray the study area was sometimes a matter of chance. While exploring one area, I would unintentionally discover other data that appeared relevant.

- Determination of relevance was made during the cross-cuing process, when I was able to see if specific data added value to the understanding of the case study. A lot of data was placed in the inactive file during cross-cuing.

I should also point out that data collection for the three perspectives did not occur sequentially, that is I did not go out and gather all of the $T$ data, then all of the $O$ data, then all of the $\mathrm{P}$ data. The collection took place simultaneously over the 18 month period, which allowed me to change my own investigative filter and validate the data as it was collected.

This was particularly important for the P perspective. I interviewed some of the people a number of times over a period of months. I observed that their personal views seemed fairly stable over time, while their organizational views varied with what was currently in vogue. $I$ believe this enabled me to separate their $P$ views from their $O$ views. I used multiple interviews as a separating device but have no proof of the validity. In a generai case, I suspect that the time between interviews must exceed the time between organizational change events, in order to detect statements which might be affected by organizational shifts. This is an area which has potential for further research.

I divided the data gathering time into thirds for each of T-O-P. This was a selfimposed discipline to examine the effects of even time distribution. I found that their was much more $\mathrm{T}$ data gathered in that third of time, due to its greater availability. Therefore, 
more $\mathrm{T}$ data was left unused in my research files because such a large volume of data was not necessary for building an understanding of the research domain.

Multiple perspectives methodology was an important contribution to the Knowledge Systems Transfer Project in that it enabled me to better assess the dynamics of the information systems organization. Without the balanced and integrated information gained through the analysis process, I doubt if the technology would have been successfully integrated in the two year KSTP time span. So I believe that the adoption of knowledge systems technology was inevitable, but it was a matter of timing. My usage of MP and the Technology Integration Model accelerated the use of knowledge systems.

Thinking about accelerating the use of new technology, I submit that a company that can productively integrate technology faster than it's competitors is going to have the competitive edge.

Being an insider to an organization provides great advantages with respect to access to information. As a research, it is easier to identify where to look for relevant data and how to recognize when it has been found. Simply knowing the people and who to talk to also helps. However, being an insider can blind an investigator by preconditioning him or her to see a situation in a particular light. Perhaps a solution to this is to have an investigative team composed of insiders and outsiders.

While the data collection process was time consuming, the integration of the data during cross-cuing was the activity with which I struggled most. The cross-cue chart as presented in Figure 48 shows 49 elements, and to many reviewers of that chart, it was about as complex as they wanted to see. Contrast this with the 121 elements in my original cross-cue chart.

I realized that 121 elements were far too many to work with. This told me that I had more chunking to do, but it could also have meant that my research area was too large. This is a potentially useful checkpoint for other practitioners to assess. 
Although I did not have to develop the goal definition for KSTP, I suggest that the mutliple perspectives methodology could also be used in that part of the TIM. This is another area that could be explored in future research.

Multiple perspectives analysis enabled me to learn about the T-O-P dimensions which affected the technology integration process. Knowing this, it was necessary to devise a way to put the technology into the hands of the IS staff. The AMF Process was developed and tested on a number of knowledge systems projects, two of which were described in Chapter VIII. Moving a potential technology user through the awareness, motivation, and functioning capability stages provides an organized way to manage the integration process with the user's needs in mind. While I have demonstrated its use in the knowledge systems domain, I believe that the AMF process is general enough to use in any technology integration process, or perhaps any change process. 


\section{REFERENCES}

Allen, Thomas J., Managing the Flow of Technology: Technology Transfer and the Dissemination of Technological Information with the R\&D Organization, 1977

Allen, Thomas J., "The Differential Performance of Information Channels in the Transfer of Technology," Factors in the Transfer of Technology, eds. W.H. Gruber and D.G. Marquis, Ch. 9, 1969

Allison, Graham, "Conceptual Models and the Cuban Missle Crisis," The American Political Science Review, September 1969, Vol. 63, No. 3

Altenpohl, Dieter and Philip D. Wilmot, "Industrial Applications and Technology Transfer - Report on the Workship," Proceedings of the NATO Advanced Study Institute on Technology Transfer, eds. Harold F. Davidson, Marvin J. Cetron, and Joel D. Goldhar, 1974, pp. 641-644

Anderson, D.F., Mathematical Models and Decision Making in Bureaucracies: A Case Story Told from Three Points of View, Doctoral Dissertation, Massachussetts Institute of Technology, 1977

Badiru, Adedeji B., "Successful Initiation of Expert Systems Projects," IEEE Transactions on Engineering Management, August 1988, Vol 35, No. 3

Benmokhtar, R. B., "Some Ideas about the Use of System Approach for Technology Development," Proceedings of the International Federation of Automatic Control Symposium, Vienna, 1983

Bennis, Warren and Burt Nanus, Leaders: The Strategies for Taking Charge", New York: Harper \& Row, 1985

Blau, BenAmi, "How IBM Technical Professionals Perceive Their Work Environment," Research'Technology Management, January-February 1989, Vol. 32, No. 1

Bowonder, B. and H.A. Linstone, "Notes on the Bhopal Accident: Risk Analysis and Multiple Perspectives," Technological Forecasting and Social Change, November 1987, vol. 32, No. 3

Burke, James, "Introduction," Connections," 1978

Burns, Tom, "Models, Images, and Myths," Factors in the Transfer of Technology, eds. W.H. Gruber and D.G. Marquis, Ch. 1, 1969

"Calling All Computers," Datamation, November 211988 Supplement 
Cavusgil, S. Tamer, "Multinational Corporations and the Management of Technology Transfers," Technology Transfer, ed. A. Coskun Samli, Ch. 13, 1985

Cetron, Marvin J. and Harold F. Davidson, eds., Industrial Technology Transfer, Preface, 1977

Chada, Skylark I.S., "An Empirical Afterstudy of Two Complex Industrial Construction Projects," Technology Transfer Project Management, Swedish Royal Insitute of Technology, 1981, Ch. 1

Chandrasekaran, B., "Expert Systems: Matching Techniques to Tasks," Artificial Intelligence Applications for Business: Proceedings of the NYU Symposium, ed. Walter Reitman, 1983

Choi, Hyung Sup, "Science Policy Mechanism and Technology Development Strategy in Developing Countries," Technological Forecasting and Social Change, May 1988, Vol. 33, No. 3

Churchman, C. West, The Design of Inquiring Systems, 1971

Civarra, J.A., B.R. Eichenbaum, J.A. McCarthy, J.A. Schelke, "Structure and Âctivities," Engineering and Operations in the Bell System, ed. R.F. Rey, 1983

Davis, Peter, and Marcia Wilkof, "Scientific and Technical Information Transfer for High Technology: Keeping the Figure in Its Ground," R\&D Management, 1988, Vol. 18, No. 1

de Bettignies, H.-C., "The Management of Technology Transfer: Can It Be Learned," Integrated Technology Transfer, ed. Jacques Richardson, 1979

Debreyne, Fernand, "Factors Making Product Innovation Successful," Proceedings of the NATO Advanced Study Institute on Technology Transfer, eds. Harold F. Davidson, Marvin J. Cetron, and Joel D. Goldhar, 1974, pp. 567-578

Dede, Christopher, "Probable Evolution of Artificial-Intelligence-Base Devices," Technological Forecasting and Social Change, September 1988, Vol. 34, No. 2

DeMuth, Laurence W., Presentation to U S WEST employees, October 30, 1984

Dror, Israel, "Forecasting Technologies Within Their Socioeconomic Framework," Technological Forecasting and Social Change, August 1988, Vol. 34, No. 1

Drucker, Peter F., "The Discipline of Innovation," Harvard Business Review, May-June 1985

Drucker, Peter F., "The Effective Decision," in Management: Tasks, Responsibilities, and Practices, 1979

Dumpieton, John H., Management of High Technology Research and Development, 1986, pp. 90-92 
Dunford, Richard, "The Suppression of Technology As a Strategy for Controlling Resource Dependence," Administrative Science Quarterly, 1987, Vol. 32, No. 4

Erdilek, Asim and Alan Rapoport, "Conceptual and Measurement Problems in International Technology Transfer," Technology Transfer, ed. A. Coskun Samli, Ch. 15, 1985

Ernst \& Whinney, "1988 RBOC Information Systems Study," Ernst \& Whinney St. Louis Consulting Group - Skip Jackson, Project Director, 1989

Eto, H., "Behaviour of Japanese R\&D Organizations - Conflict and Its Resolution by Informal Mechanisms," in R\&D Management Systems in Japanese Industry, $H$. Eto and K. Matsui, eds., Amsterdam: North-Holland, 1984

Farris, George F., "Technical Leadership: Much Discussed but Little Understood," Research-Technology Management, January-February 1988, Vol. 32, No. 1

Feigenbaum, Edward A., and Pamela McCorduck, The Fifth Generation, p. 34, 1983

Fincher, Cameron, Technology Transfer and Political Decision-making: The Conflict in Models, University of Georgia Institute of Highe: Education, 1975

Fischer, William A. and Iain McNicoll, "Empirical Approachers to Understanding Transfer Processes in Technological Change: Report on a Workshop," Industrial Technology Transfer, eds. M.J. Cetron and H.F. Davidson, 1977

Foster, George, and Norman Nisenoff, "Development and Implications of a Technique for Quantifying Technology," Industrial Technology Transfer, eds. M.J. Cetron and H.F. Davidson, 1977

Fusfeld, Alan R, "Organizing for New Business Development," presentation at the BusinessWeek Conference, January 28, 1985

Fusfeld, Alan R. and Francis C. Spital, "Technology Forecasting and Planning in the Corporate Environment: Survey and Comment," TIMS Studies in the Management Sciences, 1980

Gelb, Betsy D. and Gabriel M. Gelb, "New Coke's Fizzle - Lessons for the Rest of Us," Sloan Management Review, Fall 1986, Vol. 28, No. 1

Glasser, Alan, Research and Development Management, Englewood Cliffs: Prentice Hall, 1982

Gold, Bela, "Charting a Course to Superior Technology Evaluation," Sloan Management Review, Fall 1988

Gold, Bela, "On the Adoption of Technological Innovations in Industry: Superficial Models and Complex Decision Processes," The Trouble with Technology: Explorations in the Process of Technological Change, eds. S. MacDonald et. al., 1983, Ch. 10 
Gordon, Theodore J., and David Greenspan, "Chaos and Fractals: New Tools for Technological and Social Forecasting," Technological Forecasting and Social Change, August 1988, Vol. 34, No. 1

Graham, Margaret B. W., RCA and the VideoDisc: the Business of Research, Cambridge University Press, 1986

Gruber, William H. and Donald G. Marquis, Factors in the Transfer of Technology, Introduction, 1969

Gruber, William H. and Donald G. Marquis, "Research on the Human Factor in the Transfer of Technology," Factors in the Transfer of Technology, eds. W.H. Gruber and D.G. Marquis, Ch. 15, 1969

Gruber, William H., "The Development and Utilization of Technology in Industry," Factors in the Transfer of Technology, eds. W.H. Gruber and D.G. Marquis, Ch. 3, 1969

Hall, Arthur D., "Three Dimensional Morphology of Systems Engirieering," IEEE Transactions on Systems Science and Cybernetics, April 1969, Vol. SSC-5, No. 2

Hardy, Edgar E., "Technology Transfer: Positive Communications," Technology Transfer: Successes and Failures, ed. G.K. Manning, 1974

Haun, R.D., "Focus Group Summaries: Practice/Transformation," Managing the Knowledge Asset into the 21st Century, Debra M. Amidon Rogers (Digital Equipment Corporation) and Dan Dimancescu (Technology and Strategy Group), 1988

Hayes-Roth, Frederick, "The Knowledge-Based Expert System: A Tutorial", IEEE Computer, 17, No. 91984

"House Task Force to Study Tech Transfer," Research Management, November-December 1987, Vol. 30, No. 6

"Industrial Research Institute's Annual R\&D Trends Survey," Research॰Technology Management, January-February 1989, Vol. 32, No. 1

Iwata, Ryushi, "The New Age of Japanese Management," series on Softnomics in Look Japan, October 101985

Johnson, Neville, and Warren B. Brown, "The Dissemination and Use of Innovative Knowledge," Journal of Procduct Innovation Management, 1986, No. 3

Karatsu, Hajime, "Managing the Gray Areas," Research॰Technology Management, January-February 1989, Vol. 32, No. 1

Klimstra, Paul D., and Joseph Potts, "Managing R\&D Projects," Research•Technology Management, May-June 1988, Vol. 31, No. 3 
Kotter, John P., and Leonard A. Schlesinger, "Choosing Strategies for Change," Harvard Business Review, March-April 1979, Vol. 57, No. 2

Lendaris, George G., "On Systemness and the Problem Solver: Tutorial Comments," IEEE Transactions on Systems, Man, and Cybernetics, July/August 1986, Vol. SMC-16, No. 4

Lendaris, George G., "On Systemness and the Problem Solver: Tutorial Comments," IEEE Transactions on Systems, Man, and Cybernetics, July/August 1986, Vol. SMC-16, No. 4

Lendaris, George G., "Structural Modeling - A Tutorial Guide," IEEE Transactions on Systems, Man. and Cybernetics, December 1980, Vol. SMC-10, No. 12

Leonard-Barton, Dorothy and William Krause, "Implementing New Technology," Harvard Business Review, Nov/Dec 1985, Vol. 63, No. 6

Leonard-Barton, Dorothy, "The Case for Integrative Innovation: An Expert System at Digital," Sloan Management Review, Fail 1987, Vol. 29, No. 1

Linstone, Harold A., Multiple Perspectives for Decision-Making, Elsevier Science Publishing, 1984

Long, T.P., "A Case Study — Laser Processing From Development to Application," Research Management, January 1976

Lucas, Henry C., "Utilizing Information Technology: Guidelines for Managers," Sloan Management Review, Fall 1986, Vol. 28, No. 1

Maccoby, Michael, "Motivating Technical People," Research Management, November-December 1987, Vol. 30, No. 6

Mahler, Ed G., "Advanced Issues in Managing Knowledg-Based Systems," Decision Support Technology, Cambridge, MA, September 19-20, 1989.

"Management of Technology: The Hidden Competitive Advantage," Report of the Task Force on Management of Technology, U.S. National Research Council, 1987

Mandell, Marvin B., "Monitoring and Evaluating New Managerial Technologies," Technology Transfer, ed. A. Coskun Samli, Ch. 16, 1985

Martin, Nancy, Course notes for The Software Engineering of Expert Systems, Technology Transfer Institute, Santa Monica, Calif., 1986.

Maruyama, Magorah, "Logic of Japanese General Trading Companies," Technological Forecasting and Social Change, November 1988, Vol. 34, No. 3

Mazhar, Y.K., "An Integrated Systems Approach to Appropriate Technology Transfer," Proceedings of the International Federation of Automatic Control Symposium, Vienna, 1983 
McClelland, David C., "The Role of Achievement Orientation in the Transfer of Technology," Factors in the Transfer of Technology, eds. W.H. Gruber and D.G. Marquis, Ch. 4, 1969

McKelvy, Jack, "6 Month Delay of KSTP," U S WEST internal memorandum to G.J. Knutson and R.F. Radke, January 181989

Mensch, Gerhard, "Institutional Barriers to the Science and Technology Interaction," Proceedings of the NATO Advanced Study Institute on Technology Transfer, eds. Harold F. Davidson, Marvin J. Cetron, and Joel D. Goldhar, 1974, pp. 205-225

Miller, Richard K., and Terri C. Walker, Survey on Knowledge-based Systems, Future Technology Surveys, Inc., Madison, GA, 1988

Ounjian, Moira L. and E. Bryan Carne, "A Study of the Factors Which Affect Technology Transfer in a Multilocation Multibusiness Unit Corporation," IEEE Trans. Eng. Management, August 1987, Vol. EM-34, No. 3

Parsaye, Kamran, and Mark Chignell, Expert Systems for Experts, 1988

Pearson, A.W. and T. Rickards, "Current Problems in Transferring Science to Technology," Proceedings of the NATO Advanced Study Institute on Technology Transfer, eds. Harold F. Davidson, Marvin J. Cetron, and Joel D. Goldhar, 1974, pp. 67-75

Pinto, Jeffrey K. and Dennis P. Slevin, "Critical Success Factors in R\&D Projects," ResearchoTechnology Management, January-February 1989, Vol. 32, No. 1

Place, Geoffrey, "IRI's First 100 Years," Researche'Technology Management, JanuaryFebruary 1989, Vol. 32, No. 1

Pry, Robert H., "Forecasting the Diffusion of Technology," Proceedings of the NATO Advanced Study Institute on Technology Transfer, eds. Harold F. Davidson, Marvin J. Cetron, and Joel D. Goldhar, 1974, pp. 227-246

Quinn, James Brian, and James A. Mueller, "Transferring Research Results to Operations," Readings in the Management of Innovation, eds. Michael L. Tushman and William L. Moore, 1982, Ch. 1

Raz, Baruch, and Isak Assa, "A Model of 'Coupled' Technology Transfer: A Logistic Curve Approach," Technological Forecasting and Social Change, May 1988, Vol. 33, No. 3

Reilly, David J., "Technology Transfer: Succesful Only If the Process is Managed," Manufacturing Systems, April 1988, Vol. 5, No. 4

"Report Calls Technology Transfer Essential," Research•Technology Management, May-June 1988, Vol. 31, No. 3

Rhines, Wally, "AI: Out of the Lab and Into Business," Ioumal of Business Strategy, Summer 1985, Vol. 6, No. 1 
Richardson, George P. and Alexander L. Pugh, Introduction to Systems Dynamics Modeling with DYNAMO, The MIT Press, 1981

Roberts, Edward B. "Managing Invention and Innovation," Reearch-Technology Management, January/February 1988, Vol. 31, No. 1

Roberts, Edward B., "Entrepreneurship and Technology," Eactors in the Transfer of Technology, eds. W.H. Gruber and D.G. Marquis, Ch. 13, 1969

Roberts, Edward B., "Stimulating Technological Innovation - Organizational Approaches", Research Management, 1979, p. 26

Roveda, C. A., "An Empirical Analysis of Technology Transfer in Southern Italian Industry," Proceedings of the International Federation of Automatic Control Symposium, Vienna, 1983

Rubenstein, Albert H., "Basic Research on Technology Transfer," Proceedings of the NATO Advanced Study Institute on Technology Transfer, eds. Harold F. Davidson, Marvin J. Cetron, and Joel D. Goldhar, 1974, pp. 247-266

Runyan, Linda, "Hot Technologies for 1989," Datamation, Vol. 35, No. 2, 1989

Sacerdoti, Earl D., "The Copernican View of Artificial Intelligence," SUN Technology, Winter 1989, Vol. 2, No. 1

Samli, A.C. and Martin L. Gimpl, "Transferring Technology to Generate Effective Entrepreneurs in Less Developed Countries," Technology Transfer, ed. A. Coskun Samli, Ch. 14, 1985

Samli, A.C., "Technology Transfer: The General Model," Technology Transfer, ed. A. Coskun Samli, Ch. 1, 1985

Sapp, James C., Electricity Demand Forecasting in a Changing Regional Context: The Application of the Multiple Perspective Concent to the Prediction Process, Systems Science Doctoral Dissertation, Portland State University, 1987

Schein, Edgar H., "Organizational Socialization and the Profession of Management," Sloan Management Review, Fall 1988 (reprinted from 1968)

Schon, Donald, A., "Comments on Section I Innovation: The Development and Utilization of Technology," Factors in the Transfer of Technology, eds. W.H. Gruber and D.G. Marquis, 1969

Schwartz, Jules J., "How an Organization Decides to Innovate," Proceedings of the NATO Advanced Study Institute on Technology Transfer, eds. Harold F. Davidson, Míarvin J. Cetron, and Joel D. Goldhar, 1974, pp. 175-181

Scott, Larry, "Newsletter Purpose and Audience," U S WEST internal memorandum to Jack McKelvy, December 131988 
Scott, Lawrence G., The State of Compating: Special Report on Expert Systems, U S WEST Information Systems Technology Group Technical Report 86-02, 1986

Sharif, M.N., B. Bowonder, E.R. Cho, T. Miyake, P.T. Prapaporn, K. Ramanathan, Technology Atlas: An Interim Report, Asian and Pacific Centre for Transfer of Technology, March 1987

Sheil, Beau, "Thinking About Artificial Intelligence," Harvard Business Review, JulyAugust 1987, Vol. 87, No. 4

Sirgy, M. Joseph, A.C. Samli, and Kenneth D. Bahn, "Personality, Culture, and Technology Transfer: A Parsonian Social System Perspective," Technology Transfer, ed. A. Coskun Samli, Ch. 11, 1985

Sirgy, M. Joseph, "Achievement Motivation, Technology Transfer, and National Development: A System Model," Technology Transfer, ed. A. Coskun Samli, Ch. 12,1985

Smith, Philip L., "Tighten the Linkage between Research, Business Strategy, and Marketing," ResearchoTechnology Management, January-February 1988, Vol. 32, No. 1

Soloway, Barry H., "R\&D Should Be Run as a Business", Streams of Change, Vol.II No. 2, Woodbridge, Conn.: Grove Hill Industries

Standke, Klaus-Heinrich, "Technology Assessment: An Essentially Political Process," International Journal of Technology Management, 1988, Vol. 3, No. 3

Statland, Norman, "Quartery Update: Datamation/Price Waterhouse Opinion Survey", Datamation, Vol. 34, No. 25, 1988

Steele, Lowell W., "Selecting R\&D Programs and Objectives," Research-Technology Management, March-April 1988, Vol. 31, No. 2

Steinbruner, J.D., The Cybernetic Theory of Decision, 1974

Stoneman, P., "Theoretical Approaches to the Analysis of the Diffusion of New Technology," The Trouble with Technology: Explorations in the Process of Technological Change, , ds. S. MacDonald et. al., 1983, Ch. 9

Stotesbury, William, "Effective Communication and Understanding the Environment," Managing the Knowledge Asset into the 21st Century, Debra M. Amidon Rogers (Digital Equipment Corporation) and Dan Dimancescu (Technology and Strategy Group), 1988

Talaysum, Adil T., "Understanding the Diffusion Process for Technology-Intensive Products," Research Management, July-August 1985, Vol. 28, No. 4

Tarr, Steven C., "Information Systems Technical Workforce Planning Model," Information Systems Technology Group Report, June 1987 
Tauber, Edward MI., "How Market Research Discourages Major Innovation," in Readings in the Management of Innovation, M.L Tushman and W.C. Move, eds., London: Pitman Publishing, 1982

Teece, David J., The Multinational Corporation and the Resource Cost of International Technology Transfer, 1977, Ch. 5

Teotia, A.P.S. and P.S. Raju, "Forecasting the Market Penetration of New Technologies Using a Combination of Economic Cost and Diffusion Models," Joumal of Procduct Innovation Management, 1986, No. 4

Tomlin, Brefini, unpublished paper, Pugh-Roberts Associates, 1987.

Tressel, George W., "The Critical Role of Communication in Technology Transfer," Industrial Technology Transfer, eds. M.J. Cetron and H.F. Davidson, 1977

Uáwadia, Firdaus E., "Creativity and Innovation in Organizations: Two Models and Managerial Implications," Technological Forecasting and Social Change, June 1989, Vol. 36, No. 2

Umbdenstock, Linda M., The Perinatal Regionalization Project: A Study in Form and Development, Systems Science Doctoral Dissertation, Portland State University, 1981

United Communications Group, Making Use of Expert Systems, 1988

Vandermerwe, Sandra, "Diffusing New Ideas In-House," Journal of Procduct Innovation Management, 1987, No. 4

Warfield, John N., Societal Systems: Planning, Policy, and Complexity, John Wiley \& Sons, Chapters 5,3, 1976

Waterman, Donald A., A Guide to Expert Systems, 1986

Weizenbaum, Joseph, personal conversation, Washington State University, Pullman, Washington, December 1983

Wolff, Michael F., "Motivaûing Research Scientists to Reach for the Eagles," Research Management, Vol. XXIX No. 5, 1986

Wriston, Walter, "Technology and Sovereignty", Foreign Affairs, Winter 1988/89, Vol. 67, No. 2

Yanagishita, K., "Soft Science in Japan - Ten Year's Experience in Mitsubishi Electric Corporation," in R\&D Management Systems in Japanese Industry, H. Eto and K. Matsui, eds., Amsterdam: North-Holland, 1984

Zeldman, Maurice, "Moving Ideas from R\&D to the Shop Floor," Management Review, December 1986, Vol. 75, No. 12 
APPENDIX A

MULTIPLE PERSPECTIVES 


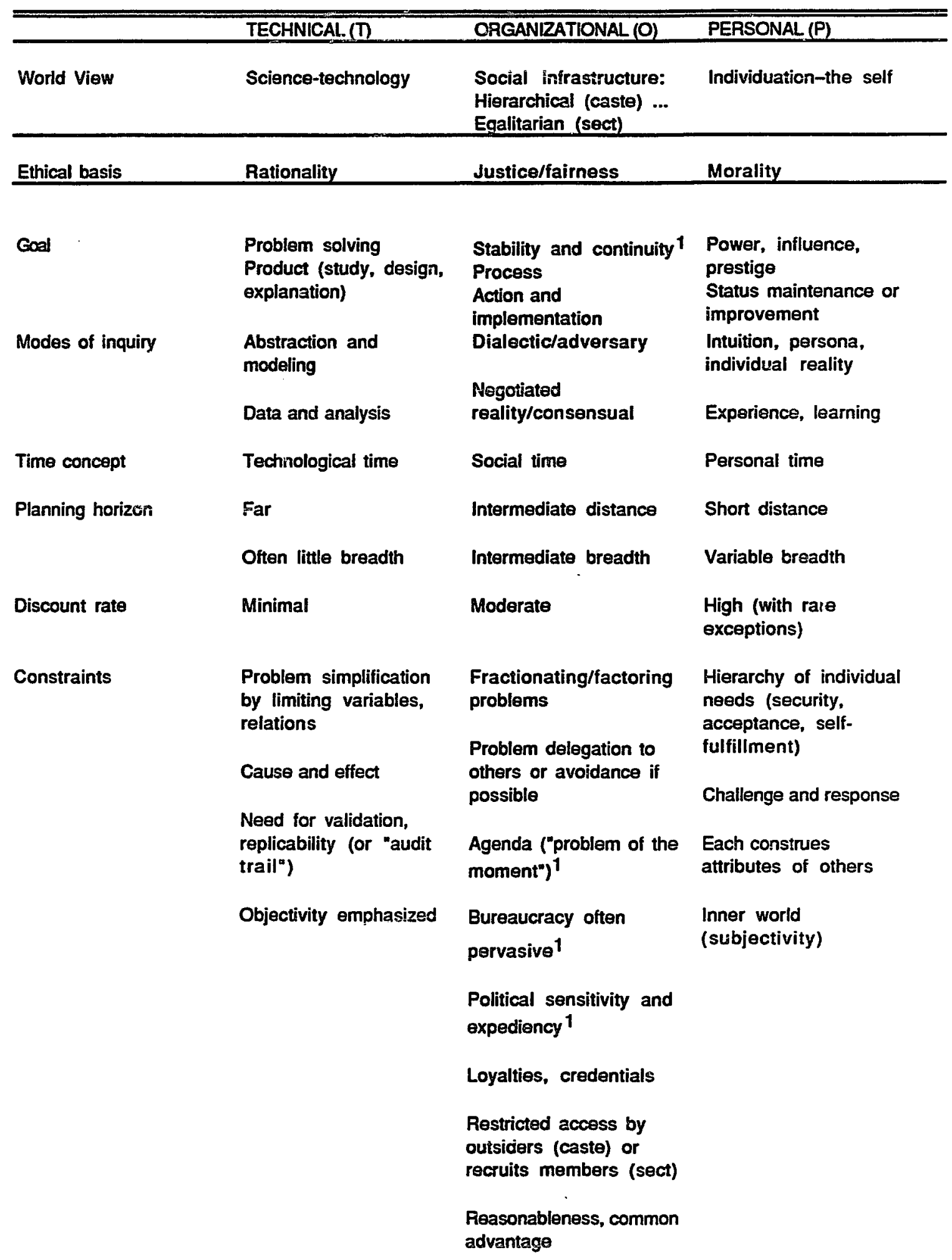

${ }^{1}$ Usually applies to hierarchical structures only 


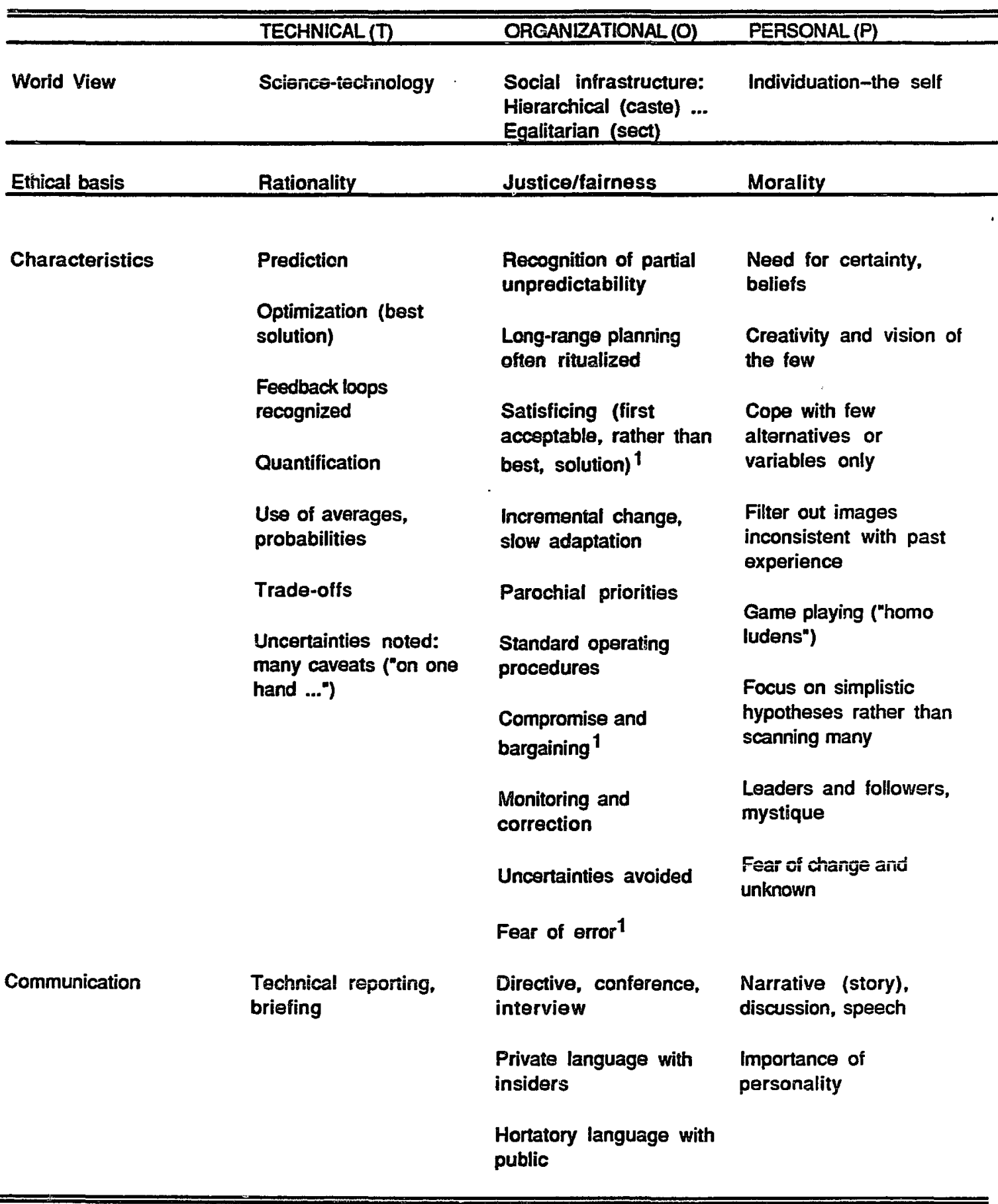

From Linstone, 1984 
APPENDIX B

APPLICATION DENTIFICATION AND SELECTION 


\section{Application Identification and Selection}

This package is intended to guide you through the assessment of a potential expert system project. In using this package it is important to realize that not all of the documents are appropriate for eveny project or user. There are many options available when contemplating an expert system project. To determine which of these options is appropriate it is imporian to first make an estimate of how large an effort a particular task will require. Many of these documents are aimed at large projects and are inappropriate for small projects, as well as intimidating to the proposer.

This brings us to the document you are now reading. This document has two purposes:

1. Provide a basic methodology for the assessment and development of an expert system application.

2. Provide a table of contents for this package, with some guidelines on the appropriateness of each document.

\section{Knowledge Based Systems Development}

There are two pieces to developing a knowledge based system:

1. Choosing and assessing the project.

2. Designing, implementing and delivering the system.

This is not much different from determining the feasibility and desirability of a possible conventional data processing system and then designing, implementing and delivering it. Some differences in the assessment and choice phase come from the need for caution in introducing any new technology. The other differences are based on the nature of knowledge based technology.

Choosina and assessinq projects

What sorts of problems are currently solvable using knowledge based system technology? How do I assess potential projects? In the next few pages we'll look at a simple worksheet which should be filled out for each potential knowledge based system 
project to help answer these questions. (A blank worksheet is one of the documents included in this package.)

\section{EXPERT SYSTEM PROPOSAL}

1. Describe the proposed application context.

(a) Describe the setting.

Business office, computer operations, network, number services, ... ? What is the overall job that is done? Do the people use terminals or PCs? How comfortable are they with the technology that they are using?

It is important to take a step back and look again at the work group and its goals. Make certain that the application is in their best interests and that you have assessed their response to a new technology.

(b) What are the tasks/decisions?

What tasks and decisions are you intending to include in the expert system? Include some detail about information sources and decision support resources.

It is important to decide on some bounds for the project rather early in the planning process. This can be changed laier, but an aftempt should be made to realistically set these boundaries.

(c) Is the task manual or mechanized today?

There may be less resistance to changing the way a mechanized system works than to mechanizing a manual system.

(d) Are there any recognized experts?

Are there one or two people who are viewed as expert at the complete task? Or are there several people who are each experis on some piece or pieces of the task? Or is there no expert at all? 
The ideal case is that of one or two experts, who agree with each other on what the right solution is? Experts who disagree on the correct solution are a large danger signal (research is being done on on how to use conflicting knowledge to obtain a better answer than either expert would gotten alone.) Miuitipie pariial experts can also be a dangerous situation and care must be taken to properly handle the politics. Cases where there is no expert and perhaps never has been are also potentially very dangerous. In these cases the knowledge engineer has to develop the expertise as she or he goes. Books and manuals are not a substitute for an expert!

(e) Who is involved? How many people are involved?

How many people does it take to make a decision or complete the task? What sorts of skills do they have? Who are they? Who are the clients?

If the decision or task involves discussion among several people, don't expect to be able to easily mechanize it. Again it is important to think about who is involved and what their skills are. Many problems that seem ideal are undoable because of the people involved.

(f) How important is the task? Why? Is it "politically" sensitive? Describe.

Does the task affect revenues, expenses, and/or senvice? Is it a regional task? Is the task part of a high visibility project?

The best projects in a sense are all of these things. They have the highest potential payoff. Unfortunately these projects also have the highest risk. It is important to balance the payoff, risk, doability and political backing of the proposed expert system. More projects die for political reasons than for any other.

2. Why does an expert system seem like a good solution?

Is there some part of the task that would be difficult to solve using conventional technology? Is there truly knowledge being applied?

If the problem can be reasonably solved using conventional technology then that is a much wiser soiution. If there is no real knowledge being applied then knowledge based technology won't help.

3. What should the expert system do?

(a) Describe a sample consultation

Think through a complete "consultation", cycle of the task or decision making process. Look back at question 1, especially (b) and (e). Make sure that you include reference materials used, questions asked, systems accessed and results. 
(b) What kinds of knowledge would it access?

Examples: Manuals, reports, databases, personal experience, standard questions.

(c) What form(s) should the output take?

Examples: Printed reports, computer display, spoken, electronic mail, messages or commands to the operating system or other applications, phone call, file, database update(s)?

These three questions are intended to make sure that you have thought through what the system will need to do. This is really preparation for the knowledge acquisition and development phases. The answers to these questions can be very useful in deciding whether to do the project or not.

4. What are the benefits the expert system would provide?

Examples: cost savings, revenue generation, decreased time to solve problems, improved performance, employee education, employee or customer satisfaction. (For more benefits look at the "Generic Expert System Benefits" document included in this package.)

Write up a first cut business case for the proposed project. If you can't find reasonable justification for it, then don't do it.

5. Who would be the players in developing your expert system? (Names, job responsibilities, \& phone numbers)

Proposer/champion:

Subject-matter expert(s):

Developer(s): 
At this time there are around six different choices for expert system development within US WEST:

- Do it yourself with assistance and consultation from the various support groups within US WEST. If the project is small to medium sized this may be an option. It is important to think about what your programming resources are if you choose this option. Medium to large projects should be done using one of the other development options, unless you have an experienced knowledge engineer on your staff.

- KBS Development Group U S WEST AT. Medium to large projects where funding is available should consider working with the KBS group in Engelwood. (For information on how projects are assessed for development by the KBS group read the "Qualifying Engagements for Expert Systems" document included in this package)

- Large projects may also consider working through the KBS group with the Carnegie Group. This company has a good deal of experience working with krowledge based systems and antificial intelligence in general.

- Large projects of a general telephone company nature should consider using the KBS Development District at BELLCORE. The desire here is to be careful of giving away a competitive advantage by having something be centrally developed.

- Other outside consultants. This should only be considered after all the other options have been considered and discarded.

6. Proposed name for the project.

For some reason project which choose a name early in the process are more likely to be treated seriously and go on to completion.

In other words (just like with a more traditional project): Is there a good reason to do this and is it doable? If not, don't! Do I nave the money, people, skills, hardware and/or software to do it? If not, can I get them? No? Tíien again, don't! 


\section{Develogment}

The development life cycls ior a knowledge based system is different from that of a more traditional technology, but not much.

\section{Table of Contents}

The following documents are all Microsoft Word 3.0 except for 5 which is an Excel spreadsheet document.

1. Expert Systerr Proposal - Brent Larson and Loren Sanderson (U S WEST IT-S, KSTP). This is a blank copy of the worksheet used above in the assessment of a potential expert system application. Generally applicable.

2. Generic Expert System Benefits - Chuck Astor (U S WEST AT, KBS). A general survey of possible benefits of using knowledge based technology in a project. Generally applicable.

3. Qualifying Engagements for Expert Systems - Alvin Vail (U S WEST AT, KBS). A look at how the KBS group determines which applications are appropriate for them to work on. Mostly appropriate for those considering KBS development of their project. (This document is in postscript and must be dumped to a postscript printer, like an Apple LaserWriter. This can be done from Microsoft Word just by choosing "Print".)

4. Estimating Return on Investments for Expert Systems Projects Alvin Vail (U S WEST AT, KBS). Explains how to figure return on investment for an expert system project. Generally applicable. (This document is in postscript and must be dumped to a postscript printer, like an Apple LaserWriter. This can be done from Microsoft Word just by choosing "Print".)

5. Return on Investment Worksheet - Alvin Vail (U S WEST AT, KBS). A Microsoft Excel spreadsheet to help in figuring return on investment. (Excel) 


\section{PLEASE NOTE:}

Copyrighted materials in this document have not been filmed at the request of the author. They are available for consultation, however, in the author's university library.

\section{These consist of pages:}

285-290 Generic Expert System Benefits

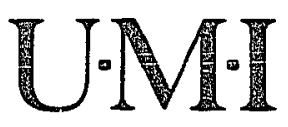


APPENDIX C

MEMORANDUM OF AGREEMENT 
Memorancium of Agreement

\section{US WEST}

Knowledge Systems Transfer Project

April 15, 1988

Bellevue, Washington

$\begin{array}{lll}\text { Memorandum for: } & \text { Tony Pearch } & \text { Judy Nelson } \\ & \text { Dan Swena } & \text { Jim Hicks } \\ & \text { Donald Malek } & \text { Bob Haberman }\end{array}$

Attached is the project memo which establishes the Knowledge Systems Transfer Project (KSTP). The purpose of this project is to facilitate the transfer of expert systems (knowledge systems) technologies (theories, methods, development tools, languages) into Corporate Information Services application, development, and maintenance groups.

KSTP i: a two-year effort within US WEST CIS and in cooperation with U S WEST Advanced Technologies. The primary sponsors are Doug Gunter, Louis Schroder, Glen Dillon, and myself.

In order to most efficiently develop our potential in expert systems, KSTP will serve as the focal point for expert systems activities within CIS, while expert system project responsibility will reside in the appropriate development organization. Please contact me or Sid Thompson if you have questions or comments.

Alan Medina

Attachments 
Knowledge Systems Transfer Project

April 15, 1988, Bellev"ne

Memorandum of Agreement Among Project Co-sponsors

This memorandum establishes the Knowledge Systems Transfer Project (KSTP), a two-year effort within U S WEST Corporate Information Services and in cooperation with U S WEST Advanced Technologies.

Sponsorship: Louis Schroder, Alan Medina, Glen Dillon, and Doug Gunter are each contributing expense dollars, head count, and/or equipment. Application set directors have also committed their support to the Knowledge Systems Transfer Project.

Purpose: $\quad$ To facilitate the transfer of expert systems (knowledge systems) technologies (theories, methods, development tools, languages) into Corporate Information Services application, development, and maintenance groups.

Start Date: $\quad$ April 16, 1988

End Date: $\quad$ April 15, 1990

Staffing: $\quad$ Sid Thompson, MTS-55, Project Leader

Reporting to Sid are: $\quad$ Loren Sanderson, MTS-44

Heinz Neuroth, MTS-44

Roy Gallegos, MTS-44

Brent Larson, MTS-11

Reporting: Sid will report to Bill Kolb of CIS Application and Data Support Services (for administrative purposes) and to Glen Dillon of the Expert Systems Technology Group, US WEST Advanced Technologies (for coordination with strategic directions).

Questions about the Knowledge Systems Transfer Project should be directed to Sid Thompson by electronic mail (sit or telephone (211-564-1122).

Louis Schroder

Alan Medina

Glen Dillon

Doug Gunter

\section{Attachment}


April 15, 1988, Bellevue

\section{Knowledge Systems Transfer Project Memorandum of Agreement among Project Co-sponsors}

This memorandum establishes the Knowledge Systems Transfer Project (KSTP), a two-year effort within U S WEST Corporate Information Services and in cooperation with U S WEST Advanced Technologies.

Sponsorship: The following organizations are contributing expense dollars, head count, and/or equipment to the project, consolidating current expert systems activities:

Louis Schroder Systems Management and Support, Computing and Communications

Alan Medina Application and Data Support Services, Application Services

Glen Dillon Expert Systems Technology Group, Advanced Technologies

Doug Gunter Small Business Systems and Information Resources, Application Services

Application set directors have also committed their support to the Knowledge Systems Transfer Project.

Purpose: To facilitate the transfer of expert systems (knowledge systems) technologies (theories, methods, development tools, languages) into Corporate Information Services application, development, and maintenance groups.

The major goal of this project will be to transfer knowledge systems technology into the CIS environment, and into the environments of the client groups CIS serves, as demand and need dictate. The specific objectives will be as follows:

- Training: develop and deliver courses in knowledge systems topics;

- Technical support: provide direct consultation to clients with development efforts;

- Technical currency: review and publicize the most up-to-date information regarding knowledge systems theories and tools;

- Development: Take a proactive role in the initiation, design, and implementation of at least one large knowledge system with important financial rewards, recognizing that the specific project responsibility will remain in the appropriate development organization.

- Advanced Technical Education: support the development of project staff capabilities via higher education in computer science.

Start Date: $\quad$ April 16, 1988

End Date: $\quad$ April 15, 1990 
Staffing: The project will have a central staff and a network of affiliates. The central staff, housed in Bellevue will be composed of a senior technical lead and four analysts:

Sid Thompson, MTS-55, Project Leader

Reporting to Sid are: $\quad$ Loren Sanderson, MTS -44

Heinz Neuroth, MTS-44

Roy Gallegos, MTS-44

Brent Larson, MTS-11

The affiliates are iocated in other data centers in the region and at U S WEST AT.

Reporting: Sid will report to Bill Kolb of CIS Application and Data Support Services (for administrative purposes) and to Glen Dillon of the Expert Systems Technology Group, U S WEST Advanced Technologies (for coordination with strategic directions). Sid will have all decision-making authority for the group's activities as well as all budget authority. 
APPENDIX D

RESEARCH COMMTTEE ON EXPERT SYSTEMS REPORT 


\section{Research Committee on Expert Systems Report}

\section{BACKGROUND \& MOTIVATTON}

Expert systems, or knowledge-based systems, represent the first technology relying on principles of artificial intelligence to achieve widespread application in mainstream computing. Systems of this relatively new genre are being constructed in a wide variety of commercial applications, e.g. financial planning, network fault diagnosis and recovery, and computer system configuration. Distinguished from traditional computing by their emphasis on knowledge and reasoning, they afford the opportunity to capture the subtle reasoning of expert practitioners in the performance of complex-but narrowly definedtasks and to make those expert methods available to less experienced personnel. Their user interfaces are designed for ease of use, and ofter can help train less experience personnel during the course of their usage. Because expert systems can be applied to a host of problems not addressed by traditional data processing methods, they are the object of much interest and experimentation within many enterprises worldwide.

Expert systems are precursors of the coming fifth generation of computer systems. And they are more different from third and fourth generation systems than those two generations are from each other. A significant area of difference is the nature of the tools which are used to build them: they rely on different programming constructs than traditional computer systems, e.g. rules and object-oriented programming. The tool marketplace is expanding rapidly, and offers a wide variation of capabilities, host computers, and prices. The methodology for developing expert systems is also somewhat different than traditional methodologies, relying heavily on "domain experts" during design and implementation, and requiring successive phases of prototyping rather than the traditional "waterfall" methodology. Experimentation without formal training is possible, but most practitioners quickly feel the need for formal training to help them select appropriate problems, tools, and programming constructs for serious efforts.

U S WEST Advanced Technologies has embraced the potential for expert systems to provide competitive advantage in its computer systems. AT has a group dedicated to working with clients within the corporation to build expert systems and has sponsored seminars to encourage its subsidiaries to exploit the new technology. Encouraged and stimulated by U S WEST AT's activities, the Information Systems Technology Group has been building expertise with expert systems since early 1986. One analyst in that group has worked with two different Pacific Northwest Bell groups to build prototype systems, has written a report introducing the technology to managers, and has assembled a testbed environment on a Sun 3/160 workstation. In 1987 that analyst was joined by another, from Interdepartmental Data Systems, to provide a path for moving prototype expert systems into production.

Summer 1987 found these two analysts fully engaged in prototype-building for clients in PNB's engineering and accounting organizations. That same timeframe saw at least four new groups in the CIS organization express serious interest in developing expertise in building expert systems. The ISTG/IDS partnership was able to provide limited consultation, but these groups were forced to go outside U S WEST to receive training, adding to already significant expenditures for training in this area stimated at 
over $\$ 80,000$ in 1986 and 1987 by Bellevue CIS staff alone). Further, these groups have largely proceeded on their own to evaluate tools in the complex and changing marketplace, despite a shallow level of expertise in the technology.

Several of these groups attended U S WEST AT's Artificial Intelligence Team meeting in August. This meeting further whetted interest in the technology and demonstrated that other organizations were exploring the technology in a variety of ways. On August 31, 1987, ISTG and U S WEST AT sponsored an all-day meeting in Bellevue on the topic of "Expert Systems Development for PNB". Based on the presentations and discussions of that meeting, the Research Committee on Expert Systems was formed from a subset of the attendees.

\section{OBJECTIVES OF THE RESEARCH COMMITTEE}

The Research Committee on Expert Systems held its first meeting in September and developed its objectives, of which this report and recommendation are the fruition. The objectives that were established were to:

- examine the expert system development activities of the entire CIS organization, and determine the level of expertise being brought to bear on those activities;

- research the activities and organizaticnal structures employed by companies which have had some success in building expert systems;

- provide consultation to groups desiring to start exploration and development immediately;

- make a recommendation as to what organizational changes, if any, should be made to facilitate successful application of expert system technology in the CIS organization.

\section{FINDINGS}

Committee members contacted representatives of all known expert system activities within CIS and U S WEST AT. A summary of activities and contact persons is provided in the appendix.

CIS activities can be categorized into three general groupings: technology-focused groups; application-focused groups; and access to consultation, training, and tools. All three IDCs and U S WEST AT have groups that are focused on expert system technology itself, and seek to find applications and clients (often outside CIS) to showcase its potential benefits. A rather recent development is the spurt of interest within CIS application groups, in some cases oriented toward specific applications and in others toward building general expertise in the technology. The U S WEST AT/Carnegie Group alliance is the only effort at this time focused on providing access to training, consultation, and a tool-in this case Carnegie's family of tools which run on Unix- and Lisp-based workstations. 
Resulting from these activities, a few prototypes have been built, several more are in progress, but no industrial-strength, production expert systems have yet been fielded. The corporation as a whole is still experimenting on a group by group basis with the plethora of tools available, and no coherent mechanism exists for sharing information about the experiences being gained. Training likewise has been garnered on an ad hoe basis by each group and has relied on outside vendors. No uniform core curriculum of training courses exists for the various individuals and groups attempting to build expertise in the technology, although the new Carnegie alliance has the potential to provide such in the future.

A picture of expert system building activities in others companies was garnered from interviews with consultants and from a survey of relevant literature. The findings are described fully in the appendix and summarized below.

Expert systems are being successfully fielded in many industries. A few, wellpublicized ones are large, but many more are small and medium-sized. The latter point argues that expert systems technology need not be prohibitively expensive to exploit. Many good applications of expert systems can be found in U S WEST that could contribute to the profitability of the corporation. In industry, as in U S WEST, many more prototypes than production systems are being built.

Small and medium-sized expert systems can be developed and maintained by the end users of the system, with appropriate training. All the publicly discussed large systems were developed by experienced knowledge engineers. Knowledge engineers are often grown from within an organization, sometimes contracted from outside, but rarely hired from outside.

The tool marketplace is volatile and expected to remain so. It is too early to set rigid standards for tool environments.

Analysis of unsuccessful expert systr . mts has linked their failure to unrealistic expectations, inadequate financing, or lack or cunnitment by domain experts.

A successful expert systems strategy focuses on the technology as a solution to appropriate problems, not on the technology itself. The most successful formal expert system groups have not centralized development, but rather acted as points of technology transfer.

Both industry-wide and U S WEST-specific experience indicates that need exists for a centralized group to support building expert system expertise in the following areas:

- training

- matching tools with problems

- prototyping

- maintaining technical currency.

The committee considered three alternatives to providing support to the CIS organization's burgeoning demand for consultation, training, and tool evaluations. Continuing in the current uncoordinated fashion would not prevent CIS groups from adopting expert systems technology; but it would not leverage the expertise being developed across the region to the corporation's maximum advantage. In a worst case, it 
might result in duplicate efforts or even costly mistakes in training or tool selection. A logical approach might be for U S WEST AT to provide support activities, in addition to its current functions of project development and Carnegie services management. Two problems surface with this approach. First, the AT staffs would potentially need to be enlarged to manage these functions in addition to their current missions of developing systems for clients in the IDCs and the unregulated subsidiaries. Secondly, the AT staff consists of highly qualified technologists, largely hired from outside the corporation; as such they are somewhat removed from many CIS issues and concerns. The third approach, the recommendation below, would utilize existing CIS employees with expertise in expert systems development to supplement U S WEST AT's larger corporate mission with support tailored to the CIS organization and its clients in the IDCs.

\section{RECOMMENDATION}

The Research Committee on Expert Systems recommends the formation of a two-year project, jointly sponsored by CIS and U S WEST Advanced Technologies, entitled the Knowledge Systems Transfer Project, or KSTP.

Goal and Objectives: The goal of this project will be to transfer expert systems technology into the CIS environment, and into the environments of the client groups CIS serves, as demand and need dictate. The specific objectives will be as follows:

- Training: develop and deliver courses in expert systems topics;

- Technical support: provide direct consultation to clients with development efforts;

- Technical currency: review and publicize the most up-to-date information regarding expert systems theories and tools;

- Development: design and implement at least one large expert system with important financial rewards;

- Advanced Technical Education: support the development of project staff capabilities via higher education in computer science.

Organization: The project will have a central staff and a network of affiliates. The central staff, housed in Bellevue will be composed of a senior technical lead and four analysts experienced in various aspects of expert systems technologies. The affiliates will be located in other data centers in the region and at U S WEST AT.

The central staff will be attached to a second-level group for administrative purposes only. The technical lead will have all decision-making authority for the group's activities as well as all budget authority. Four analysts for the central staff have been identified. The technical lead for the project requires a level of skills and knowledge not present within the CIS work force. It is the opinion of the committee that securing this expertise may require an outside hire. 
Distribution of Resources: Over the two year life of the project, the project's focus will start with providing technical support and building technical currency, shift toward developing training, then shift again to a major development effort. The projected distribution of project resources is illustrated below:

\begin{tabular}{|c|c|c|c|c|}
\hline & $\begin{array}{l}\text { Year } 1 \\
\text { 1st half }\end{array}$ & 2nd half & $\begin{array}{l}\text { Year } 2 \\
\text { Ist haif }\end{array}$ & 2nd half \\
\hline Training & - & $30 \%$ & $25 \%$ & $10 \%$ \\
\hline Technical Support & $30 \%$ & $15 \%$ & $15 \%$ & $15 \%$ \\
\hline Technical Currency & $40 \%$ & $20 \%$ & $15 \%$ & $15 \%$ \\
\hline Development & $15 \%$ & $20 \%$ & $30 \%$ & $45 \%$ \\
\hline ATEP & $15 \%$ & $15 \%$ & $15 \%$ & $15 \%$ \\
\hline
\end{tabular}

Specific Objectives: The Training objective is targeted primarily at the key players in an expert system development project: the knowledge engineer, his or her manager, and the domain expert. The project will produce a core curriculum of courses covering basic and advanced expert systems concepts. Potential courses include:

- Artificial Intelligence \& Expert Systems Overview

- Introduction to Expert Systems

- Knowledge Representation

- Knowledge Acquisition Techniques

- Expert Systems Project Míanageñentît (uased on Triad 2000)

- Specific Expert System Building Tools.

The Technical Support objective is targeted at potential and active knowledge engineers. The project staff will deliver talks and demonstrations on demand to groups interested in learning about the technology in general. To leverage the expertise developed by groups with development efforts across as wide an audience as possible, the project staff will organize and support a users group. In addition, the staff will provide direct consultation to clients with development efforts, including problem identification, preliminary design, rapid prototyping, project-tool matching, and testing and validation.

The Technical Currency objective is targeted at active knowledge engineers and CIS support groups such as SDME and $\mathbb{R}$. Project staff will be responsible for ensuring that the most up-to-date information regarding expert systems theories and tools are reviewed. Via the users group, that information will be shared with all groups actively developing expert systems. Support groups will be kept current on the state-of-the-art of tools in the environments of their areas of responsibility.

The Development objective is targeted at the company at large, focused through client organizations. Project staff will design and implement at least one large expert system with important financial rewards. This effort is intended to be both an opportunity to build full- 
scale development expertise in the project staff and the client group, and a major vehicle for delivering the benefits of the technology to the corporation. Potential candidates exist today for this application in efforts currently in various phases within PNB: the completed ISTGEngineering Planning prototype, in-progress U S WEST-CIS Storage Management prototype, in-progress CIS CCR Design Advisor, and proposed CIS Accounting projects. (Other candidate applications will likely surface in coming months.) The project staff will work with the client group from its current state to a finished production system, and provide support necessary to enable the client organization to maintain the finished system.

The Advanced Technical Education objective is targeted at the company at large, focused through selected members of the project staff. Members of the project staff will participate in ATEP to develop advanced computer science knowledge required to maximize the benefit of the transfer of expert systems and artificial intelligence technology, as they mature, into the mainstream of CIS systems.

Project Staff Responsibilities: All the project staff will be involved in personal training, tool evaluation, reviewing literature and attending professional associations related to expert systems work, preparing and delivering talks and/or demonstrations, rapid prototyping, and the delivery of training. In addition, each of the staff members will have major responsibilities in certain key activities:

- Technical Lead: Responsible for overall coordination and decision making. Will determine training curriculum for staff, conduct training where feasible, provide quality assurance on course development, set objectives for tool evaluation, assign consulting duties, and play a major role in the development and implementation of a production system. In addition, the technical lead will be the principal liaison to U S WEST Advanced Technologies.

- Technician \#1: Training coordination, including setting objectives, working with corporate training facilities, setting schedules and time lines, publicity, evaluation and follow-up. Principal technical consultant on training and education issues, both internal and external.

- Technician \#2: Technical support coordination, including initial interviews with prospective clients, development of consulting assignments with Technical Lead, maintain published materials, tool evaluations, other information resources.

- Technician \#3: Expert Systems Users Group chair, and coordinator of the KSTP regional affiliates. Principal function is to develop and maintain expert system users network.

- Technician \#4: Production system project coordinator. Principal function is to define and conduct process for the identification of major developmental project.

Approximately fifteen percent of the project staff activities will include ATEP participation on the part of KSTP staff members. This will involve enrollment in graduate school or graduate level courses specifically related to expert systems technologies or techniques. Fifteen percent of the staff time is equivalent to 30 hours per week, or one Tier I and one Tier II scholarship throughout the duration of the project. 
Working Environment: The KSTP staff will be located in Bellevue, in close proximity to the ISTG laboratory facilities, in order to share tools. In addition, the KSTP will acquire the hardware and software resources it requires for development, consultation, tool evaluation, and training. Members of the staff will travel throughout the region as necessary to consult with clients, confer with affiliates, and present training courses.

Budget: The budget over the life of the project is estimated below. Uncertainties in particular estimates are described in the succeeding text.

Year 1

$\$ 30,000$

$\$ 100,000$

$\$ 130,000$

$\$ 36,000$

$\$ 7,500$

$\$ 10,000$

$\$ 10,000$

$\$ 323,500$

$\$ 250,000$

$\$ 573,500$

Total Annual Budget
Year 2

$\$ 0$

$\$ 0$

$\$ 0$

$\$ 36,000$

$\$ 2,500$

$\$ 10,000$

$\$ 10,000$

$\$ 58,500$

$\$ 250,000$

$\$ 308,500$

$\$ 882,000$

GRAND TOTAL PROJECT BUDGET

Uncertainty in the estimate for staff train Carnegie alliance can best be leveraged to redrse overall outlays. The objective of staff training is to bring all members of the project staff to the same level of exposure to expert system concepts, to provide training on specific software tools, and to develop expertise in the training of others.

It is premature to specify exactly what software will be purchased for the project. The experience of the technical lead will strongly influence this decision, which will be one of the first tasks once the project is underway. It is anticipated that software resources will include one or more PC-based tools and one or more workstation-based tools. Assuming significant improvement in mainframe-based tools, a mainframe-based tool may be purchased as well. 
The hardware budiget is intended to provide workstations, one for each analyst, connected by a local area network to each other and to a laser printer. The workstations must be frowerful enough to support both desktop publishing for creating training materials and to function as a development environment using PC-based expert system building tools.

No internal candidate for the technical lead position is known to the committee; filling this position may require an outside hire. It is anticipated that his or. her salary will be shared between CIS and U S WEST AT. The rest of the staff will cc:ne with their own budget allocations (i.e. no backfill), so that real salary dollars will be much less than indicated.

The research committee estimated that approximately $\$ 84,000$ was spent in 1986 and 1987 by CIS staff in Bellevue alone on tuition for outside training courses equivalent to those which will be offered through the KSTP. The savings which will be realized by teaching these courses in-house will recover a significant portion of the expense budget.

In addition to savings on training, the KSTP can have important influence over major tool purchase decisions, saving the corporation from waste due to redundancy and/or misinformation.

At the time of this writing, the full extent of the co-sponsorship of U S WEST Advanced Technologies is not known, but whatever involvement will further reduce CIS dollar commitment.

Project Progress Reports: The project staff will supply CIS and U S WEST management with semi-annual progress reports. 
APPENDIX E

LOANER PROGRAM PROPOSAL 


\section{U S WEST Communications}

TO: Mike Moore

FROM: $\quad$ Knowledge Systems Transfer Project

SUBJECT: Expert System Proposal

DATE: $\quad$ February 23, 1989

Thank you for your interest in developing an expert system application through the Knowledge Systems Transfer Project Loaner Program. Enciosed are the guidelines of the Program and the Expert System Proposal worksheets.

Please complete the Proposal and return it to:

$$
\begin{aligned}
& \text { Joe Martin } \\
& \text { U S WEST } \\
& \text { Koll Center Bellevue } \\
& \text { 555 328th Ave NE } \\
& \text { Bellevue, WA } 98004
\end{aligned}
$$

The KSTP team will evaluate your proposal and contact you within 5 days of receipt. If you have other questions or expert system ideas, feel free to call 206-555-1111. 
1. Due to the limited number of the loaner expert systems tools available, certain criteria will be used to ensure that interesis of U S WEST are best served. These criteria fall into three basic categories:

a. Business case of the application (potential benefits, savings to the company).

b. Skills of requestor. Considerations here include PC experience, programming experience, and $A I$ or ES exposure.

c. Resources of the requestor (access to PC, people available to commit to the project).

2. There is some flexibility to each loaner agreement, but here are some guidelines to what the KSTP expects to generally be the case:

a. The loan of the tool is for two months.

b. If at the end of that two months the requestor has finished the tutorial and has a working prototype of the application, they are free to keep the tool. There are no preset size requirements in defining a "working prototype." The key is enough functionality to demonstrate that the application is at least feasible.

c. If at the end of two months a working prototype is not completed, a renegotiation between the project and the KSTP is possible. That renegotiation would perhaps include some additional services on the part of KSTP to facilitate the project development.

3. The KSTP offers services during the 2 month loan period.

a. Normai training support services such as tutorials, supplemental reading, and course recommendations.

b. Shoring up deficiencies in decision criteria

c. Refining application idea

d. PC usage training (enough to use VP-Expert and back up their files)

e. Helping with tutorial

f. Arswering VP-Expert specific questions

g. Helping with knowledge representation questions

h. Presenting your project with you to management or peers

4. The KSTP also will offer further support with a successful application prototype:

a. Normal support services: training, tools, contact with ESTG, CGI, etc.

b. If there is a good business case, we'll review and help polish it 